\title{
Examining changes in learning and engagement of higher education students in a fully online flipped learning distance education classroom
}

James David Riel

djriel75@gmail.com

Follow this and additional works at: https://researchrepository.wvu.edu/etd

Part of the Adult and Continuing Education Commons, Curriculum and Instruction Commons, Educational Methods Commons, Educational Technology Commons, Higher Education Commons, and the Online and Distance Education Commons

\section{Recommended Citation}

Riel, James David, "Examining changes in learning and engagement of higher education students in a fully online flipped learning distance education classroom" (2021). Graduate Theses, Dissertations, and Problem Reports. 8140.

https://researchrepository.wvu.edu/etd/8140

This Dissertation is protected by copyright and/or related rights. It has been brought to you by the The Research Repository @ WVU with permission from the rights-holder(s). You are free to use this Dissertation in any way that is permitted by the copyright and related rights legislation that applies to your use. For other uses you must obtain permission from the rights-holder(s) directly, unless additional rights are indicated by a Creative Commons license in the record and/ or on the work itself. This Dissertation has been accepted for inclusion in WVU Graduate Theses, Dissertations, and Problem Reports collection by an authorized administrator of The Research Repository @ WVU.

For more information, please contact researchrepository@mail.wvu.edu. 


\title{
Examining changes in learning and engagement of higher education students in a fully online flipped learning distance education classroom
}

\author{
James David Riel \\ Dissertation submitted \\ to the College of Education and Human Services \\ at West Virginia University \\ in partial fulfillment of the requirements for the degree of \\ Doctor of Philosophy in \\ Learning, Instructional Design and Technology
}

Sam Stack, Ph.D, Co-Chair

Ugur Kale, Ph.D, Co-Chair

Denise Lindstrom, Ph.D

Jared Simmer, J.D., Ed.D

Department of Counseling and Learning Sciences

Morgantown, WV

2021

Keywords: engagement, learning, flipped classroom, distance education, online learning, elearning, e-learning, retention, cyberlearning

Copyright (C) 2021 J. David Riel 


\title{
ABSTRACT \\ Examining changes in learning and engagement of higher education students in a fully online flipped learning distance education classroom
}

\begin{abstract}
J. David Riel
The challenge of implementing effective online distance education courses for academics and institutions is a centuries-old task. We can look across early developments in the $18^{\text {th }}$ century with the creation and delivery of correspondence courses; into the $20^{\text {th }}$ century with teaching and learning across analog methods such as audio and video; and now in the current era of digitized mechanisms that enable the online classroom. This includes advances in internet technologies and computing abilities that are the empowering the backbone processes, bridging connectivity between the student and the instructor. As society has trended toward massive increases in online modes of instructional delivery, major gaps are still apparent when attempting to adapt traditional and modern teaching and learning methods to online learning landscapes. These pertain to the students' abilities to retain knowledge as well as in having an engaging classroom experience. These gaps can include the misalignment of the motivations of the teacher and the learner, the ability to gain and retain the attention of the student when not physically face-toface, and the propensity of retaining knowledge based on the effects of an experience in the online classroom. This study analyzes the flipped classroom model of instruction in a fully online course. The purpose of this study is to examine potential change in student learning and engagement and determine the impact of a flipped classroom model of instruction on the learning outcomes and engagement experiences of the student. These interests are the gauges in which to examine whether this model of instruction can contribute to more informed instructional design decisions in the future of online education.
\end{abstract}




\section{Dedication}

"Science is the first expression of punk, because it doesn't advance without challenging authority. It doesn't make progress without tearing down what was there before and building upon the structure." - Greg Graffin

The work herein is dedicated to my wife, buddy, and Doctor Emily Joyce Jones, for without her love, support, and most excellent coffee skills, this would never have been possible.

To my parents, James Richard and Pamela Joyce Riel, whom have always pushed me and believed in me to do great things, as well as being an inspiration to take my education and work to the next level, to my youngest brother Christopher Adam Riel who fueled some of my late night studies with delicious dinners from your restaurant and inspired with your relentless work ethic, and my late brother Aaron Thomas Riel, with whom we shared many pre-class conversations over a coffee and some "timbits" while you worked to complete your undergrad, I so wish you could be here with me to celebrate this moment but I know that you are looking down and smiling with pride from afar.

I would also like to send a special dedication to the late Dr. Terence C. Ahern, who was my original committee chair and one of the nicest and most intelligent people I have had the honor to meet and work with. Terence unexpectedly passed away during the candidacy phase of my studies. Rest in peace my friend and know that your guidance and insight were a major influence on getting me to the finish line. 


\section{Acknowledgments}

The path to the $\mathrm{PhD}$ can seem like the never-ending journey to enlightenment. It is an arduous, difficult, painful, sometimes depressing, and one of the most rewarding tasks I have had the honor to accomplish. It would be difficult to express my gratitude to the multitude of those that have had an impact on my life and work up to this point, as they have all had a role into building me into who I am today, but several important influences that I owe my deepest gratitude and thanks to have to start with my committee: Dr. Samuel F. Stack, for taking on the extreme responsibility of chairing my committee, I have enjoyed learning from you through my early days in completing my coursework with some of your classes, to your direction through the process of the research, Dr. Ugur Kale, for your expertise in instructional design and in examining and questioning the data to better refine the outcomes, Dr. Denise Lindstrom, for the opportunities to work with you in your research and for always giving insightful feedback and reviews of the work from your knowledge and expertise in the field, and Dr. Jared D Simmer, with whom gave me my opportunities to experience the life of an academic through my role as your teaching assistant, which motivated me to pursue the next level of my lifelong learning path, as well as your dedication and colorful feedback to my work for which this dissertation would have never been possible without.

I have also been blessed to have worked with and been given much support from many colleagues and friends at Carnegie Mellon University, and would like to extend a special thanks for your guidance and experience to Kristen S. Kurland, Dr. Joseph A. Mertz, Andrew Wasser, Dr. Ramaya Krishnan, Dr. Michael Ian Shamos, Matthew Bass, Allison Frankoski, and Ari Lightman. I would also like to extend my personal gratitude to my editor, Ronald Crow. 


\section{Table of Contents}

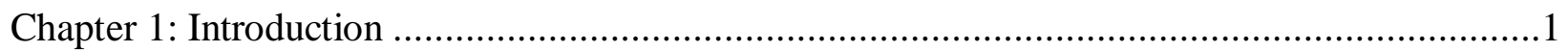

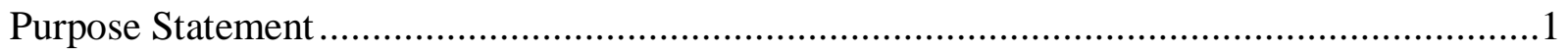

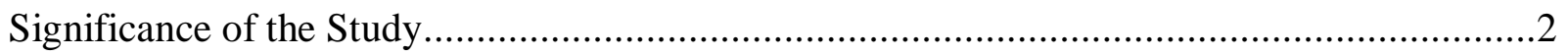

What This Study Works to Discover and Validate ……...................................................6

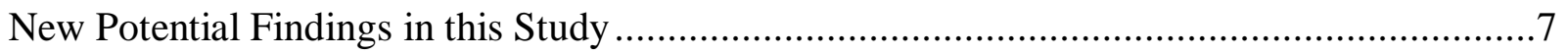

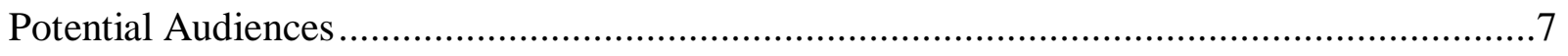

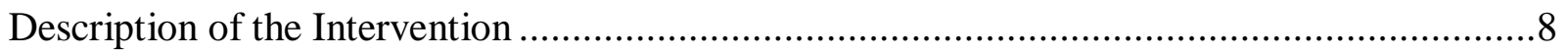

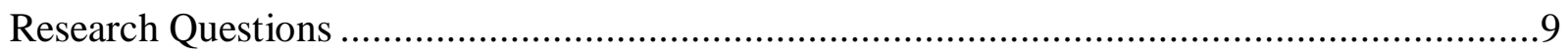

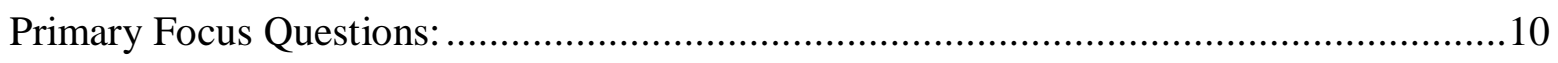

Description of the Research Study Chapters ....................................................................

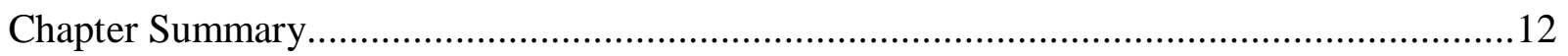

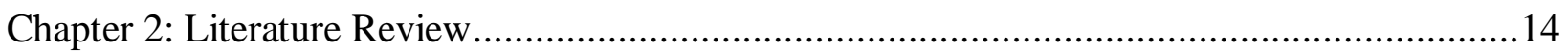

The Current State of the Higher Education Classroom .........................................................14

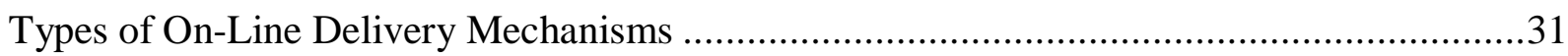

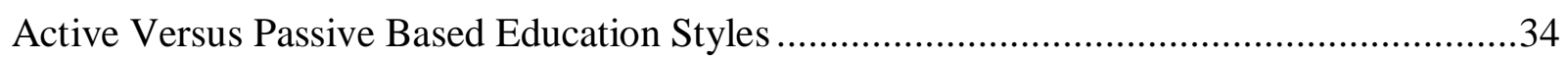

Applying Active Learning Instructional Design to Online Distance Education Technology ...37

Reviewing the Flipped Classroom Active Learning Instructional Design and Applicability to

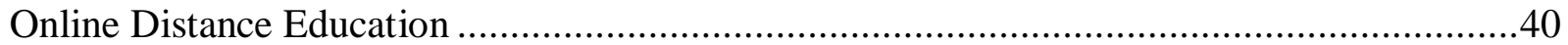

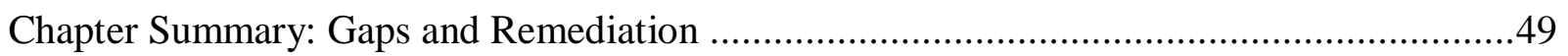

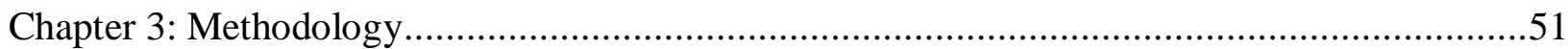

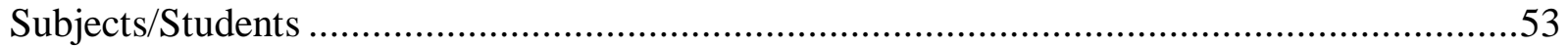

The Subjects or Participants of this Research Study ….....................................................53

How Participants are Chosen (Listed Procedures) ……....................................................55

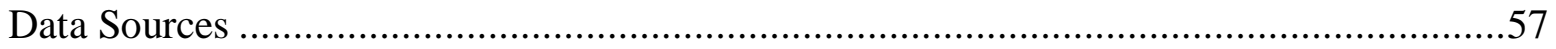

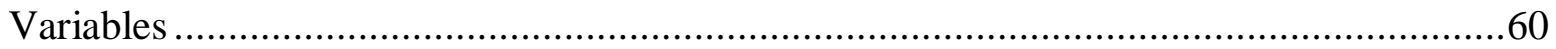

Summary of the Methodology Needed to Answer the Research Questions ..............................61

The Overall Strategy/Approach for Answering the Research Questions ...............................61

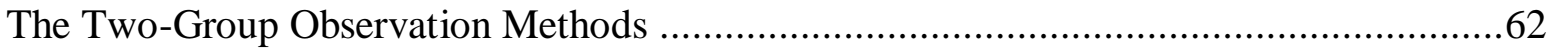

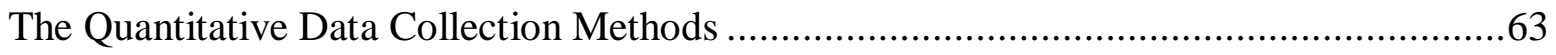

Weekly Assessment, Overall GPA and Testing Methods ............................................66

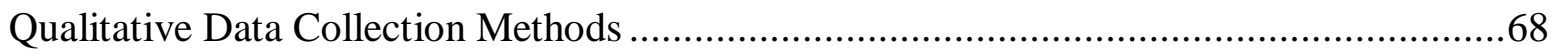

Methodology: Limitations and How Each Were Addressed ..................................................70 
Participant Limitations and Addressing/Minimizing Each............................................

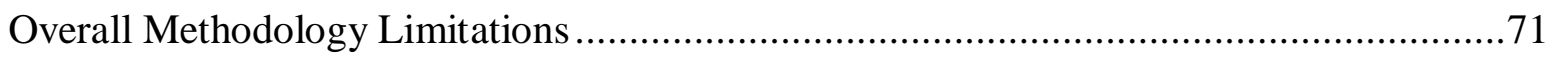

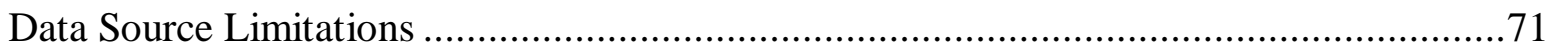

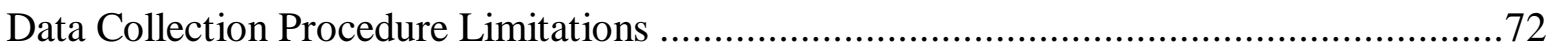

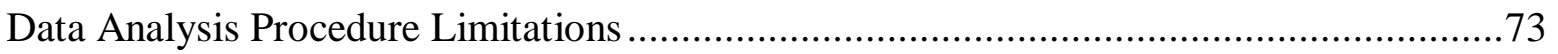

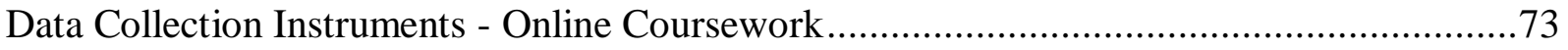

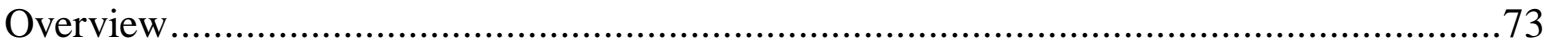

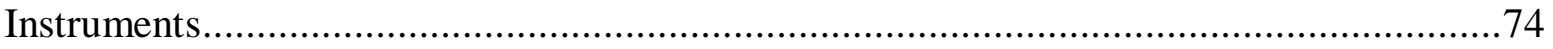

Quantitative Analysis - Course Completion (Weekly and GPA) ……….......................75

Quantitative Analysis - Perceived Learning Pre-Post Assessments..................................76

Qualitative Analysis - Learning Engagement Assessments...........................................76

Qualitative Analysis - Other Instruments ................................................................78

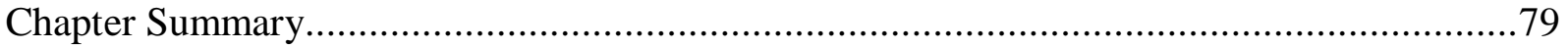

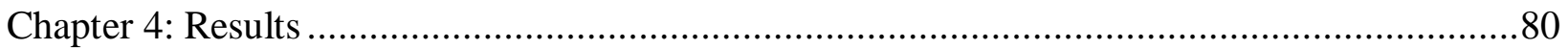

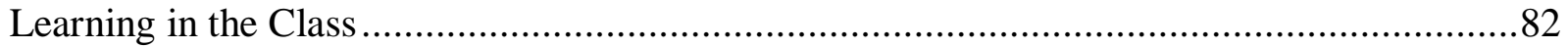

Learning: Analysis of the Changes in GPA Scores.........................................................

Learning: Analysis of the Outcomes of Assessment Scores............................................85

Learning: Analysis of the Perceived Changes in Learning Through Pre- and Post-Test

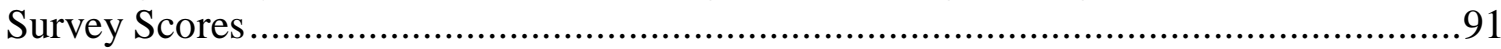

Comparing a Flipped Online Distance Class to Prior Distance Class Experiences ...............95

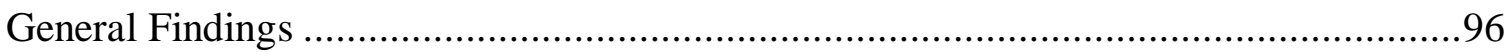

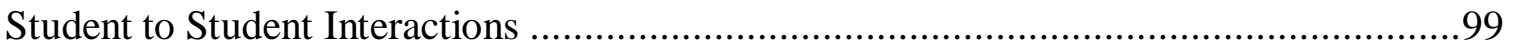

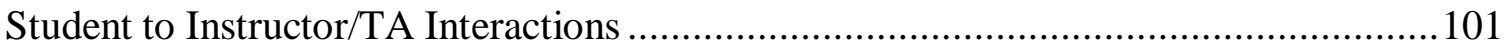

Comparing Current Distance Class Activities to Previous Distance Class Activities ....102

Overall Comparisons to Prior Distance Class Experiences .............................................104

Comparing a Flipped Online Class to Prior In-Person Lecture-Based Class Experiences .106

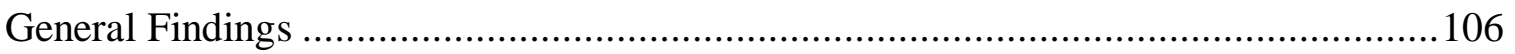

Student-To-Student Interaction Experiences ............................................................ 109

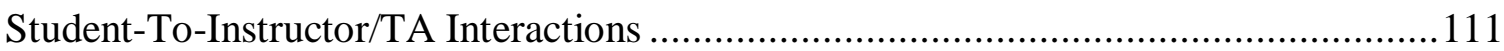

Comparing Engagement in Activities Between Distance and In-Person Classes............113

Overall Comparisons to Prior Experiences in Traditional Lecture-Based In-Person

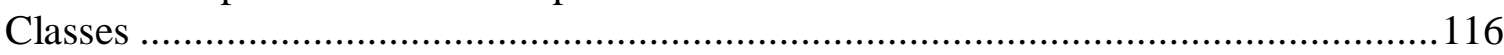

Looking at Overall Experiential and Engaging Components of the Flipped Online Class.117

Evaluations of the Course and Class Observations .....................................................117

Evaluations of the Course and Class Observations - Engagement.................................119 
Evaluations of the Course and Class Observations - Learning ......................................123

Evaluations of the Course and Class Observations - Overall Experience …………......126

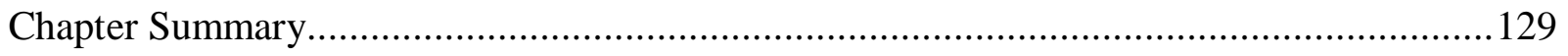

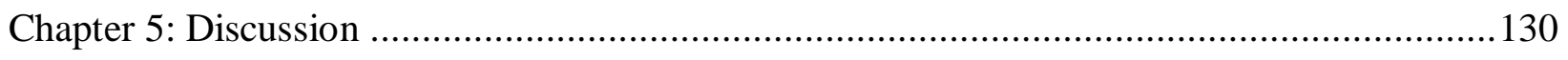

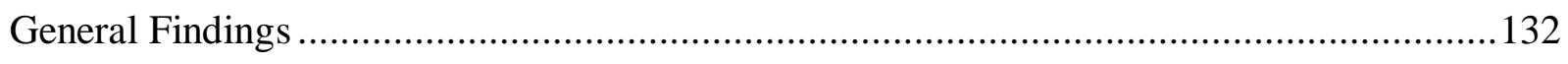

RQ1: Effects on Learning: Theoretical and Pedagogical/Andragogical Implications ............134

Actual Learning Through Analysis of the Overall Class Grade (GPA) .............................136

Actual Learning Through Analysis of the Assessment Grades .........................................137

Perceived Learning Through Analysis of the Assessment Scores.....................................138

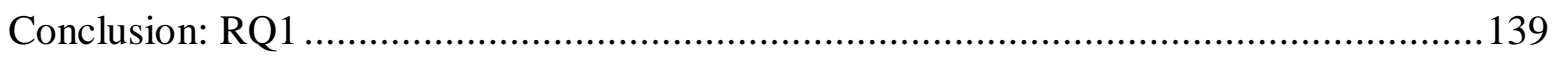

RQ2: Effects on Engagement: Theoretical and Pedagogical/Andragogical Implications ......140

Comparing Engagement Experiences Between Current and Prior Distance Classes ......... 143

Engagement Comparisons Between Current Distance and Prior Traditional Classes .........145

Perceptions/Sentiments in the Current Online Flipped Classroom Design for Engagement,

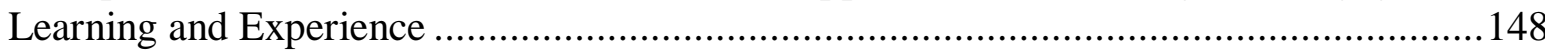

Analysis of Students' Strictly Positive and Neutral/Negative Sentiments Across Learning, Engagement and Overall Class Experience .................................................................149

Correlations of Positive Versus Neutral and Negative Perceptions/Sentiments in Current Online Flipped Classroom for Engagement, Learning and Overall Experience...................151

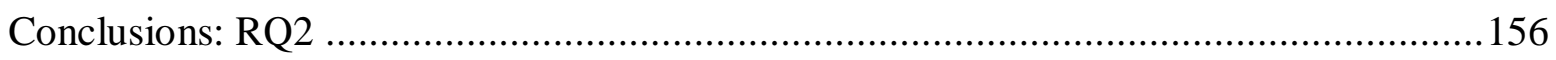

Correlations Between RQ1 Learning and RQ2 Engagement Findings ...............................158

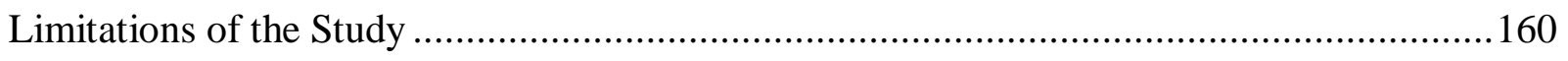

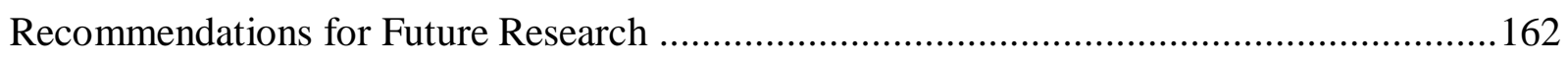

Impacts of COVID-19 and Correlations to Shifts from In-Person to Online Classes......... 162

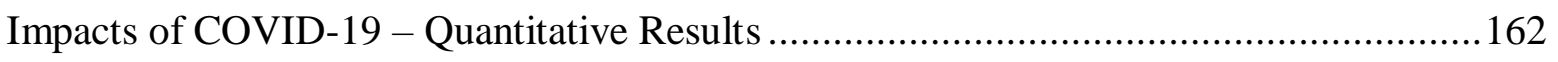

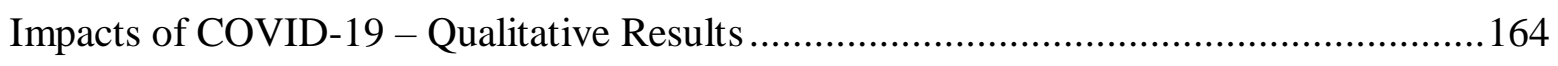

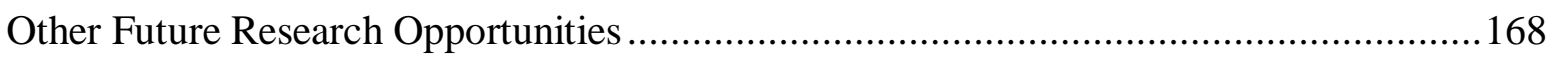

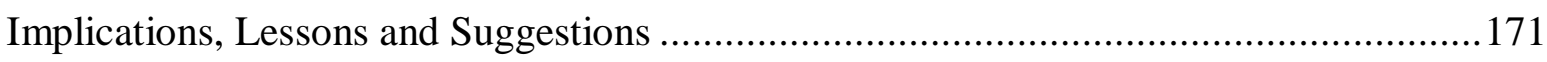

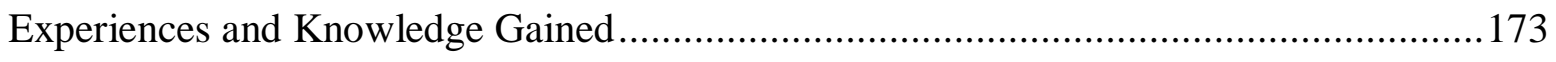

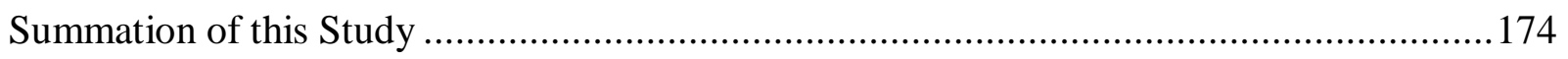

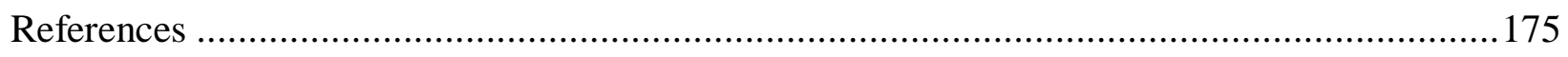

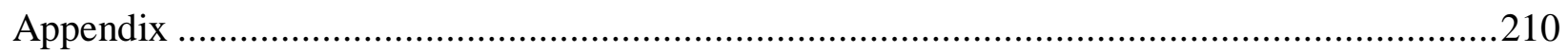

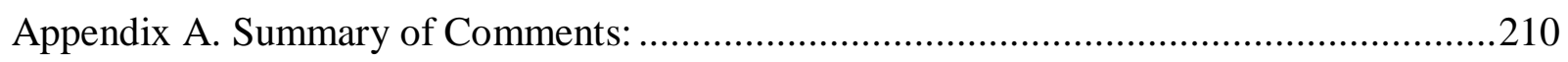

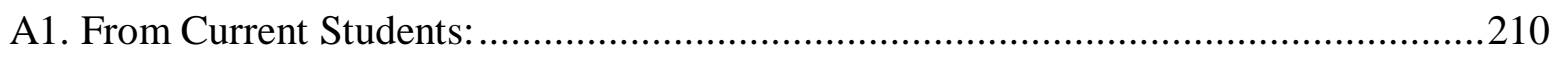

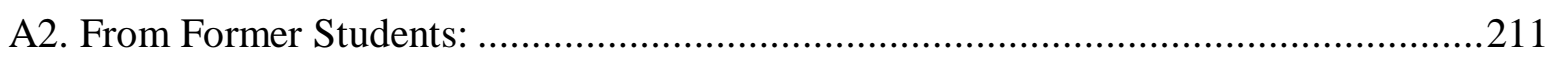




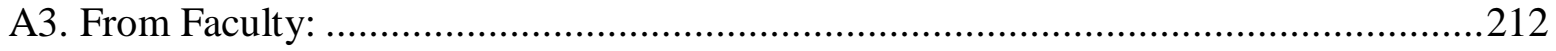

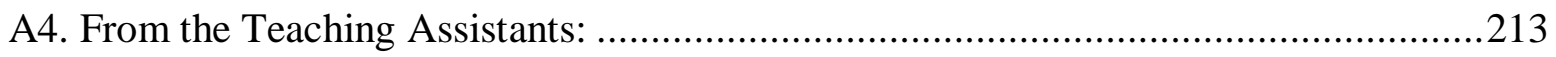

Appendix B. Faculty Course Evaluation (FCE) Form for Engagement Assessment ............214

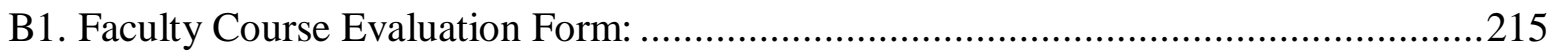

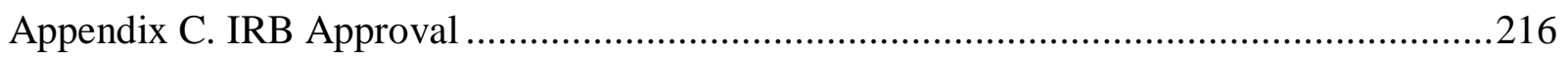

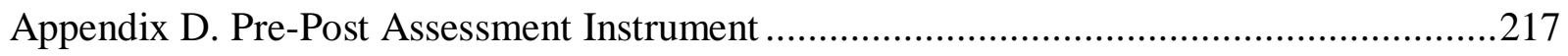

Appendix E. Quantitative Learning Assessment Instrument...........................................218

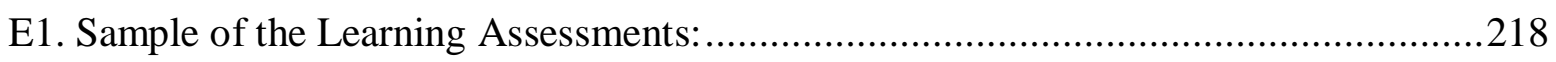

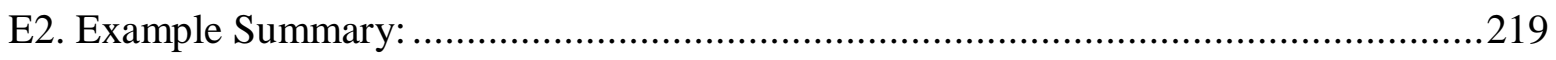

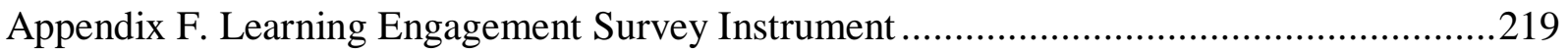

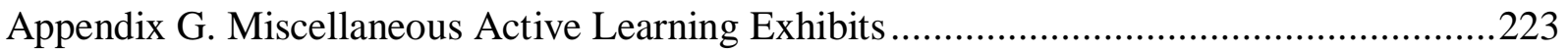

Figure G1. A Chart of Active Versus Passive Learning Retention....................................223

Figure G2. A Chart of Characteristics of Passive and Active Learners. .............................224

Appendix H. Future Research Questions and Opportunities................................................224

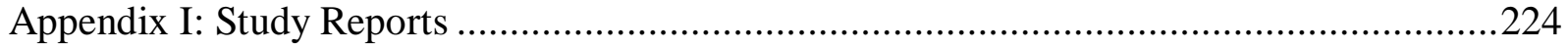

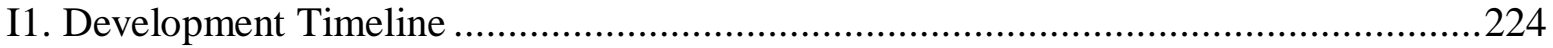

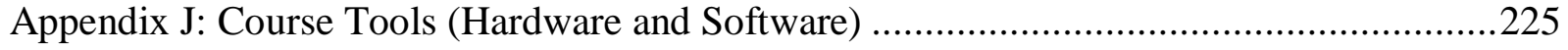

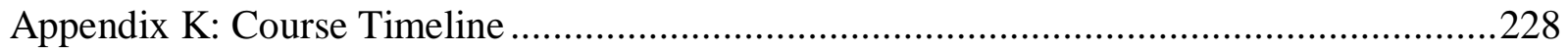

Appendix L: The Flipped Distance Education Model (FDEM) ……..................................231

L1. Implications of the Applicability of the FDEM .........................................................231

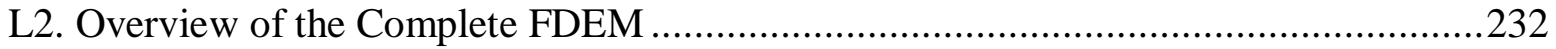

L3. The Identity, Implementation, Analysis (IIA) Model ................................................23

L4. The Flipped Classroom Workbook (FCW) .............................................................23

L4a. The Learning Objectives and Outcomes Model (LOOM) ....................................233

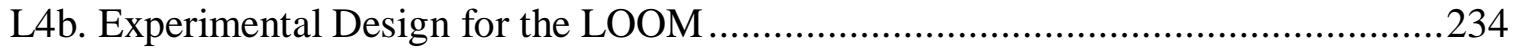

L4c. Learning Objectives and Outcomes Template ……….........................................2236

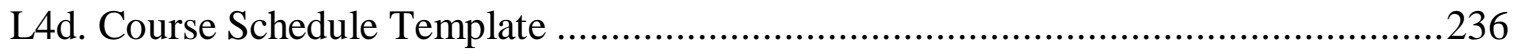

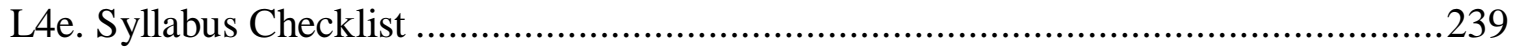

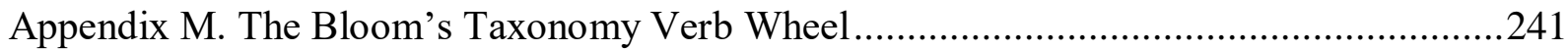

Appendix N. The ADDIE and ASSURE Models of Instructional Design ...........................242

Appendix O. Looking at the Current EdTech Landscape …….........................................24

Appendix P. A Historical Look at Distance Education ....................................................24 


\section{Table of Tables}

Table 1 Table showing students degree program and total number of students per degree........53

Table 2 Instructional delivery per semester with the number of subjects in each course ..........56

Table 3 Participant instructional delivery types and total number of each...........................57

Table 4 Semesters and types of students (traditional versus distance) ................................58

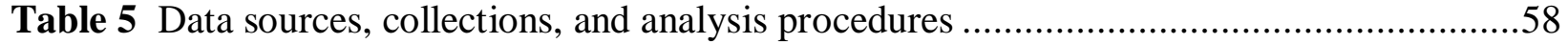

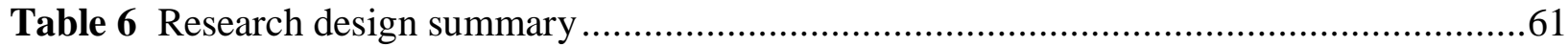

Table 7 Cook and Campbell notation applied for the two-group design................................63

Table 8 Matrix of quantitative data capture methods and components ...............................65

Table 9 Matrix of quantitative data comparisons and observations ...................................66

Table 10 Example collection and calculation of GPA across lecture and flipped learning

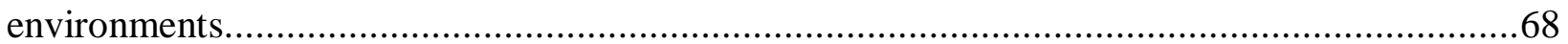

Table 11 Matrix of qualitative data capture methods and components ................................69

Table 12 Focus and description for the content collected through the instruments ..................74

Table 13 Table of criteria and instruments used in the research study ...............................74

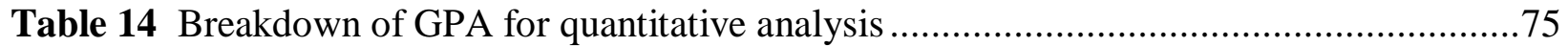

Table 15 Breakdown of pre-and post-test analysis criteria..........................................76

Table 16 A breakdown of the engagement survey content ........................................... 77

Table 17 A breakdown of the FCE and observation notetaking for qualitative analysis ...........78

Table 18 Background of the courses and number of courses used in the study ......................80

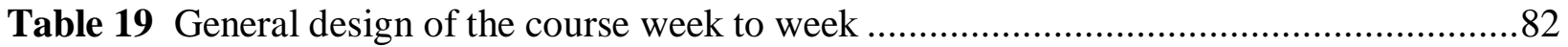

Table 20 Class GPA averages across traditional and flipped classes of all students ................83

Table 21 Descriptive statistics and ANCOVA results for class grade point average by delivery mechanism adjusting for pretest score ................................................................... 84

Table 22 Class averages on quiz assessments across traditional and flipped classes given per module.

Table 23 Descriptive statistics and ANCOVA results for average assessment score by delivery

mechanism adjusting for pretest score....

Table 24 Descriptive statistics and ANCOVA results for assessment 1 by delivery mechanism adjusting for pretest score.

Table 25 Descriptive statistics and ANCOVA results for assessment 2 by delivery mechanism adjusting for pretest score.

Table 26 Descriptive statistics and ANCOVA results for assessment 3 by delivery mechanism adjusting for pretest score.

Table 27 Descriptive statistics and ANCOVA results for assessment 4 by delivery mechanism adjusting for pretest score.

Table 28 Descriptive statistics and ANCOVA results for assessment 5 by delivery mechanism adjusting for pretest score.

Table 29 Class averages on weekly pre and post assessments across traditional and flipped classes....

Table 30 Descriptive statistics and ANCOVA results for posttest score by delivery mechanism adjusting for pretest score.

Table 31 Engagement survey descriptives among randomly selected students (distance flipped

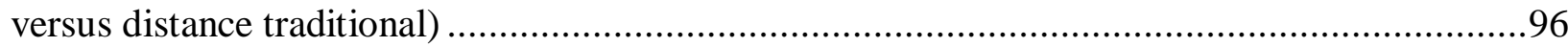

Table 32 Student-to-student interactions in online classroom comparisons.......................... 100 
Table 33 Student-to-TA interactions in online classroom comparisons 101

Table 34 Student to activity interactions in online distance education classroom comparisons 103

Table 35 Comparing overall experiences in online distance education classrooms

Table 36 Engagement survey descriptives among randomly selected students (flipped online versus traditional in-person lecture)

Table 37 Student-to-student interactions compared in online versus in-person classrooms .....110

Table 38 Student-to-student experiences in online classroom compared to in-person classroom

Table 39 Activity interaction experience comparisons in online and in-person classrooms .....113 Table 40 Overall engagement experience comparisons between online and in-person classrooms

Table 41 Observation results for engagement, learning and experience in an online flipped classroom.....

Table 42 Key observation points for results in changes in learning and engagement

Table 43 High-level outcomes of the two research questions and five observable points

Table 44 Comparing learning results between traditional and flipped instructional design ......135

Table 45 Comparing engagement results between traditional and flipped instructional design 141

Table 46 Analyzing class observables within the flipped classroom instructional design .........142

Table 47 Correlations between students' observed keywords in engagement, learning and overall experience

Table 48 Overall correlations and comparisons of the research questions

Table 49 Comparing learning results between T2DF and traditional/flipped instructional design

Table 50 Comparing engagement results between T2DF and traditional/flipped instructional design .....

Table 51 Comparing engagement results between traditional and flipped instructional design through observations 


\section{Table of Figures}

Figure 1 Differentiating synchronous and asynchronous learning in digital classrooms.............3

Figure 2 A proposed flipped classroom approach model ...........................................4

Figure 3 Current and future transistor growth ....................................................... 15

Figure 4 Students continue to increase taking online courses ....................................... 17

Figure 5 Scaffolding learning process model example ............................................21

Figure 6 Broad measurements of quality and effectiveness factors.....................................22

Figure 7 Example of a flipped classroom model for in and out-of-class learning....................26

Figure 8 Adapting a MOOC to instructional design for synchronous (2-way) engagement.......32

Figure 9 Contextual learning through passive modes of information delivery .......................34

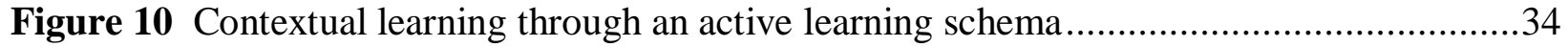

Figure 11 An Example Framework for Student-Centered Guest Lecturing ............................36

Figure 12 Modeling a course sequence for chunking components from class topics ................43

Figure 13 Passive and active models........................................................................52

Figure 14 The a priori power analysis used in the study for t-test analysis and ANCOVA .......54

Figure 15 Using RAND and RANK to do random selection in Excel (GPA Example) ............55

Figure 16 Path of learning for passive and active learners with data collection points .............62

Figure 17 Example screen capture of an assessment question answered partially correct. .......64

Figure 18 Course trajectory and data collection points............................................65

Figure 19 Course trajectory and qualitative data points ............................................68

Figure 20 Scatterplot of traditional versus flipped classroom by GPA...............................84

Figure 21 Flipped distance (left) versus traditional in-person lecture (right) quiz assessment

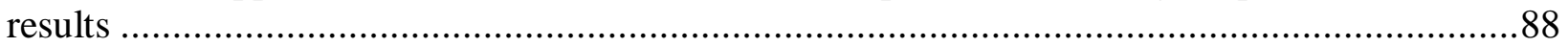

Figure 22 Flipped distance (left) versus in-person lecture (right), perceptions in pre-course

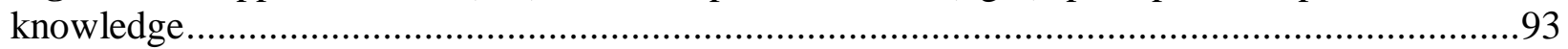

Figure 23 Flipped distance (left) versus in-person lecture (right), perceptions in post-course knowledge....

Figure 24 Flipped distance (left) versus in-person lecture (right), change in perceived learning

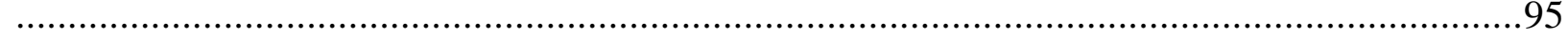

Figure 25 Comparison of responses for prior online classes that included live participation .....98

Figure 26 Comparison of responses for prior online classes that did not include live participation

Figure 27 Student-to-student interactions in online distance education classroom comparisons

Figure 28 Student-to-Instructor/TA interactions in online distance education classroom comparisons

Figure 29 Student activity interactions in online distance education classroom comparisons .. 103

Figure 30 Comparing engagement in online distance education classrooms 105

Figure 31 Comparison of flipped online distance education to traditional lecture-based in-class delivery

Figure 32 Student-to-student interactions in distance versus in-person classroom comparisons

Figure 33 Student-to-TA/Instructor interactions in online versus in-person classrooms..........112

Figure 34 Activity interaction comparisons in distance versus in-person classrooms.............114 
Figure 35 Overall engagement experience comparisons in distance versus in-person classrooms

Figure 36 Comparing flipped online to active and passive lecture-based in-person classes.....117

Figure 37 Observation data for engagement in a flipped online classroom .........................120

Figure 38 Word cloud of positive engagement key terms and phrases.............................. 121

Figure 39 Word cloud of key terms and phrases for neutral or negative engagement.............122

Figure 40 Observation results for learning in a flipped online classroom ............................ 123

Figure 41 Word cloud of key terms and phrases about positive learning experiences ............. 124

Figure 42 Word cloud of key terms and phrases in neutral or negative learning experiences .. 125

Figure 43 Observation data for overall experiences in a flipped online classroom design ....... 126

Figure 44 Word cloud of key terms and phrases in positive overall experiences................... 127

Figure 45 Word cloud of key terms and phrases for neutral or negative overall experiences ..128

Figure 46 Percentage of perceived sentiments separated by category ............................... 143

Figure 47 Percentage of perceived sentiments across the three categories ........................... 157

Figure 48 Examining positive keyword phrasing for learning, engagement and experiences in

T2DF students 167

Figure 49 Three charts showing engagement, learning and experience sentiments of T2DF students. 


\section{Chapter 1: Introduction}

\section{Purpose Statement}

Educational strategies through distance education have been examined throughout the history of teaching and learning by theorists, practitioners and many others with interests in academic and nonacademic areas. The challenge of the teacher is to scrutinize and evaluate the best models of instruction to create the most effective ways to implement a conceptual framework of learning. In higher education, and especially in science, technology, engineering and mathematics (STEM) classes, instructors and students generally use passive modes of teaching and learning, and these modes of instruction continue to be used in online courses. These instructional decisions are often the result of instructors' lack of knowledge about the benefits of active learning, and how to use technology to support active learning in online environments.

Close to 6.4 million students, or about $43 \%$ of all higher education students, are taking at least one fully online course (Seaman et al., 2018), and approximately 50\% of those are taking online courses exclusively. It's important to note these numbers represent a continual increase in the number of students taking online courses year after year and coincide with a steady decline in the number of traditional on-campus students. These trends are expected to continue into the 2020s and beyond. Lifelong learning continues to not only become more popular, but also more of a necessity. Humans are living longer with advances in medication, healing and nutrition, which leads to a higher average life expectancy, which is at 79. Generations $Y, Z$ and Alpha are expected to have a $50 \%$ greater chance of living to 100 (Grushka-Cockayne, 2018) than prior generations. This has profound effects on the dynamics of the job market as workers average about 13 job changes in a career. Seventy years ago, most individuals would work a single job and retire at the age of 65 (Grushka-Cockayne, 2018). These changes in employment dynamics result in a need for more opportunities to gain new knowledge or learn new skills. Generally, this puts more of a reliance on online education needs as the student juggles other commitments including work, family and other interests. Having the flexibility and financial means to take classes becomes of even greater importance to the student. This is an area where online distance 
education can regularly garner better results than its traditional counterpart (Allen \& Seaman, 2017).

Retaining attention in the classroom is a challenge when students, instructors and distracting technologies are all in the same room. Some research suggests attention spans for lecture retaining are about $70 \%$ for the first 10 minutes and $20 \%$ thereafter (Prince, 2004). Even as new technology for tracking student engagement is developed, the difficulty in comparing inperson students and instructors with those separated by a computer screen is still apparent (Garza Mitchell, 2009). Students can easily be distracted by the multitude of attention-grabbing opportunities at their fingertips, and instructors often cannot see the student to determine if they are engaged. The challenges of technology and what can potentially affect learning, many times negatively, are challenges with the current teaching models employed through online distance education. One study (Ke \& Kwak, 2013) has shown that active learning as one of five key constructs may not just be an enhancement but actually necessary for student satisfaction in an online class, along with technological competence, learner autonomy, authentic learning and relevance of the material to the learner.

\section{Significance of the Study}

One key focus in this study is the exploration of and building on the assumptions that a learning-through-doing experience can create a positive level of learning, which has been explored in prior research (Michel et al., 2009) reinforcing learning from student action. That engagement from the learner's perspective is validated and this type of learning environment can encourage positive output through online mechanisms that deliver content with a rich and full educational experience, mimicking or increasing current in-class experiences. This study examines the flipped classroom model of instruction, which involves putting the traditional inclass instructional lecture on a video that students watch on their own time. The model also removes the traditional take-home assignment and re-creates it as an in-class assignment for the students and instructor to work on together (Jon Bergmann \& Sams, 2014). There is minimal current research or application of the flipped classroom design, but there is research that construction of context created through active learning can address issues with problems in transmitted data not being retained by the learner to be utilized in the future (Kumar et al., 2017). 
It should also be noted that there is research showing that simply comparing learning in an online class to a traditional face-to-face (F2F) class is negligible, as online technologies have evolved (Abrami et al., 2011) and will continue to evolve. The following figure illustrates how synchronous (live or active, occurring simultaneously) participation can improve interest and personal introspection while asynchronous (not live or passive, occurring in a different time) methods can lead to more cognitive reflection (Hrastinski, 2008). Studies have shown this to be the case in traditional classrooms, but it has become much more profound in digitized learning where balancing active versus passive modes of learning become even more important.

\section{Figure 1}

Differentiating synchronous and asynchronous learning in digital classrooms

\section{Cognitive and Personal Dimensions of E-Learning}

Asynchronous E-Learning

$\checkmark$

\section{Cognitive Participation}

Increased reflection and ability

to process information

Synchronous E-Learning

Personal Participation Increased arousal, motivation and convergence on meaning

Note: From "A study of asynchronous and synchronous learning methods discovered that each supports different purposes" by (Hrastinski, 2008), Educause Quarterly, 4, p. 54.

Current research considers the use of the flipped classroom instructional model in an online environment to improve student learning and engagement. Historically, the flipped classroom model is based on the reversal of in-class and out-of-class roles. The in-class roles of the instructor-driven lecture, discussion and activity are out of the classroom, while class time is used to create an environment that allows for application of the out-of-class learning in hopes of promoting positive information dissemination and application. By supporting a teaching and learning approach of flipping the instruction out of the classroom, class time can be utilized for 
active learning approaches such as activities, team-based learning and other methods of problem solving (M. K. Kim et al., 2014).

\section{Figure 2}

A proposed flipped classroom approach model

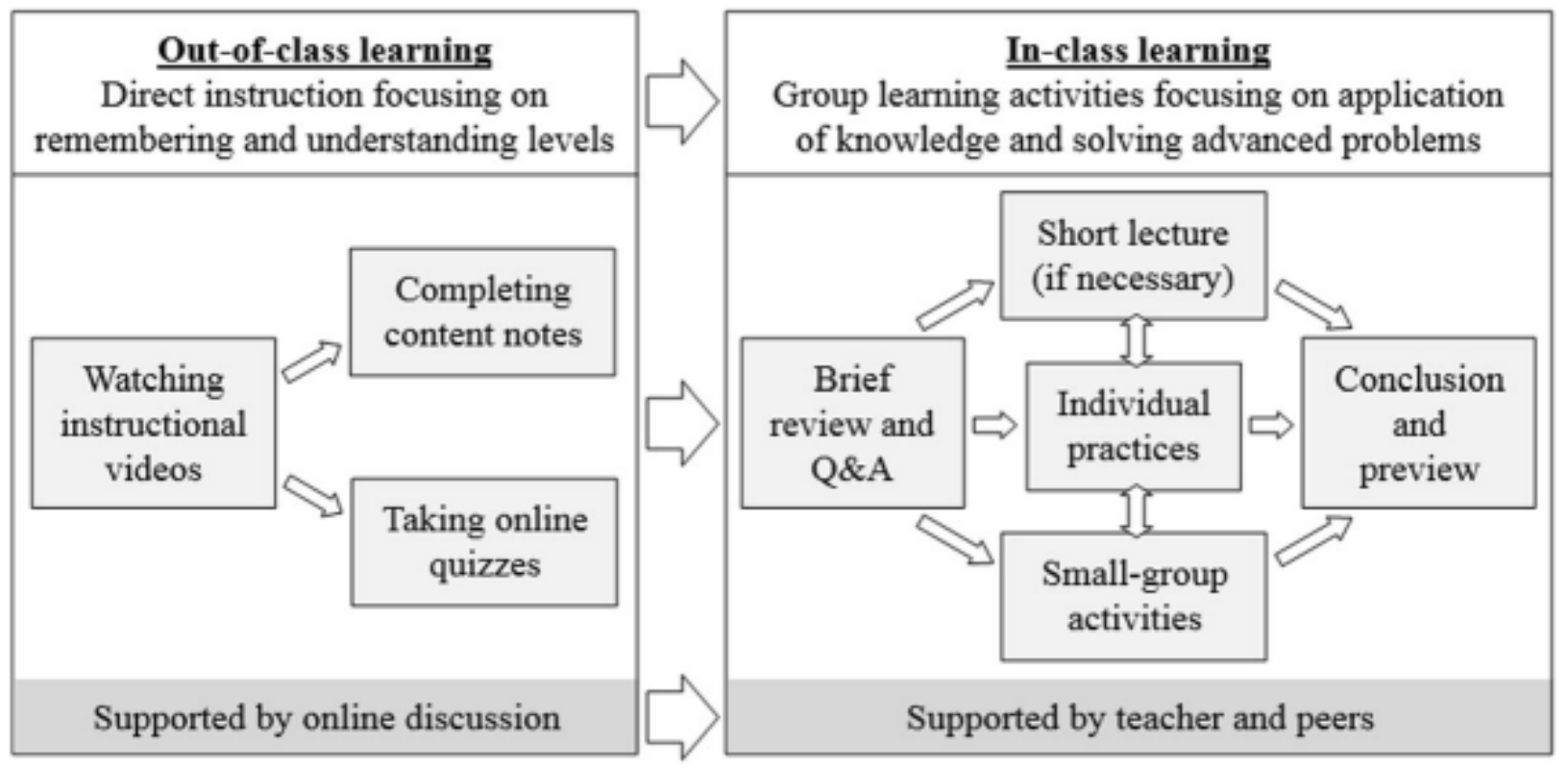

Note: From "A critical review of flipped classroom challenges in K-12 education: possible solutions and recommendations for future research" by (Lo \& Hew, 2017), The International Journal of Management Education, 16, p. 13.

The flipped classroom model encourages the student to learn about the material prior to entering an active learning environment in a classroom. The instructor now has a chance for more individualized instruction and more thorough group discussions. (Lo \& Hew, 2017). He or she can now guide the class into a more practical application of the tools learned instead of solely utilizing or relying on rote memorization, which is often ineffective for real-world learning beyond the student's ability to regurgitate the material. Memorization of content is only one part of learning to apply new skills.

In many cases, to have the most effective engagement of students and to promote higher orders of learning, one needs to move past traditional forms of lecture-based or lecture-only styles of instruction (O'Flaherty \& Phillips, 2015). Going beyond the lecture and applying 
engaging activities has the effect of increased retention of skills through application. As one study points out (Jonassen, 2012), "learning is a willful, intentional, active conscious, constructive practice that includes reciprocal intention-action-reflection activities." For example, one can learn to play a guitar chord through repetition, while memorizing the shape of a chord may entail occupation of the entire working memory (Abeysekera \& Dawson, 2015). In data collected from students subjected to static listening for learning, the goal of the lecture as an "ends to the mean" to transmit static data may not be the best approach, and is shown as less effective in personal development, teaching skills and educational values (Abeysekera \& Dawson, 2015).

A prime example of flipped learning is in how the information of the proposed topics in the class can be disseminated to students. The challenges arise when addressing students for critical problem solving and deeper thinking, as well as enhancing motivations and aspirations for increasing students' efforts and formulating ways that work across student bodies (Pienta, 2016). Instead of the traditional in-class lectures where students receive information and learn at the same pace, the instructor can deliver the material to individuals remotely who find their own time to review and learn the information. This in turn gives the student the increased flexibility to better choose their own time and place of learning and performing subsequent class tasks and responsibilities (Sun et al., 2017). When classes are in session, the instructor can concentrate on engaging the students individually through a variety of in-class activities that could include group or individual assignments, practical application, examinations or other interactive ways of deeper analysis. In this kind of class environment, students are more likely to be in control of their own learning and become more participatory in higher-order tasks and engagements (M. K. Kim et al., 2014).

With online education becoming extremely popular, particularly with technology continually increasing the ability to reach students outside of a traditional brick-and-mortar institution, there is a need to explore how learning can be effectively conveyed through these delivery mechanisms. A lot of current research charges higher education institutions are failing to adequately train or prepare students and as such are facing widening scrutiny of their responsibilities. The structure of education in general has changed only slightly over the past two decades, even though online learning technologies have advanced, allowing for adaption of newer pedagogical approaches (M. Kim et al., 2016). Variations of course creation and content 
can be attributed to the roles of the teacher creating and maintaining most of the content, overshadowing instructional design by others and taking a "lone ranger" approach (Anderson, 2004).

\section{What This Study Works to Discover and Validate}

The broad issues addressed in this research study are to examine ways to improve education, and more specifically, to concentrate on how a student learns, retains and applies skills related to the course content. This is through current online education mechanisms and through expected future platforms at institutions of post-secondary education. Schools can encourage more social constructivist educational theories and enhance environments for increasing deeper learning from students with the many different learning management systems available, particularly in higher education institutions (Abdallah, 2009). This focus explores whether increases in the potential of learning on current platforms can be increased by utilizing active learning models of instruction, and whether students experience increased engagement in a flipped distance classroom more so than the traditional on-campus classroom. In effect, this study questions and seeks to answer whether the active learning model of online instruction can be can be more effective for post-secondary students than a passive, lecture-based approach to online education.

This study looks at the potential of applying the flipped classroom model to a fully online classroom and whether the delivery of content can mimic or enhance what traditional classes offer through the use of modern communication and digital technology. In the current generations of $\mathrm{Y}, \mathrm{Z}$ and even $\mathrm{X}$, these learners are adapted to a digital world that includes the use of many devices and experiences through the internet and their mobile phone. To encourage better learning, didactic aids and methods can help in the development of study skills, encourage more student abilities and increase intelligence (Ferrer-Torregrosa et al., 2016).

There is limited empirical data to show the effects of flipped classroom learning through technology-enhanced online education, as well as a lack of proven formulas to guide instructional design of effective flipped classrooms. However, flipped learning benefits are shown more through accurate assessment (enhanced by positive technology use), efficient use of class time and individualized attention. What this does is allow for independent learners to be encouraged through differentiated instruction (Abdurachmanov, 2016). In examining online 
instruction, bridging the gaps between technology and instructional design are the keys to successful flipped online learning environment and so are a focus in this study.

\section{New Potential Findings in this Study}

This study concentrates on mechanisms of online distance education and passive versus active learning (utilizing the flipped classroom instructional design). Comparisons and contrasts are drawn to show potential changes in learning, engagement and overall experiences in the different instructional designs and platforms. It will also be shown that we need to look more indepth at using this type of instructional design across online education because of the lack of research available on how to apply flipped classroom models to a fully online classroom. The concentration of coursework in this study crosses through STEM subjects as well as business applications that don't exist in the minimal research offerings. In the process of this study, and in the research questions identified above, there may be findings that show an increase in learning and engagement specifically for these areas of concentration. There may also be findings that show an increase for the level of students, varying ages, degree program, ethnicities and other factors that are collected in the study. Reviews of potential correlations across all areas can be done in future studies and may provide increased benefits in determining other factors that are applicable to learning and engagement through the data collection and analysis performed.

\section{Potential Audiences}

There is potential for a wide array of audiences for this research which would include those working in different roles in secondary and post-secondary schools as well as professional learning environments. The highlighted focus is post-secondary, but the research can be amply applied to secondary schools as it focuses on the three types of interactions (M. G. Moore, 1972) and how the flipped classroom can increase student engagement. This research could also apply to companies that have an interest in professional development or skill-building courses such as executive education, boot camps, short coursework and certifications. In another setting, educational scenarios that require physical interactions (e.g. working with electronic components or chemicals) could also be improved if students have access to the proper equipment during the class. In many cases, students have an added benefit of working with instructors without the restrictions of time-based or scheduled in-class instruction. 
Furthermore, any other systems of education could potentially use the results of this study to encourage use of a flipped classroom model through online distance education to potentially enhance underperforming models. For example in one study (Koper, 2014), a school is evaluated in their approach to online distance education and questions whether it's performed correctly, what the added value is and what the performance of online education is by the school. To summarize, interested audiences for this research would include teachers, instructors, professors, principals, deans, researchers, managers, directors, team leaders, professional development employees, human resources personnel and others interested in teaching or disseminating information through online learning mechanisms.

\section{Description of the Intervention}

The intervention of modifying the instructional design (ID) is implemented through changes in the (ID) model. The study takes what is referred to as the traditional model of instructional design, described as an in-person or in-classroom lecture driven model and flips the in-class portion to an assignment outside of the class. This is done through a prerecording of the lecture that is given to students to watch on their own time. This will help to prepare them for the now open classroom time the lecture formerly would have taken. Class time is now used for discussion of the material, doing activities that would have formerly been given as assignments to be done outside of the class, and review of pre-learning and engagement activities. What makes the flipped classroom truly active compared to the traditional class is the engaging activities and live, in-person class time dedicated to these activities. As the lecture-based class still gives some room for interactions and can be considered to support active learning through discussion, its primary focus is on the lecture. The flipped classroom in this study, however, embraces most of the predetermined class time to promote active engagements. Lecture-based classes, to the contrary, generally support more one-way communication and dissemination of information and have less time for active engagements. These are the two main intervention areas from which the study will collect and analyze data. Another task would be to determine whether there are changes necessary to the course based on the instructional design. In the case of the course used in this study, there were no changes deemed to be necessary to support the changes in the ID. 
The first area of this intervention looks at student outcomes through the flipped classroom model. Learning is to be determined by the output of the student based on the work they perform, which would be reviewed through a culmination of their grades, referred to in this study as the grade point average (GPA). This will include all results except for bonus quizzes that are given throughout the semester. The quizzes are used as the second instrument to gauge learning changes from the five collection points and are separate from the GPA. The third instrument to gauge intervention results involves the perceptions of learning. Students will take a pretest determining baseline knowledge, and then a test after the class to determine changes in knowledge.

Student and instructor motivations are an important part of this study, and so looking at the potential of instructional design to have a positive effect on the student is thoroughly examined. Student motivations are determined as changes in the experience and/or the perceptions of engagement within the classroom, and these can be with the classroom itself, with the instructor, with classroom peers, or a combination of any of these criteria. Two separate instruments used for gathering data from students are applied to analyze perceptions of their engagement and experiences in the course.

The first instrument is the Faculty Course Evaluation (FCE), which is given at the end of the semester (see appendix B) and incorporates both quantitative and qualitative components to gather data. The quantitative data can be used to scale the perceptions of engagement, whereas the qualitative data can be used to show perceived experiences of engagement, both showing subjective measures. The second instrument is an Engagement Survey Assessment (see appendix F) also given at the end of the semester that focuses on comparing experiences with other online courses as well as online courses not utilizing the flipped classroom model of instruction to gauge perceptions of engagement through correlations between their experiences. Both evaluations include quantitative and qualitative metrics for gauging and examining changes, perceived experiences and the potential of change in overall engagements with the learner.

\section{Research Questions}

The following are the two major research questions used to guide the study that look at the effects of a specific instructional design of active learning through the flipped classroom across online platforms. 


\section{Primary Focus Questions:}

RQ1: What are the differences in student learning in an online course designed to support active learning using a flipped classroom model versus learning in a traditional instructional model?

H1: Active learning with a flipped, online classroom strategy will increase learning more so than passive learning through the traditional lecture-based inclass approach.

RQ2: How do students experience engagement in an online course designed to support active learning using a flipped classroom model of instruction versus a traditional instructional model?

$\mathrm{H} 2$ : Students experience more engagement in an online course designed to support active learning in a flipped classroom than in a traditional lecture-based in-person class.

These questions address whether a social constructivist approach with the flipped classroom through online education shows increased learning and engagement in post-secondary students as opposed to those in the traditional, lecture-based face-to-face course.

The social constructivist approach is a theory of learning that stresses a focus on knowledge building by linking the cognitive components to the social components through collaborations within the learning environment (Windschitl, 2002). This adds an alternative component of creating more social interaction and experience to the traditional constructivist view of learning, where the concentration is in the independence in active learning, creating worldly experiences by developing a process to knowledge building that comes from dialog and interaction (Alt, 2017). This is then broken down into the two research questions to look at a type of constructivist approach, the technologies used to host the approach and the learning and engagement experiences compared between the online and traditional class. 


\section{Description of the Research Study Chapters}

This study includes five chapters that examine the research questions provided in the following areas: introduction, literature review, methods, results and discussion. The first chapter includes the motivation for the research, background on what makes research into instructional design and digital platforms important, what this study proposes to explore and validate, how this might affect learning and engagements through current digital mechanisms and the audiences that would be most interested in this type of research. Students may also be interested in this study as it shows multiple ways of information dissemination as well as how interventions of learning can take place. Finally, showing the research questions that ground the study into two unique and pointed areas of learning and engagement help to guide the reader into what to expect from the introductory content. This will allow a better understanding of the direction the research takes in examining changes of learning and engagement of learners.

Chapter 2 describes the landscape of research from several areas including looking at higher education from both an academic and business perspective, with each having major impacts on what takes place within the environment of teaching and learning as well as a reflection on historical contexts that have ramifications for the trends and developments of academia. Understanding the roles of digital platforms and technologies in education is extremely important to this research. Knowing the differences and nuances in technology types and how each fits within the teaching and learning landscape is key. Instructional design methods from active and passive perspectives play a vital role in comparing and looking at contrasts in the different styles of instructional design and delivery of content, looking for similarities and differences in delivery and outcomes.

Application of flipped classroom models in online education is the primary focus of this study, as is looking at current research that can help guide our knowledge of what has taken place and what may be missing. This review shows there is a wide gap in this type of applicability up to the time of providing this research. Looking at applicability of flipped classrooms in online education is another fundamental part of this study and delves deeper into understanding synergies between the two. Understanding what gaps still exist and ways to fill the gaps make up the primary focus and applicability of expectations from this work.

Chapters 3 and 4 discuss the methodology and results of the data collection and analysis, which took place over the course of seven semesters and two years of coursework between 2018 
and 2020. Data collection reviews the selection of students in the study including their backgrounds, demographics and what types of learners they are, as well as the data sources that correlate to those students. The research questions are reviewed through the strategies of the models of instruction applied and limitations of the data sources, data collection procedures, and analysis. The data collection instruments are reviewed as well, including quantitative assessments and qualitative surveys. Observational data and examples of these instruments are shown in the appendices which include how the content was gathered. The results are analyzed through the measures provided and are used to draw conclusions through the discussions given in chapter 5. These show the varying correlations across the two types of classrooms, traditional and online, and the results of the application of passive versus active instructional design.

Chapter 5 gives a full summarization of the findings and analysis of those, including an understanding of the theoretical implications of the research findings, implications to development of pedagogy and more pointedly for this research study, andragogy and the focus on adult learning. The research drives recommendations for instructional design, issues and limitations in the research, as well as do's and don'ts of applying this research that can also be wrapped up in a summation of potential and future research opportunities stemming from this work.

\section{Chapter Summary}

The purpose of this study is to explore, develop and validate a model of instruction that will increase the potential of learning and engagement via fully online education (Web 2.0/3.0 and the future of 4.0) technologies (Hemmi et al., 2009) with the application of the flipped classroom. This study asks whether building from social constructivist style approaches as applied to online education can show increased learning in post-secondary students, and can they have an enhanced experience over traditional and more passive learning environments. Other benefits of flipping the classroom are opportunities in which other active measures can be applied, such as in-class exercises, team-based work and deeper critical thinking activities. Many face-to-face courses developed for online distance education are passively connected and involve the use of documents (PowerPoint, Word, PDF, etc.), audio/video mechanisms (MOOC's, pre-recorded videos, audio books, etc.), and one-way synchronous approaches to collaboration between students and the instructor (through learning management 
systems such as Canvas, Blackboard, Edmodo, etc.). These can all be very valuable and have proven in many cases to be educationally beneficial through redesign of academic approaches while still adhering to the pedagogical principles of the learning environment (Rawlings et al., 2017). This research, however, looks at increasing educational value through other effective asynchronous methods that encourage engagement such as online chatrooms, virtual classrooms, flipped classroom instructional strategies (having the learner perform actions in online sessions instead of lectures), in-class synchronous activities, and team-based projects that could be utilized to enhance the learning experience. The promise of increasing educational value is based on supporting research (Martin \& Bolliger, 2018) that shows the importance of engagement in online learning environments to learner motivation, reducing the feelings of isolation and increasing overall satisfaction in the course.

This study explores whether an active flipped classroom can be more effective for postsecondary students than a passive, lecture-based approach to online education. The research looks to gain additional insight into whether engagements increase, experiences are more robust, and obtaining and applying content can be obtained at a much deeper level than current methods can provide. As I have been an instructor in higher education over the past 10 years, part of my motivation for this research is to answer the questions of whether online distance education is providing enough learning and engagement in the current state, and whether alternative instructional design methods need to be considered. Considering my experience as a student in classes that mostly employed passive-based modes of instruction (both in-person and online), and the difficulties of learning through extended lectures, better instructional design may increase relevancy of learning through digital mechanisms, particularly in a world where increases in online education continue and become more relevant. 


\section{Chapter 2: Literature Review}

Addressing the flipped classroom in online education requires a full assessment of several topics in the literature review. These topics include covering the current state of higher education, online delivery mechanisms, active versus passive delivery of instruction, reviewing the research of combined delivery mechanisms with the flipped classroom models of instruction to encompass the enriching of the learner's experience (examining both learning and engagement), and looking at the flipped classroom as a specific active learning instructional design as applied to the online classroom.

\section{The Current State of the Higher Education Classroom}

Classrooms in the United States and globally have seen a dramatic change over the last 20-plus years. Gordon Moore, a computer engineer and originator of "Moore's Law," made an observation during the development of the transistor and wrote a paper stating his projection that the number of transistors in a dense integrated circuit would double about every two years $(\mathrm{G}$. E. Moore, 1998). What Moore's findings led to is what we are experiencing in the modern era: the exponential gains of computer and networking abilities which have moved from the labs, colleges and businesses (that at the time were the only entities that could afford and/or fit one on their premises), to ones that became more affordable and small enough to fit in an individual's pocket. Even though this doubling has slowed over the past few years, new and emergent technologies such as nanosheet transistors, 5G wireless technology and DNA storage all continue to follow and support Moore's Law growth through the next decade (Greengard, 2020). 


\section{Figure 3}

\section{Current and future transistor growth}

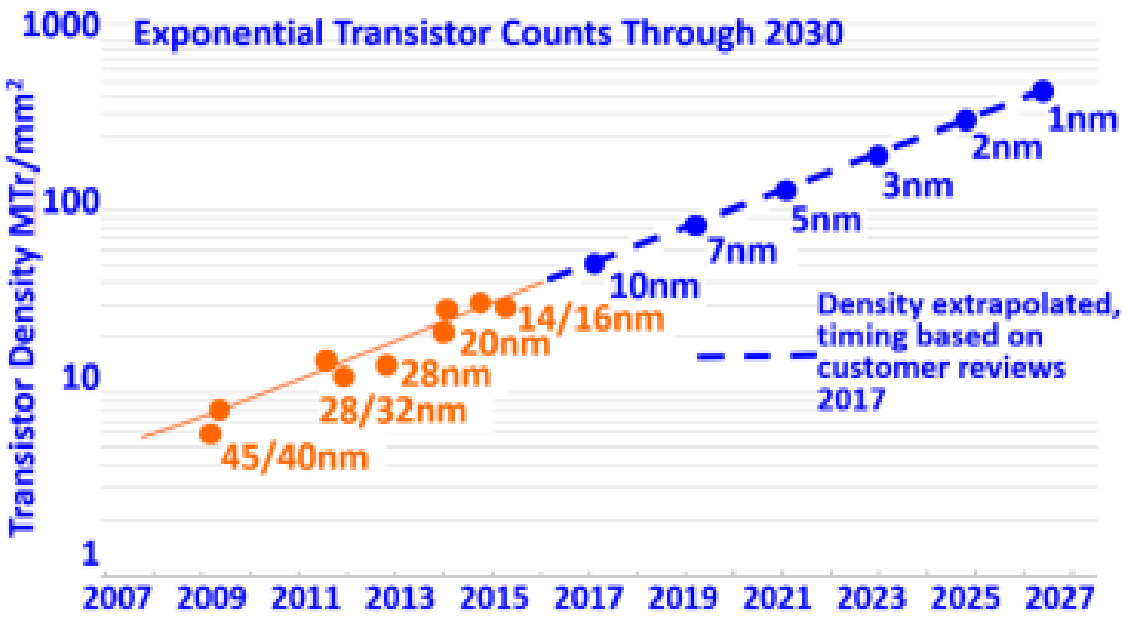

Note: from “Saving the Future of Moore's Law," by (Yellin, 2019), Dell Technologies, p. 29.

Hardware devices such as augmented reality (AR) and virtual reality (VR) headsets, new classes of Internet of Things (IoT) devices, robotics and increasingly more adaptive learning systems (Petkovics, 2018) are publicly available with wider adoption around the corner. Looking into 2021 and beyond, computer technology has permeated and affected almost every aspect of human life. IT will continue to become more broadly used as these technologies become as cheap and ubiquitous as prior disrupters turned utility, such as electricity when it energized our houses and factories, or the power of the steam engine (Carr, 2007) to move large quantities of goods at a fast rate. Advancements in quantum computing have also increased our ability to solve difficult algorithmic problems and are challenging traditional computing platforms to solve complex problems through redefining how the use of transistors as the mechanism behind computing power is changed into use of qubits. Technology similarly has created a buzz among administrators and faculty over the basic approach to student education, questioning the traditional methods with opportunities derived from newer technological innovations (Bacow et al., 2015) driving online education and other forms of educational technologies. At the same time, not all educators will have the necessary skills to implement appropriate technologies (Scaffhauser, 2020). The rapid advances are pushing more schools to consider technology training for educational environments. 
Starting with multimedia computers, the boom of networking (Zong et al., 2018) and creation of the widely accessible internet in the mid to late 1990s, colleges have been trying to leverage these technologies to figure out better ways to deliver content, create a better learning experience and to generally increase learning potential to entice students to enroll. Part of the popularity in digital disruption and transformation of education is due to student demands for increased educational flexibility that fits in with the demands of work, home and school priorities (Galusha, 1997). These demands have put colleges into a position that requires a way to create this flexibility through increasing use of computer and networking technologies to create online classrooms, which can be accessed anytime, anywhere and from any internet-enabled device. With the use of technology in mind, schools are faced with figuring out the best information and communication technologies (Petkovics, 2018) to better meet those needs in a rapidly changing technological society.

What this has led to is a boom in online education shown by the National Center for Education Statistics (NCES) and the Babson Survey Research Group (Seaman et al., 2018). The reality is that universities in 1999 were showing a smaller but respectable $8 \%$ of all students taking at least one class online and that has increased substantially to $43 \%$ in 2016 . About $35 \%$ of universities in 2002 were offering at least one fully online degree, and that number almost doubled by 2016. Students are also showing increases in online education access, with around 1.6 million taking at least one online course in 2002. That increased threefold to 5.8 million in 2016. This is not due to an increase of the student population (overall enrollment decreased by $7 \%$ between 2010 and 2017) and are much more about a shift in how students are taking courses, as the number of students studying on campus and not taking any distance courses has declined by $6.4 \%$ (approximately 1.2 million).

It's also important to note that for-profit institutions have seen a bigger overall decrease in enrollments over public and private institutions (over 40\%). For example, two statistics in West Virginia show that $87 \%$ of non-resident students were taking distance classes at all schools in that state, and over $50 \%$ of students enrolled in West Virginia in higher education classes were taking them online. Access to education is also an issue where technology can solve a lot of these issues and level the playing field, but where internet access (e.g. 1.2 million Missourians still without broadband access in 2020) being required to utilize these educational platforms is still a big issue (Frederick, 2019). Understanding the technology that supports components of the 
flipped classroom is also important, as well as what the students will have and will need to have to support the learning environment (A. Miller, 2012).

\section{Figure 4}

Students continue to increase taking online courses

Number of Students TAKING No Distance Courses: 2012 TO 2016

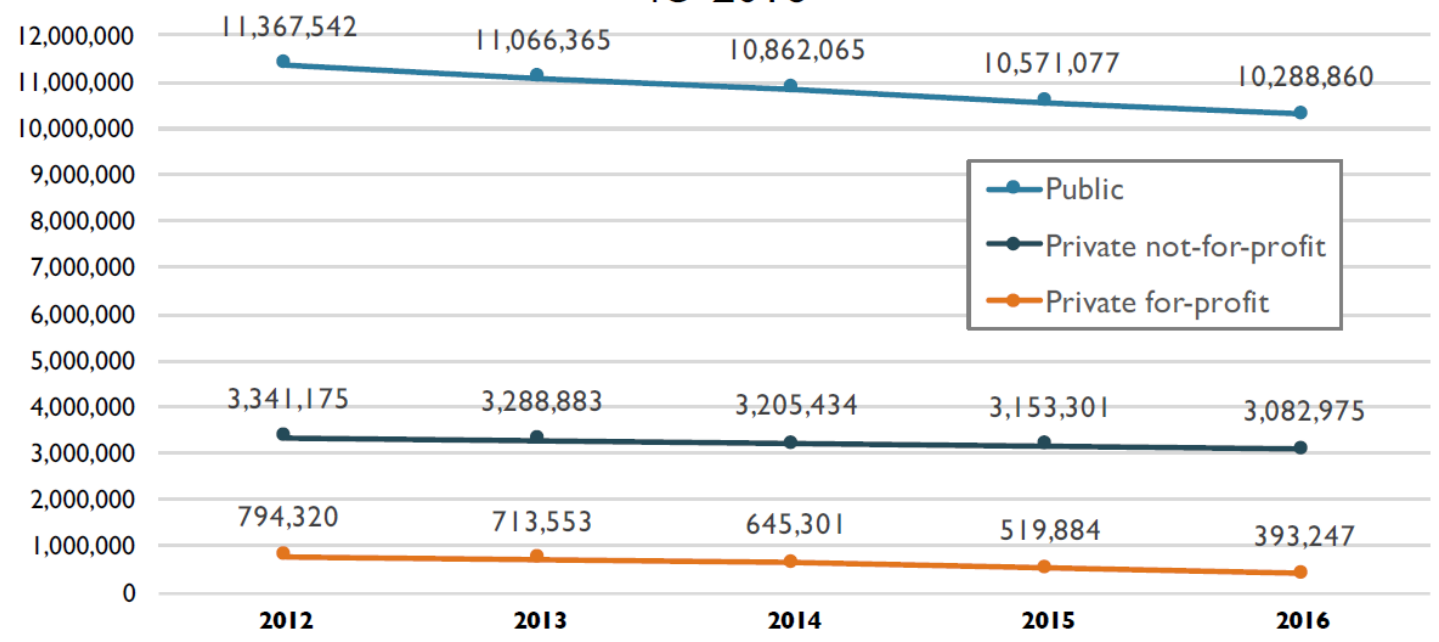

Note: From "Tracking Distance Education in the United States" by (Seaman et al., 2018), Babson Survey Research Group, p. 27.

Colleges are also seeing a need to move away from the pipeline business model to a more "platformized" one and are not safe from the transformation other businesses are experiencing (Manyika et al., 2017) due to the data processing and collection that drives academics and research. The pipeline model refers to the information and research universities produce and can disseminate to students and the global community in terms of value of the research. The platform model refers to the extension into new, digitized areas that increase the value of the school for the student going there. These areas could include reward systems or links to other digital content or services outside of normal academia and outside of the school's immediate control, or corporate partnerships that link platforms (Blumenstyk, 2014). The pipeline data has changed from a physical product written in books, magazines and research papers to digital data, creating a more pervasive and ubiquitous learning experience (Anshari et al., 2016). Not only are new products being created digitally, but the back catalog of this work is also becoming more 
digitized. This is important because digital media changes the very nature of how consumers (the learners, students, etc.) can access and consume these materials.

The first characteristic change is in replication and access to data. Prior to computer technology, if you wanted to replicate a book, magazine, video or audio recording, you would have to make a physical copy of that media. In the Second Machine Age, (Brynjolfsson and McAfee, 2014) the authors identify the ease of copying media to increasingly vast storage mediums, a continual decrease in cost per gigabyte of storage as well as an increase in the ability to access and download media more quickly. As the globe becomes more connected through the internet and cloud computing, accessibility to data is basically instantaneous if it is published to a publicly accessible location.

The second characteristic that is unique to digital media is the ability of it to be a nonrival component. Digital media can be accessed by anyone at any time with no concerns of one's access being denied by another. This barrier exists with physical media, as for example reading a book meant that it generally couldn't be shared to others without giving them the book, but digital media has changed those rules. The third characteristic change is in the cost to produce digital media. The cost of producing data is borne by those actually creating it. Once this content is created however, the data falls into the earlier two characteristics which makes copies of it cost-free. In turn, these platforms allow skilled humans to collaborate and allow drivers of the gig economy (crowdfunding, crowdsourcing, crowd creating, etc.) to cheapen this process even further, in many cases making the content virtually free for the owner (Powell, 2017). We have seen this in many examples. Wikipedia is a good example of a digital media platform that meets a culmination of these characteristics that has made encyclopedias such as Britannica and Funk and Wagnall's, a thing of the past (Greenstein, 2017).

Digital media shares similar characteristics with technological developments in the past. Clay tablets inscribed with archaic cuneiform writing to preserve information and thoughts were written over 40,000 years ago. In 1826, Joseph Niepce developed a light sensitive varnish that allowed for a live image to be replicated onto a piece of pewter. In 1876, Alexander Graham Bell developed a way to send analog audio across a wire, and then in 1878, Thomas Edison created a way to record that audio for repeated replay. Guglielmo Marconi came up with a way to broadcast this audio wirelessly in 1894. Edison developed the picture projector to replay captured images in the form of a video in 1895. The culmination of these abilities has 
corresponded to new ways to send, receive and capture data. Now we are seeing the evershrinking transistor allow these types of analog transmissions to be digitized for mass consumption, leading to easier and less costly ways to access education and changing the paradigm of how learners access it.

Long before digitization and online access, distance education has met with differing success over the past few centuries (K. Lee, 2017). The Boston Gazette offered correspondence courses in 1728 through the postal service. The University of London had similar offerings of degrees from a distance in 1858, and in 1892 the University of Wisconsin offered courses using the term "distance learning" for the first time. With the advent of audio and video came increased use of distance education. In 1906, the University of Wisconsin started recording and sending lectures through the postal service. Pennsylvania State University started offering courses broadcast over AM radio in 1922. The first fully distance learning institution, the Open University, was launched in London in 1969.

The third wave of distance education was enhanced through a digital transformation where universities in Canada and Germany harnessed their networking capabilities to give students around the world access to their academic offerings. The invention of the World Wide Web started a cultural shift of content accessibility globally, leading to the first fully online course on record at Penn State called "Commentary on Art" in 1995.

The coining of the term "e-learning" in 1999 brings us into the current landscape of online education where we are seeing a disruption to the learning and experience through a massive increase in distance educational offerings within all types of higher education institutions. There are also new players in the form of Massive Open Online Courses (MOOCs) (Hollands and Tirthali, 2014; Kumar et al., 2017) offered by for-profits companies such as EdX, Udacity and Kahn Academy, which do not have a traditional campus, and Grand Canyon University, which is heavily online (approximately $77 \%$, with campus enrollment about 23\%). According to a 2017 report from the Digital Learning Compass, over six million higher education students are taking online courses and $30 \%$ of all higher education students now take at least one course online (Allen \& Seaman, 2017).

We are also seeing an unbundling and re-bundling of services provided by educational institutions to better meet the needs of students, leading to more short-term academic awards such as certifications that fill the gaps for vacant positions (Darkwa, 2019). This is in tandem 
with the myriad educational offerings, whether positive or negative (negative being information that is incorrect, inaccurate or otherwise deceptive), that anyone has access too. Instructional videos on YouTube, professional lessons on LinkedIn Learning and scholarly work on Google Scholar are just a few of the many examples of the changing education landscape from a brickand-mortar institution to one that offers a "learn at home" style of education. This is requiring academic institutions to continually and radically evolve, or at least take a hard look at changing traditional forms of educational delivery in fear of not being relevant in the $21^{\text {st }}$ century (Vey et al., 2017).

With ease of access from a distance come certain barriers that keep students from being successful, such as a loss of face-to-face contact with teachers and peers that reduces motivation (Galusha, 1997) and a focus on memorization of content rather than memorization of actions. Learning should be concentrating on connecting and manipulating content rather than memorizing isolated facts (Gee, 2003). An example of this is through scaffolding and encouraging creation of neuropathways, which can increase the retention of learning and proficiency of what is being learned. Fading of scaffolds tends to take place as the locus of responsibility shifts to the independent learner, but with classroom scaffolding the learning can be greatly enhanced between active participants providing scenarios that cannot be realized independently (M. C. Kim \& Hannafin, 2011). The following figure outlines a process for scaffolding learning that can be harnessed through the flipped classroom model and that can directly apply to the focus of this research study with a flipped classroom mode of instructional design and delivery. 


\section{Figure 5}

\section{Scaffolding learning process model example}

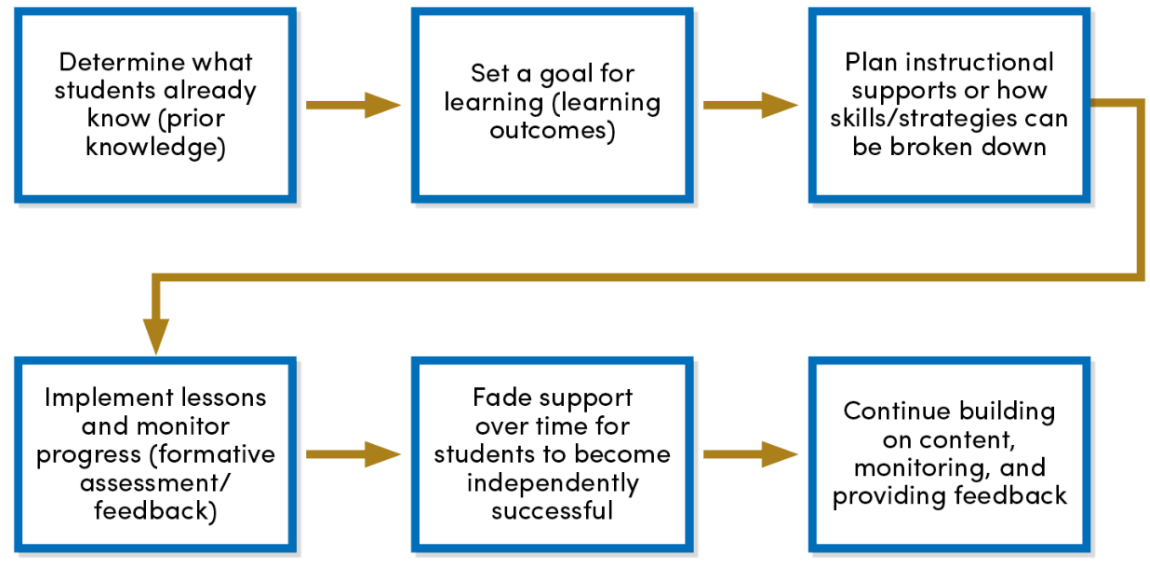

Note: From "The Center for Educational Innovation (CEI) by the (University at Buffalo, 2020)

These types of learning models of instruction are, according to research (M. C. Kim \& Hannafin, 2011), still showing slow progress as use of technological tools in schools has been scarce for problem-solving styles of teaching and learning. The study (M. C. Kim \& Hannafin, 2011) also notes there is no substantial or sustainable support for student-centered problemsolving due to old teaching tricks based on traditional, didactic beliefs. There is, however, research that shows active learning, such as that which promotes engagement in problem-solving as social interactions, can positively increase formative assessments of student learning $(\mathrm{F}$. H. Wang, 2017). Assessment and curriculum pressures based on limited resources, and timing creating competition between those resources, make promotion of student-centered and technology-rich problem-solving very challenging for teachers to employ enhanced teaching and learning practices.

One of the bigger problems facing universities is how to best implement good instructional theory into an online learning platform that meets students' learning needs. There are concerns about the quality of technologies and their impact (Ally \& Prieto-Blázquez, 2014) on students, suggesting teachers and instructors may need to adapt their styles of academic instruction to the different technologies (Clow, 1999) afforded to them. This also created the growing concern that online classrooms cannot match the rigor, experience or the one-on-one 
time that a learner can get through an on-campus class. Professors struggle to adapt their teaching styles to their curriculum or refuse to make changes that may work more effectively through an online platform or have lost control of the curriculum deployment (Caruth \& Caruth, 2013). E-learning mechanisms for which an instructor isn't properly trained or that involve significant paradigm challenges (Thompson, 2012), especially when pushing content that's less clear or lacking some coherence, can cause disorganization within the classroom. This can diminish the learner's experience, as well as lead to organizational change that can modify the perceptions throughout the ecosystem (Garza Mitchell, 2009).

As shown in the following figure, subjective versus objective learning in terms of the effectiveness of distance education has been explored in the past (Shachar \& Neumann, 2003) which can allow for examining between a quantitative and qualitative approach to learning as well as the overall experience and characteristics of such.

\section{Figure 6}

Broad measurements of quality and effectiveness factors

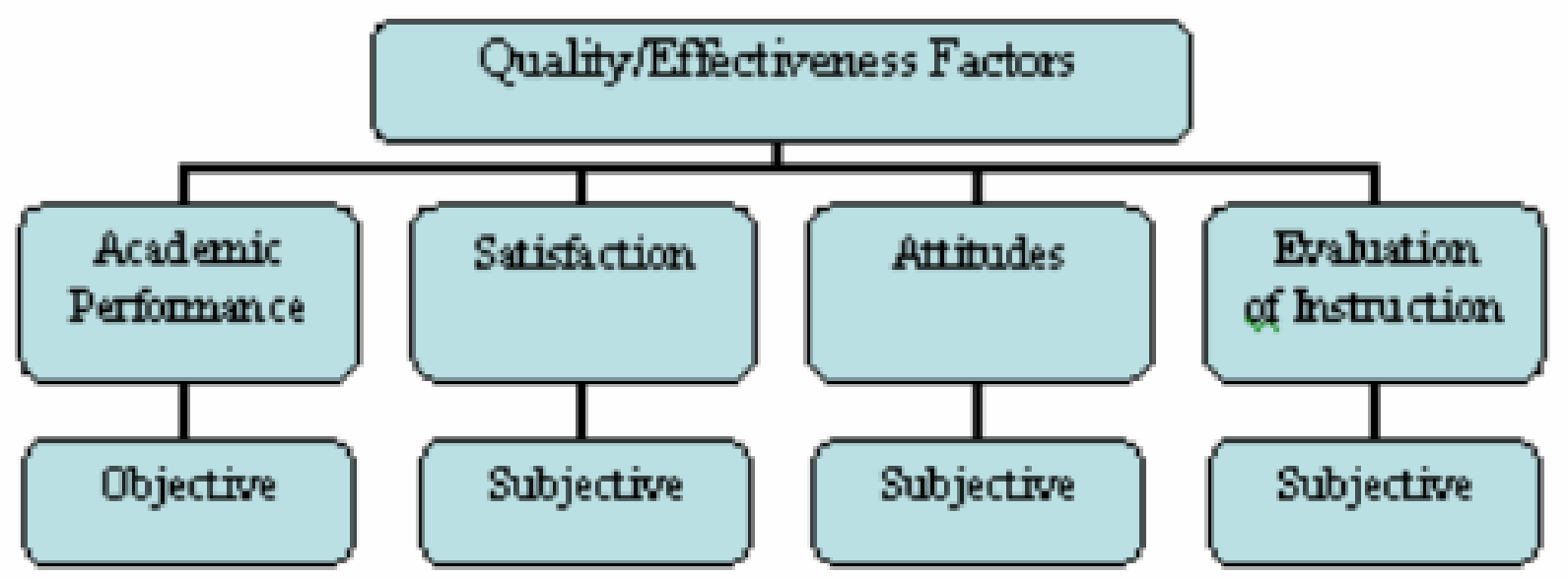

Note: From "Differences Between Traditional and Distance Education Academic Performances: A meta-analytic approach," by (Shachar \& Neumann, 2003), International Review of Research in Open and Distance Learning, 4, p. 4.

Schools also have a vested interest in the risks and rewards of online distance education. One of the major implications of adoption of distance education is due to a potential decline in the perception (Jaschik \& Lederman, 2014; Seaman et al., 2018) of the curriculum being offered 
from a distance, which could lead to a lower quality learning experience (Caruth \& Caruth, 2013; Graham, 2011). The same perception can also come via stakeholders including the school, students, faculty and future employers. This decline can also be seen through transactional distance theory (M. G. Moore, 1972) which is derived from the transactional education concept (Handy et al., 1973), and of which shows interdependence of actors within the system which can reduce psychological and pedagogical experiences based on the further distance created between students, instructor, interface and mediums (Yilmaz, 2015) employed.

Another obstacle seen in adopting distance education is in the disruption of the established economic models of the affected schools. Distance education can change a lot about how the model operates, which can include some positives and negatives. One positive is that it can give universities access to new students, such as adults and those in continuing education that may have an established job they can't afford to leave while they attend school for two years without a paycheck, although undergraduates represent a much higher number of students (Seaman et al., 2018) but can still have similar life experiences. If the class is based on a MOOC, the school can also add as many students as it wants, as the marginal cost per student is close to nothing (Friedman \& Friedman, 2013). The downside of this is that the school is battling for the business of that student with everyone else that offers the same, or similar degree, so the advantage of offering online distance education starts to diminish (Black et al., 2019). The school finds other ways to win the battle, in many cases, reducing the cost of tuition (Ahlstrom, 2016; Bryan, 2018; S. Wang, 2015), accepting less academically prepared students or creating new partnerships to increase enrollment (Blumenstyk, 2014).

U.S. Education Secretary Margaret Spellings made a profound statement about the current landscape of the higher education system in 2006. She said the current university was in a mature state, very risk-averse and self-satisfied, but also very expensive. She noted that in a globalized society, universities don't like to address rapidly growing technologies that shift paradigms and create new consumers, but continue to hold onto the model that serves the aging population (C. Christensen \& Eyring, 2011). To transform from such a state means the institution must shift into a new model by developing its own, or following what others have done, which carries its own risks.

The third risk to adopting distance education would be institutions that do take a hard look at the transformation but tend to perseverate on the problem to the point of preservation 
through perpetuation instead of providing a solution, also known as the "Shirky Principle" (Sehgal, 2010). The decision to lead or follow carries these risks, and the landscape of adoption of online distance education across universities has been quite different. In many cases adoption is lagging because schools either do not see the benefit of having distance education or they see it as an unnecessary disruption (Downs \& Nunes, 2013) to their current business or academic model.

Schools may also be stuck in the traditional ways of what works, being focused on their pipeline, but ignoring the demands of the shift in the taste of the consumer (Crosman, 2019). Reluctance can also be seen when there is difficulty adapting to a new delivery method, where the schools do not have the experience or know-how to properly deploy an online classroom effectively, or a lack of exposure to new tools and processes hinder their progress. Faculty pushback is also a huge setback in terms of online distance education. Many see distance education as an unnecessary waste of time where there is a reduced perception of work or recognition, reduced compensation, or a lack of the proper tools to be successful, either from the university or from the instructor (Bruner, 2007).

However, other schools may see online education as the next big thing to lock in to their academic model to ensure future enrollment of a student who is more tech savvy and willing to access their education online. Creating an environment to ensure retaining of top-quality instructors also comes into play. Schools may develop small think tanks in a skunkworks (lockheedmartin.com) style of organization to allow for full autonomy to explore and develop cutting-edge educational delivery methods (Eyal-Cohen, 2019) that will reach the next crop of students without disrupting the existing business model (C. M. Christensen, 1997; Useem, 2014). What this would allow for is combining information technology that can be purchased and a process or processes that can be developed to create a unique, technologically advanced and competitively advantageous opportunity. This would also create new sources of data collection that can be utilized for metrics to help drive schools in the right direction, and in a way that has never been seen prior to current technological advances.

Around the topic of critical theory within online education, universities are also tasked with answering whether sociological, psychological, cultural or philosophical factors change the learning experience for students and if instructors are kept engaged and empowered in their roles (Burnette, 2015). There is also the question of whether a disruption to the overall grounding of 
an online student exists in a way that is damaging to social learning, especially in a time of techno-utopianism (Bina et al., 2020) which leads us to believe technology is an incontestable progress regardless of any difficulties. Some research (Beckett, 1998; Starr, 1996) asserts virtual classrooms will remove the overhead of culture (race, gender, age, location, income, disability) and is irrelevant to the pathology of the classroom, allowing for engaged content building within the new virtual world. However, culture within the virtual classroom can have many positive additions to the experience of those involved, such as in internationalized or internationalizing of curriculum (Bodycott et al., 2014) to create social tasks that bridge cultures. These have seen positive results, so de-identifying those in the virtual classroom could potentially be viewed as a disadvantage to participants.

In taking all of this into consideration, adding the flipped classroom to the IT infrastructure that is hosting online courses can be done through activities that promote interaction (team-based exercises, live presentations, students performing actions in online sessions instead of lectures, etc.) and can also have the benefit of being a continually unique learning experiences. One application of instructional design that has been explored to increase the viability of online education through active learning is in the flipped classroom instructional design.

The flipped classroom was developed in the 1990s as the "inverted classroom" (Noonoo, 2012). It was renamed in the mid-2000s as the "flipped classroom" (Jonathan Bergmann \& Sams, 2012) and was seen as a way to enhance the use of technology to meet the needs of teachers and students. It involved pre-recording lectures, as is done in a Massive Open Online Course, and using those videos as a way to give lecture content normally delivered during faceto-face classroom time. The lectures could be reviewed passively with other material before the active teaching content of the classroom, which could contain reviews of the material. This in turn could allow for deeper discussion of the topic, increased peer collaboration and personalized instructor guidance (Francl, 2014) within the live classroom. Having class time reserved to engage students triangularly allows for exploration of individual characteristics, such as learner motivation, self-efficacy and epistemological beliefs that might affect learning outcomes in a flipped classroom (Chuang et al., 2018). The following figure gives an overview of utilizing a flipped classroom model for in- and out-of-class learning, as well as the components that can be built into the model from a higher-level example. 


\section{Figure 7}

Example of a flipped classroom model for in and out-of-class learning

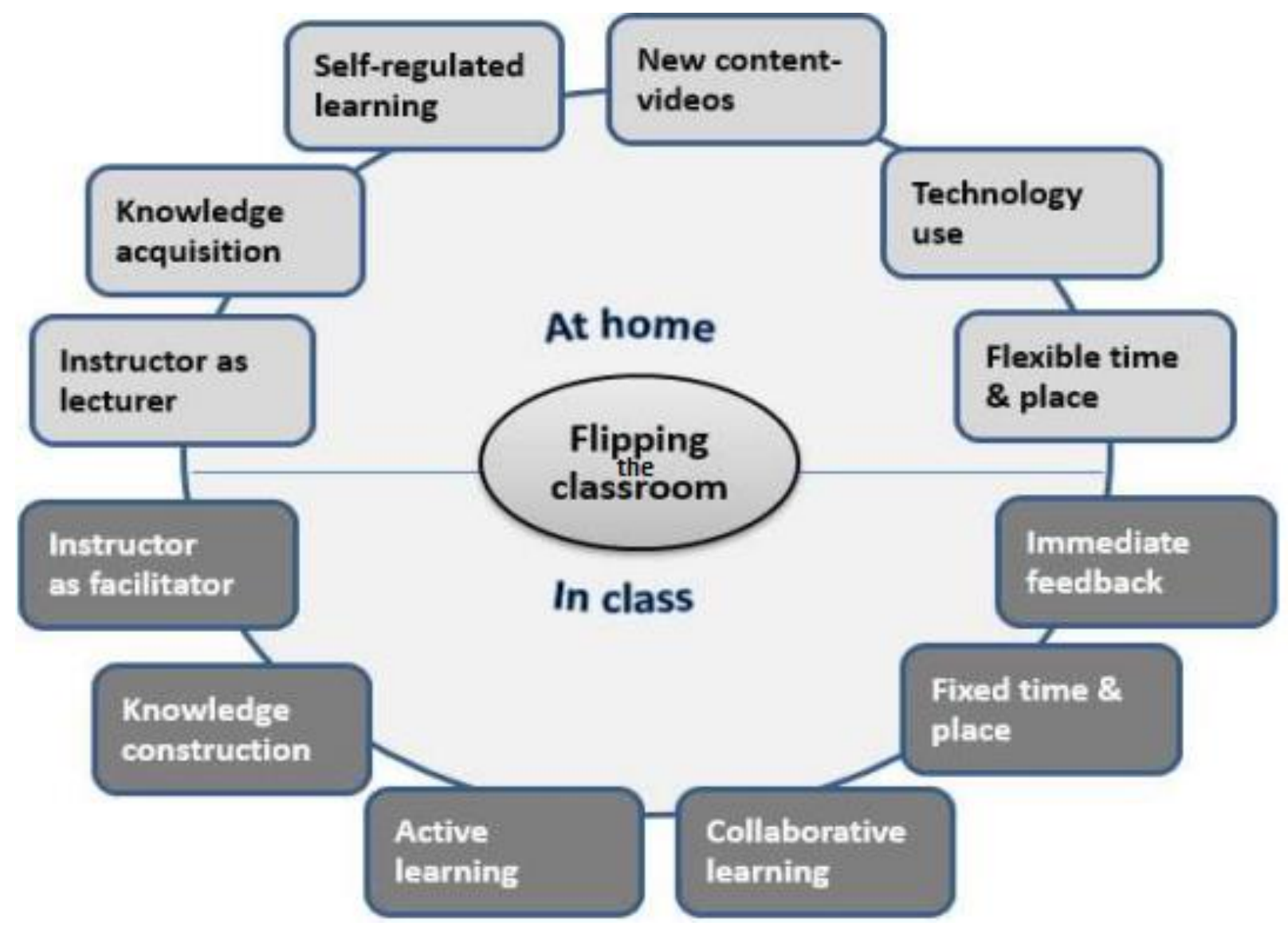

Note: From "Re-designed flipped learning model in an academic course: The role of co-creation and co-regulation," (Blau \& Shamir-Inbal, 2017), Computers \& Education, 115, p. 9.

In using digitized mechanisms for the online classroom, instructional designers need to look at several distinct development criteria that meet the needs of distance students. This is with the assumption the student's school selection has already been met, as the top two reasons for a student to select an online program tend to be cost and reputation (Aslanian et al., 2019). However, beyond these types of preferences that the designer can't control, the ability to access course content that is platform agnostic anytime, anywhere and from most internet enabled devices is critical to the success of an online student. The platform needs to meet scalability demands from the potential access of large amounts of students. Mobile device compatibility is extremely important, and classes should be designed in a way that works for the student through 
many mediums. The consulting firm Deloitte says its statistics from college students 18 to 24 years old show a strong reliance on mobile devices. It said $46 \%$ of respondents continually look at their device, $48 \%$ have confidence in mobile banking, $74 \%$ communicate regularly through social media and 56\% watch videos regularly on their device (P. Lee \& Roddis, 2020). All of this should be considered for expectations of what a student's device is capable of and what they will want in terms of learning through their devices, also referred to as m-learning or mobile learning (G. Moore, 2012; Sharples, 2013; Suner et al., 2019). Also, courses need to be delivered in a way that does not reduce the learning experience compared to similarly taught courses in face-to-face classes. They also need to meet flexibility demands that can include compressed courses (Holzweiss et al., 2019). This may mean delivering the content in a similar fashion, or in a new way that enhances the course in terms of the teaching and learning process, temporally, functionally and/or structurally (Koper, 2015). It's only recently becoming common for instructional designers to have expertise in this type of development where traditionally it would be solely the responsibility of the instructor to develop.

As an example, MOOCs have been used in classrooms in various ways with varying degrees of success, both in-house to schools developing them for personal use, and on standalone platforms such as Udacity, Coursera and edX. Some more recent success stories come from utilizing MOOCs as a blended approach to the traditional classroom, introducing more engaging content rather than passive content (Israel, 2015) to increase content knowledge through materials such as interactive video rather than textbooks and lectures alone. Keys to understanding MOOC success can be derived from student confirmation that positive interest, favorable experience and overall satisfaction lead to continued use (Lu et al., 2019).

Examples of studies having shown modest improvements in teaching to blend MOOCs into the classroom include a 35\% improvement in finals scores over prior years in the traditional class across three sections of an electrical engineering class (Ghadiri et al., 2014) Other research (Yousef et al., 2015) shows positive trends for bMOOCs in self-organization skills such as in a "work at your own pace" level, openness in course content (barring copy write issues), support of network learning, high satisfaction in flexibility, and overall quality of content. Another example can be found in a study (S.-F. Tseng et al., 2016) identifying and comparing three types of MOOC learners: active, passive and the bystander. Active participants showed the greatest rates of completion and better grades due to activity in asynchronous areas of the course. Other 
types include the xMOOC, which are more static and encourage assembly learning and the cMOOC, which encourage more creativity through engagement and "connectivism" (Rawlings et al., 2017).

MOOCs as a learning platform have shown plenty of failures, however, with problem areas being a lack of interest, passion and willingness to engage in serious learning activities in the context of problems with personal meaning/sentiment and/or an overloading of information that can dilute or disorient leaners (Fischer, 2014). One example, at the University of Pennsylvania's Graduate School of Education (Stein, 2013), provided research data on MOOCs with an average size between 13,000 and 110,000. Two startling areas of this research showed 50 percent of those who registered for a course didn't even view a lecture, and only about 4 percent on average completed a full course. This is in line with other research (Jordan, 2014) that looked at 279 courses with a median of 43,000 students per course across 100-plus universities. It found that the majority of MOOC completion rates across universities to be less than $10 \%$. A survey by The Chronicle of Higher Education in February 2013 suggested the average MOOC enrollment is 33,000 students per course, with an average completion rate of 7.5\% (Kolowich, 2013). Even though the numbers are discouraging, there are components to MOOCs (quizzes, video lectures and materials) that can be adapted into successful flipped classroom design and considered in the flipped classroom strategy.

Online courses are generally designed similarly to the traditional classroom courses, but without the face-to-face interaction. Some of the problems that arise in distance education are that instructors cannot engage with the students as easily and the students are too easily distracted by constant pinging from their mobile devices or other things on their computers. Research (Lim et al., 2008) shows that $45 \%$ of students examined report that online learning increased or greatly increased the amount of work needing to be performed. This may be due to instructors making up for a lack of student interaction by assigning more work, making the assignments more difficult or increasing what needs to be memorized for tests. Usually this is due to "limited understanding of how to support technology-enhanced student problem-solving in everyday classrooms and the lack of a coherent framework to guide their design" (M. C. Kim \& Hannafin, 2011). Students become stressed as they are now under more pressure outside of class to keep up with this added responsibility. In applying all of this, there is minimal evidence to accurately gauge whether the learner can successfully apply the knowledge gained through the 
course, and instead learning becomes a regurgitation of terminology, vocabulary, facts and other topics retained through rote memorization.

In another angle, students feel online distance education creates a disconnect between institutions of higher education and students, resulting in perceptions that the "instructor is perceived as being less prepared, less responsive to questions and needs of students, and less enthusiastic" (Clow, 1999). Schools need to emphasize that "educators who refuse to adapt and continue to insist the only way to learn is via "chalk and talk" methods will find themselves hopelessly obsolete" (Gee, 2003). This mentality of static delivery and learning does not fit the model of the current and future generations of students that need to be able to create connections in learning that cannot easily or effectively be performed through passive learning. This is particularly the case in current students who rely more heavily on social media, internet and other technologies to help ground their education. Instructors have an opportunity to embrace 21 st century learning by incorporating combinatorial methods of information technology and flipped classroom techniques into the coursework to improve student ability to apply learning to real world situations.

Research (Abrami et al., 2011) shows wide variability between online distance education and classroom instruction, even though most studies agree distance education is effective. Another study (S. Young \& Duncan, 2014) examined face-to-face and online delivery and compared student ratings for these two delivery modes. It showed higher ratings for face-to-face courses versus online courses in the areas of communication, faculty-student interaction, grading, instructional methods and course outcomes. One area in the study showed the opposite, however, in student effort. This could align with the earlier suggestion around increases in work requirements for online courses correlating to the need for increases in student effort. This fact is bolstered by research (Maki \& Maki, 2007) suggesting students were often required to take on a heavier load in online courses than in traditional courses. However, in most areas, this shows the wide gap between the experiences in a face-to-face versus online course which aligns with areas that show a degradation in the learning experience through online delivery. Another study (Alonso et al., 2009) shows the difference in grades and satisfaction levels between a traditional and constructivist online style course were negligible, but that visualized content driven through online education most interestingly decreased the grades given and the learners satisfaction levels. 
Alternatively, other research (Lim et al., 2008) compared face-to-face courses to online ones as well as combinations of the two delivery methods to measure student achievements based on pre- and post-course knowledge tests to measure the skills and knowledge mastered during the course. Interestingly, students' achievements were shown to be much higher in online (17.3, SD 8.3) and combined courses (17.8, SD 14.1) versus traditional courses (11.4, SD 13.1) in the mean scores between the pre- and post-tests. This research shows statistically significant increases in learning achievements (15\%), student satisfaction (13.5\%) and student experience (18\%) between fully online and quasi-online as compared to traditional classes. Learning experience satisfaction and overall learning rated more closely for the three groups, but still shows an online or a mixed-methods of synchronous and asynchronous delivery made a perceptive difference among students due to convenience, flexibility and quality of the material. Similar results were shown in a study (Robinson \& Hullinger, 2008) of online students who reported higher levels of engagement than both freshmen and senior on-campus students in each benchmark examined (level of academic challenge, student-faculty interaction, active and collaborative learning, and enriching educational experience) in their study.

Factors that could lead to differences in online learning may be a mix of the types of online delivery mechanisms being used, active versus passive instructional designs and more specific flipped classroom models of instruction which will be discussed in the following sections. A positivist approach says there is nothing to distinguish differences between a research subject and social phenomena or interpretation and a non-positivist approach holds that social constructions build interpretations and thus are based on that particular or pointed moment and could have completely different meanings to different people (Alessandrini, 2012). Taking a non-positivist stance that online distance education is not based on a natural order of evolutionary change is difficult due to there being so little quantitative or qualitative empirical data. Considering the technology and combinations of models of instruction, online education could be considered infantile in terms of the history of education.

Looking at the research from an interpretivist stance to see how education technology is interpreted socially rather than fundamentally or based on quantitative science may also be beneficial (Mlitwa \& Belle, 2010). This can also be reviewed in terms of collaboration and engagement. It's also still up for debate whether the future of online distance education will drive changes in learning outcomes based on technological and pedagogical evolution (White, 2005). 
Though we can see the increases in online education that have been driven by computer technology, where $8 \%$ of students took at least one online course in 1999, with that number growing to $32 \%$ in 2016 (Seaman et al., 2018), it's still unclear if online education could eventually revert to a face-to-face or a more blended approach as it has from historical perspectives.

\section{Types of On-Line Delivery Mechanisms}

There are many types of online learning mechanisms available, with new technological opportunities being developed almost daily. These include Massive Open Online Courses (MOOCs), learning management systems (LMS), virtual classrooms (Edmodo, Schoology, Google Classroom) and social networking applications such as aggregators (for online events) and bookmark managers (for storing and sharing web content). Many other course tools allow for a wide variety of digitized course empowerment and are often referred to as Web 2.0 technologies. Web 3.0 and 4.0 technology is out there too, through areas like artificial intelligence, machine learning, computer vision, Internet of Things (IoT) and cloud computing.

Online sites handle the storage, facilitation and environment that strives to create an effective educational experience. These mechanisms are designed to enable the learner's abilities through collaborative learning, or asynchronous means for reflections that can allow for a more thorough or thoughtful process to take place with additional time before collaborations with peers and instructors. (Abdallah, 2009).

What this means is that in a cyber-classroom, the notion of immediate response is removed as the social aspect of learners in the presence of each other is removed. This can change expectations of response rates when in asynchronous digital environments, which generally are blogs, podcasts, social networking and virtual environments (Friedman \& Friedman, 2013) and in some of the higher and commonly used social media style tools applied in online education (Aslanian et al., 2019). Response variables can change thinking and elicit repercussion with a less desirable response, which in turn modifies the experience for both the learners and the instructor. Changing the experience of a cooperative community of learning may lead to changes in the psychological adjustment of the learner through these different online delivery mechanisms. 
The main goal of these types of mechanisms is to deliver online activities to supplement some of the face-to-face teaching while providing a cost-effective and accommodating learning solution without hindering the learning experience. While MOOCs only provide a direct, passive lecture-based learning experience by design, an LMS or social networking application can utilize a MOOC while creating a more active learning environment by encouraging use of synchronous tools while still incorporating the traditional classroom components (Anderson \& Dron, 2018; Homavazir \& Gopal, 2018).

The use of these tools is entirely up to the instructor, as all can be kept as a passive, asynchronous-based instruction if desired. However, it is imperative that schools understand the importance of effective collaboration between peers and instructors which can be taught and encouraged in the class. The notion of "how to be engaged, informed $21^{\text {st }}$ century citizens" (Smith, 2007) is highly important and can be lost in the current state of society. This identifies some of the failings in online technology. Students require mimicked connectivity to their peers and their instructors similar to what they'd get in a classroom. Without this, students can lose out on the ability to work though problems in the moment through the experiences of others. Incorporating synchronous, active communication can promote this ability.

\section{Figure 8}

Adapting a MOOC to instructional design for synchronous (2-way) engagement

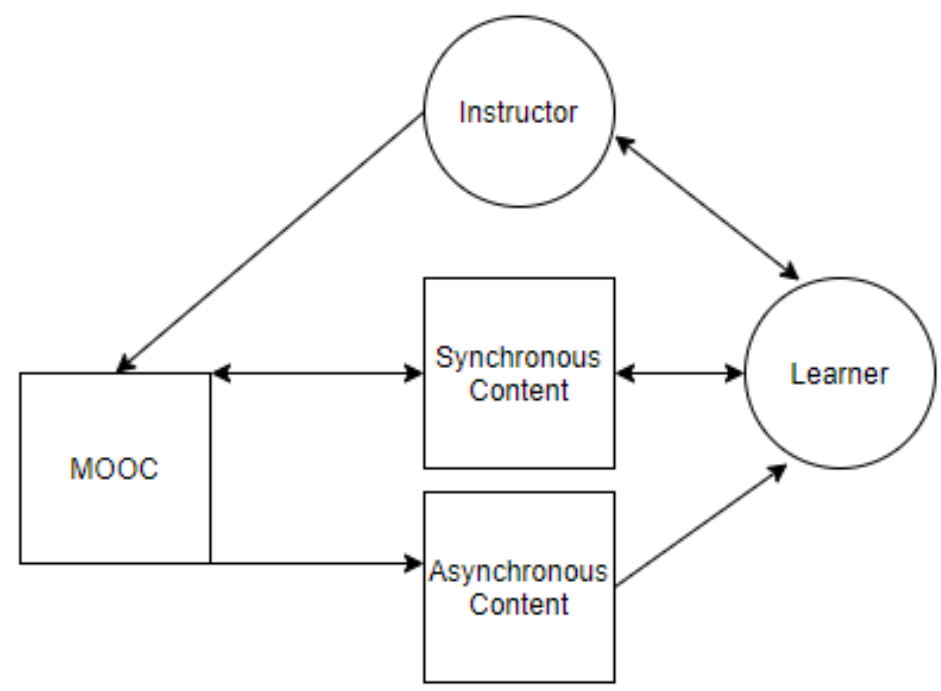

Note: Outlining example engagements to content in a MOOC instructional design 
Popular use of synchronous online delivery mechanisms is either as an enhancement to a currently taught on-campus course via a mixed-delivery method (also known as blended learning), or as a fully online course taught through a university. These tools can be very effective as they allow for higher-order learning environment creation which can encourage better self-direction and development of more critical thinking skills, as well as the learner utilizing the extra time to understand and reflect before collaborating with others (Abdallah, 2009). With Web 2.0 tools already extremely popular outside of education, there is increasing excitement within educational realms due to the desire of increasing the "5 Cs," which are communication, collaboration, community, creativity and convergence (Friedman \& Friedman, 2013). Further increasing the potential of these mechanisms are the reduction in cost and greater access to personal computers, mobile devices and laptops, making university-owned computer labs less necessary and more obsolete. Computer knowledge also continues to increase, helping universities offer technology-enhanced learning environments outside of the brick-and-mortar institution.

Increases in online courses also puts more reliance on the need for the student to bring their own devices (BYOD). Students tend to own several mobile devices that are continually evolving technologically (Mizad et al., 2018). However, these devices are generally shown to be used mostly for social engagements and other entertainment purposes (Ally \& Prieto-Blázquez, 2014) rather than as a learning device. Part of this is due to schools that traditionally have been slow in adapting new learning platforms even though demands from students to have a digitized platform continues to increase for both in-person and on-campus classes. Students report the growing importance of these devices to academic success with the laptop (85\%), tablet (45\%) and smartphone (37\%) all being utilized (B. Chen \& deNoyelles, 2013). As devices become more commonplace, mobile learning can play an important role in the effectiveness of a flipped classroom. It will be up to the instructional designer and/or platform developer to duplicate successful MOOC implementations through important features like full interactions, appropriate user interface design, easy navigation, simplistic layout, linear pathways and high-definition audio and video (Jia \& Zhang, 2018). 


\section{Active Versus Passive Based Education Styles}

As has been discussed previously, passive lecture-based courses have been the more popular mode of learning in the classroom, both in-class and online, based on numerous reasons, such as the tradition of lecture, the unwillingness to change tradition or the income based around lectures, just to name a few. Didactic, or teacher-centric courses, are typically passive within the classroom as time is spent on instructor-led lectures, while the active components of course projects and solving problems on assignments takes place outside of the classroom (Weir, 2004). This style of teaching is still widely used due to the ability to disseminate lots of data to large swaths of learners at once, and then allowing for the singular learner to digest and utilize this information in their own time. Technology hasn't changed this much, as it has given the instructor the ability to post relevant information in a centralized way, lecture through synchronous and asynchronous communications and enhance in-class work by increasing the breadth of knowledge.

\section{Figure 9}

Contextual learning through passive modes of information delivery

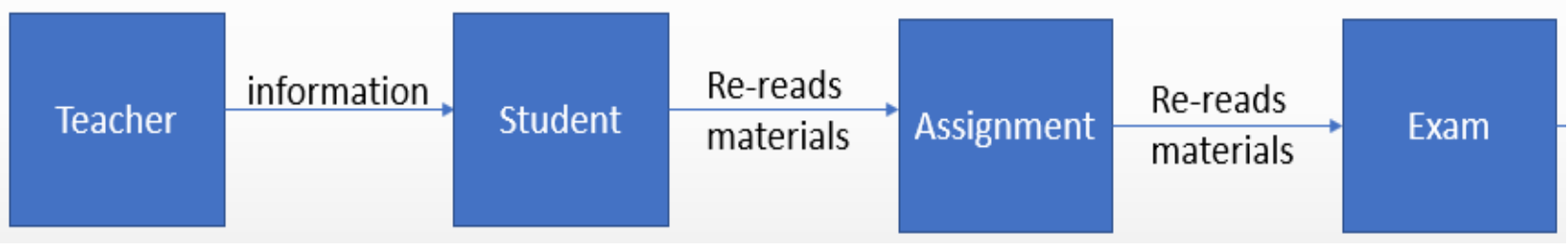

Note: Showing the trajectory of passive modes of learning

\section{Figure 10}

Contextual learning through an active learning schema

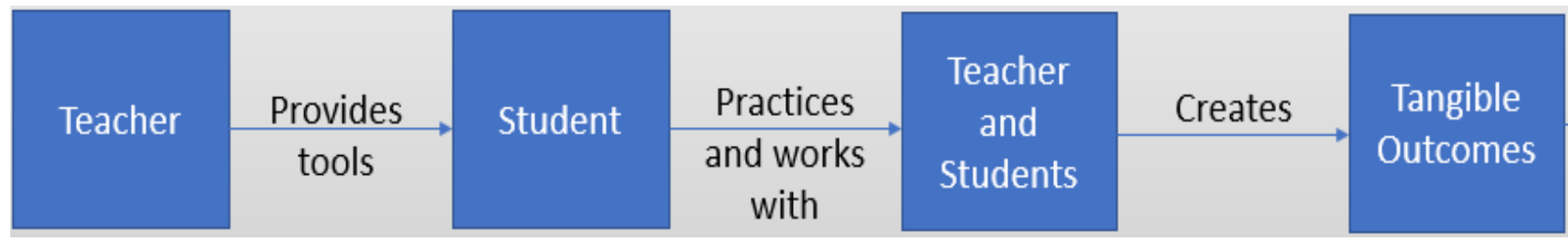

Note: Showing the trajectory of active modes of learning 
The bigger problem is that education in a passive style focuses more on proving rote memorization and regurgitation of content and less on areas that look to enhance higher-order skills and complex communications (Abdallah, 2009). This perception has shown true for students' higher approval of passive-based learning as they felt that in-class time used for active learning didn't prep them for assessments and examinations as well (Carpenter et al., 2006) and required more studying (Rivkin \& Gim, 2013) leading students toward learning that more ensures the grades that they expect, particularly among Generation Y students (Pološki Vokić \& Aleksić, 2018).

Active learning, also known as learning by doing, engaged learning, task-based learning, and its predecessor, constructivism, (Freeman, 2014; Prince, 2004) encompasses all theories that look at creating educational experiences through multiple perspectives, creating realistic contexts, creating ownership by the learner and encouraging social interaction as a method of embedded learning. The stage is set by the instructor to create a vivid and powerful learning environment for active construction of knowledge (Dewiyanti et al., 2007) through defining outcomes and objectives, taking ownership of what is being learned including experiences within, self-assessments and presenting original ideas and concepts (Koohang et al., 2016). The learners then guide themselves through this by working through the scenarios and constructing their own knowledge through critical thinking (Michel et al., 2009). This effect is also shown in studies (Larson \& Christensen, 1993) that point to increased memory retention through better processing of information exchanged between active participants.

It is also worth mentioning the research shows that cultural influences can change the nature of the experience in collaborative learning and open access and learning to underrepresented minorities (B. Chen et al., 2018) and those with gender differences (Caspi et al., 2008; A. Young \& Norgard, 2006). Some respondents report enjoying the experience of deeper knowledge of content, while others are bothered by a lack of guidance from instructors in collaborative settings (Zhu, 2012). Most, however, still show positive results overall. As seen in the following figure, utilizing active learning through guest lecturing can bring potential changes to the overall learning and engagements in the classroom. 


\section{Figure 11}

An Example Framework for Student-Centered Guest Lecturing

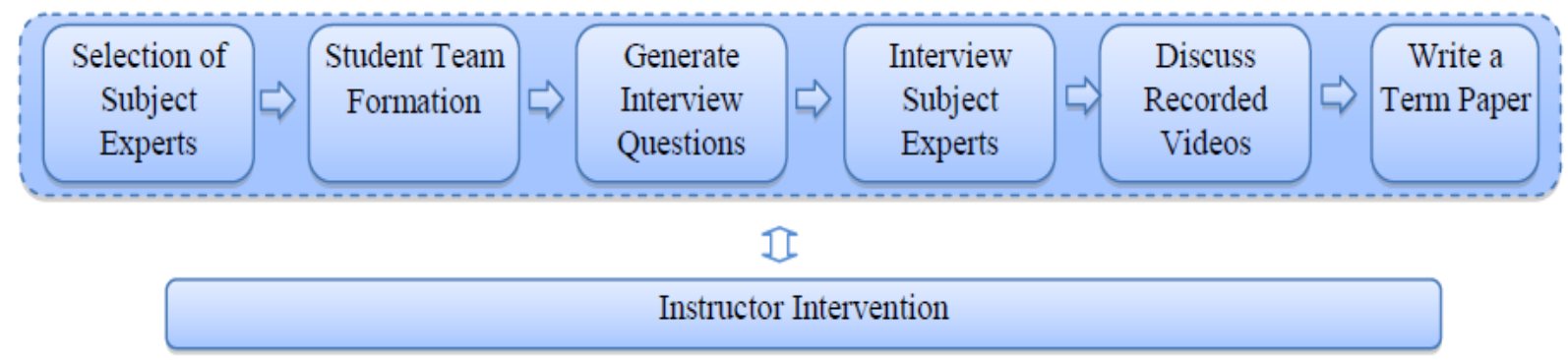

Note: From "Promoting Active Learning in Distance Education: A Case of Student-Centered Guest Lecturing”, (Li et al., 2014), Association for Information Systems, 21, p. 2.

Arguments for and against use of active learning in online settings are prevalent based on existing research and can be based on looking at student success, satisfaction and perceived value. Studies (Dixson, 2010) show that student engagement through cooperative and collaborative active learning is the priority in effective online teaching, (C. Wang et al., 2020) that interactive learning outperforms passive absorption of video or text alone by improving processing and retention of information, and (Dewiyanti et al., 2007) reveals positive student responses in terms of experience, opportunities and satisfaction with collaborative learning. Some research (H. Jeong \& Hmelo-Silver, 2016) also addresses the technological and pedagogical supports that come with collaborative learning, specifically in understanding that there are many mechanisms and processes at play when designing this type of learning environment. This can develop coordination patterns in groups where each participant brings tacit domain knowledge with expertise to complete the specified task (C. Wang et al., 2020). Integrating active learning activities, engagements and assessment designs were shown (B. Chen et al., 2018) to increase satisfaction and student perceptions based on the efficacy of those specific design elements. This was shown to be true across all subpopulations for online STEMrelated coursework and shows increased applicability to this research study.

However, other studies show no statistical significance in broad learning outcomes (Michel et al., 2009) or even decreased learning performance in active learning as opposed to passive, traditional courses. An analysis has shown (Chu, 2014; F. G. W. C. Paas and Van 
Merriënboer, 1994) that excessive exchanges of information can lead to a cognitive load state that can potentially reduce performance and achievements of the learner if costs of the collaboration overtake the potential benefits (Dillenbourg, 1999; Nokes-Malach et al., 2012). This can result from active learning engagements through excessive positive participant information from a myriad of online and class-assigned resources, or negative information including competitiveness, lack of trust or tension between participants (Goldman et al., 2008). Many research studies and institutions of higher education have shown, or have had a tendency towards a prevalence of passive, asynchronous collaborations over synchronous activities mainly due to synchronous modes requiring real-time engagements that can be a burden to both the learner and the instructor. As well, passive-based collaborations can show effects of allowing for better reflective work on the content (Derry et al., 2006) as they give more time for research and thought and tend to give a static source of information that allows others within the network to read and comment (W. Chen et al., 2010) It can also provide another form of group communication and share similar features of face-to-face work (Gritsenko, 2016).

The key may be in a better understanding of what type of active application to use, when to apply active learning to a potential task or problem that will be beneficial to the learner and whether active learning shows increased benefits over potential costs in implementation. This could be due to the collaborations being outside of their zone of proximal development, originally identified by Vygotsky (Shabani et al., 2010) and affecting the scaffolding of concepts. Instructors have the task of minimizing these effects which can be difficult in classes that do not afford the time to learn and develop ideal collaborations.

\section{Applying Active Learning Instructional Design to Online Distance Education Technology}

Online learning mechanisms allow for a centralized experience that can give the learner many advantages. One of the reasons these mechanisms are not combined with active learning when creating the educational environment is "the challenge(s) to exercise online and instant teaching," and "not just merely rely on the technologies and system efficiency, but to satisfy the usability and friendliness of the system as to replicate the traditional class environment during the deliveries of the class" (Safei et al., 2011, p. 84). Some of these include the ability to learn from a distance, self-paced learning through static materials and creation of a learning community that can be accessed any time. 
Active learning through online mechanisms has become more popular through Web 2.0 technologies, giving an ability to continue the face-to-face classroom social experience. (Web 2.0 being the third evolution of web-based technologies incorporating read/write/storage of earlier technologies and incorporating the abilities of activity and automation. Through active learning in online settings, learning can be "enhanced by giving learners control of their interactions and prompting learner reflection and self-monitoring of understanding" (Ke \& Kwak, 2013, p. 99) through interactions both with the instructor and their peers. It's also been shown in research (Gaytan and McEwen, 2007) how effective active learning can be through collaborative activities, group discussions, and other forms of student-to-student interactions that open and maintain communication channels to increase student success through online courses. This should be coupled with encouraging more student-instructor and triangular collaborations within the class (Martin \& Bolliger, 2018) that confirms the importance of interactive design and the facilitation of the online courses which focused on engagement and interaction. This research shows learner-to-instructor communications is the highest rated engagement strategy, followed by learner-to -learner communication (e.g. icebreaker conversation) and learner-to-content scenario work, all of which aligns with the benefits of creating more engaging environments through online mechanisms.

Reasons instructors may not decide to teach in an active online environment can be based on a myriad of issues, including a fear of unknown technology or lack of computer competency disrupting the normal flow of teaching, uncertainty of how to employ a real-time social constructivist style of teaching through online mechanisms, and recorded video or audio instead of live talks due to the challenges of trying to meet the flexibility demands of the learners which can create coordination issues in dealing with multiple people and global time zones. (Li et al., 2014), or inability to effectively create activities and scenarios online that are equal or greater than what can be accomplished in the classroom.

Another challenge for instructors can be students' lack of knowledge or experience with the learning environment or topic, and so "if each individual is responsible for knowledge construction, then designers cannot determine and ensure a common set of outcomes for learning" (Karagiorgi \& Symeou, 2005, p. 22).

These areas will be addressed in this study by looking at how the flipped classroom model of instruction increases instructor involvement, thus creating more comfort for them in 
terms of teaching online, as well as giving the learner the experiential needs the traditional classroom provides. Secondly, the flipped classroom requires some type of groundwork to get students started, and this will be provided prior to the flipped classroom task assigned.

Challenges with scheduling and other administrative issues are not necessarily the primary focus in the study, but will be addressed with amicable solutions provided, if applicable.

Technology continually makes the social constructivist approach more viable through mechanisms that create more synchronous and asynchronous modes of interaction. Several methods of employing the flipped classroom through online education can be accomplished through current developments in learning management systems and Web 2.0 technologies. Instructor-led discussions can take place synchronously including real-time feedback from students and discussions between all parties. Work can be accomplished through several different applications with immediate feedback. Learners will be taught to adapt from a solitary style of the traditional, passive perspective and approach of listening, observing and note-taking (Ke \& Kwak, 2013). This would include more encouraged engagement, both through discussion and activities. Role play can be done through asynchronous activity, simulations and strategizing can be discussed and explored and continual coaching can be applied.

Many studies have shown that implementation of active learning models of instruction can increase student learning and decrease failure rates. One study (Freeman et al., 2014) shows "effect sizes" indicating that on average, student performance on examinations and concept inventories increased by 0.47 SDs with active learning $(n=158$ studies), and that the odds ratio for failing was 1.95 under traditional lecturing ( $n=67$ studies). These results indicate average examination scores improved by about $6 \%$ in active learning sections and that students in classes with traditional lecturing were 1.5 times more likely to fail than those in classes with active learning.

On the contrary, even though some research (Dixson, 2010) reports several active learning activities have been verified as being engaging through different criteria including distance courses, through examination of application activities in case studies, group projects, synchronous online discussions and assignments requiring activity in real-time between learners and instructors, the findings also showed that passive activities such as reading, quiz taking and video lectures were similarly engaging based on the reports of students' perception of engagement. Reviews of online discussion boards through constructivism and normalization 
(Gulati, 2008) conclude compulsory active learning impairs the openness, flexibility and democracy of learning, all very important factors for this type of education delivery.

Given that this examination of in-class active learning models of instruction show differing outcomes in learning and engagement, this study will look at supporting similar increases in student learning and engagement through a more specific mode of online education - the flipped classroom.

\section{Reviewing the Flipped Classroom Active Learning Instructional Design and Applicability to Online Distance Education}

A popular example of efficient active learning is the blended flipped classroom teaching and learning model (Jonathan Bergmann \& Sams, 2012; O’Flaherty \& Phillips, 2015), also known as the "inverted" model. "FLIP" equates to four components of the design: flexible environment (students choose when and where they learn, instructors are flexible in assessments and expectations); learning culture (moving from the sage-on-the-stage to student-centered approach); intentional content (maximize class time for application of conceptual understanding); and professional educator (expertise shifts from giving lectures to directing faceto-face time for knowledge building) (Hamdan et al., 2013). One study (Y. Chen et al., 2014) also identifies the last three letters "PED" as: progressive activities (learning by doing, networking); engaging experiences (increased peer-to-peer-to-instructor dialog and less of a prestructured environment); and diversified platforms (seamless ways to deliver content anytime and anywhere). This instructional design style was developed in the early 2000s by Bergmann and Sams for promoting a new approach to lecturing and learning more difficult assignments (Jon Bergmann \& Sams, 2014).

However, the roots of this style of teaching can be traced back to Harvard University professor Eric Mazur, who in 1990, asked his students to learn content outside of the class while creating interactive sessions within it. In 1996, the definition of flipping the classroom was created by University of Miami professors Maureen J. Lage and Glenn J. Platt and was applied to undergraduate economics students in the form of learning activities in class and teaching outside of it (Xu \& Shi, 2018). The new approach created an inversion of the two teaching paradigms of the lecture (in-class) and assignment (homework) by reversing those roles (Findlay-Thompson \& Mombourquette, 2014). Empowering this type of model are technological advances that allow 
for generation of visual content (Elfeky et al., 2020) that can be more easily reviewed by students outside of the classroom. Some instances of flipped classroom instructional design in use include the Kahn Academy, which has a library of over 20,000 videos for enhancing and supporting lecture components, or the "Flipped-Mastery Classroom" developed by Bergmann and Sams and widely used today. The flipped classroom model is applicable in flipping the traditional face-toface class and in popularizing the online distance class and has seen varying success.

In flipped classrooms, lectures that are normally delivered in-class and coupled with supportive readings are assigned as homework in the form of videos to be watched before class. The traditional homework assignments are performed as higher-order active learning activities in class (Cheng et al., 2017; McLean et al., 2016; Sletten, 2017) which look to improve thinking skills, performance and learner outcomes (Lewis et al., 2018; Tune et al., 2013). This allows the time outside of class to be spent on learning the topic of interest, at the pace and flexibility of the student, but prior to the meeting in the classroom (O'Flaherty \& Phillips, 2015; Roehl et al., 2013). Once the student has arrived at class, they will have the basic building blocks of what they will need to accomplish the tasks assigned in the class. These tasks, for example, can be group or team discussions, field work, case studies, presentations and/or problem-based assignments (Nichols et al., 2017), but with the guidance of the instructor to complete them.

This also supports what was historically incompatible in active learning - studentcentered components such as peer tutoring, peer-assisted learning, collaborative learning, cooperative learning and problem-based learning (Bishop et al., 2013). Although studies have shown a mix of positive and negative outcomes with the flipped classroom, there are numerous positive effects from the addition of an online-only class. This is shown in the changing demographics of online or distance students who prefer more engagement over passive-based instruction (Vaughan, 2014).

Research (McLean et al., 2016) shows three emergent themes in integrating a flipped classroom: adjustment of learning behaviors, encouraging multitasking and incorporating strategies for deep and active learning. Deep learning has been identified (Biggs, 1988) as metalearning, which is to take control of one's own learning capability. This can further improve learning capacity, bring different learning outcomes and can further the ability to think critically about the problem or task at hand (Jackson, 2004). In this regard, the student is given practical application of the topic, with increased attention from the instructor which also gives the 
instructor the ability to better understand and act on students' difficulties as well as unique learning styles (Tomas et al., 2019). This also gives the instructor a real-time look at the diverse student cohort and how collaborations happen across them (Fulton, 2012). In reviewing the research, flipped classroom learning incorporated into the online platform has the potential to become an effective use of instructor time in teaching practical use of material and effective use of student time in learning how to apply the course material more critically, as well as empower the student through combinations of the instructional design and the learning management system (Lopes \& Soares, 2018).

The flipped classroom can be a natural fit for online courses since the lecture materials in many cases are already handled as prerecorded videos and can be accessed 24/7 from any internet enabled device such as smartphone, personal computer or tablet (Elfeky et al., 2020). The challenge is in how the instructor creates the active learning component that enhances or complements the traditional lecture component. Some of this can be handled through teacherstudent interaction and active learning activities in the classroom such as debates, content analysis, guest speakers and team-based work (McLean et al., 2016), but can also be built from the traditionally assigned work that students would be expected to do for later review. Again, this leads to the challenge of how to do this through a digital classroom, but technological advances are creating a more mimicked version of the traditional classroom via learning management systems that allow these activities to be played out in the virtual classroom (AlJarrah et al., 2018).

What can be viewed as a fundamentally basic task but can also be the most important part of the flipped classroom is the prerecording of lectures as subject or topic-oriented videos that can be reviewed before a class. Another effective method for video consumption is to divide the video up into chunks or separate the content into smaller parts, which can lead to better and easier absorption of the materials (G. A. Miller, 1956). This can allow for learning not only on the student's own time, but also at the student's own pace, either in reversal and/or review of lecture material. It also allows learners to rebuild from the materials in a skilled fashion (Afflerbach et al., 2008; Shank, 2018). There is also research showing the use of concept mapping tools such as advance organizers (Cutrer et al., 2011; Elfeky et al., 2020) that can also fit into the prerecorded lecture model adding to the benefit of the flipped classroom. 


\section{Figure 12}

Modeling a course sequence for chunking components from class topics

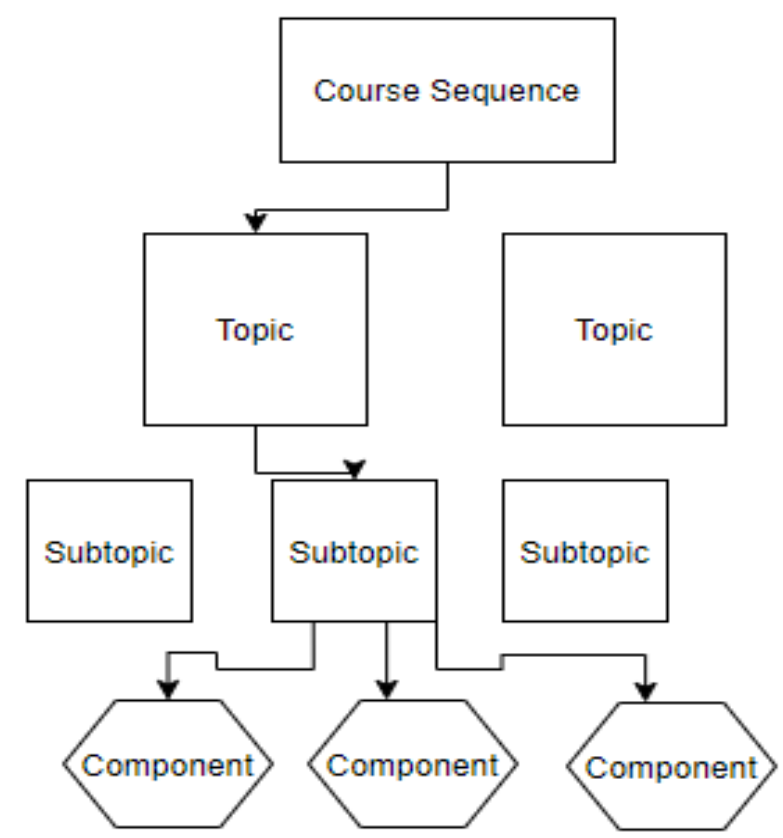

Note: Showing a flow of chunking content for dissemination to the student

Research (Lah et al., 2014) identifies three main types of chunking division. This includes breaking one bigger unit into smaller, different numbered units (mixed chunking), breaking the bigger unit into equally sized smaller units (similar chunking), or breaking a bigger unit into smaller equal or unequal size but of relational content (characteristics chunking). Other types of chunking have also been researched (Gilchrist, 2015) and show that a focus on internal cognitive processes, coupled with neurophysiological recording and computational modeling, can increase learning capacity through separation of large units into smaller ones.

Chunking can be done by the instructor or learner. An instructor might chop the lecture components into smaller bits for learner consumption. Or a singular or larger lecture can be divided by the learner, based on their attention to the materials. Allowing for attention to be set on smaller amounts of content has the potential to lead to better long-term recall (Jones et al., 2007). Cognitive load theory takes working (short-term) memory and builds through scaffolding a more schematic (long-term) memory (F. Paas et al., 2003). This takes small chunks of material, which can be lecture snippets based on segments of a specific subject, and allows the learner to 
concentrate on just those concepts that will help to build the long-term schema (Gobet et al., 2015).

Flipping the classroom can also have some disadvantages, but many of these are due to it being a newer concept and the challenge of finding the right match of flipping to the course, content and delivery mechanism(s) (Hao, 2016). This is especially true in research that looked at undergraduate versus graduate students' (Howitt \& Pegrum, 2015) approach to the new environment. One way to look at this is it being in contention with learners' daily commitments outside of class, and in this regard the flipped components should consider time constraints similar to how they would be performed within the class. Another topic is in disengagement of the instructor to the learner, as students see videos as being not as dynamic as an active lecture (Bergmann \& Sams, 2012). Part of this can be due to challenging concepts that the learner doesn't understand or can't figure out or the need for extended time to work through the concepts (Tomas et al., 2019) since the instructor can't be immediately reached to help or answer questions (Gilboy et al., 2015). Though the lecture isn't in real-time, learners can still take an opportunity to address questions to the instructor through asynchronous methods or in synchronous modes (or modalities) that would follow the asynchronous components.

Some studies have also shown that most students in a flipped classroom do watch the videos and in some cases will watch them more than once (Tomas et al., 2019), leading to two conclusions, both of which can be positive or negative. The first conclusion is that students are not getting the material figured out in the first pass, leading to the assumption that the video isn't as effective as the live lecture, or that they are building upon what they learned with another pass. However, there is an obvious positive benefit here over a traditional lecture, and that is an ability to repeat the video lecture.

Another potential problem is a disruption in the learning process if the student hasn't met the obligations of learning the material before class. This can be due to the new flexibility of the responsibility of watching and learning from the materials, including shying away from the perceived increased workload, which can encourage poor time management and further lead to procrastination (Herreid \& Schiller, 2013; Milman, 2012). This can also lead to disruption of the class learning, as not everyone is on the same level of preparedness for the topic. However, if the learner does the pre-work they generally find a better use of class time through engagement 
(McLean et al., 2016), leading to a deeper approach (Bauer \& Haynie, 2017) to the material that is learned.

Multitasking has also been shown to have negative effects on the learning process (Bailey $\&$ Konstan, 2006; Fried, 2008), and it can be assumed that multitasking would become easier in a flipped classroom with lectures being consumed outside of the classroom. However, some research (McLean et al., 2016) shows that students in a flipped classroom tend to be more active and engaged in the face-to-face classroom which reduces the ability or temptation to pick up a device to check social media or email.

In exploring the research on application of the flipped classroom, one can find studies that show learners did not experience positive changes, positive engagements or even displayed a decrease in learning output from the learner compared to traditional methods. An undergraduate business course (Findlay-Thompson \& Mombourquette, 2014) reports findings of no change in the quantitative output of students based on class grades, though qualitatively students reported a much better experience in the flipped classroom such as in being able to ask more questions of peers and the instructor. A study (Tomas et al., 2019) looked at applying a flipped classroom approach to a first-year science and sustainability course and saw a mix of results. There was higher engagement and preparation with the videos, but not all watched the videos due to time or commitment constraints. And students were split on whether the flipped classroom created more in-class engagement including planned activities and whether it encouraged more motivation to learn.

In another negative result, research (Burke \& Fedorek, 2017) examined a crime control class for undergraduate criminology students in three modalities: traditional in-class, online and traditional flipped in-class. The results showed investment in time, preparation and assignments very similar across all three modalities, except for test preparation where approximately $10 \%$ of flipped and online students showed higher investment. In terms of engagement, the study shows students were less engaged in the flipped classroom (42\%) compared to traditional (68\%) and online (79\%) students. Flipped students also displayed retaining of the class materials in the middle of the three with $90 \%$ compared to $94 \%$ of traditional students and $86 \%$ of online students. This and the other previous studies show surprisingly lower scores and experiences that contradict the following positive studies. 
But, there is plenty of research that shows a positive outcome from the flipped classroom. A medical sciences course (McLean et al., 2016) shows students' positive experience is increased with the added interactions in class, and this encouraged deeper learning. A study (Rivera, 2015) examining a library instruction class showed a doubling of increases in comparative test scores in a flipped versus non-flipped course. Applying a flipped classroom to a management course showed statistically significant increases in student performance comparative to earlier traditional courses (Albert \& Beatty, 2014), generally ranging in 2 to 3 point increases overall. Two undergraduate nutrition courses also show positive increases in engagement, including $75 \%$ of students preferring video versus face-to-face lectures with $62 \%$ learning more and 64\% preferring in-class activities over the lecture, and more than half feeling more confident with the materials through this instructional design (Gilboy et al., 2015).

A three-year study comparing flipped and traditional financial mathematics undergraduate students (Lopes \& Soares, 2018) reports substantial increases in exam results. The flipped classroom showed a $71.4 \%$ to $91.2 \%$ change ( $19.8 \%$ overall increase), while the traditional classroom showed a $49.2 \%$ to $62.7 \%$ change ( $13.5 \%$ overall increase). There was also a sizeable difference between the methods outcomes (flipped classroom $22.2 \%$ to $29.5 \%$ greater than the traditional classroom). Students also reported overwhelming support of the video lecture compared to the traditional delivery, as well as the online exercises, but were more scattered in terms of choosing one model over the other, with most in-between strongly preferring the flipped classroom pedagogy and being indifferent to the environment. Recent research (Wasserman et al., 2017) adds a flipped instructional design to an undergraduate level calculus course and shows slight to moderate $(5 \%-10 \%)$ positive effectiveness in testing as opposed to traditionally led classes, particularly in conceptual components.

Data from student engagement perceptions in this class also showed higher interactions, with more opportunities for online engagements, but lower effective use of class time which could be based on norms versus conditioning to the new structure. This study also reported that a flipped classroom equips students with modern day skills such as problem solving, socialization, collaborative skills (Chan, 2010), critical thinking (Kay \& Greenhill, 2011), computer literacy, and linguistic competence (Middleton \& Prince, 2011). These are skills it said are necessary to address the demands and needs of a society that is experiencing dynamic transformations (Kurt, 
2017; Wan \& Gut, 2011). Many other successfully flipped classes (Özkurkudis \& Bümen, 2019; Prevalla \& Uzunboylu, 2019; Unal et al., 2017) also support these previous research studies.

There is limited data from research examining the use of a flipped classroom approach to a fully online course (Lin et al., 2019; Van Wyk, 2019), with examples being either blended or containing some type of face-to-face contact. More recently, however, there have been some studies in this regard and the results have been mixed. One project (Phillips \& O'Flaherty, 2019) studied nursing students in a fully online flipped classroom compared to a face-to-face and traditionally taught online class. The results showed little difference in academic achievement in flipped classes based on final course scores. Seventy-four percent reported a much heavier workload and student satisfaction decreased overall by $32 \%$. However, $30 \%$ of students reported being more engaged and 20\% reported an increase in critical thinking skills. The self-pace style got high marks, but no change in class preparedness was noted. Another study (Romero et al., 2019) shows mostly positive results between flipped and passive modes of course delivery. Grades for flipped learners showed no statistically significant difference between groups, but approximately $95 \%$ of individuals showed higher grades. Students in the flipped class also reported heavier workloads and time investments, but higher satisfaction in terms of content comprehension, higher motivation and interest, and better use of classroom time with activities instead of a passive lecture.

Though some research shows negative or mixed results, there have been some success stories for utilizing flipped classrooms designed specifically for online education. One of the first studies (Lin et al., 2019) of a wholly online flipped classroom looked at increases in engagement and learning for synchronous activities. Positive results were reported especially from those that enabled their webcam, which "provides additional nonlinguistic messages and paralinguistic information" (Lin et al., 2019, p.1587) to increase social presence and body linguistics. Those students with the most proactive and frequent interactions with the instructor and peers experienced higher overall grades, which mimics the need for investment into the learning environment by the learner for it to be most effective as scores decreased with limited lecture recording viewership.

Another research (Van Wyk, 2019) examined the use of a flipped classroom pedagogy integrated with open distance eLearning as a way to reduce knowledge gaps in practice as well as see the implications of an instructional design on this platform for an economics course. Tests 
showed better effectiveness in the flipped classroom versus direct instruction, with an approximately three-point differential (out of 100) between them and higher final exam scores with an average being about nine points higher. Students also perceived the flipped classroom experience as positive overall and empowering through more application and practice of the learning. But they also experienced increased time commitments due to more work, more responsibilities and learning new skills to adapt to the flipped classroom. Another study looked at learning Mandarin through a fully online flipped classroom (M. Tseng et al., 2018) for K-12 students. Though not a higher education setting, the research is helpful to understanding students' responses to a more popular online platform setting (Lin et al., 2019) and creating a flipped environment for it by incorporating daily synchronous activities. Their results (on a scale of 1-7, 1 being the highest) show increases in language skill proficiencies (higher in listening and speaking, 3.84 point difference between designs overall), high satisfaction (synchronous sessions ranking much higher than asynchronous, $M=6.77$ versus $5.97,5.84$ ) and positive engagement experiences (instructor $M=6.74$, peers $M=6.03$ ) with lower levels of anxiety over the course $(M=2.29,3.26)$, which could also be directly related to the feeling of being a part of a social community within the class. This did not come without effort, as the class reported a doubling of average time spent compared to other courses.

Some other blended studies also show mixed results. Research (Y. Chen et al., 2014) looking at applying a flipped classroom model derived from a holistic flipped classroom environment (N. Chen et al., 2005), blending in- and out-of-class instruction. This study shows that motivation plays a bigger role in "transactional distance" (Bozkurt et al., 2020), with highly motivated students faring well while less motivated students performing lower than expected. All students generally fell back to passive learning habits because they had trouble adapting to the new learning environment. This was due to time constraints, the inability to understand lecture materials to correlate to in-class assignments which led to a feeling of being lost without instructor contact, and a heavier-than-average course load. However, students also reported advantages to the environment including more practice time in the hands-on sessions in class, more and improved interactions, flexibility for a work-at-your-own-pace style, and an easier approach to identify solutions to problems. Another study (Radunovich \& Acharya, 2018) looked at a social sciences course for undergraduates that took a traditional classroom and created a hybrid flipped instructional design coupled with a learning management system but with face-to- 
face in-class activities. Two statistics from this study don't speak well for the flipped classroom instructional design. Viewing rates were 67 out of 78 on the first lecture and 40 out of 78 on the second with $33 \%$ reporting not watching it at all. The percentage of the content of the lecture viewed was less than $50 \%$.

Specific to online distance education in the $21^{\text {st }}$ century, technology acceptance and access to networking technologies for real-time connectivity are primary factors to consider for classroom flipping in an online classroom. Another important factor is the ability to adjust how interactions and communications take place within the online environment (Knapp, 2018; Widyasari et al., 2019) to improve learning behavior and enhance learner experience. As students become more dependent on technology for education and more comfortable with the flipped classroom models of instruction, and as flipped classroom approaches become more adaptable to the technology, it is expected that applying the flipped classroom approach to online education can create benefits for the current and future learner as well as address the issues in current online modalities (Alsaadat, 2018; K.-J. Kim et al., 2005; McInnerney \& Roberts, 2004; Yang et al., 2016) which are a necessity to address in the future of online education.

\section{Chapter Summary: Gaps and Remediation}

Use of the flipped classroom instructional design is fairly new in terms of the breadth of education dissemination, with early versions of it identified by the paper "Inverting the Classroom" (Lage et al., 2000) only 20 years ago. It has just been the last 10 years since classrooms have been including and popularizing the instructional design by pre-broadcasting lectures (Jonathan Bergmann \& Sams, 2012). The last 20 years have also seen an exponentially increasing student population taking online courses. Nearly $50 \%$ of the student population is taking at least one online course. In that time, there have only been a handful of papers written or research studies conducted about utilization of flipped classroom instructional design across online education mechanisms, with most studies looking at flipping in traditional face-to-face classrooms. Secondly, understanding the experience and engagement of students in these distinct modes of education delivery is important to gauging their effectiveness.

One of focal points of this study is to continue filling in the gaps of applying flipped classroom instructional design across online education mechanisms in a way that can enhance the learning experience and create better engagement and learning outcomes from a method of 
education that is still in its infancy. One study (Trach, 2020) asserted that even though flipped classrooms garner a lot of press, they are rated very low in terms of application of instructional approaches overall. This study works to remove any bias as to whether online instructors should consider flipping their online classroom for improved student outcomes. 


\section{Chapter 3: Methodology}

This research study explores of the use of active learning models of instruction, and specifically, the flipped classroom approach, to examine whether this type of instructional design and learning environment can address and support whether active versus passive learning experiences can give greater experiences and educational benefits through online distance education. Explorative areas include whether the flipped classroom can be successful through current online technologies, how this success can be measured through the applied instructional design and platform, whether the flipped classroom allows instructors to develop distance coursework that is as experiential or that creates a learning environment than surpasses traditional coursework, and whether a flipped classroom approach can change learning and engagement for the students in an online setting.

To investigate these areas further, students taking similar online and an on-campus courses are provided with similar learning materials delivered through either active or passive instructional design, which is set for each type of class (active distance versus passive oncampus) to see if there are differences in learning and engagement outcomes. Observations are made between several data collection points across traditional and flipped classrooms including examining changes in students' grade point average within the class (over the breadth of the eight-week course), examining differences in learning assessments (given in weeks 2,3,4,6,7), examining perceived learning differences before and after taking the course (given at the beginning and end of the class), analyzing students' perceptions in experience and engagement in the classes (with comparisons to former classes including online classes and given at the conclusion of the class), analysis of the faculty course evaluation for learning and engagement (given at the conclusion of the class), and analysis of observations of students in the two types of instructional design (collected and reviewed during the breadth of the course). Two research questions guide the study to look at changes in the learner:

RQ1: What are the differences in students' learning in an online course designed to support active learning using a flipped classroom model of instruction versus a traditional instructional model? 
H1: Active learning with a flipped classroom instructional strategy through online distance education will increase learning more so than passive learning through the traditional lecture-based in-class approach.

RQ2: How do students experience engagement in an online course designed to support active learning using a flipped classroom model of instruction versus a traditional instructional model?

$\mathrm{H} 2$ : Students experience more engagement in an online course designed to support active learning through a flipped classroom approach than a traditional lecture-based in-class approach.

This chapter reviews (a) the subjects/students examined in the study for the sources of data, (b) the summary of the methodology needed to answer the research questions, (c) the limitations and addressment of the methodology used including data sources for those limitations, (d) a review of the instruments used for data collection, and (e) a summary of the methodology. The following figure shows the modeling for passive versus active (flipped classroom) instructional design as applied to each course.

\section{Figure 13}

Passive and active models

Passive Instructional Design

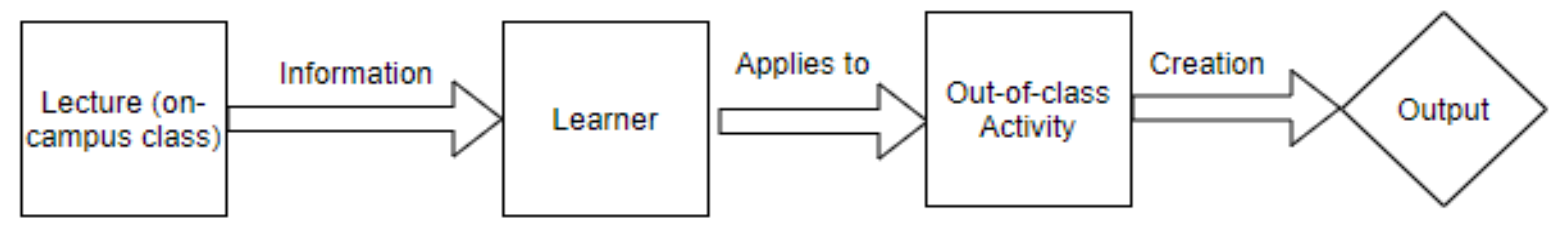

Flipped Classroom Instructional Design

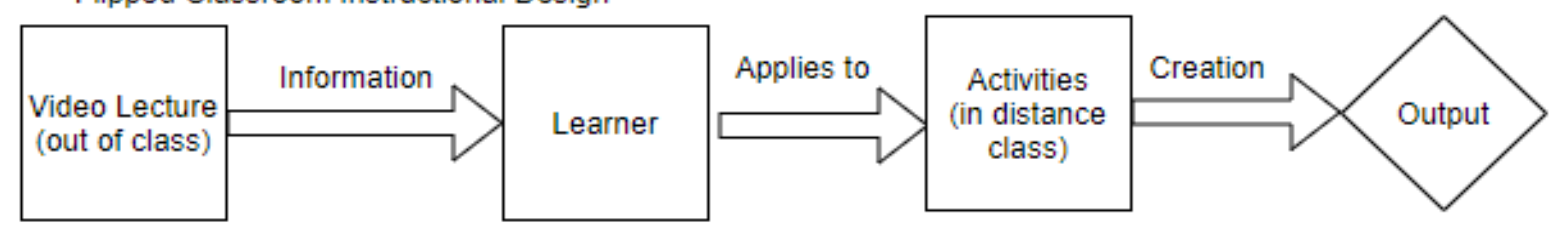

Note: Linear trajectory of active and passive modes of instructional delivery 


\section{Subjects/Students}

\section{The Subjects or Participants of this Research Study}

The sample selected for participants in this study are graduate-level students enrolled in a Master of Information Systems Management (MISM) or branch of the MISM degree in a degree granting program at one accredited university, selected from a population of 223 students. The demographic of the student population used in this study is approximately $45 \%$ Caucasian, $20 \%$ Indian, 25\% Chinese, 5\% African American and 5\% other ethnicities. Branches of the MISM degree include the business intelligence and data analytics (BIDA) track, and the information technology (MSIT) track. The following table gives a breakdown of each type of student per degree program track.

\section{Table 1}

Table showing students degree program and total number of students per degree

\begin{tabular}{cc}
\hline Degree & \# of Students' \\
\hline MISM & 106 \\
MISM-BIDA & 50 \\
MSIT & 67 \\
\hline Total & $\mathbf{2 2 3}$ \\
\hline
\end{tabular}

An a priori power analysis was conducted (Faul et al., 2009), for both the main study (ANCOVA or analysis of covariance) and separate Covid-19 analysis (t-test). For the t-test analysis, it was determined that a minimum total sample size of 52 (26 per independent group) would be required to successfully reject the null hypothesis with a power of .80 , based on a true difference of 1 between the two independent variables. This is derived from a t-test analysis with a type I error probability of .05 and an estimated effect size of .80. Students selected are the same students used for the three quantitative analysis areas in the study. For the ANCOVA analysis, it was determined that using the same minimum total sample size of 52 (26 per independent group) would be required to successfully reject the null hypothesis with a power of .885 , based on a true 
difference of 1 between the two independent variables. This is derived from the ANCOVA analysis with a type I error probability of .05 and an estimated effect size of .45. Students selected are the same students used for the three quantitative analysis areas in the study. A new selection of 26 students is then used strictly for the evaluation of the qualitative methods and analysis.

The following figure shows the a priori power analysis per sample size.

\section{Figure 14}

The a priori power analysis used in the study for t-test analysis and ANCOVA
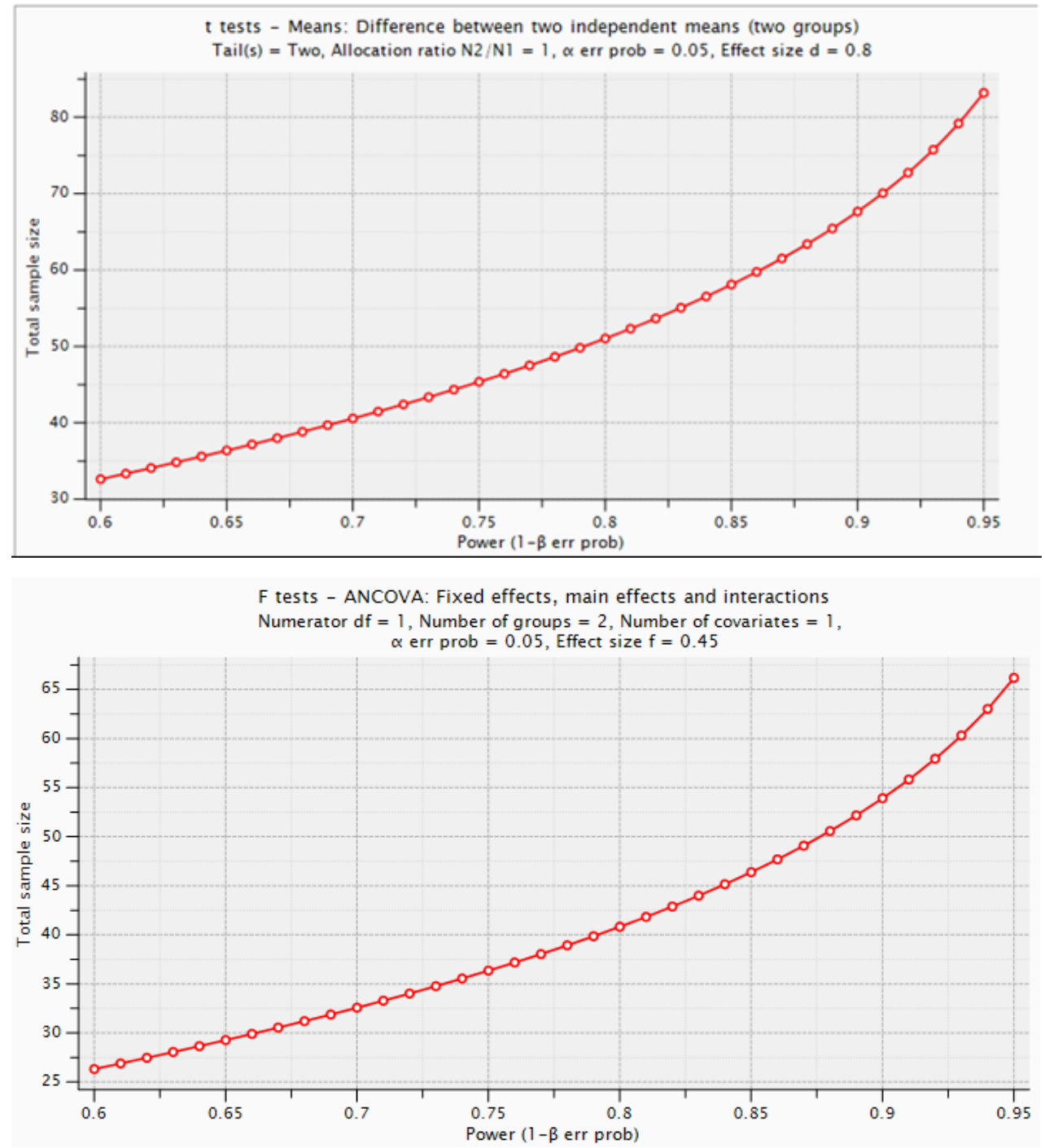

Note: Screen captures of the a priori power analysis chart from GPower 3.1 
How Participants are Chosen (Listed Procedures)

Students were selected through a randomized selection following their completion of the "Digital Transformation" classes that were used in the study and ranging over eight semesters between 2018-2020 that met the requirements for participation (Glennerster \& Takavarasha, 2013). The students selected took a pretest that was distributed to a minimum of 223 students from nine classes to meet our goal of 52 students total combined from the school that match the two types of students for the experiment. These selections were randomly drawn and assigned to each population, using a randomizing function in Excel (Random Number: $=\operatorname{RAND}()$ ) and (Random Name: =INDEX (\$D\$84:\$D\$93, RANK(F84, \$F\$84:\$F\$93),1) against the full list of students. The following figure gives an example of randomized selection used for the study.

\section{Figure 15}

Using RAND and RANK to do random selection in Excel (GPA Example)

\begin{tabular}{|c|c|c|c|}
\hline S20 & & Random Number & Random Name \\
\hline 49113 & 91.36 & 0.386839911 & 49310 \\
\hline 55605 & 88.93 & 0.988299472 & 49113 \\
\hline 49712 & 91.57 & 0.38423534 & 49836 \\
\hline 48587 & 93.43 & 0.042334664 & 48649 \\
\hline 51124 & 87.64 & 0.675426341 & 48587 \\
\hline 50259 & 91.21 & 0.974971866 & 42772 \\
\hline 49310 & 90.71 & 0.891216178 & 43279 \\
\hline 49836 & 83.64 & 0.233541366 & 7606 \\
\hline 50548 & 94.64 & 0.537846756 & 42771 \\
\hline 48649 & 94.86 & 0.433896203 & 42773 \\
\hline 46767 & 92 & 0.163260401 & 12089 \\
\hline 49024 & 92.36 & 0.897409667 & 30715 \\
\hline 51146 & 95.79 & 0.946435302 & 42776 \\
\hline 51020 & 91.57 & 0.534493072 & 42779 \\
\hline 50120 & 91.43 & 0.51088955 & 42777 \\
\hline 40404 & 86.14 & 0.661973812 & 43370 \\
\hline 52199 & 91.79 & 0.457875623 & 18579 \\
\hline 49665 & 93.21 & 0.789791638 & 6985 \\
\hline 35260 & 90 & 0.624394467 & 43392 \\
\hline 48729 & 90.36 & 0.572378934 & 7610 \\
\hline
\end{tabular}

Note: Screen capture of sample randomization taken from Microsoft Excel. 
Estimations of prior attendance of classes put participation at around 20 students per class to allow for more accurate estimations for required classes. Actual enrollments for all classes are shown in the following table.

\section{Table 2}

Instructional delivery per semester with the number of subjects in each course

\section{Component}

\section{Course Details}

Instructional Distance Distance Distance Distance Traditional Traditional Traditional Delivery

$\begin{array}{cccccccc}\text { Semester } & \text { Spring } & \text { Spring } & \text { Spring } & \text { Summer } & \text { Summer } & \text { Fall } & \text { Spring } \\ & 2018 & 2019 & 2020 & 2020^{*} & 2019 & 2019 & 2020 \\ \text { \# of } & 16 & 26 & 25 & 9 * & 38 & 40 & 66\end{array}$

\section{Participants}

Note: *Summer 2020 data is collected but not utilized in the main study, however it is used in addendum to the study (looking at differences in on-campus versus distance classes for those mandated to moving to a distance-only mode of instruction based on the Covid-19 pandemic)

This study was developed to examine the application of active learning models of instruction specifically utilizing the flipped classroom instructional design in online distance education, and particularly those courses used with a complete detachment of physical connection between the instructor and learner. Students were chosen based on this application to ensure an appropriate balance for the sample size. Since what the students themselves would learn did not change and only the method of delivering that learning changed, the institutional review board (IRB) approval was not immediately necessary during the data collection and was subsequently approved in the fall of 2019 (see appendix C). The actions and outputs from these students answer the questions surrounding what the flipped classroom is and how it can increase learning potential, how distance courses can be enhanced from their current form through learning and instructional design changes, if incorporating the flipped classroom into a distance 
course shows significant changes in learning retention, and whether online technologies effectively support the flipped classroom. The following table gives a high-level overview of the number of students in each modality of learning, either in distance-only mode or in an in-person, on-campus mode.

\section{Table 3}

Participant instructional delivery types and total number of each

\begin{tabular}{cc}
\hline Student Type & \# of Students \\
\hline Online Distance Education & 79 \\
On-Campus Education & 144 \\
\hline Total & $\mathbf{2 2 3}$ \\
\hline
\end{tabular}

\section{Data Sources}

This study utilizes classrooms between two modalities across seven semesters worth of instruction to determine changes in learning and engagement. Figure 1 below shows the semesters for data collection, the types of students used for data collection within those semesters, and the instructional design applied to both. In some cases, traditional and online modes of instructional delivery were performed in the same semester and thus allowed for collection across both platforms. The following table shows how active versus passive instructional design methods were utilized for each semester and each type of classroom. 


\section{Table 4}

Semesters and types of students (traditional versus distance)

Spring 2018, Spring 2019, Online Distance Education

Spring 2020, Summer 2020*

Summer 2019, Fall 2019,

Spring 2020

On-Campus Education

Note: *Summer 2020 data is collected but not utilized in the main study, however it is used in addendum to the study (looking at differences in on-campus versus distance classes for those mandated to moving to a distance-only mode of instruction based on the Covid-19 pandemic)

The following table shows how the recording of data took place, and of which was used to answer each of the research questions. These data sources are taken from the two types of courses identified as traditional in-person lecture based (passive) courses and flipped learning (active) classes through online mechanisms. Eight different data points were collected, four for each research question. These help guide the discussion surrounding learning and engagement of students within each type of instructional design.

\section{Table 5}

Data sources, collections, and analysis procedures

\begin{tabular}{lccc}
\hline $\begin{array}{l}\text { Research } \\
\text { Questions }\end{array}$ & Data Source(s) & $\begin{array}{l}\text { Collection Instruments } \\
\text { and Procedures for } \\
\text { each Data Source }\end{array}$ & $\begin{array}{l}\text { Analysis Procedures } \\
\text { for each Data Source }\end{array}$ \\
\hline RQ1 & $\begin{array}{l}\text { 1. } \begin{array}{l}\text { Courses taught for } \\
\text { the topic Digital } \\
\text { Transformation for } \\
\text { both online and in- } \\
\text { person courses }\end{array} \\
\text { 1. Pretest } \\
\text { questionnaire } \\
\text { assessment } \\
\text { (Passive and } \\
\text { Active) }\end{array}$ & $\begin{array}{l}\text { 1. Recording of } \\
\text { pretest } \\
\text { questionnaire } \\
\text { assessment } \\
\text { scores. }\end{array}$ \\
& $\begin{array}{l}\text { Other considered } \\
\text { (optional) data sources: }\end{array}$ & $\begin{array}{l}\text { Post-test } \\
\text { questionnaire } \\
\text { assessment } \\
\text { (Passive and }\end{array}$ & 2. $\begin{array}{l}\text { Recording of } \\
\text { assessment } \\
\text { scores. }\end{array}$ \\
& & & \\
\hline
\end{tabular}




\begin{tabular}{|c|c|c|c|}
\hline $\begin{array}{l}\text { Research } \\
\text { Questions }\end{array}$ & Data Source(s) & $\begin{array}{l}\text { Collection Instruments } \\
\text { and Procedures for } \\
\text { each Data Source }\end{array}$ & $\begin{array}{l}\text { Analysis Procedures } \\
\text { for each Data Source }\end{array}$ \\
\hline & $\begin{array}{l}\text { 2. Course(s) outside } \\
\text { of the selected } \\
\text { courses that meet } \\
\text { similar needed } \\
\text { criteria. }\end{array}$ & $\begin{array}{l}\text { Active) } \\
\text { 3. Assessments (5 } \\
\text { total) (Passive and } \\
\text { Active) }\end{array}$ & $\begin{array}{l}\text { 3. Recording of } \\
\text { post-test } \\
\text { questionnaire } \\
\text { assessment } \\
\text { scores. }\end{array}$ \\
\hline & $\begin{array}{l}\text { 3. Volunteers for a } \\
\text { 4-week research } \\
\text { study. }\end{array}$ & $\begin{array}{l}\text { 4. Overall GPA } \\
\text { (Passive and } \\
\text { Active) }\end{array}$ & $\begin{array}{l}\text { 4. Examining of } \\
\text { changes } \\
\text { between pre- } \\
\text { and post-test. }\end{array}$ \\
\hline & & & $\begin{array}{l}\text { 5. Examining } \\
\text { changes } \\
\text { between } \\
\text { assessments }\end{array}$ \\
\hline & & & $\begin{array}{l}\text { 6. Examination of } \\
\text { changes } \\
\text { between the } \\
\text { questionnaire } \\
\text { and assessment }\end{array}$ \\
\hline & & & $\begin{array}{l}\text { 7. Examination of } \\
\text { changes } \\
\text { between final } \\
\text { GPA scores }\end{array}$ \\
\hline \multirow[t]{3}{*}{ RQ2 } & $\begin{array}{l}\text { Same as RQ1 with a new } \\
\text { selection of } 26 \\
\text { randomized students. }\end{array}$ & $\begin{array}{l}\text { 1. Collection of } \\
\text { comments and } \\
\text { observations in } \\
\text { video of } \\
\text { presentations and } \\
\text { in-class } \\
\text { discussions }\end{array}$ & $\begin{array}{l}\text { 1. Recording of } \\
\text { all data through } \\
\text { transcripts of } \\
\text { the four } \\
\text { collection } \\
\text { procedures }\end{array}$ \\
\hline & & $\begin{array}{l}\text { (Passive and } \\
\text { Active) } \\
\text { 2. Collection of } \\
\text { student responses } \\
\text { through a course } \\
\text { evaluation }\end{array}$ & $\begin{array}{l}\text { 2. Decoding of } \\
\text { content that } \\
\text { includes } \\
\text { components of } \\
\text { engagement or } \\
\text { disengagement }\end{array}$ \\
\hline & & (Passive and & $\begin{array}{l}\text { 3. Examination of } \\
\text { correlations of }\end{array}$ \\
\hline
\end{tabular}




\begin{tabular}{|c|c|c|c|}
\hline $\begin{array}{l}\text { Research } \\
\text { Questions }\end{array}$ & Data Source(s) & $\begin{array}{l}\text { Collection Instruments } \\
\text { and Procedures for } \\
\text { each Data Source }\end{array}$ & $\begin{array}{l}\text { Analysis Procedures } \\
\text { for each Data Source }\end{array}$ \\
\hline & & $\begin{array}{l}\text { Active) } \\
\text { 3. Collection of } \\
\text { responses through } \\
\text { an engagement } \\
\text { survey of students } \\
\text { (Passive and } \\
\text { Active) }\end{array}$ & $\begin{array}{l}\text { engagement } \\
\text { and } \\
\text { disengagement } \\
\text { between active } \\
\text { and passive } \\
\text { courses }\end{array}$ \\
\hline & & $\begin{array}{l}\text { 4. Collection of data } \\
\text { from an } \\
\text { introduction to } \\
\text { DT survey } \\
\text { (Passive and } \\
\text { Active) }\end{array}$ & \\
\hline
\end{tabular}

Variables

The following table summarizes the research design used for this study. Succinctly, we are looking to apply the independent variable, which is the instructional design of either the flipped classroom (active learning) approach or the traditional lecture-based (passive learning) approach across the same classroom modules from which both sets of students will learn and engage. The passive learning group would be considered the control group utilizing traditional classroom instruction, with each class having lecture and discussion between instructor, students and vice versa during the live classroom, while working on assignments outside of the live classroom. The flipped classroom group will watch the prerecorded lectures outside of classroom time and will then work on assignments as activities and apply outside learning while in the live class. The flipped classroom group would be considered the treatment group that experiences learning from a flipped classroom approach. 


\section{Table 6}

Research design summary

\begin{tabular}{llll}
\hline $\begin{array}{l}\text { IV - Instructional } \\
\text { Design }\end{array}$ & $\begin{array}{l}\text { Active Learning } \\
\text { (Flipped } \\
\text { Classroom) }\end{array}$ & $\begin{array}{l}\text { Passive Learning } \\
\text { (Traditional } \\
\text { Lecture) }\end{array}$ & $\begin{array}{l}\text { DV - } \\
\text { Learning/Engagement }\end{array}$ \\
\hline Module 1 & Group 1 & Group 2 & Module 1 Outcomes \\
Module 2 & Group 1 & Group 2 & Module 2 Outcomes \\
Module 3 & Group 1 & Group 2 & Module 3 Outcomes \\
Module 4 & Group 1 & Group 2 & Module 4 Outcomes \\
Module 5 & Group 1 & Group 2 & Module 5 Outcomes \\
\hline
\end{tabular}

Note: As an eight-week course with modules taking one week each, three weeks are dedicated to non-graded activities without data collection opportunities

\section{Summary of the Methodology Needed to Answer the Research Questions}

The following section describes the overall strategy required for answering the research questions. This contains the observational methods and data collection methods used to address the questions.

\section{The Overall Strategy/Approach for Answering the Research Questions}

Specifically, this study was conducted over eight half semesters (also called minisemesters by the accredited university) between 2018-2020 with data extracted from five weeks of the six to eight weeks (six weeks for summer semesters, eight weeks for fall/spring semesters) of the course for review and analysis of changes in learning based on assessments, and across all eight weeks to determine changes in learning and engagement. Students taking the Digital Transformation course are selected as participants and tracked throughout the study period. 


\section{Figure 16}

Path of learning for passive and active learners with data collection points

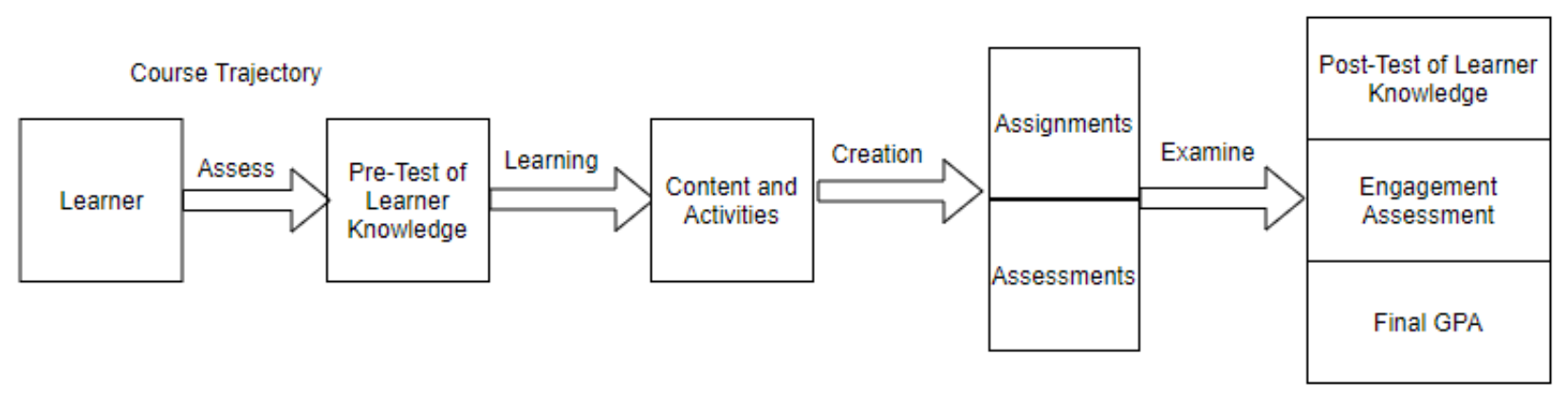

Students are selected based on the type of digital transformation course they are registered for and are then taught materials through either a passive (control level-2) or active (treatment level-1) style of teaching; 50\% making up each independent variable based on randomized drawing of students from the pool. Two types of data were gathered to conduct a mixed-methods study. Academic and other related objectives do not differ between groups. The assignments and general coursework are identical with current teaching practices. The method of class delivery is the difference and thus the control group is developed opposite of the treatment group (passive teaching model of instruction versus an active teaching model of instruction).

\section{The Two-Group Observation Methods}

The following table shows the pretest, post-test and assessment (covariate adjusted) twogroup design to show random assignment $(\mathrm{R})$, treatment conditions for the two independent variables (control $(\mathrm{Y})$ and treatment $(\mathrm{X})$, and the observation of the pretest and the behavior $(\mathrm{O})$. For the possibility of switching replication, the same design can take place with the IVs reversed in subsequent learning modules. 


\section{Table 7}

Cook and Campbell notation applied for the two-group design

\begin{tabular}{ccccc}
\hline $\mathrm{R}$ & $O_{1}$ & $O_{2}$ & $\mathrm{X}$ & $O_{3}$ \\
$\mathrm{R}$ & $O_{1}$ & $O_{2}$ & $\mathrm{Y}$ & $O_{3}$ \\
\hline
\end{tabular}

Note: Adapted from "Quasi-experimentation: design \& analysis issues for field settings," (Cook \& Campbell, 1979)

All assessments are conducted via the Canvas learning management system and an example of the assessment can be reviewed in the appendices. All assessments require responses to all questions (see appendix E for a sample of an assessment). Any assessment not completed or not started was discarded. Completed assessments are used in the overall tabulation. Discarded student responses were replaced by other students from the population. The study's data collection was designed to last approximately 33 months. Data was collected from students in the spring and summer of 2018, the full school year of 2018-2019 and spring and summer* of 2020.

\section{The Quantitative Data Collection Methods}

The quantitative data captured was handled in the following manner. Prior to starting the course, students took a 10-question pretest questionnaire that determined which students were eligible for participation in the study (based on the requirements for participation) and touched on areas of the class that determine pre-knowledge of course theories and content. The questionnaire was developed and implemented into the study for evaluating student learning in the classroom, and uses a 10-point Likert-style scale with scoring ranges between 1-10, which were determined to be appropriate for the range of lowest (1 per question, total of 10) to highest (maximum score of 100) ratings of knowledge in any given category (Andrews, 1984; Courser \& Lavrakas, 2012; Cox III, 1980; Garratt et al., 2011; Schwarz et al., 1991). Construct validity is determined to reflect the underlying theoretical construct intended for measurement (Bornstein, 2011) through selection of core topic areas to be learned in the class and representative of interest of measurement. This is given for each class in each semester and is followed up by a post-test at the end of the semester asking the same questions to determine increases in confidence of course objectives. This was then compared to the major study of determining 
change in learning based on active versus passive teaching. Quantitative comparisons are done through a Likert-scale comparison of the two outcomes. Unequal baselines are covered through an ANCOVA test to control for the differences in the pretest when comparing the post-test and results.

For determining changes throughout the semester in learning, active and passive students have taken an assessment once they completed the requirements at the end of each one of the five study weeks. The assessment contains 20 questions based on the selected materials for that week for comparison of the dependent variable from each group, looking for increases (or changes) in learning (See Appendix D - pre/post-test). Quantitative comparisons are done through a Likert-scale comparison of the two outcomes. As mentioned, unequal baselines will be determined and will be covered through an ANCOVA test to consider differences in assessments.

Learners are asked to select from four possible answers to address the question, with some questions requiring selections of multiple answers. Questions are worth five points and can go be recorded based on either missing a required answer, or selecting a wrong answer, in which case the learner would be given partial credit if the question was answered partially correct. Canvas handles scoring of partially correct answers.

\section{Figure 17}

Example screen capture of an assessment question answered partially correct.

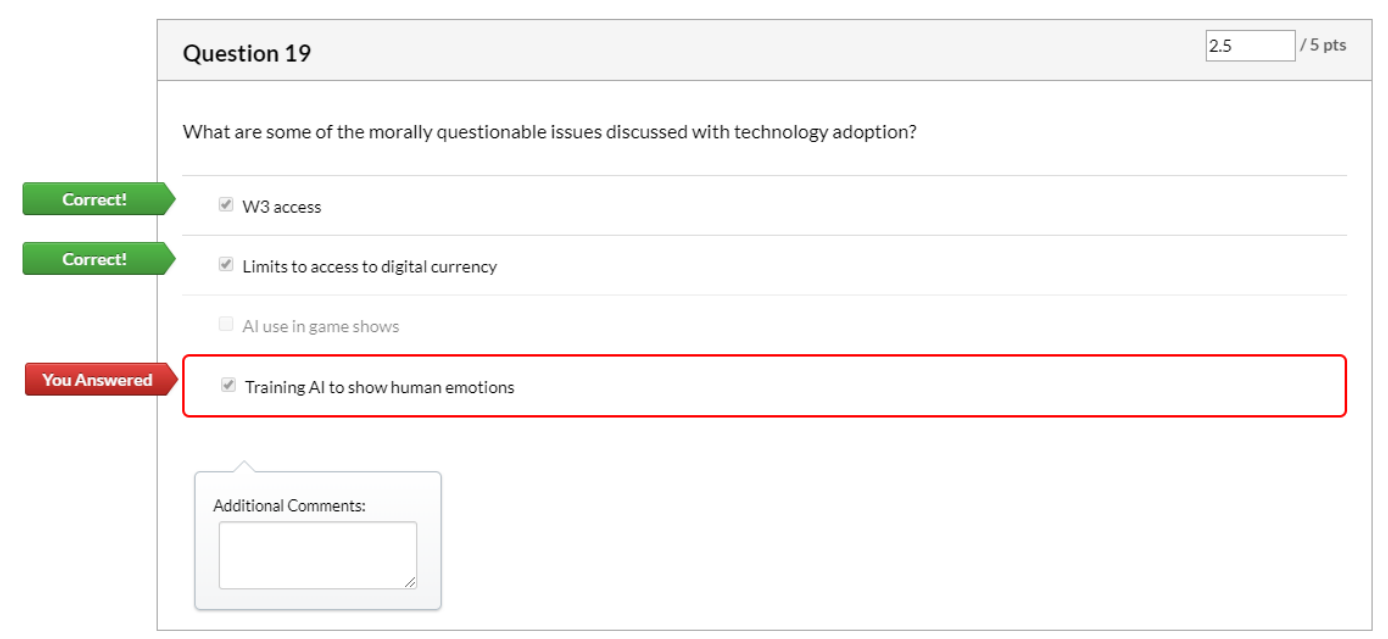

Note: Screenshot of a sample question taken from the Canvas LMS 
The following table outlines the method employed to gather the quantitative data points, the observation data points that were used to observe changes in learning and the method or instrument used to capture those data points.

\section{Table 8}

Matrix of quantitative data capture methods and components

\begin{tabular}{ccc}
\hline Quantitative Method & Observation Data Point & $\begin{array}{c}\text { Observation Data } \\
\text { Collection }\end{array}$ \\
\hline Weekly Assessments (5 Total) & $\begin{array}{c}\text { One-hour, 20-question } \\
\text { assessment based on prior } \\
\text { learning }\end{array}$ & $\begin{array}{c}\text { Canvas LMS quiz creator } \\
\text { and administrator }\end{array}$ \\
Overall GPA from the course & $\begin{array}{c}\text { End-of-class assessment of } \\
\text { all work completed }\end{array}$ & $\begin{array}{c}\text { Canvas LMS grade capture } \\
\text { Pretest and Post-test }\end{array}$ \\
& $\begin{array}{c}\text { Beginning and end-of-class } \\
\text { evaluation of knowledge of } \\
\text { components of the course }\end{array}$ & $\begin{array}{c}\text { Canvas LMS quiz creator } \\
\text { and administrator for two } \\
\text { assessments }\end{array}$ \\
& $\begin{array}{c}\text { Comparison of the pretest } \\
\text { and post-test observations }\end{array}$ & \\
\hline 3 total methods & 4 data points & 3 data components \\
\hline
\end{tabular}

The following figure outlines the trajectory of data collection points through the entirety of the class. All results are captured and analyzed throughout the class.

\section{Figure 18}

Course trajectory and data collection points.

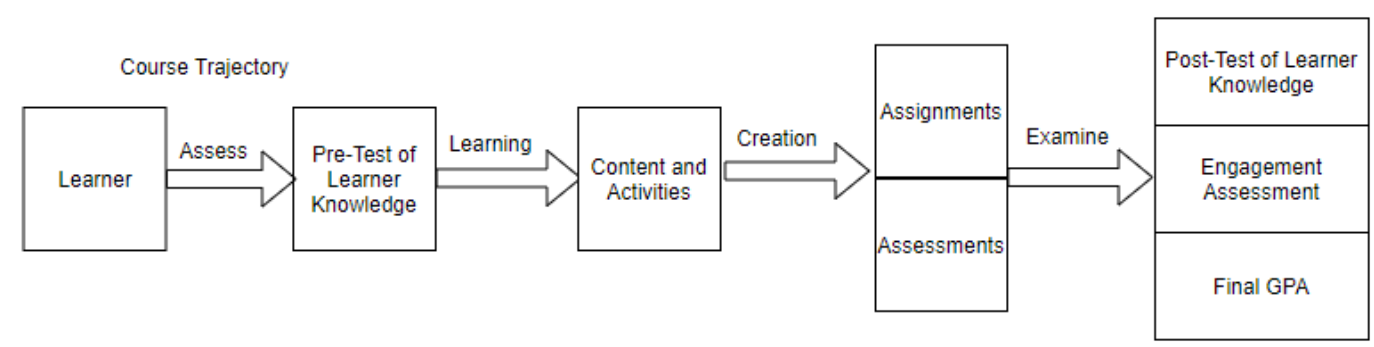




\section{Weekly Assessment, Overall GPA and Testing Methods}

As an approach to determining causal factors to increases in learning rates, this research looks at comparisons in weekly assessments and totals, the overall grades of each student and the perceived learning through the pretests and post-tests that have been administered and completed in the online course and compared to the traditional on-campus course, with the online distance education courses utilizing an active learning approach through a flipped classroom, and the on-campus courses using passive teaching models of instruction through the traditional lecture.

The following figure shows the data points, comparisons and observations used for each student in the study.

\section{Table 9}

Matrix of quantitative data comparisons and observations

Data Point Data comparison

\section{Observation}

Weekly assessments (5 total)

Assessments completed, oncampus versus distance

Overall GPA from the course

Pretest and post-test
Beginning and end of class evaluation of knowledge of components of the course, comparison of the pretest and post-test observations between on-campus and distance

Differences between the 5 data points (Objective)

Differences between a combination of all 5 data points (Objective)

Differences between GPAs of the two data points (Objective) 
Two of the three data points show the grades for each assessment and each class taken (and does not count dropped classes) based on a 100-point scale, and the test shows just the results of the increase between the pretest and post-test as well as the concluding results of the post-test which is also based on a 100-point scale.

All three look specifically at the numerical values to evaluate whether taking an online class with the flipped classroom type of instructional design and the learning generally received can correlate to the lecture-based, on-campus course delivery. This looks at the probability level of change through evaluation of the means of the dependent variables across the independent variables while controlling statistically for effects of other continuous variables or covariates that are not a part or of interest to the study. The ANCOVA multiple regression model used for this is

$$
y_{1}=\beta_{0}+\beta_{1 i}+\beta_{2} X_{2 i}+\beta_{3} X_{1 i} X_{2 i}+e_{i}
$$

Prior to running an ANCOVA, a t-test analysis was applied using the following formula as was used for the Covid-19 analysis performed outside of the main research study:

$$
t=\frac{\bar{x}_{1}-\bar{x}_{2}}{\sqrt{\left(\frac{S S_{1}+S S_{2}}{n_{1}+n_{2}-2}\right)\left(\frac{1}{n_{1}}+\frac{1}{n_{2}}\right)}}
$$

The following table shows an example collection and calculation of the mean, standard deviation and t-scores of the GPA of the two types of students' coursework in both online courses and traditional on-campus courses. 


\section{Table 10}

Example collection and calculation of GPA across lecture and flipped learning environments

\begin{tabular}{|l|l|l|l|}
\hline Student Type & Mean $\mathbf{G P A}^{\mathbf{h}}$ & Standard Deviation $^{\text {t-Score }}$ \\
\hline Traditional & 3.1 & 1.11 & $0.0003^{*}$ \\
\hline Online & 2.7 & 1.15 & \\
\hline
\end{tabular}

Note. Maximum score for all grades is 4 (A). Minimum grade is 0 (F) or (I).

${ }^{\mathrm{h}} n=104$ (traditional) 104 (online)

$* p>.05$

This shows scores compared by using a t-test for independent samples. As the above example indicates, scores between the control sample and the experimental groups are significantly different. The motivation is that this type of data will determine the strength of the comparison of support between online versus on-campus teaching, and this will be in support of or in rejection of the hypothesis stated in response to the research questions. The ANCOVA, however, will strengthen the results for the study to show how or if any baseline effects are present in the study.

Details on the instruments used for data collection are outlines in the instruments section of the methodology.

\section{Qualitative Data Collection Methods}

For the qualitative component to the research study to examine experience and engagement during the course, student data was captured throughout the entirety of the course as seen in the following figure.

\section{Figure 19}

Course trajectory and qualitative data points

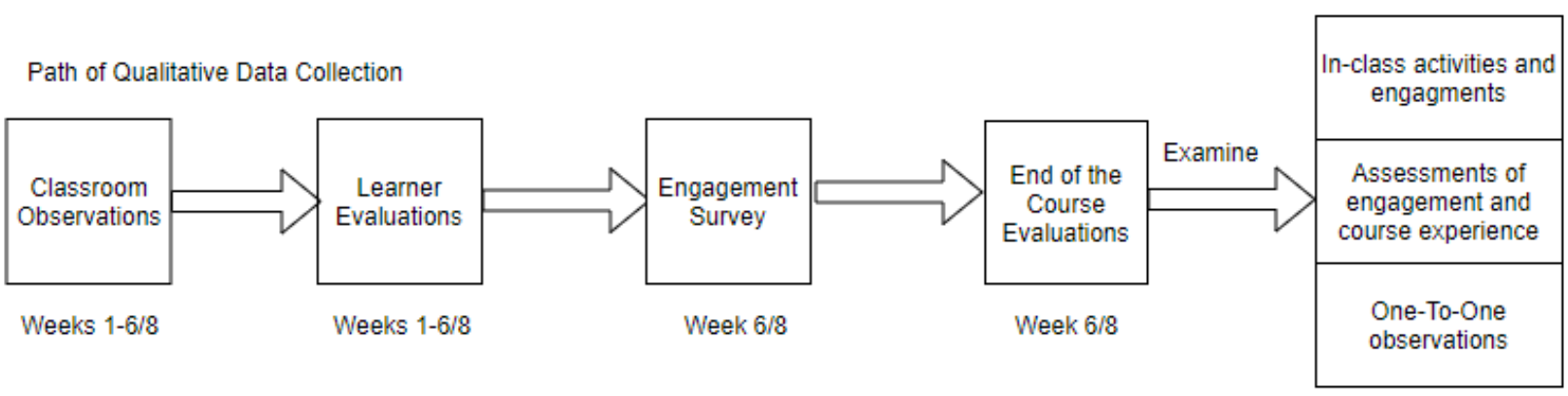


First, student class observations were taken from video recordings during the active sessions within the class, including giving presentations, reviewing peer presentations, in-class activities, and follow-up review of the week's content based on the assignment completed within the class. Secondly, the students were asked to fill out a course evaluation that can be used to review the course in general. The third component is an engagement survey that is used to compare active versus passive components of the course. Finally, randomized selections of students were selected and interviewed specifically regarding their experiences in engagement of all course content (assignments, communications, peer involvement, team-based learning) for comparisons between active and passive courses. All data captured is utilized in comparing student engagement levels through both active and passive courses.

\section{Table 11}

Matrix of qualitative data capture methods and components

\begin{tabular}{|c|c|c|}
\hline Qualitative Method & Observation Data Point & $\begin{array}{c}\text { Observation Data } \\
\text { Collection }\end{array}$ \\
\hline Classroom observations & $\begin{array}{l}\text { In-class activities } \\
\text { Open discussions }\end{array}$ & $\begin{array}{l}\text { Live classroom chat log, } \\
\text { audio and video capture } \\
\text { (Subjective) }\end{array}$ \\
\hline Engagement assessment & End-of-class assessment & $\begin{array}{c}\text { Canvas LMS assessment } \\
\text { capture (Subjective) }\end{array}$ \\
\hline Faculty course evaluation (FCE) & $\begin{array}{l}\text { End-of-class private course } \\
\text { evaluation }\end{array}$ & $\begin{array}{l}\text { Qualtrics assessment } \\
\text { capture (Subjective) }\end{array}$ \\
\hline Learner evaluation & $\begin{array}{l}\text { Email, in-person and Zoom } \\
\text { conversations }\end{array}$ & $\begin{array}{c}\text { Emails, notes, and video } \\
\text { and audio captures } \\
\text { (Subjective) }\end{array}$ \\
\hline 4 total methods & 7 data points & 6 data components \\
\hline
\end{tabular}

Details on the instruments used for data collection are outlined in the instruments section of methodology. 


\section{Methodology: Limitations and How Each Were Addressed}

\section{Participant Limitations and Addressing/Minimizing Each}

There have been several limitations that have been identified and derived from the students in this study. Those taking the class used to gather data were limited to graduate students at the selected school. Each student must be in good standing with the university, be eligible to take the "Digital Transformation" elective course and take at minimum the two weeks that are used for data gathering. Most students who drop a course tend to do this within the first week and can be accounted for easily. They must drop the course by the add/drop deadline which generally happens by the end of the second week. The course must also be available for the minimum number of students needed for a minimum of two weeks, which can assist in gathering switched replication data of independent variables switched between weeks 1 and 2, or 1 week for assessment data. Pretest and post-test data will require the students taking the entire course (six to eight weeks). Qualitative data was collected throughout the course but there are benefits to collecting data from partial participants when there is relevant data for a specific week and relevant experience. However, students generally drop a course within the first two weeks to not experience negative results such as showing a dropped course or having a tuition cost associated with a partially completed class, and thus all data in this study was collected from full participants.

To address participant limitations, students were selected based on their enrollment in the course being used for data gathering and research. Students were selected up to and beyond the minimum required amount needed for power analysis requirements. Students that did not complete the required tests were dropped from the study and replaced. Students that did not complete the engagement survey at the end were also dropped.

Alternative courses were identified and used for collection of data from needed students that meet the criteria for the research. These were not necessary but can be used for future studies. This also included creating a non-class participant-based study that would utilize the same criteria as the selected course for gathering data. The data relies on criteria that can effectively study the effects between active and passive learning. The focus groups for this study met the identified criteria for eligible participation listed above, reducing potential limitations and/or problems with participants. 
It is important to note there were no limitations for participation based on race, gender, ethnicity, age, religious beliefs, economic status or other demographics as these do not apply to this specific study.

\section{Overall Methodology Limitations}

Although care has been taken to reduce the number of limiting factors within this research, there are some limitations to be aware of in the overall design. This study is confined to the quantitative and qualitative data points from the Digital Transformation course, without use of other courses at the same or other institutions (but have been identified that meet the criteria for testing), and without utilization of a developed participation based on volunteer research study conducted outside of the classroom (but has been considered in the case of a limited participant pool). Participant limitations could affect the methodology's success if there were not enough eligible students or enough data gathered from those that participated, however this turned out to not be a defining limiting factor. Finally, the data itself could have shown minimal differences that would work against the hypothesis. However, the result is looking at change rather than direction, so this limitation has been reduced.

\section{Data Source Limitations}

Source limitations are based on the three identified areas of potential data gathering; the Digital Transformation course at an accredited university, an alternative course taught at the accredited university or WVU (or another affiliate), or through a volunteer-based study conducted with students that meet eligibility that can be enrolled into a two- to four-week session for data gathering.

Limitations of the data source from the Digital Transformation course and an alternative course are similar in nature. These limitations would include lack of enrollment, lack of completed assignments or assignments that do not meet standards for data gathering, and cancellation of the course due to unforeseen circumstances. To address these limitations, the course can be redelivered and/or rescheduled for another semester, or an alternative course can be used for data gathering. The content is not the focus, rather the outcomes from the models of instruction, so this would not affect the results.

Limitations with a volunteer-based research study include a lack of students, attrition of students during the study, possible testing effects, possible diffusion effects and potential 
selection bias dependent on who volunteers for the study. Lack of participants would have to be addressed by continuing to find students from several sources, including the two schools and potentially outside schools that have graduate students. Similarly, attrition would need to be addressed by finding new students to make up for the loss of current students, which may also require running a new study segregated from the current one. There could be testing effects from the pretest questionnaire that could create slight bias in knowledge of the course or study materials, however this would hold true across the participant pool and should not show unreasonable differences in outcomes. Diffusion effects are addressed through the switching replication format of the study, which looks at how both teaching and learning models of instruction affect the participant. Finally, selection bias is addressed by ensuring that the participant pool meet the criteria mentioned in the participant selection.

\section{Data Collection Procedure Limitations}

Limitations to data collection would only arise in the case that a participant did not complete the requirements of the module from which data would be collected. In this instance, the student would not be able to complete the course and thus would be dropped from the class, effectively removing them as an active participant in the study. Course assignments are not variable and are not optional, so all must be completed for proper participation.

There are three points of data collection that could potentially have limitations. The first is the introductory questionnaire. It is possible the participant could respond to the questionnaire without answering the questions thoughtfully or honestly, skewing the data. To help thwart potentially bad data, the questionnaire would contain a control question to prevent random results. Any questionnaire that is not answered with a correct control question would be rejected.

The second data collection point is the first observation evaluation. As in the first questionnaire, this is developed to ask questions based on the students' knowledge of the subject matter. This also could be answered incorrectly through hastily selecting random answers. In the same regard as the intro questionnaire, there would be a control question to help thwart this problem and any incorrectly answered evaluation is rejected.

The third data collection point to consider is the follow-up evaluation at the completion of the module. Like the first two data collection points, the final data collection area could also experience lack of honest response. This limitation can be addressed in two ways. First, the final 
evaluation has a grading component to it, so there is increased interest in the participant to take the evaluation seriously. Second, the evaluation, much like the first two, also contains a control question to ensure questions are answered honestly.

\section{Data Analysis Procedure Limitations}

Potential limitations in data analysis include longitudinal effects and access to the data collected for analysis. To address the longitudinal effects, a schedule has been created to adhere to data collection and analysis timelines. The time for completing the study successfully is limited to a minimum of one year and a maximum of two years. Data collection access limitations were addressed through proper IRB approval for use of the data for research purposes and adhered to within this research study.

\section{Data Collection Instruments - Online Coursework}

\section{Overview}

The data derives from post-secondary students taking an on-campus and distance course that can utilize both passive and active learning models of instruction. The course content consists of assignments that are currently given to students in those courses that, being predetermined, met the criteria for data collection comparisons. The classes utilized for data collection are the "Digital Transformation" courses currently taught at an institution of higher education. The determination was also made that collection could be expanded to incorporate other courses as deemed necessary for data collection purposes, including the same class taught by other professors. The courses were required to meet the requirements outlined in the following table. 


\section{Table 12}

Focus and description for the content collected through the instruments

Focus Description

Data

Course must have a minimum of 2 weeks that assessment data can be pulled for analysis, and 6-8 weeks for questionnaire data.

Power Analysis

A minimum sample size of 52 (26 per independent group) needed for each type of instructional design.

\section{Instruments}

There are three types of instrument criteria for data collection. The first criteria look at the numerical outcomes of learners through completion of the coursework. The second criteria examine perceived learning through the eyes of the participant through a numerical Likert-style scale. The third criteria look at perceptions of engagement through experiences within the classroom. The following table outlines each criterion with the instrument and type of data to be collected.

\section{Table 13}

Table of criteria and instruments used in the research study

\begin{tabular}{ccc}
\hline Criteria & Instrument & $\begin{array}{c}\text { Observation Data } \\
\text { Collection }\end{array}$ \\
\hline Coursework completion & Weekly assessments (5 total) & $\begin{array}{c}\text { Weekly assessments } \\
\text { and overall GPA }\end{array}$ \\
Perceived learning & Pre- and post-test surveys & $\begin{array}{l}\text { Outcomes of the pre- } \\
\text { and post-test and } \\
\text { numerical change } \\
\text { between them }\end{array}$ \\
& & $\begin{array}{l}\text { betweok } \\
\end{array}$
\end{tabular}




\begin{tabular}{ccl}
\hline Criteria & Instrument & \multicolumn{1}{c}{$\begin{array}{c}\text { Observation Data } \\
\text { Collection }\end{array}$} \\
\hline $\begin{array}{c}\text { Perceived engagement and } \\
\text { observations of engagement }\end{array}$ & Engagement survey & $\begin{array}{l}\text { Outcomes of the } \\
\text { survey and course } \\
\text { evaluation. }\end{array}$ \\
& Course evaluation & $\begin{array}{l}\text { Notes regarding } \\
\text { student interactions in } \\
\text { the class }\end{array}$ \\
& & $\mathbf{3}$ data components \\
\hline
\end{tabular}

As seen above, the study uses several instruments for data observation and collection. The collection builds into a mixed-methods style of research collecting quantitative and qualitative data across both learning and engagements.

Quantitative Analysis - Course Completion (Weekly and GPA)

The weekly assessments make up the first part of the quantitative analysis, which looks at the assessment scores of five separate quiz-style activities. Each assessment contains 20 multiple choice questions. The purpose of collecting these scores is to analyze and compare differences in retaining of course content between the two types of instructional design. Each assessment scores at a maximum of 100 points and gives an opportunity for a total of 500 points. Overall GPA makes up the second part of the quantitative assessment and is a collection of grades from the entire course. The following table outlines the types of criteria that make up the entire GPA for a student.

\section{Table 14}

Breakdown of GPA for quantitative analysis

\begin{tabular}{ccc}
\hline Assignments & \# of Assignments & \% of Overall Grade \\
\hline $\begin{array}{c}\text { Class attendance, activities } \\
\text { and evaluations } \\
\text { Projects }\end{array}$ & 19 & $36 \%$ \\
Final exam & 5 & $50 \%$ \\
\hline Total assignments and grade & 1 & $14 \%$ \\
\hline
\end{tabular}




\section{Quantitative Analysis - Perceived Learning Pre-Post Assessments}

The pre- and post-test assessments look at 10 criteria to gauge learning of specific courserelated materials and topics. These assessments are given just prior to the start of the course with a time and date limit set with similarities to all classes, whether distance or in-person. The design is to gauge the perceived (or subjective) abilities or knowledge of the specific course content, rated on a scale of 1 to 10 with 1 being the lowest and 10 being the highest. At the final week of the course, the students are given the same assessment to again gauge their perceived knowledge or skills in the content areas of the class. The final scoring is then used to gauge the change in their perceived learning.

\section{Table 15}

Breakdown of pre-and post-test analysis criteria

\begin{tabular}{ccl}
\hline Pretest & \multicolumn{1}{c}{ Post-test } & \multicolumn{1}{c}{ Final Scoring } \\
\hline $\begin{array}{c}1 \text { assessment given per } \\
\text { student }\end{array}$ & 1 assessment given per student & $\begin{array}{l}\text { tPost-tPre }= \\
\text { numerical change in } \\
\text { learning }\end{array}$ \\
$\begin{array}{c}\text { Scored on an overall scale } \\
\text { of } 10-100\end{array}$ & Scored on an overall scale of $10-100$ & tPost $/$ Pre $=\%$ change \\
in learning
\end{tabular}

Scoring and evaluation among online and in-person students would then take place to determine differences in perceived learning between the traditional and flipped instructional designs to show any variance between them. An example of the pre- and post-tests given can be viewed in Appendix D.

\section{Qualitative Analysis - Learning Engagement Assessments}

The engagement assessments are given during the final week of the class to both traditional and online students. This instrument is used to evaluate perceived experiential learning through engagement in the class as identified by the learner through a series of verbal and rating criteria. There are 10 questions, with four of them requiring a yes/no answer, four being a rating style of question (more, less, about the same, or does not apply) that contain four 
sub-questions each (totaling 16 sub-questions), and two questions that allow for an open-ended, paragraph style response.

The engagement survey also looks at identifying those that have had previous learning experiences through online mechanisms, whether those experiences included active learning styles of participation, and how they would rate the class they are currently taking compared to those prior experiences. Finally, there is a field to allow the learner to share any other notes that they would like to discuss about their engagement experiences within the class, as well as comparisons to other classes. The following set of five questions then asks the learner to follow the same types of questions but compare the current class to other in-person classes.

\section{Table 16}

A breakdown of the engagement survey content

\begin{tabular}{|c|c|c|}
\hline Assessment Questions & Analysis criteria & Final Scoring \\
\hline Q. 1,2 & $\begin{array}{l}\text { Background on experience of taking } \\
\text { online distance education or active } \\
\text { learning in online distance education }\end{array}$ & $\begin{array}{l}\text { Analysis of yes or no } \\
\text { responses }\end{array}$ \\
\hline Q. 3,4,8,9 & $\begin{array}{l}\text { Coding based on rating questions ( } 4 \\
\text { with } 4 \text { sub-questions each, } 16 \text { total) } \\
\text { Scored on an overall scale of } 0-3 \text { : } \\
\text { 0: Does not apply } \\
\text { 1: Less engaging } \\
\text { 2: About the same engagement } \\
\text { 3: More Engagement }\end{array}$ & $\begin{array}{l}\text { Analysis of the } 4 \text { types of } \\
\text { responses }\end{array}$ \\
\hline Q. 5,10 & $\begin{array}{l}\text { Open-ended response field to give } \\
\text { perceptions of engagement in the } \\
\text { class as well as comparisons to other } \\
\text { classes }\end{array}$ & $\begin{array}{l}\text { Coding and analysis of } \\
\text { the open-ended responses } \\
\text { for engagement-related } \\
\text { criteria }\end{array}$ \\
\hline Q. 6,7 & $\begin{array}{l}\text { Background on experience of taking } \\
\text { in-person and/or active learning in } \\
\text { online distance education }\end{array}$ & $\begin{array}{l}\text { Analysis of yes or no } \\
\text { responses }\end{array}$ \\
\hline
\end{tabular}


The 10 questions in the previous engagement-based questionnaire are looked at from the perspectives of experiences in traditional lecture-based and in-person styles of classes, as well as their prior experiences in online distance classes. These two criteria are also examined for prior classroom experiences that include active learning models of instruction, such as the flipped classroom, or others, but were not strictly passive-based in the class time given to the students for lecture or activities.

\section{Qualitative Analysis - Other Instruments}

The other instruments gather data in a verbal, paragraph or other style of data collection. The two major category of instruments are the FCE and the notes taken from observations of classroom activities, both synchronous and asynchronous.

The FCE allows for the student to give open-ended responses regarding their experiences within the class. These are then coded to determine experiences of engagement within the current class and especially those that correlate to the flipped classroom learning and/or active learning engagement. The observation notes are coded for determining engagements from the flipped classroom approach and in looking at active classroom actions, done through different styles of embedded student activities, as well as synchronous and asynchronous actions through communications, activities through the LMS, or chats through the Zoom chat log.

\section{Table 17}

A breakdown of the FCE and observation notetaking for qualitative analysis

\begin{tabular}{|c|c|c|}
\hline Assessment & Analysis criteria & Final Scoring \\
\hline Course evaluations (FCE) & $\begin{array}{l}\text { Coding out responses from FCE } \\
\text { submissions }\end{array}$ & $\begin{array}{l}\text { Coding and analysis } \\
\text { of the open-ended } \\
\text { responses for } \\
\text { engagement-related } \\
\text { criteria }\end{array}$ \\
\hline
\end{tabular}

\section{Observations:}

In Class (Via Zoom) 


\begin{tabular}{ccc}
\hline Assessment & Analysis criteria & Final Scoring \\
\hline $\begin{array}{c}\text { Synchronous chat } \\
\text { (via Zoom) }\end{array}$ & & \\
$\begin{array}{c}\text { Asynchronous postings } \\
\text { (via Canvas LMS) }\end{array}$ & & \\
$\begin{array}{c}\text { Asynchronous conversation } \\
\text { (via email, Canvas mail } \\
\text { system) }\end{array}$ & & \\
Synchronous conversation & Notes based on observable actions & $\begin{array}{l}\text { Coding and analysis } \\
\text { (via Zoom) }\end{array}$ \\
& (conversation, activity, etc.) & $\begin{array}{l}\text { for engagement- } \\
\text { related criteria }\end{array}$ \\
& & \\
\hline
\end{tabular}

\section{Chapter Summary}

The main goals of this research study were to employ an experimental design with a quasi-focus on both quantitative (measurable) and qualitative (observational) data points. The data points have a focus on learning, both perceived and actual that are measured through the quantitative instrumentation. Measurement of engagement takes place through two branches of observations with the end-of-course evaluations (FCEs) and a full range of observable criteria that take place within the classroom as well as outside of it but that actively take place by the learner though some type of communication platform, whether email, LMS or other mechanism. Guiding the methodology within the study includes the overall plans for statistical analysis of this collected data, the guiding research questions, the data collection instruments and procedures, and the activities driving these. Chapter 4 reviews the results of the data analysis. 


\section{Chapter 4: Results}

This chapter is dedicated to the documentation and development of results from analyzing the differences in learning and engagement through flipping an online classroom as opposed to its traditional, in-person and lecture-based counterpart. The two major changes we are looking at in this study are within learning, both perceived and numerical, as well as engagement, which is also perceived and observed. The class utilized for this study involves one graduate-level course taught to graduate-level students from similar branching degree programs at the same university. These are required "core" courses and must be taken to satisfy degree requirements. The courses are also taken in the final semester of a student's degree program without exception. On-campus courses are taught with the traditional lecture-based model of instructional design, while the online variety are taught with the flipped classroom approach of active learning. Use of all instrumentation across all courses remained identical and collected similar types of data for analysis.

\section{Table 18}

Background of the courses and number of courses used in the study

\begin{tabular}{lll}
\hline \multicolumn{1}{c}{ Courses } & Delivery and Instructional Design & Semester and Year \\
\hline Course A & $\begin{array}{l}\text { Online distance education/flipped } \\
\text { classroom }\end{array}$ & Spring 2018
\end{tabular}

Course B Online distance education/flipped Spring 2019 classroom

Course C On-campus/traditional lecture $\quad$ Summer 2019

Course D $\quad$ On-campus/traditional lecture $\quad$ Fall 2019 


\begin{tabular}{lll}
\hline \multicolumn{1}{c}{ Courses } & Delivery and Instructional Design & Semester and Year \\
\hline Course E & On-campus/traditional lecture & Spring 2020
\end{tabular}

Course F Online distance education/flipped Spring 2020 classroom

Course $\mathrm{G}^{*} \quad$ Online distance education/flipped $\quad$ Summer 2020* classroom*

\section{7 total courses}

$\begin{array}{cl}5 \text { online distance } & 7 \text { semesters } \\ \text { education/flipped classroom, } & \text { over } 2 \text { years } \\ 4 \text { on-campus/traditional } & \end{array}$

Note: *Summer 2020 data is collected but not utilized in the main study, however it is used in addendum to the study (looking at differences in on-campus versus distance classes for those mandated to moving to a distance-only mode of instruction based on the Covid-19 pandemic)

To flip the classroom in this research study, the instructional design focuses on reducing or eliminating the lecture component from live class time and replacing it with activities that would be built off of the lecture content normally used as take home assignments. In the traditional classes, the delivery does not change and sticks with a format of using class time for the lectures, while the online class takes the live component and utilizes it for activities such as group-based work, presenting findings on a case, debating two sides of a subjective argument, or other individual or group activities that can be done within the class. The lectures are recorded and given to the students before the activity sessions. The remaining instructional design stays intact and closely mimics that of the traditional classroom. Courses have two days per week in which they have live meetings in a classroom. 


\section{Table 19}

General design of the course week to week

\begin{tabular}{|c|c|c|}
\hline Weekly Schedule & Flipped Activities & Supporting Materials \\
\hline Day 1 & $\begin{array}{l}\text { Case study presentations, debates, } \\
\text { Q\&A and closing arguments }\end{array}$ & $\begin{array}{l}\text { Prerecorded lecture } \\
\text { readings } \\
\text { Case analysis } \\
\text { Piazza discussions }\end{array}$ \\
\hline Day 2 & $\begin{array}{l}\text { In-class activities, materials review, } \\
\text { assignments review, Q\&A }\end{array}$ & $\begin{array}{l}\text { Prerecorded lecture } \\
\text { readings } \\
\text { case analysis } \\
\text { Piazza discussions }\end{array}$ \\
\hline Day 7 & N/A (See above) & Weekly assessment \\
\hline 6-8 total weeks & $\begin{array}{l}\text { Lectures reduced or removed } \\
\text { from live sessions }\end{array}$ & $\begin{array}{l}\text { Materials give required } \\
\text { information for active } \\
\text { learning in class }\end{array}$ \\
\hline
\end{tabular}

Courses run from six to eight weeks dependent on the semester, with summer semesters running two weeks shorter. Freeing up live classroom time means more active student engagements can happen within the class, increasing more critical thinking on materials through activities, with weekly assessments given that correspond to all materials including the lectures to ensure mastery of the materials. Assessments are 20 multiple-choice questions to be answered in 60 minutes.

\section{Learning in the Class}

An analysis of learning takes place through three different criteria to gauge differences in learning outcomes. These criteria include the final GPA of the learner from each class, the assessment scores from five total assessments taken during the course, and perceived learning from the learner which is handled through a pre- and post-test that is scored on a Likert-style scale to determine changes and final scoring of their perceptions of learning the class content. The following is an analysis of the three criteria. Students are selected based on a randomized 
draw of 26 students per instructional design delivery, either an online flipped classroom or a traditional lecture-based, face-to-face class.

All quantitative results are tabulated through IBM SPSS Version 25 and Microsoft Excel.

\section{Learning: Analysis of the Changes in GPA Scores}

Overall GPA is analyzed between traditional and flipped classrooms to evaluate differences in overall learning outcomes. The GPA includes all activities and assignments that are graded during the length of the course. Negative differences show a higher outcome for the traditional versus flipped classroom which can be viewed in the following table.

\section{Table 20}

Class GPA averages across traditional and flipped classes of all students

\begin{tabular}{cccc}
\hline Class & $\begin{array}{c}\text { Traditional GPA } \\
\text { and participant \# }\end{array}$ & $\begin{array}{c}\text { Flipped GPA and } \\
\text { participant \# }\end{array}$ & Numerical Difference \\
\hline All Classes & $\begin{array}{c}91.23 \\
\mathrm{n}=144\end{array}$ & $\begin{array}{l}88.92 \\
\mathrm{n}=67\end{array}$ & -2.31 \\
& & & \\
\hline
\end{tabular}

Early results show a smaller difference in outcomes for the traditional learner at approximately 2.3 percentage points higher. In conducting the ANCOVA, the delivery mechanism did not have a significant effect on class GPA in adjusted models $(\mathrm{F}(1,49)=.02, \mathrm{p}$ $=.903 ; \eta p 2<.001)$. GPAs for participants in the distance flipped classroom (adjusted mean: $88.83 ; 95 \%$ CI $(86.60,91.07))$ were similar to the GPAs of their peers who took the traditional in-person class $($ adjusted mean $=89.03 ; 95 \%$ CI $(86.80,91.27)$ ). 


\section{Table 21}

Descriptive statistics and ANCOVA results for class grade point average by delivery mechanism adjusting for pretest score

\begin{tabular}{|c|c|c|c|c|c|c|c|}
\hline Delivery Mechanism & $\mathbf{N}$ & \multicolumn{2}{|c|}{ Observed Mean } & \multicolumn{2}{|c|}{ Adjusted Mean } & \multicolumn{2}{|c|}{$95 \% \mathrm{CI}$} \\
\hline Traditional in-person lecture & 26 & \multicolumn{2}{|c|}{89.18} & \multicolumn{2}{|c|}{89.03} & \multicolumn{2}{|c|}{$[86.80,91.27]$} \\
\hline Distance flipped classroom & 26 & 88 & & & 83 & {$[86.60$} & 1.07] \\
\hline Source & & SS & df & MS & $\mathbf{F}$ & $p$ & $\eta_{p}^{2}$ \\
\hline Corrected model & & 17.15 & 2 & 8.58 & .28 & .758 & .011 \\
\hline Intercept & & 24665.10 & 1 & 24665.10 & 800.32 & $<.001$ & .942 \\
\hline Pretest score & & 13.89 & 1 & 13.89 & .45 & .505 & .009 \\
\hline Distance flipped classroom & & 0.46 & 1 & 0.46 & .02 & .903 & $<.001$ \\
\hline Error & & 1510.13 & 49 & 30.82 & & & \\
\hline
\end{tabular}

Note: Adjusted means based on adjustment for pretest scores; $\mathrm{R}^{2}=.011$, adjusted $\mathrm{R}^{2}=-.029$

In looking at the following figure the distribution gives an overview of the students and frequency of GPA scores for traditional lecture-based classes and the distance flipped classes.

\section{Figure 20}

Scatterplot of traditional versus flipped classroom by GPA

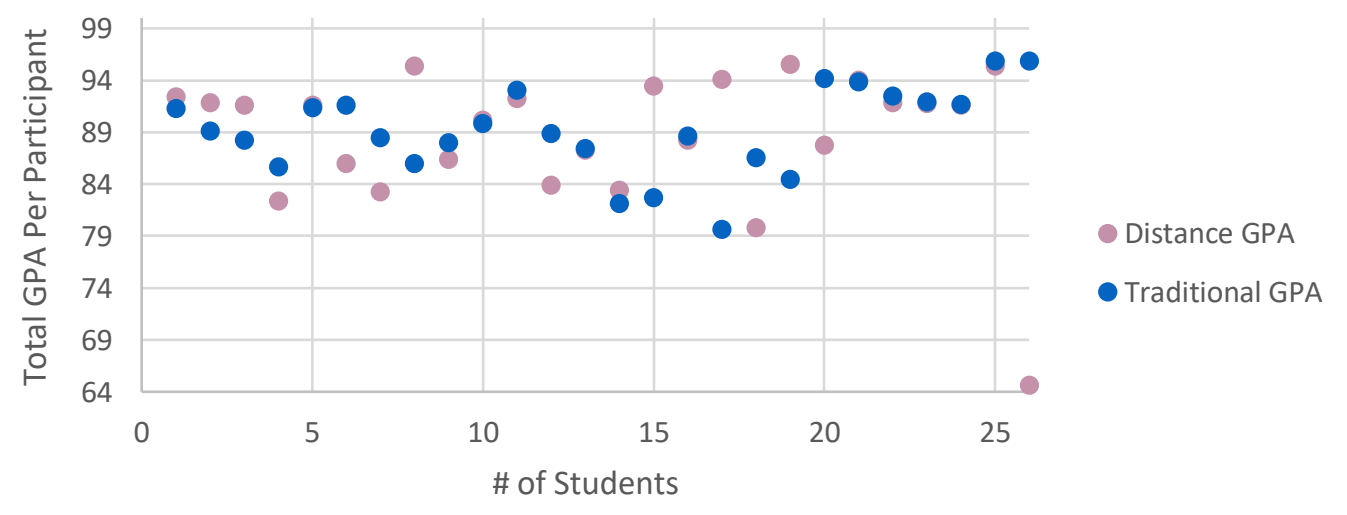


In looking at the randomized selection of 52 students ( 26 for each instructional design), there appears to be a normal pattern of distribution across both modalities. There is a singular outlier in flipped distance education but neither instructional design differs significantly from the other. This leads to the valid assumption that the data points are normally distributed.

\section{Learning: Analysis of the Outcomes of Assessment Scores}

Assessment formats examine learning on the topics covered in the week they are assigned. Learners have the option of taking the assessment as a bonus activity to get extra credit for the week's assignment, allowing them to make up any points lost on other assignments for that week. Any assessments not taken are excluded from the analysis. The following table outlines the five assessments, the number of students and the average grades of those participant pools, both in the traditional and the flipped classroom, as well as the difference in score outputs between the traditional and the flipped classrooms. Negative differences show a higher outcome for the traditional versus flipped classroom which can be viewed in the following table.

\section{Table 22}

Class averages on quiz assessments across traditional and flipped classes given per module

\begin{tabular}{lccc}
\hline $\begin{array}{c}\text { Quiz } \\
\text { Assessment \# }\end{array}$ & $\begin{array}{c}\text { Traditional Score } \\
\text { (Avg.) and } \\
\text { participant \# }\end{array}$ & $\begin{array}{c}\text { Flipped Score } \\
\text { (Avg.) and } \\
\text { participant \# }\end{array}$ & Numerical Difference \\
\hline Quiz & 85.96 & 70.31 & -15.65 \\
Assessment 1 & $\mathrm{n}=30$ & $\mathrm{n}=65$ & \\
Quiz & 80.76 & 62.65 & -18.1 \\
Assessment 2 & $\mathrm{n}=30$ & $\mathrm{n}=60$ & \\
& & & -13.56 \\
Quiz & 83.03 & 69.47 & \\
Assessment 3 & $\mathrm{n}=24$ & $\mathrm{n}=60$ & \\
& & & .45 \\
Quiz & 71.67 & 72.11 & \\
Assessment 4 & $\mathrm{n}=24$ & $\mathrm{n}=57$ &
\end{tabular}




\begin{tabular}{lccc}
\hline $\begin{array}{c}\text { Quiz } \\
\text { Assessment \# }\end{array}$ & $\begin{array}{c}\text { Traditional Score } \\
\text { (Avg.) and } \\
\text { participant \# }\end{array}$ & $\begin{array}{c}\text { Flipped Score } \\
\text { (Avg.) and } \\
\text { participant \# }\end{array}$ & Numerical Difference \\
\hline Quiz & 82.16 & $\begin{array}{l}74.74 \\
\mathrm{n}=60\end{array}$ & -7.42 \\
Assessment 5 & $\mathrm{n}=22$ & $\mathbf{6 9 . 8 6}$ & $\mathbf{- 1 0 . 8 5 6}$ \\
\hline Averages: & $\mathbf{8 0 . 7 2}$ & & \\
\hline
\end{tabular}

On average, traditional learners' assessment scores were approximately 10.9 points higher than flipped classroom learners, with only one assessment showing the opposite pattern at approximately one-half a point difference.

In ANCOVA models adjusting for baseline knowledge, the delivery mechanism had a significant effect on three out of the five assessment scores. More specifically, the delivery mechanism had a significant effect on Assessment $1(\mathrm{~F}(1,49)=17.64, \mathrm{p}<.001)$, Assessment 2 $(\mathrm{F}(1,49)=12.32, \mathrm{p}=.001)$ and Assessment $3(\mathrm{~F}(1,49)=5.93, \mathrm{p}=.019)$ such that students in the distance flipped classroom scored significantly lower on the first three assessments compared to students in the traditional in-person class. The effect sizes were large across Assessments 1-3 $(\eta p 2=.265, .108$ and .201 respectively).

Students in the distance flipped classroom did not significantly differ from their traditional in-person peers on their scores for Assessment $4(\mathrm{~F}(1,49)=.04, \mathrm{p}=.846 ; \eta \mathrm{p} 2=.001)$ and Assessment $5(\mathrm{~F}(1,49)=3.08, \mathrm{p}=.085 ; \eta \mathrm{p} 2=.058)$.

An average assessment score was calculated by taking the mean across the five assessments. After a covariance for pretest scores, there was a significant effect of delivery mechanism on average assessment score $(F(1,49)=10.37, \mathrm{p}<.002)$ and the size of this effect was large $(\eta p 2=.175)$. Students in the distance flipped classroom earned significantly lower scores (adjusted mean $=71.26 ; 95 \% \mathrm{CI}(66.85,75.67))$ compared to students in the traditional inperson class (adjusted mean $=81.45 ; 95 \% \mathrm{CI}(77.05,85.86)$ ). 


\section{Table 23}

Descriptive statistics and ANCOVA results for average assessment score by delivery mechanism adjusting for pretest score

\begin{tabular}{lrrrrrr}
\hline & N & Observed Mean & Adjusted Mean & 95\% CI \\
\hline Delivery mechanism & & & & & & \\
$\quad$ Traditional in-person & 26 & & 81.38 & & 81.45 & {$[77.05,85.86]$} \\
$\quad$ distance flipped classroom & 26 & & 71.33 & & 71.26 & {$[66.85,75.67]$} \\
& & & & & & \\
Source & SS & df & MS & F & \multicolumn{1}{c}{$\boldsymbol{p}$} & $\boldsymbol{\eta}_{\mathbf{p}}^{2}$ \\
\hline Corrected model & 1317.77 & 2 & 658.88 & 5.50 & .007 & .183 \\
$\quad$ Intercept & 16929.95 & 1 & 16929.95 & 141.23 & $<.001$ & .742 \\
$\quad$ Pretest score & 2.78 & 1 & 2.78 & .02 & .88 & $<.001$ \\
$\quad$ Distance flipped classroom & 1243.08 & 1 & 1243.08 & 10.37 & .002 & .175 \\
Error & 5873.90 & 49 & 119.88 & & & \\
\hline
\end{tabular}

Note: Average assessment score $=$ mean across 5 assessments; Adjusted means based on adjustment for pretest scores; $\mathrm{R}^{2}=.183$, adjusted $\mathrm{R}^{2}=.150$

The results show a significant difference in learning from the traditional in-person lecture model compared to the flipped distance education classroom. The following figure gives an overview of the students and frequency of assessment scores for traditional lecture-based classes and the distance flipped learning classes. The $\mathrm{x}$-axis references the number of students while the $y$-axis represents the scoring range of the assessments. Moving from the left to the right starts at assessment 1 and shows the instructional design correlated to the range of scores and deviations between them. 


\section{Figure 21}

Flipped distance (left) versus traditional in-person lecture (right) quiz assessment results

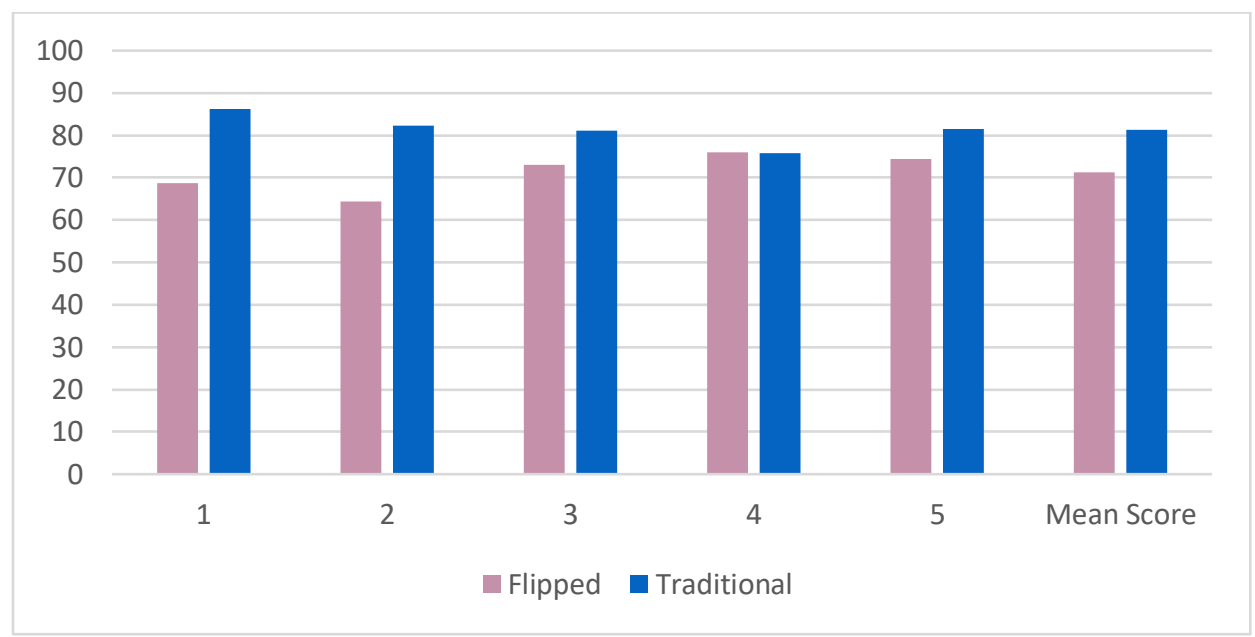

In looking at the randomized participant selection of 52 students ( 26 for each instructional design), there appears to be an unequal pattern of distribution across both modalities. The traditional in-class lecture design differs significantly from the flipped classroom design which assumes that the data points are unequally distributed.

The following tables show the descriptive statistics and ANCOVA results for each individual quiz assessment. 


\section{Table 24}

Descriptive statistics and ANCOVA results for assessment 1 by delivery mechanism adjusting for pretest score

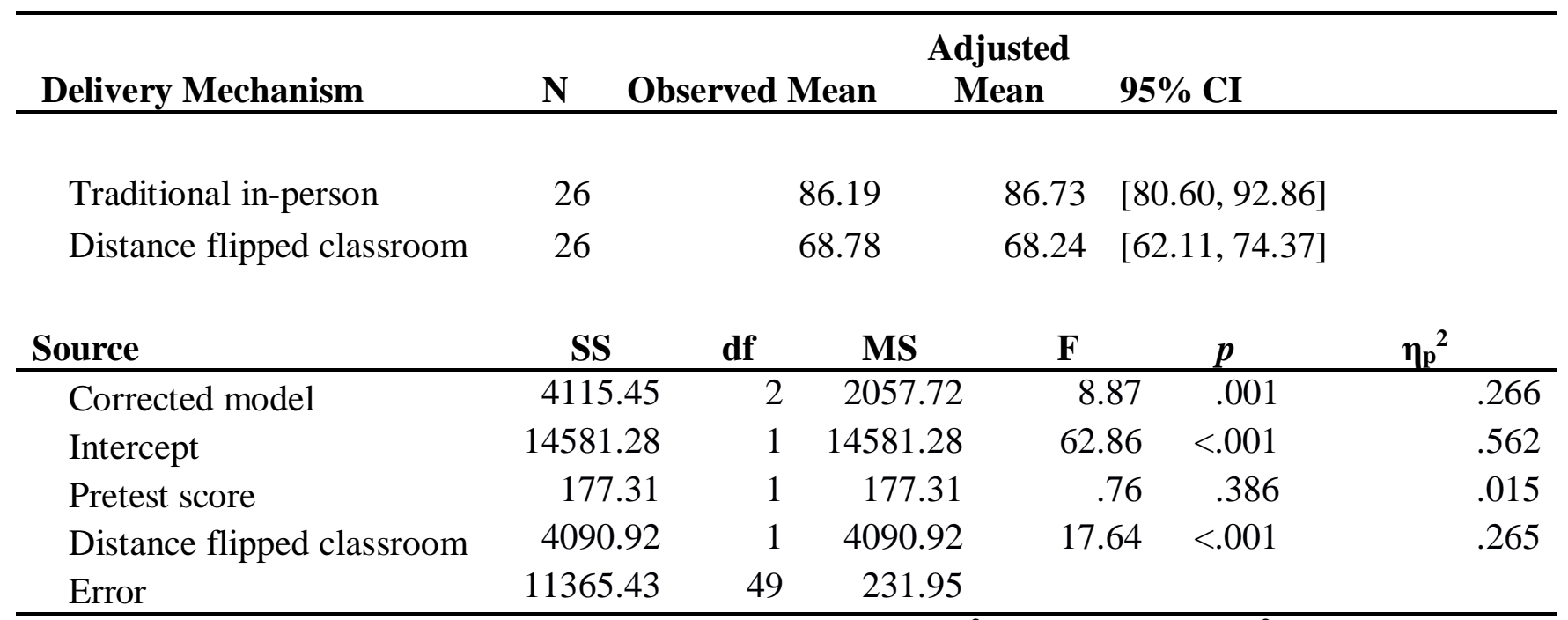

Note: Adjusted means based on adjustment for pretest scores; $\mathrm{R}^{2}=.266$, adjusted $\mathrm{R}^{2}=.236$

\section{Table 25}

Descriptive statistics and ANCOVA results for assessment 2 by delivery mechanism adjusting for pretest score

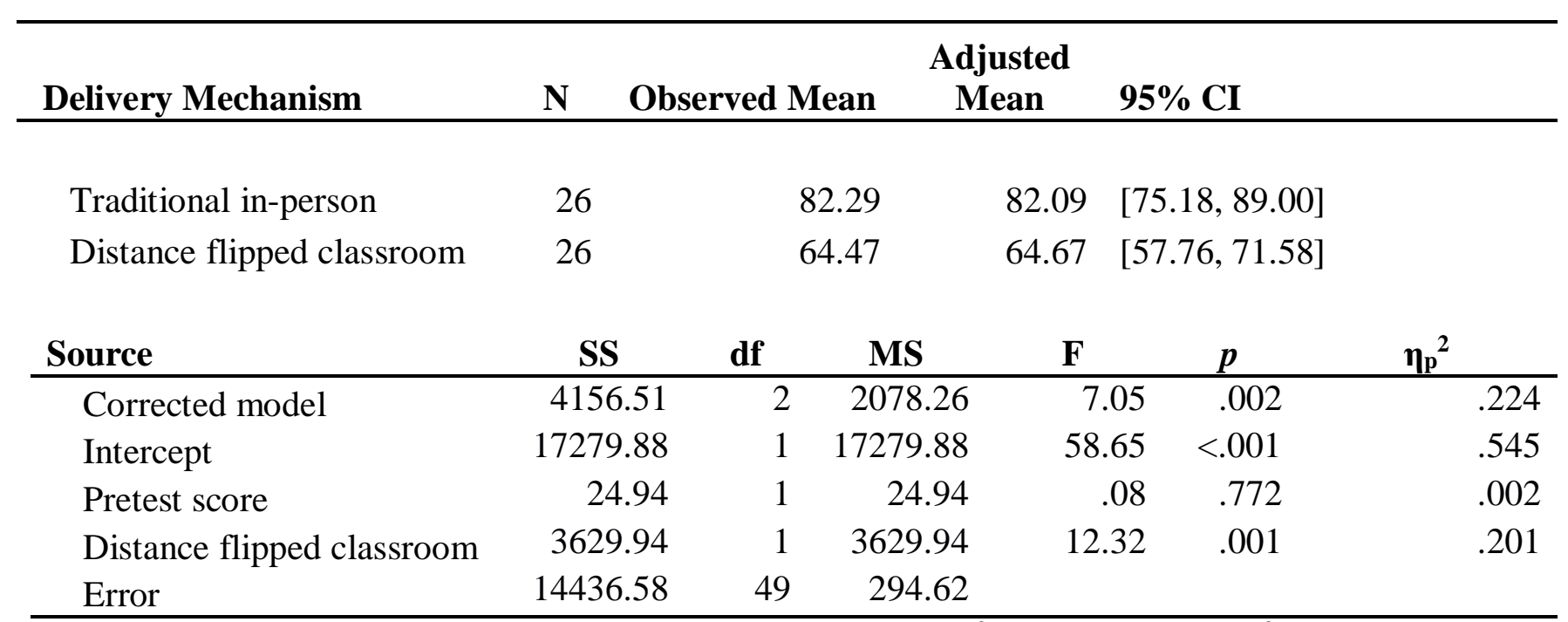

Note: Adjusted means based on adjustment for pretest scores; $\mathrm{R}^{2}=.224$, adjusted $\mathrm{R}^{2}=.192$ 


\section{Table 26}

Descriptive statistics and ANCOVA results for assessment 3 by delivery mechanism adjusting for pretest score

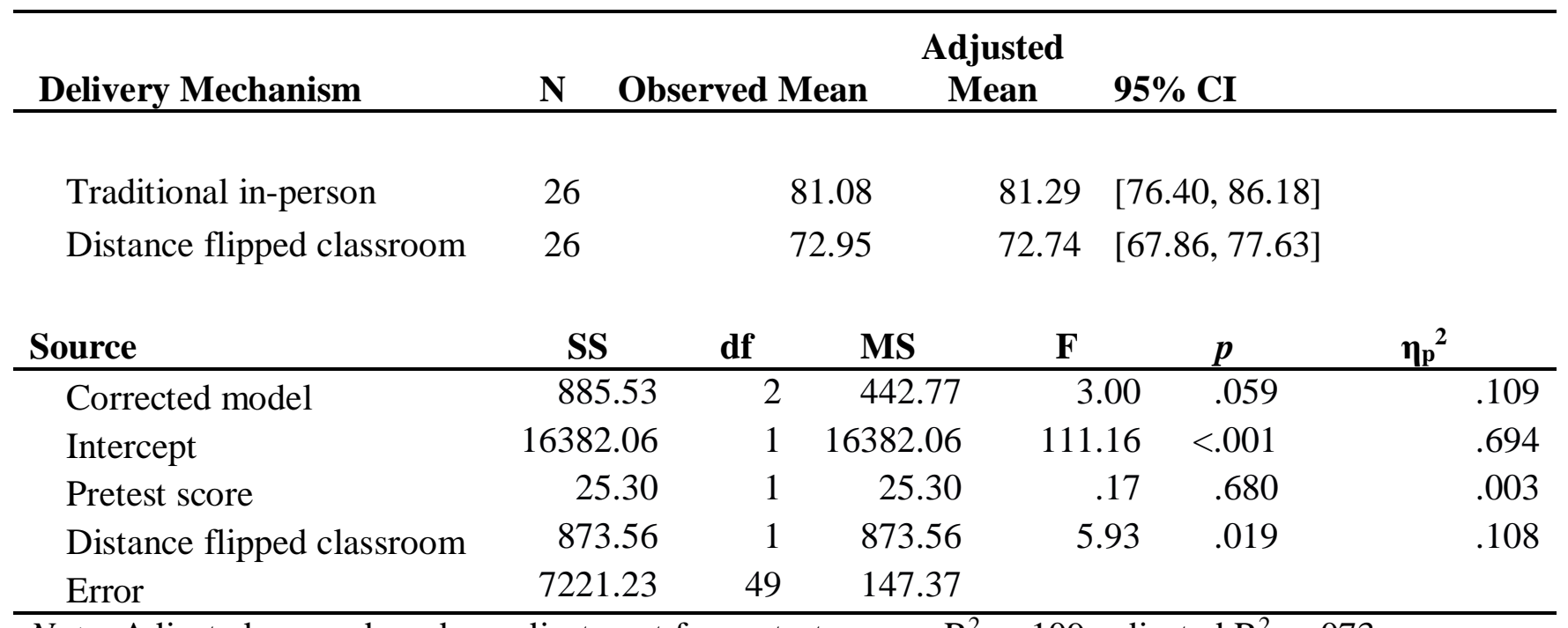

Note: Adjusted means based on adjustment for pretest scores; $\mathrm{R}^{2}=.109$, adjusted $\mathrm{R}^{2}=.073$

Table 27

Descriptive statistics and ANCOVA results for assessment 4 by delivery mechanism adjusting for pretest score

\begin{tabular}{|c|c|c|c|c|c|c|}
\hline Delivery Mechanism & \multicolumn{6}{|c|}{ Adjusted } \\
\hline Traditional in-person & 26 & & 5.88 & 75.57 & $01,81.13]$ & \\
\hline Distance flipped classroom & 26 & & 5.03 & 76.35 & $79,81.91]$ & \\
\hline Source & SS & df & MS & $\mathbf{F}$ & $p$ & $\eta_{p}^{2}$ \\
\hline Corrected model & 60.82 & 2 & 30.41 & .16 & .853 & .006 \\
\hline Intercept & 19210.94 & 1 & 19210.94 & 100.62 & $<.001$ & .673 \\
\hline Pretest score & 60.54 & 1 & 60.54 & .32 & .576 & .006 \\
\hline Distance flipped classroom & 7.29 & 1 & 7.29 & .04 & .846 & .001 \\
\hline Error & 9354.92 & 49 & 190.92 & & & \\
\hline
\end{tabular}

Note: Adjusted means based on adjustment for pretest scores; $\mathrm{R}^{2}=.006$, adjusted $\mathrm{R}^{2}=-.034$ 


\section{Table 28}

Descriptive statistics and ANCOVA results for assessment 5 by delivery mechanism adjusting for pretest score

\begin{tabular}{|c|c|c|c|c|c|c|}
\hline Delivery Mechanism & \multicolumn{3}{|c|}{ Observed Mean } & $\begin{array}{c}\text { Adjusted } \\
\text { Mean }\end{array}$ & \multicolumn{2}{|l|}{$95 \% \mathrm{CI}$} \\
\hline Traditional in-person & 26 & & 1.47 & 81.58 & {$[75.80,87.37]$} & \\
\hline Distance flipped classroom & 26 & & 4.41 & 74.29 & {$[68.51,80.07]$} & \\
\hline Source & SS & df & MS & $\mathbf{F}$ & $p$ & $\eta_{p}^{2}$ \\
\hline Corrected model & 656.72 & 2 & 328.36 & 1.59 & .214 & .061 \\
\hline Intercept & 17364.35 & 1 & 17364.35 & 84.21 & $<.001$ & .632 \\
\hline Pretest score & 7.69 & 1 & 7.69 & .04 & .848 & .001 \\
\hline Distance flipped classroom & 636.14 & 1 & 636.14 & 3.08 & .085 & .059 \\
\hline Error & 10104.10 & 49 & 206.21 & & & \\
\hline
\end{tabular}

Note: Adjusted means based on adjustment for pretest scores; $\mathrm{R}^{2}=.061$, adjusted $\mathrm{R}^{2}=.023$

\section{Learning: Analysis of the Perceived Changes in Learning Through Pre- and Post-Test Survey}

\section{Scores}

The third component to determining potential learning changes in the class looks at perceived learning from the perceptions of the leaner based on several criteria that are taught in the class. An overview of the instrument used for data collection can be viewed in Appendix D. Surveys that were not completed were discarded, and learners that took only one survey were also discarded. The survey is taken in the first and the last week of the class. The results can be seen in the following table to show differences between the traditional and flipped classroom instructional designs. Positive numerical differences show higher outcomes for the flipped classroom over traditional instructional design. 
Table 29

Class averages on weekly pre and post assessments across traditional and flipped classes

\begin{tabular}{lccc}
\hline Survey Type & $\begin{array}{c}\text { Traditional Score } \\
\text { (Avg.) and } \\
\text { participant \# }\end{array}$ & $\begin{array}{c}\text { Flipped Score } \\
\text { (Avg.) and } \\
\text { participant \# }\end{array}$ & Numerical Difference \\
\hline Pretest & $\begin{array}{c}57.25 \\
\mathrm{n}=102\end{array}$ & $\begin{array}{c}65.66 \\
\mathrm{n}=29\end{array}$ & +8.41 \\
Post-test & 78.39 & 90 & +11.61 \\
\hline $\begin{array}{c}\text { Combined } \\
\text { pre/post } \\
\text { numerical } \\
\text { change }\end{array}$ & $\mathbf{n}=102$ & $\mathrm{n}=29$ & \\
\hline
\end{tabular}

Scoring on the survey can be totaled in a range of 10 (lowest) to 100 (highest), with each individual question scored between 1 (lowest) and 10 (highest). The early results show that perceived learning from the flipped classroom on average is a higher value than the traditional instructional design, with a post-test score of 11.61 points higher and a combined numerical change of approximately 3.2 points higher for flipped online education over traditional in-class lecture instructional design.

The delivery mechanism was significantly associated with post-test knowledge $(F(1,49)=$ $.18 .10, p<.001)$ and this effect was large $\left(\eta_{\mathrm{p}}{ }^{2}=.270\right)$. Participants in the distance flipped classroom rated their post-test knowledge (adjusted mean: 92.78; 95\% CI $(88.63,96.92)$ ) significantly higher than their peers in the traditional in-person class (adjusted mean $=80.11$; 95\% CI (75.97, 84.25)). 


\section{Table 30}

Descriptive statistics and ANCOVA results for posttest score by delivery mechanism adjusting for pretest score

\begin{tabular}{|c|c|c|c|c|c|c|}
\hline Delivery Mechanism & \multicolumn{6}{|c|}{ Adjusted } \\
\hline Traditional in-person & 26 & & .85 & 80.11 & {$[75.97$,} & \\
\hline Distance flipped classroom & 26 & & 3.04 & 92.78 & {$[88.63$,} & \\
\hline Source & SS & df & MS & $\mathbf{F}$ & $p$ & $\eta_{p}^{2}$ \\
\hline Corrected model & 2304.06 & 2 & 1152.03 & 10.87 & $<.001$ & .307 \\
\hline Intercept & 20413.93 & 1 & 20413.93 & 192.56 & $<.001$ & .797 \\
\hline Pretest score & 41.58 & 1 & 41.58 & .39 & .534 & .008 \\
\hline Distance flipped classroom & 1919.07 & 1 & 1919.07 & 18.10 & $<.001$ & .270 \\
\hline Error & 5194.77 & 49 & 106.02 & & & \\
\hline
\end{tabular}

Note: Average assessment score $=$ mean across 5 assessments; Adjusted means based on adjustment for pretest scores; $\mathrm{R}^{2}=.307$, adjusted $\mathrm{R}^{2}=.279$

In the following figure, normal distribution of pretest scores between both types of instruction design are seen. In the following figures, you can notice a change in the distribution where the flipped distance students are more evenly distributed between the 40- and 90-point range with minimal outliers below the 40-point range, while the lecture based in-person students are more tightly conjugated in the average confidence range between $40-70$ with minimal outliers present below the 40-point range.

\section{Figure 22}

Flipped distance (left) versus in-person lecture (right), perceptions in pre-course knowledge
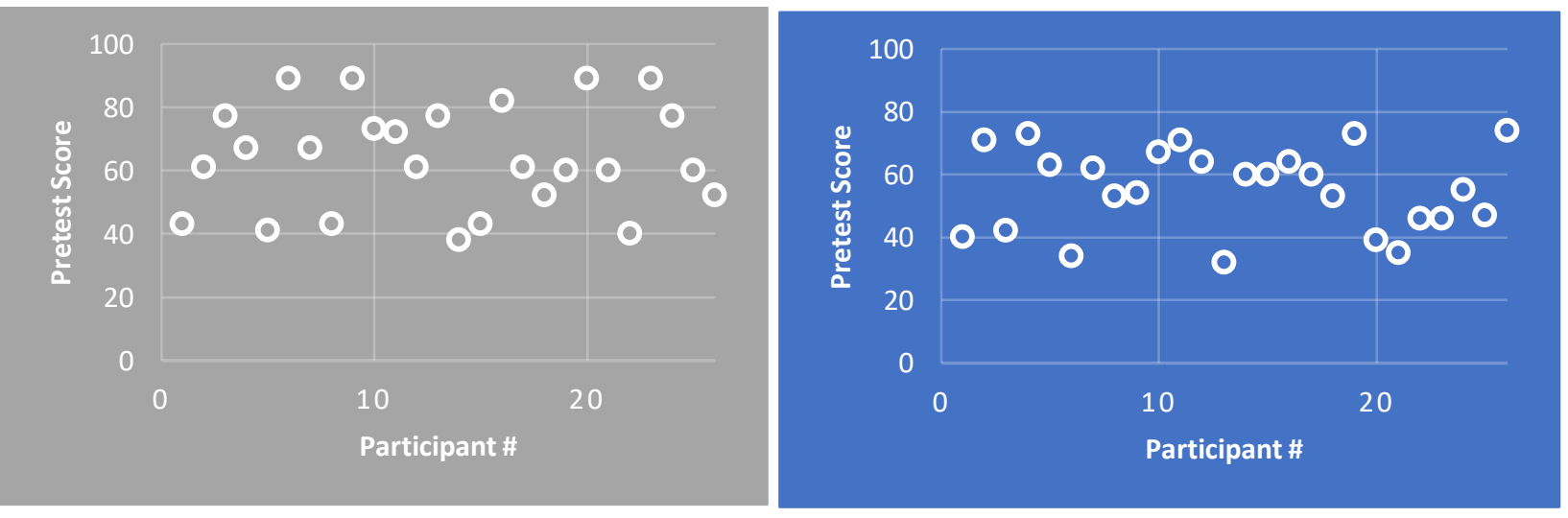
In the next figure, normal distribution of post-test scores between both types of instruction design are seen. In the following figures, you can notice a change in the distribution where the flipped distance students are more tightly conjugated between the 80- to 90-point range with minimal outliers just below the 80-point range, while the lecture based in-person students are more evenly distributed in the average confidence range between 65 and 95 with minimal outliers present below the 65 -point range.

\section{Figure 23}

Flipped distance (left) versus in-person lecture (right), perceptions in post-course knowledge

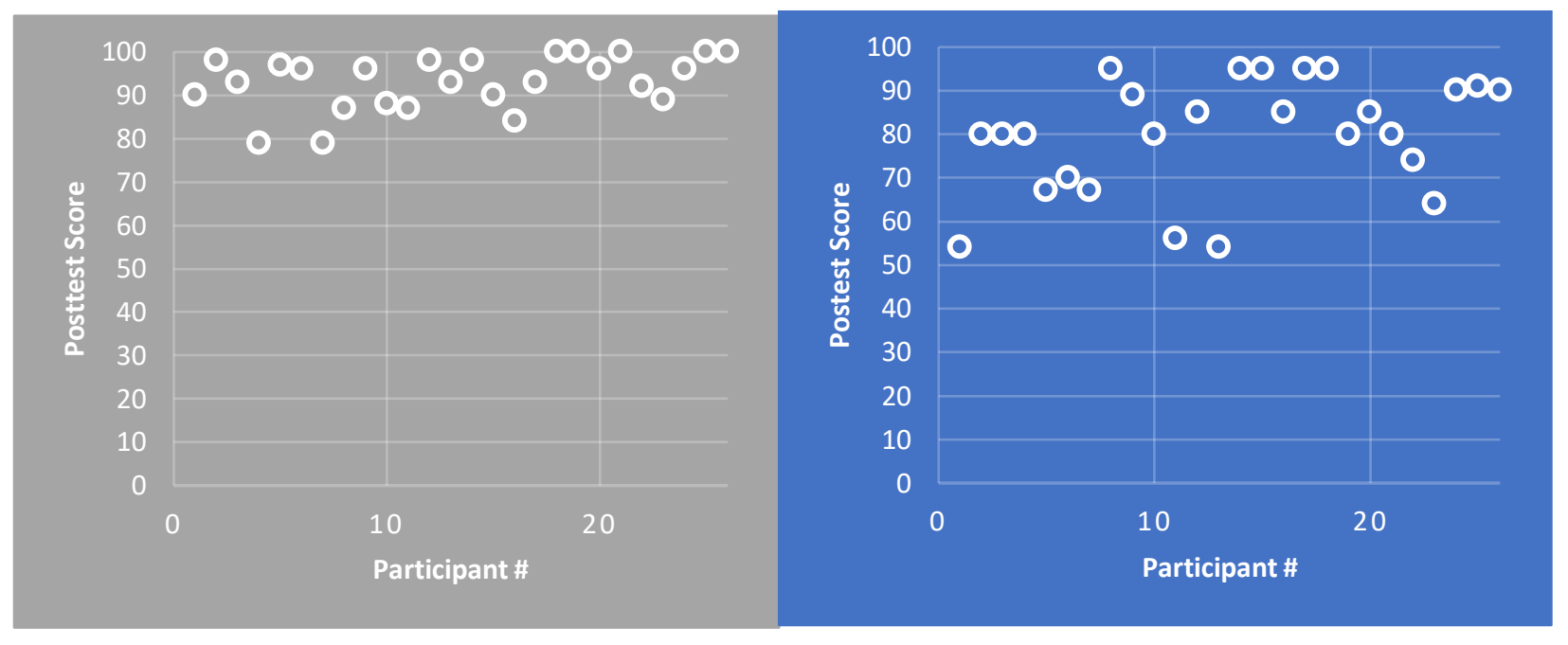

In the final figure, the distribution differences between pre- and post-test are strikingly similar between the flipped distance classroom and traditional in-person lecture class whereas most students see minimum change in the 0-20-point range, or a maximum change in the range of 30-50 points. It's also important to note that there is one outlier that reports a negative change in the traditional lecture class. 


\section{Figure 24}

Flipped distance (left) versus in-person lecture (right), change in perceived learning

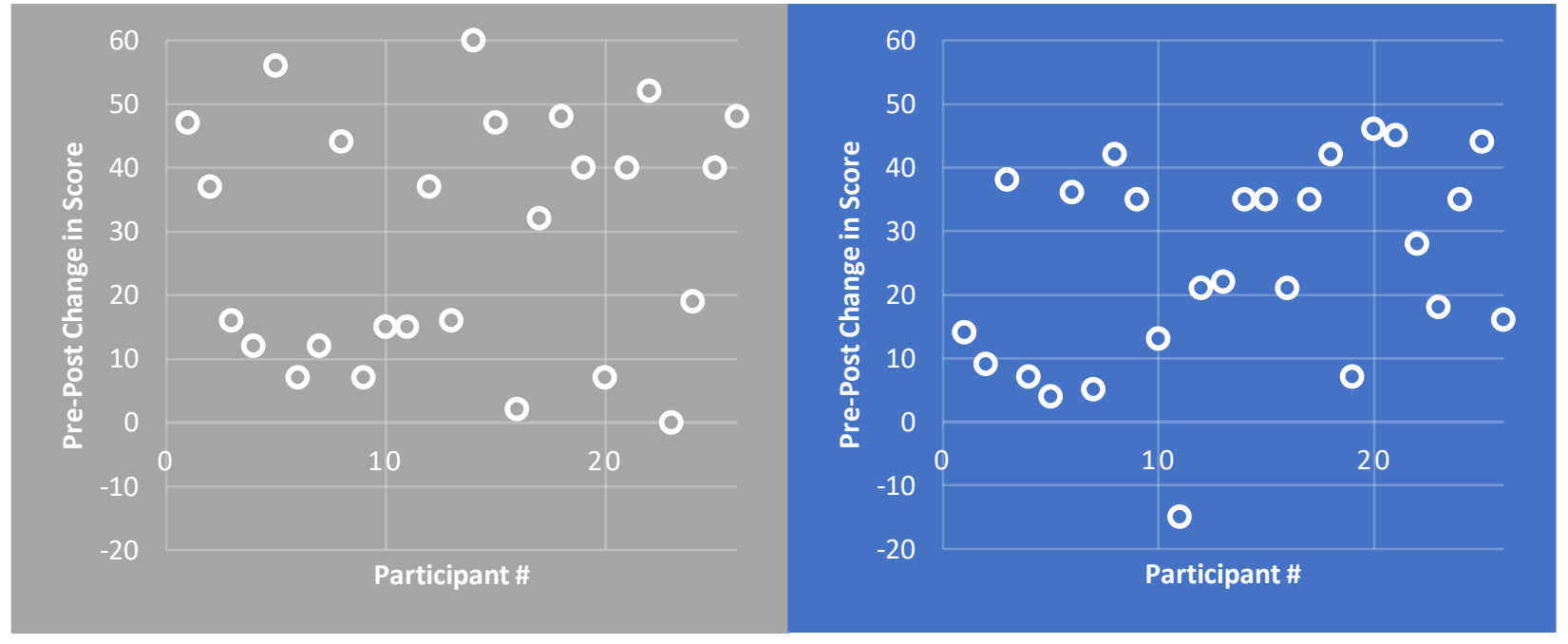

In looking at the randomized participant selection of 52 students ( 26 for each instructional design), there appears to be an unequal pattern of distribution across both modalities. The traditional in-class lecture design does not differ significantly from the flipped classroom design, but the visible pattern of distribution is observed as unequal. This is covered through an ANCOVA to adjust for the baseline scores between each instructional design.

\section{Engagement Experience in the Class}

In measuring engagement in online classes utilizing a flipped classroom instructional design, as compared to other online and in-person classes in traditional lecture style, the research looks at the perceptions of the learner experiences of engagement for drawing these comparisons. The results are from 26 randomized students that completed the survey at the end of the class.

\section{Comparing a Flipped Online Distance Class to Prior Distance Class Experiences}

The following section looks at comparisons of experiences and engagement through online students taking a flipped online class that they compare to other online and traditional inperson lecture-based classes. Comparisons are based on a series of eight questions and are broken down into five areas; general findings (covering all eight), peer-to-peer interactions, peer- 
to-instructor/TA interactions, comparing activities to other distance classes and overall comparisons to other distance classes.

\section{General Findings}

The first comparison looks at eight different criteria to gauge experiences in engagement based on a survey taken by the student at the end of the class. Students are asked to gauge each question between four different responses based on prior online distance education experiences: more engaging (asking if the current class is more engaging), about the same amount of engagement (this course is of equal engagement to prior classes), less engaging (asking if the current class is less engaging), or does not apply (the question has no applicability to their learning experiences). Each question asks about comparisons to distance classes that either had built-in active learning components, or no type of active learning. The following table gives numerical and percentage-based results from the student surveys. The table does not include the category for "does not apply" as no students selected that. The category "less engaging" is all zeroes but is left in the table to keep continuity of the survey per the respondents.

\section{Table 31}

Engagement survey descriptives among randomly selected students (distance flipped versus distance traditional)

\section{Engagement survey descriptives among randomly selected subsample of 26 distance students (comparing distance course to previous distance courses taken) \\ Less (1) Same (2) More (3)

n $(\%) \quad$ n $(\%) \quad n(\%)$

How would you rate this class in terms of engagement with

$0(0) \quad 6(23.1)$

$20(76.9)$ students in the class, compared to your experiences with engaging students in a distance education class (that also included live participation)?

How would you rate this class in terms of engagement with students in the class, compared to your experiences with engaging students in a distance education class (that did not include live participation)? 


\section{Engagement survey descriptives among randomly selected subsample of 26 distance students (comparing distance course to previous distance courses taken)}

How would you rate your experience in this class in terms of engagement with the professor(s) and TA(s), compared to your experiences with them in a distance education class (that also included live participation)?

How would you rate your experience in this class in terms of engagement with the professor(s) and TA(s), compared to your experiences with them in a distance education class (that did not include live participation)?

How would you rate your activities in this class in terms of engagement compared to those in a distance education class (that included active participation)?

How would you rate your activities in this class in terms of engagement compared to those in a distance education class (that did not include active participation)?

Overall, did your experiences in this class in terms of engagement compared to your experiences in distance education classes (that included active participation) seem:

Overall, did your experiences in this class in terms of engagement compared to your experiences in distance education classes (that did not include active participation) seem:
Less (1) Same (2) More (3)

$\mathrm{n}(\%) \quad \mathrm{n}(\%) \quad \mathrm{n}(\%)$
$0(0) \quad 6(23.1) \quad 20(76.9)$

$0(0) \quad 14(53.8) \quad 12(46.2)$

$0(0) \quad 6(23.1) \quad 20(76.9)$

$0(0) \quad 8(30.8) \quad 18(69.2)$

$0(0) \quad 2(7.7) \quad 24(92.3)$

An initial review of the results shows several interesting points of note. The most lopsided result is that no online distance education students felt the engagement in the flipped online classroom was less than their prior experiences in online classrooms. This leads to the assumption that the flipped classroom instructional design at least meets similar engagement experiences as other online classrooms, regardless of their modes of synchronous or asynchronous delivery.

The second result to note is that there are five questions that rate in the highest percentages ( $75 \%$ or more of respondents selecting more engaging). The higher engagement areas include interactions with peers compared to other classes that also included live 
participation, interactions with the professor and/or teaching assistants compared to other classes that included (or did not include) active participation, activities in this class compared to other classes that did not include active participation, and the overall experience of this class compared to other classes that did not include active participation.

The third result to note is that two questions are just under the highest percentile but still rank close to $70 \%$ of all respondents in terms of being higher engagement compared to prior online classes. This includes engagement with peers in other online classes that did not include active participation, and an overall rating of their experience in this class compared to other classes being more engaging.

The only question to rate as a split between being the same amount of engagement and higher engagement was the question around activities within this class compared to activities in other online classes that also included active participation. Although the findings are split, the results still show engagement as at least equaling, if not exceeding, experiences in other online classes.

In terms of how the online class compares to other online classes that include live participation (questions 1, 3,5 and 7), the following figures show most prefer the engagement within the flipped online class over their experiences with engagement in their prior online classes that also included active or live participation.

\section{Figure 25}

Comparison of responses for prior online classes that included live participation

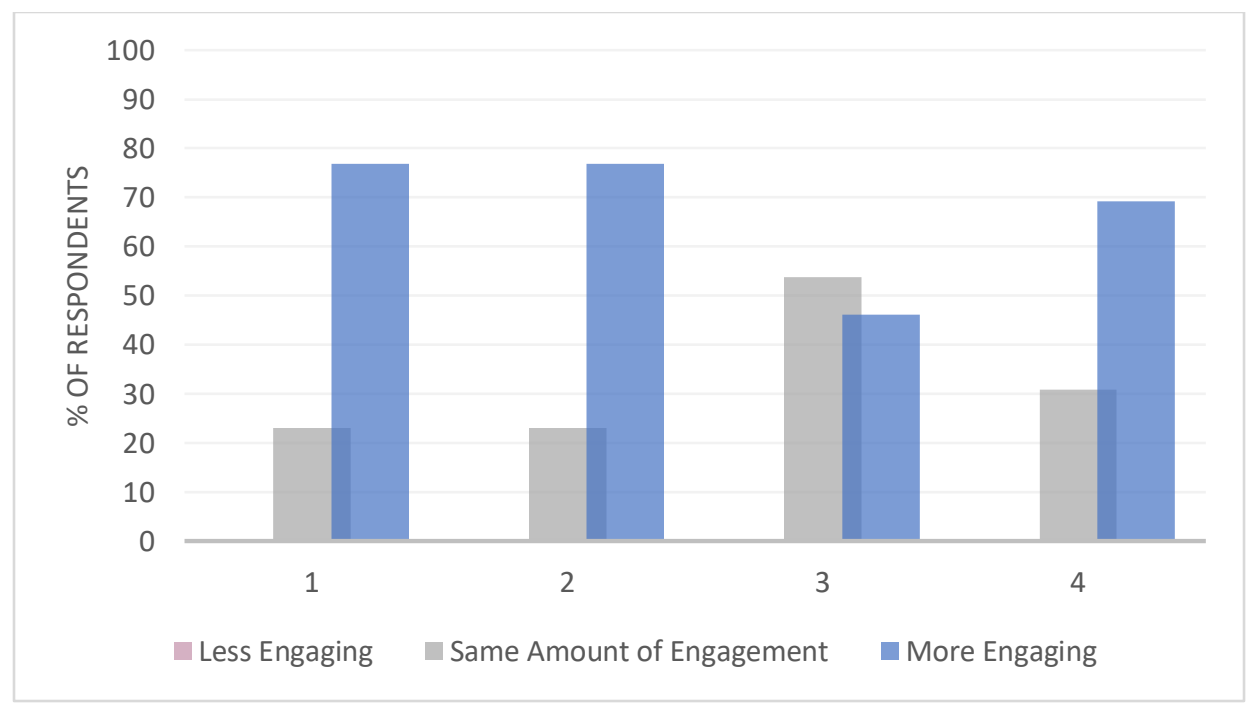


In comparing the online class to other online classes that did not include live or active participation (questions 2, 4, 6 and 8), the following figures show most also prefer the engagement within the flipped online class over their experiences with engagement in their prior online classes that did not include active or live participation.

\section{Figure 26}

Comparison of responses for prior online classes that did not include live participation

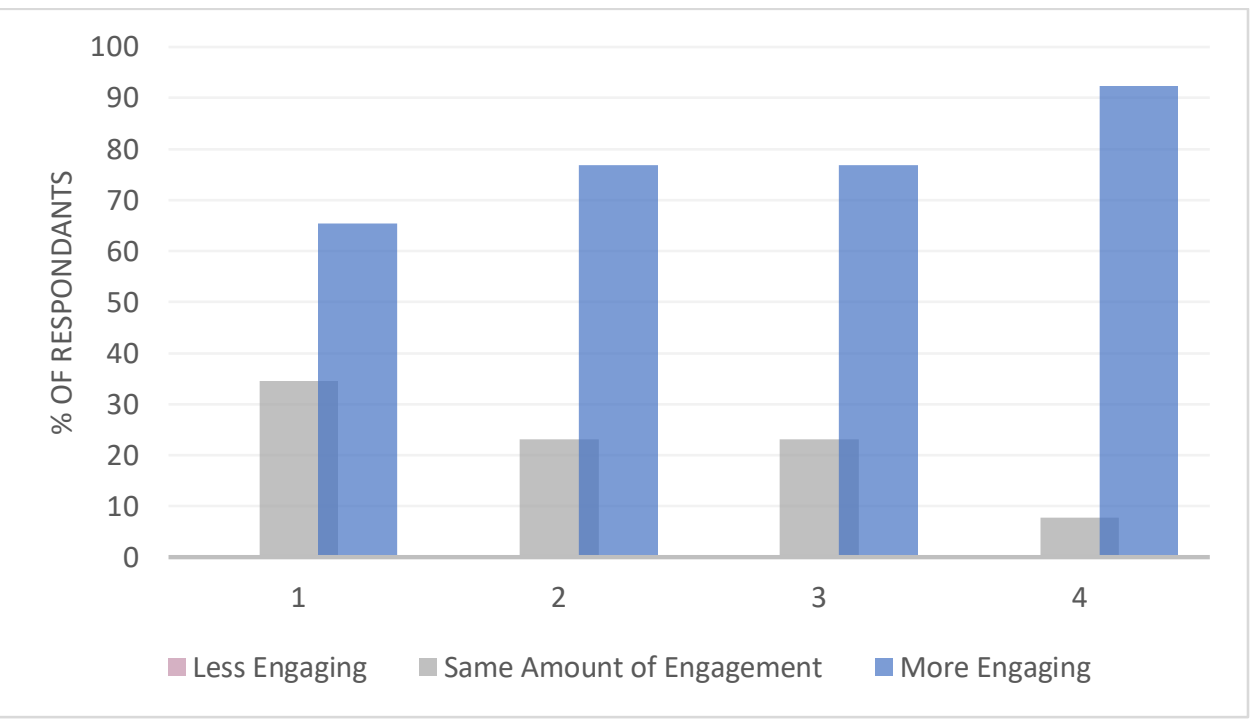

Overall, students seem to report a much higher experience of engagement in the flipped online classroom as compared to active versus passive courses, regardless of the level of activity in the class.

\section{Student to Student Interactions}

The next criteria to evaluate is in looking at student engagement in the class and engagements with other students during the course. The following table shows the results from the students and their comparisons to other online education experiences that included and did not include live participation. 


\section{Table 32}

Student-to-student interactions in online classroom comparisons

\section{Engagement survey descriptives (student-to-student) among randomly selected subsample of 26 distance students (comparing distance course to previous distance courses taken)}

$\begin{array}{ccc}\text { Less } & \text { Same } & \text { More } \\ \text { n }(\%) & \text { n }(\%) & \text { n }(\%)\end{array}$

$0(0) \quad 6(23.1) \quad 20(76.9)$

How would you rate this class in terms of engagement with
students in the class, compared to your experiences with engaging students in a distance education class (that also included live participation)?

How would you rate this class in terms of engagement with students in the class, compared to your experiences with engaging students in a distance education class (that did not include live participation)?

In looking at lower student interactions, no students found the flipped online class to have less interactions with peers as compared to previous online classes, regardless of live participation experiences. In terms of having similar or more engagement in the flipped online class, the differences were only slight, as seen in the following figure.

\section{Figure 27}

Student-to-student interactions in online distance education classroom comparisons

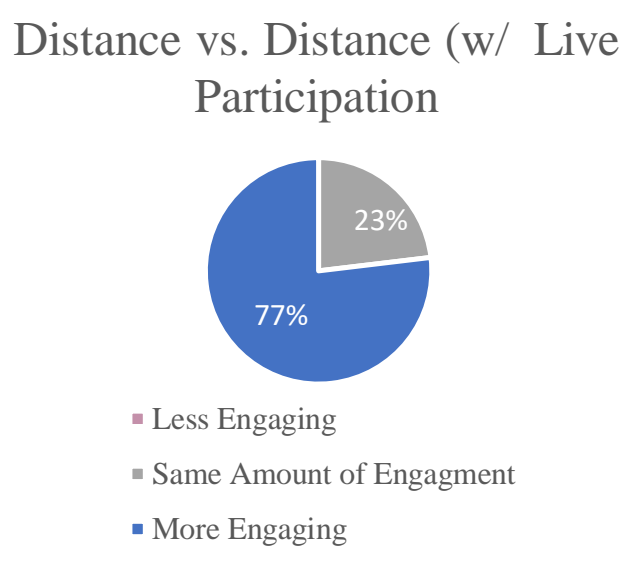

Distance vs. Distance (w/ Live Participation
Distance vs. Distance (No Live Participation)

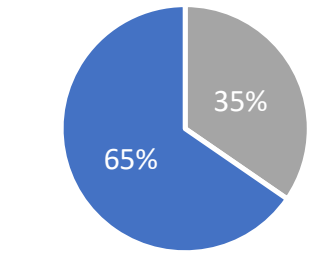

- Less Engaging

- Same Amount of Engagment

- More Engaging

The same amount of student interactions shows a difference of three students $(11.5 \%)$ with similar amounts of engagement in other online classes that included live participation. In 
terms of having a more engaging experience, the students show a difference of three students (11.5\%) experiencing a more engaging classroom in the flipped online instructional design over other online distance education experiences that did not include live participation. Interestingly, engagement levels were higher in comparison to live participation versus no live participation.

\section{Student to Instructor/TA Interactions}

The next criteria to evaluate is in examining experiences of engagement of students in the class and their engagements with the instructor and/or TA during the course. The following table shows the results from the students and their comparisons to other online education experiences that included and did not include live participation.

\section{Table 33}

Student-to-TA interactions in online classroom comparisons

\begin{tabular}{|c|c|c|c|}
\hline $\begin{array}{l}\text { Engagement survey descriptives (student-to-instructor/TA) } \\
\text { among randomly selected subsample of } 26 \text { distance students } \\
\text { (comparing distance course to previous distance courses } \\
\text { taken) }\end{array}$ & $\begin{array}{c}\text { Less } \\
\text { n }(\%)\end{array}$ & $\begin{array}{l}\text { Same } \\
\text { n }(\%)\end{array}$ & $\begin{array}{l}\text { More } \\
\text { n }(\%)\end{array}$ \\
\hline $\begin{array}{l}\text { How would you rate this class in terms of engagement with the } \\
\text { instructor/TA in the class, compared to your experiences with } \\
\text { engaging the instructor/TA in another distance education class } \\
\text { (that also included live participation)? }\end{array}$ & $0(0)$ & $6(23.1)$ & 20 (76.9) \\
\hline $\begin{array}{l}\text { How would you rate this class in terms of engagement with the } \\
\text { instructor/TA in the class, compared to your experiences with } \\
\text { engaging the instructor/TA in another distance education class } \\
\text { (that did not include live participation)? }\end{array}$ & $0(0)$ & $9(34.6)$ & $17(65.4)$ \\
\hline
\end{tabular}

In looking at a less interactive experience, no students found the flipped online class to have less instructor/TA interaction as compared to previous online classes, regardless of live participation experiences. In terms of having similar or more interactions in the flipped online class, there were no differences, as seen in the following figure. 


\section{Figure 28}

Student-to-Instructor/TA interactions in online distance education classroom comparisons

Distance vs. Distance (w/ Live Participation

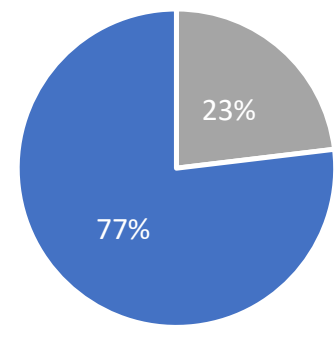

- Less Engaging

- Same Amount of Engagment

- More Engaging
Distance vs. Distance (No

Live Participation)

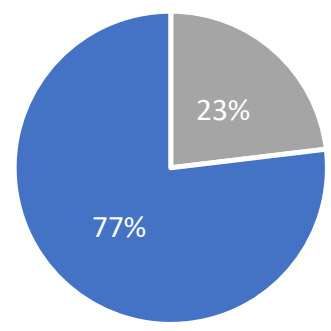

- Less Engaging

- Same Amount of Engagment

- More Engaging

The chart for the same amount of engagement with no live participation shows the same result from six students (23\%) across similar engagements in other online distance classes that also included live participation. In terms of having a more engaging experience, the research shows the exact same result of 20 students (77\%) experiencing a more engaging classroom in the flipped online instructional design over other online experiences that did not include live participation. Interestingly, it was reported that interaction levels with the TA and/or professor were the same in comparison to live participation versus no live participation.

\section{Comparing Current Distance Class Activities to Previous Distance Class Activities}

The next criteria evaluated is student engagement experiences with activities in the class and comparing those engagements with activities in prior classes. The following table shows results from student comparisons to other online distance education experiences that included and did not include live participation. 


\section{Table 34}

Student to activity interactions in online distance education classroom comparisons

\begin{tabular}{|c|c|c|c|}
\hline $\begin{array}{l}\text { Engagement survey descriptives (student to activities) among } \\
\text { randomly selected subsample of } 26 \text { distance students } \\
\text { (comparing the current distance course to previous distance } \\
\text { courses taken) }\end{array}$ & $\begin{array}{c}\text { Less } \\
\text { n }(\%)\end{array}$ & $\begin{array}{l}\text { Same } \\
\text { n }(\%)\end{array}$ & $\begin{array}{l}\text { More } \\
\text { n (\%) }\end{array}$ \\
\hline $\begin{array}{l}\text { How would you rate this class in terms of engagement with } \\
\text { activities in the class, compared to your experiences with } \\
\text { activities in a distance education class (that also included live } \\
\text { participation)? }\end{array}$ & $0(0)$ & $14(53.8)$ & $12(46.2)$ \\
\hline $\begin{array}{l}\text { How would you rate this class in terms of engagement with } \\
\text { activities in the class, compared to your experiences with } \\
\text { activities in a distance education class (that did not include live } \\
\text { participation)? }\end{array}$ & $0(0)$ & $6(23.1)$ & $20(76.9)$ \\
\hline
\end{tabular}

In looking at a less interactive experience, no students found the flipped online class to have fewer interactions with activities as compared to previous online classes, regardless of whether or not there was live participation. In terms of having similar or more interactions in the flipped online class, there were major differences, as seen in the following figure.

\section{Figure 29}

Student activity interactions in online distance education classroom comparisons

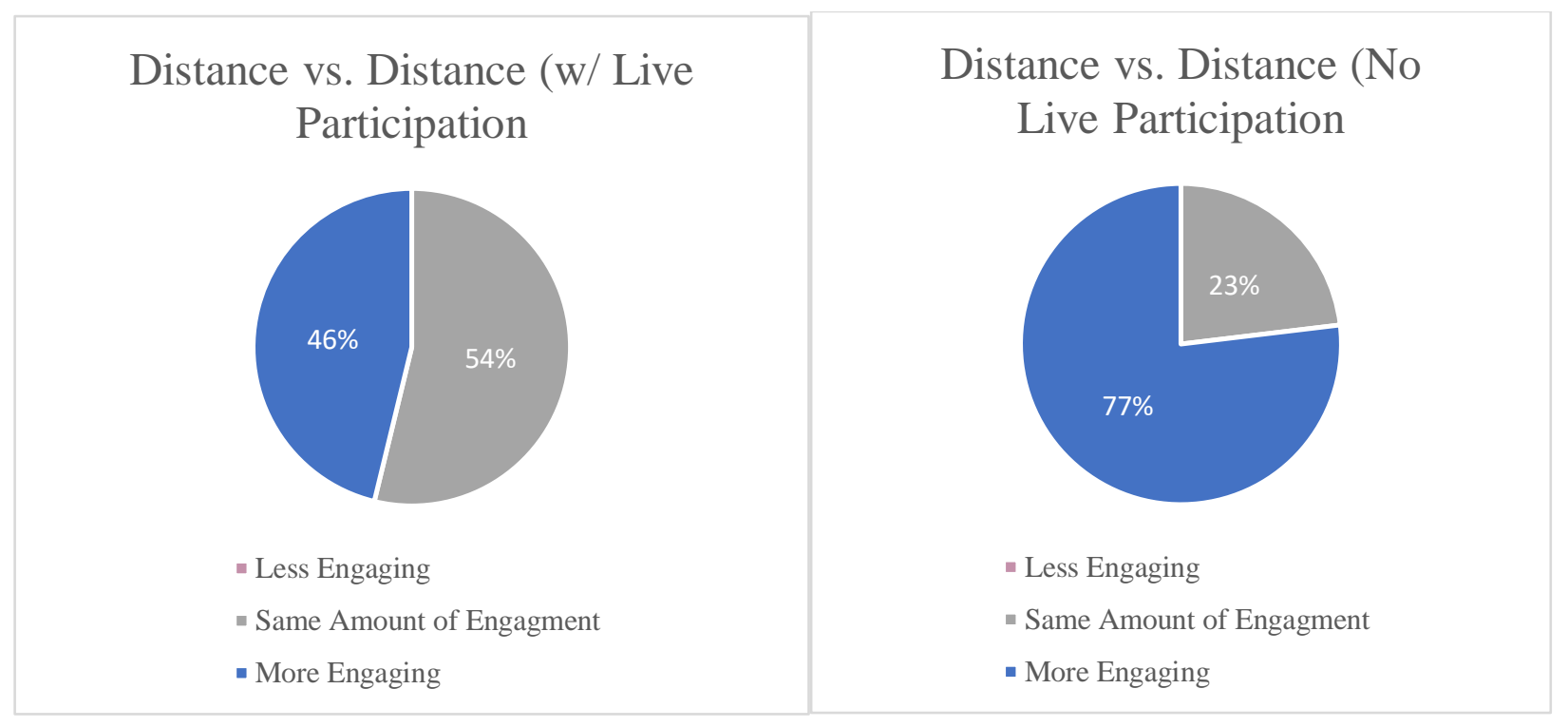


In looking at comparisons of interactions in activities, 14 students (54\%) report similar interactions across similar activities in other online classes that also included live participation, and six students (23\%) in distance classes that did not include live participation. In terms of having a more interactive experience, the students show a slight decrease in results with 12 students (46\%) experiencing a more engaging classroom in the flipped online distance education instructional design, but 20 students (77\%) that show increases in engagement experiences in prior online distance education classes that did not include live participation.

The results show that live participation changes perceptions of engagement, with the flipped online classroom still showing improvement over prior live participation distance classes, but overwhelmingly more so in comparison to prior distance classes without live participation.

\section{Overall Comparisons to Prior Distance Class Experiences}

The final criteria to evaluate is the experience of interaction in the flipped online class and comparing student engagement in prior distance classes. The following table shows the results from the students and their comparisons to other online distance education experiences that included and did not include live participation.

\section{Table 35}

Comparing overall experiences in online distance education classrooms

\begin{tabular}{llll}
\hline $\begin{array}{l}\text { Engagement survey descriptives (overall experiences) among } \\
\text { randomly selected subsample of } 26 \text { distance students } \\
\text { (comparing the current distance course to previous distance } \\
\text { courses taken) }\end{array}$ & $\begin{array}{c}\text { Less } \\
\mathbf{n}(\%)\end{array}$ & $\begin{array}{c}\text { Same } \\
\mathbf{n}(\%)\end{array}$ & $\begin{array}{l}\text { More } \\
\mathbf{n}(\%)\end{array}$ \\
\hline $\begin{array}{l}\text { Overall, did your experiences in this class in terms of engagement } \\
\text { compared to your experiences in distance education classes (that } \\
\text { included active participation) seem: }\end{array}$ & $0(0)$ & $8(30.8)$ & $18(69.2)$ \\
$\begin{array}{l}\text { Overall, did your experiences in this class in terms of engagement } \\
\text { compared to your experiences in distance education classes } \\
\text { (that did not include active participation) seem: }\end{array}$ & $0(0)$ & $2(7.7)$ & $24(92.3)$
\end{tabular}

In looking at a less interactive experience, no students found the flipped online class to have fewer interactions with their activities as compared to previous online classes, regardless of 
live participation experiences. In terms of having similar or more engagement in the flipped online class, there were substantial differences, as seen in the following figure.

\section{Figure 30}

Comparing engagement in online distance education classrooms

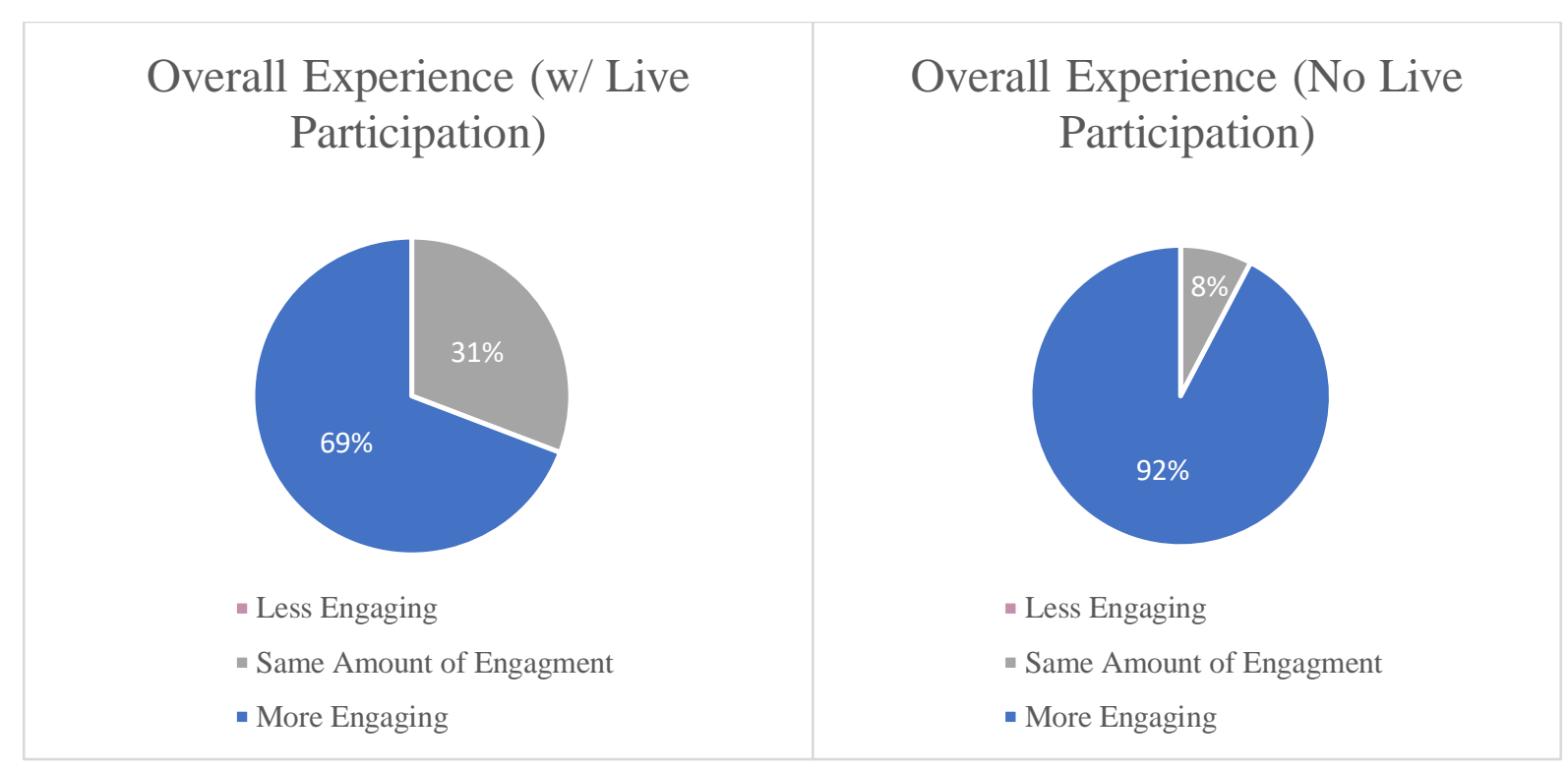

When rating their overall experience, eight students (31\%) reported the same amount of engagement in other online classes that also included live participation, more than the two students (8\%) that reported the same amount of engagement in distance classes with no live participation.

In terms of having a more interactive experience, 18 students (69\%) reported experiencing a more engaging classroom in the flipped online instructional design with live participation. Twenty-four students (92\%) reported more engagement in other online education experiences that did not include live participation. The results show live participation changes perceptions of engagement, with the flipped online classroom still showing improvement over prior live participation distance classes, but overwhelmingly more so in comparison to prior distance classes without live participation. 
Comparing a Flipped Online Class to Prior In-Person Lecture-Based Class Experiences

The following section compares experiences and engagement of online students in a flipped classroom to their prior experiences with traditional in-person lecture-based classes. Comparisons are based on eight questions that are broken down into five areas: general findings (covering all eight); student-to-student interactions; student-to-instructor/TA interactions; comparing activities to other in-person classes; and overall experience comparisons to other inperson classes.

\section{General Findings}

The second comparison, which looks at differences between in-person lecture-based classes and an online flipped classroom, involves the same eight criteria to gauge experiences in engagement based on the same survey taken by the student at the end of the class. Students are asked to gauge each question between four different responses based on prior traditional, inperson lecture-based experiences. The four responses are: more engaging (asking if the current class is more engaging), about the same amount (that this course is of equal engagement to prior classes), less engaging (asking if the current class is less engaging), or does not apply (the question has no applicability to their learning experiences). Each question asks about comparisons to the in-person lecture-based classes that either had active learning components built in or had no type of active learning. The following table gives numerical and percentagebased results from the surveys taken by students in the class.

\section{Table 36}

Engagement survey descriptives among randomly selected students (flipped online versus traditional in-person lecture)

\begin{tabular}{|c|c|c|c|c|}
\hline $\begin{array}{l}\text { Engagement survey descriptives among randomly } \\
\text { selected subsample of } 26 \text { distance students } \\
\text { (comparing distance course to previous traditional } \\
\text { in-person lecture courses taken) }\end{array}$ & $\begin{array}{c}\text { Less (1) } \\
\text { n (\%) }\end{array}$ & $\begin{array}{c}\text { Same (2) } \\
\text { n (\%) }\end{array}$ & $\begin{array}{c}\text { More (3) } \\
\text { n (\%) }\end{array}$ & $\begin{array}{l}\text { Not } \\
\text { applicabl } \\
\text { n }(\%)\end{array}$ \\
\hline $\begin{array}{l}\text { How would you rate this class in terms of engagement } \\
\text { with students in the class, compared to your } \\
\text { experiences with engaging students in an in-person } \\
\text { education class (that also included live participation)? }\end{array}$ & 7 (26.9) & $13(50.0)$ & $5(20.0)$ & $1(3.8)$ \\
\hline
\end{tabular}


Engagement survey descriptives among randomly selected subsample of $\mathbf{2 6}$ distance students (comparing distance course to previous traditional in-person lecture courses taken)

Less (1) Same (2) $\quad$ More (3) $\begin{gathered}\begin{array}{c}\text { Not } \\ \text { applicable }\end{array} \\ \text { S }\end{gathered}$

$\mathrm{n}(\%) \quad \mathrm{n}(\%) \quad \mathrm{n}(\%) \quad \mathrm{n}(\%)$

How would you rate this class in terms of engagement $\quad 4(16.0) \quad 12(48.0) \quad 9(36.0) \quad 1(3.8)$ with students in the class, compared to your experiences with engaging students in an in-person education class (that did not include live participation)?

How would you rate your experience in this class in $6(26.1) \quad 10(43.5) \quad 7(30.4)$ terms of engagement with the professor(s) and TA(s), compared to your experiences with them in an inperson education class (that also included live participation)?

How would you rate your experience in this class in terms of engagement with the professor(s) and TA(s), compared to your experiences with them in an inperson education class (that did not include live participation)?

How would you rate your activities in this class compared to those in an in-person education class (that included active participation)?

How would you rate your activities in this class compared to those in an in-person education class (that did not include active participation)?

Overall, did your experiences in this class compare to your experiences in an in-person education class (that included active participation) seem:

Overall, did your experiences in this class compared to your experiences in an in-person education class $4(16.7) \quad 9(37.5) \quad 11(45.8) \quad 2(7.7)$ (that did not include active participation) seem:

An initial review of the results shows several interesting points not found in the earlier distance class comparisons. Contrary to those earlier findings that no online students felt the flipped online classroom was less engaging than their prior experiences in online classrooms, there are a small percentage that found this class to be less engaging than the traditional in- 
person lecture-based class. In some cases, up to $30 \%$ of the respondents reported that. Still, the fact many of the respondents had responses of "similar" or "more engaging" leads to the assumption that the flipped classroom instructional design generally has similar engagement experiences as other traditional in-person lecture-based education classrooms, but not all of them compared to other online distance education classes.

The second interesting result is that there are three questions that rate in the middle percentage (between. $45-52 \%$ of respondents selecting more engaging) out of the eight questions. The higher engagement areas include interactions with the professor and/or teaching assistants compared to other traditional lecture-based in-person classes that did not include active participation, activities in this class compared to other traditional lecture-based in-person classes that did not include active participation, and the overall experience of this class compared to other traditional lecture-based in-person classes that did not include active participation.

The third interesting result is that responses to only three of the eight questions rated the flipped online class as less engaging than the traditional lecture-based in-person class, which included student interactions with other students, activities in the classroom, and the overall experience in the classroom, with all three of these in terms of active or live participation in the traditional lecture-based in-person class. The only question regarding active or live participation that did not show less engagement in the flipped online class was in experiences with the professor and/or TAs.

Generally, the students rate the experience of their interactions between the flipped online classes higher, with the largest percentages in the same or more engaging areas. The following figure shows a sample of how the two types of instructional designs compare. 


\section{Figure 31}

Comparison of flipped online distance education to traditional lecture-based in-class delivery

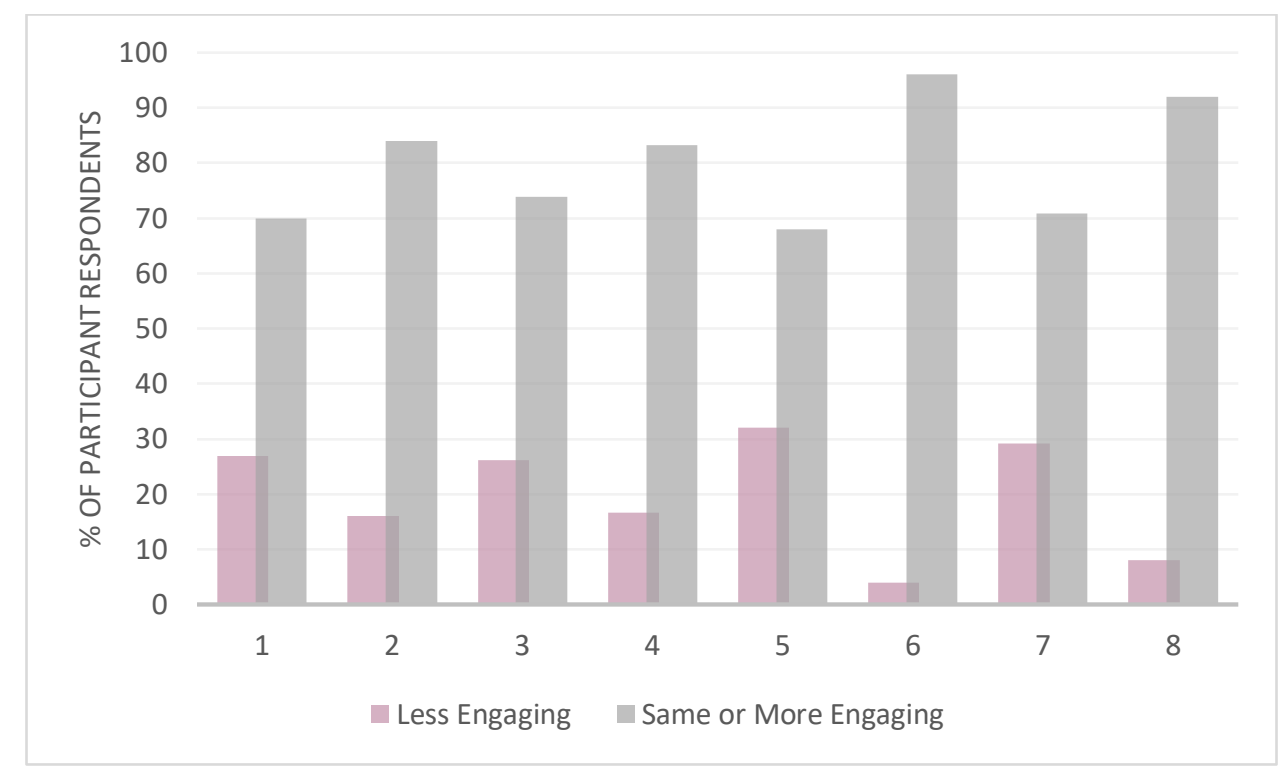

It's encouraging to note that a smaller number of students report fewer engagement experiences in the flipped classroom overall, with most preferring the engagement within the flipped online class over their experiences with engagement in their prior traditional in-person lecture-based classes. The following sections break down the questionnaire into four subsets of questions looking at active and non-active instructional designs. There is a possibility that some students have not taken an on-campus course. Their response is "does not apply" and they have been excluded from the results.

\section{Student-To-Student Interaction Experiences}

The first criteria to evaluate is in looking at engagement through peer-to-peer experiences in the flipped online distance education class and comparing that to peer-to-peer interactions in prior traditional lecture-based in-person classes. The following table shows the results from the students and their comparisons to other in-person education experiences that included and did not include live participation. 


\section{Table 37}

Student-to-student interactions compared in online versus in-person classrooms

Engagement survey descriptives (student to student

experiences) among randomly selected subsample of 26

Less Same More

distance students (comparing distance course to previous inperson courses taken)

n $(\%) \quad$ n $(\%) \quad n(\%)$

How would you rate this class in terms of engagement with

7 (26.9)

$13(50)$

$5(20)$

students in the class, compared to your experiences with engaging

students in an in-person class (that also included live

participation)?

How would you rate this class in terms of engagement with

$4(16) \quad 12(48)$

students in the class, compared to your experiences with engaging

students in an in-person class (that did not include live

participation)?

In looking at a less interactive experience, seven students (about 28\%) found the flipped online class to have less engagements with their activities as compared to previous in-person education classes, regardless of live participation experiences. In terms of having similar or more engagement in the flipped online class, there were some differences to note, as seen in the following figure.

\section{Figure 32}

Student-to-student interactions in distance versus in-person classroom comparisons

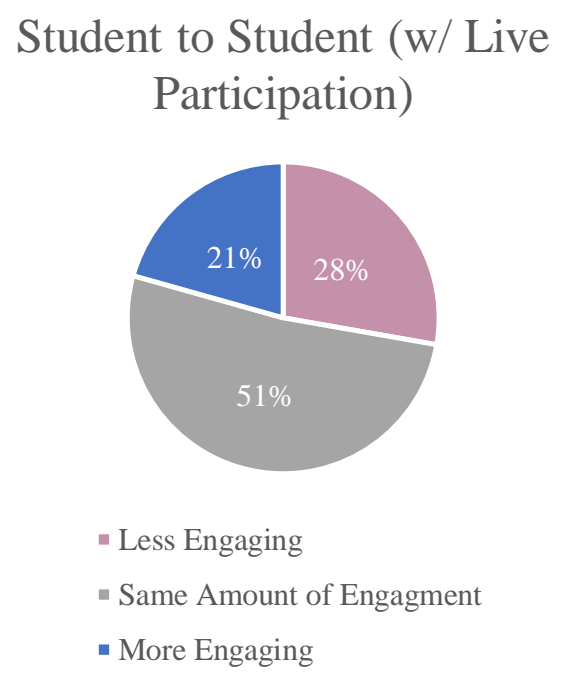

Student to Student (w/ Live Participation)

- Less Engaging

Same Amount of Engagment

More Engaging

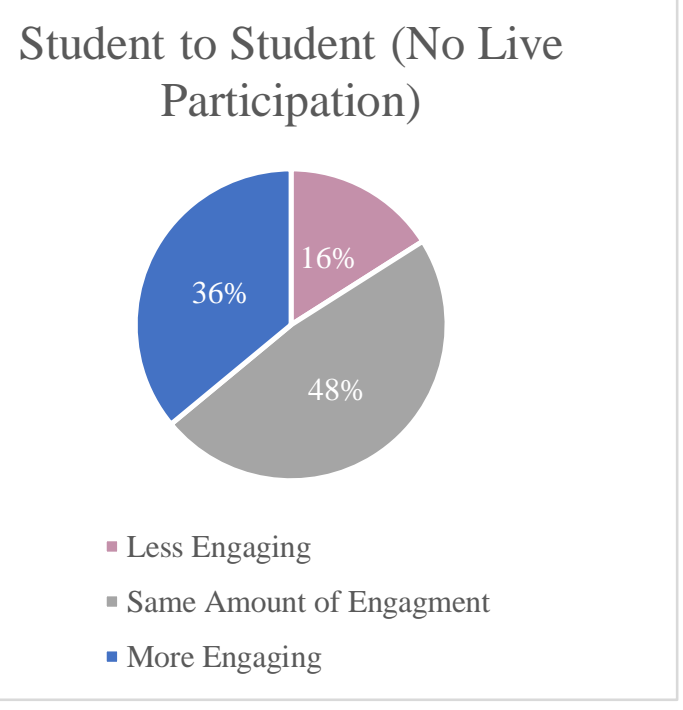


The results show 13 students (51\%) across similar engagements in other online classes that also included live participation had a similar interaction experience with other students. In terms of having a more engaging experience, the results show that five students $(21 \%)$ experienced a more engaging classroom in the flipped online model over other online experiences that included live participation, and nine students (36\%) reported more engagement in classes with no live participation.

In conclusion, live participation changes perceptions of engagement, with the flipped online classroom still showing improvements over prior live participation in-person classes, but even more so in comparisons to prior in-person classes without live participation. The flipped online design has more interaction between students than the traditional in-person lecture design with $69 \%$ of all students experiencing at least similar engagements in live participation settings, and $81 \%$ in non-live participation settings.

\section{Student-To-Instructor/TA Interactions}

The second criteria to evaluate student engagement through their instructor and TA interactions in the flipped online class and comparing their interactions with the overall experience in prior traditional lecture-based in-person classes. The following table shows results from the students' comparisons of interactions with the instructor and/or TA in the online flipped class to other traditional lecture in-person experiences that included and did not include live participation. 


\section{Table 38}

Student-to-student experiences in online classroom compared to in-person classroom

\section{Engagement survey descriptives (student to instructor/TA) among randomly selected subsample of 26 distance students (comparing distance course to previous in-person courses taken)}

$\begin{array}{ccc}\text { Less } & \text { Same } & \text { More } \\ \mathbf{n}(\%) & \text { n }(\%) & \text { n }(\%)\end{array}$

How would you rate this class in terms of engagement with $6(26.1) \quad 10(43.5)$ $7(30.4)$ students in the class, compared to your experiences with engaging students in an in-person education class (that also included live participation)?

How would you rate this class in terms of engagement with $4(16.7) \quad 9(37.5)$ $11(45.8)$ students in the class, compared to your experiences with engaging students in an in-person education class (that did not include live participation)?

In looking at a less engaging experience, six students (approximately 26\%) found the flipped online class to have less interactions with instructors and/or TA's as compared to previous in-person classes with live participation experiences, but only four students (about $17 \%$ ) reported a less engaging experience without live participation. In terms of similar or more engagement in the flipped online class, there were some differences to note, as seen in the following figure.

\section{Figure 33}

Student-to-TA/Instructor interactions in online versus in-person classrooms

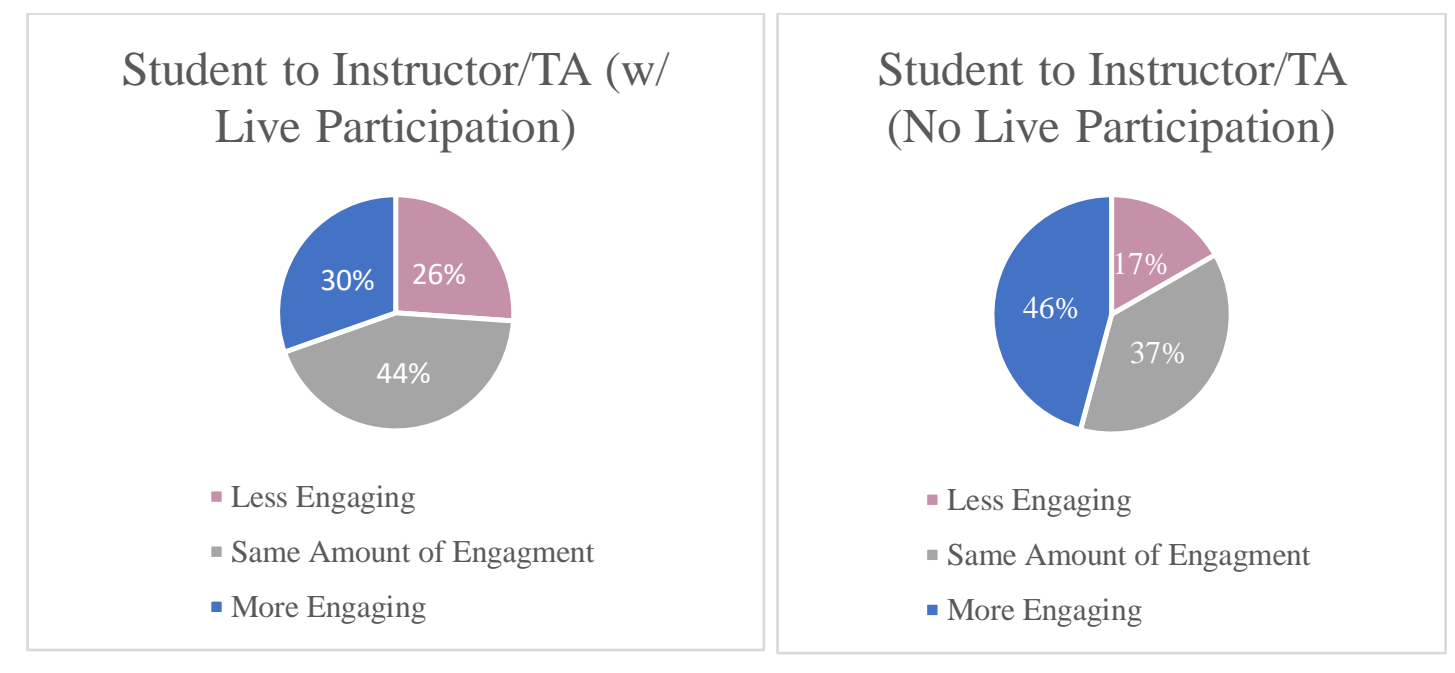


Results in the amount of interaction with the instructors and/or TAs shows a difference of two students (9\%) across similar interactions in other in-person classes that also included live participation compared to without. In terms of having a more engaging experience, four more students $(15 \%)$ reported a more engaging classroom in the flipped online design over in-person experiences that included live participation.

In conclusion, live participation changes perceptions of interaction with the instructors and/or TAs, with the flipped online classroom still showing improvements over prior live participation in-person classes, but even more so in comparison to prior in-person classes without live participation. The flipped online instructional design outweighs the traditional in-person lecture design with $74 \%$ of all students experiencing similar or higher engagements with the instructor and/or TAs in live participation settings, and $83 \%$ in non-live participation settings.

\section{Comparing Engagement in Activities Between Distance and In-Person Classes}

The third evaluation criteria is to examine interactions through student experiences with activities in the flipped online class and comparing those interactions with the overall experience in prior traditional lecture-based in-person classes. The following table shows the results from the students and their comparisons to other in-person education experiences that included and did not include live participation.

\section{Table 39}

Activity interaction experience comparisons in online and in-person classrooms

\begin{tabular}{|c|c|c|c|}
\hline $\begin{array}{l}\text { Engagement survey descriptives (student to activity) among } \\
\text { randomly selected subsample of } 26 \text { distance students } \\
\text { (comparing a distance course to previous in-person courses } \\
\text { taken) }\end{array}$ & $\begin{array}{c}\text { Less } \\
\text { n }(\%)\end{array}$ & $\begin{array}{l}\text { Same } \\
\text { n }(\%)\end{array}$ & $\begin{array}{l}\text { More } \\
\text { n }(\%)\end{array}$ \\
\hline $\begin{array}{l}\text { How would you rate this class in terms of interactions with } \\
\text { activities in the class, compared to your experiences with } \\
\text { activities in an in-person education class (that also included live } \\
\text { participation)? }\end{array}$ & $8(32)$ & $11(44)$ & $6(24)$ \\
\hline $\begin{array}{l}\text { How would you rate this class in terms of interactions with } \\
\text { activities in the class, compared to your experiences with } \\
\text { activities in an in-person education class (that did not include live } \\
\text { participation)? }\end{array}$ & $1(4)$ & $11(44)$ & $13(52)$ \\
\hline
\end{tabular}


In looking at a less engaging experience, eight students (approximately 32\%) said they had less interaction with their activities in the flipped online class as compared to previous inperson education classes with live participation experiences, but only one participant (about 4\%) had the same experience but without live participation. In terms of having similar or more engagement in the flipped online class, there were some similarities and differences to note, as seen in the following figure.

\section{Figure 34}

Activity interaction comparisons in distance versus in-person classrooms

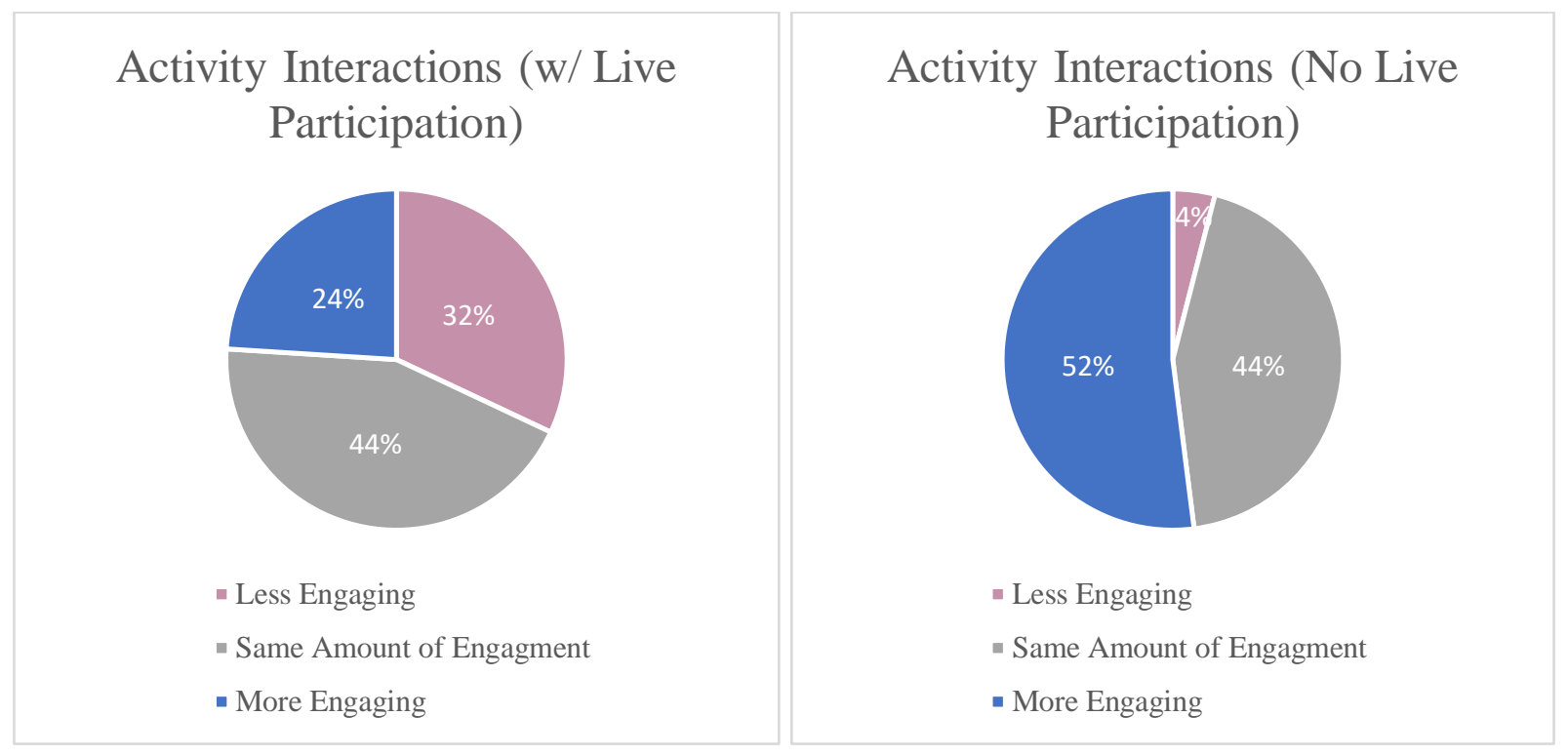

Eleven students (about 44\%) reported the same amount of engagement with activities across similar activities in other online classes that also included live participation compared to those without. In terms of having a more engaging experience, the seven students $(28 \%)$ reported experiencing a more interactive classroom in the flipped online model as opposed to in-person experiences that did not include live participation. 


\section{Table 40}

Overall engagement experience comparisons between online and in-person classrooms

\begin{tabular}{|c|c|c|c|}
\hline $\begin{array}{l}\text { Engagement survey descriptives (student to activity) among } \\
\text { randomly selected subsample of } 26 \text { distance students } \\
\text { (comparing a distance course to previous in-person courses } \\
\text { taken) }\end{array}$ & $\begin{array}{c}\text { Less } \\
\text { n }(\%)\end{array}$ & $\begin{array}{l}\text { Same } \\
\text { n }(\%)\end{array}$ & $\begin{array}{l}\text { More } \\
\text { n (\%) }\end{array}$ \\
\hline $\begin{array}{l}\text { Overall, did your experiences in this class compared to your } \\
\text { experiences in an in-person class (that included active } \\
\text { participation) seem: }\end{array}$ & 7 (29.2) & $11(45.8)$ & $6(25.0)$ \\
\hline $\begin{array}{l}\text { Overall, did your experiences in this class compared to your } \\
\text { experiences in an in-person class (that did not include active } \\
\text { participation) seem: }\end{array}$ & $2(8.0)$ & $10(40.0)$ & $13(52.0)$ \\
\hline
\end{tabular}

In looking at overall engaging experiences by the student, seven students (approximately $29 \%$ ) found the flipped online class to have less interaction with activities as compared to previous in-person classes with active participation experiences, but only two students (8\%) had the same experience but without active participation. In terms of having similar or more engagement in the flipped online class, there were some similarities and differences, as seen in the following figure.

\section{Figure 35}

Overall engagement experience comparisons in distance versus in-person classrooms

\begin{tabular}{|c|c|}
\hline $\begin{array}{l}\text { Overall Engagement } \\
\text { Experience } \\
\text { (w/ Live Participation) }\end{array}$ & $\begin{array}{c}\text { Overall Engagement } \\
\text { Experience } \\
\text { (No Live Participation) }\end{array}$ \\
\hline - Less Engaging & - Less Engaging \\
\hline - Same Amount of Engagment & - Same Amount of Engagment \\
\hline - More Engaging & - More Engaging \\
\hline
\end{tabular}


The amount of reported interaction in the students' overall engagement experience that were similar was 11 students (46\%) across similar engagements in other in-person classes that also included live participation, slightly higher than the 10 students (43\%) that reported similar findings in traditional classes with no live participation. In terms of having a more engaging experience, 13 students (52\%) reported a more engaging classroom in the flipped online design with live participation than those in traditional classes that did not have live participation. But this drops off with live participation showing only six students $(25 \%)$ experienced the same engagement. There is also a significant difference in students that report a lower engagement experience, with seven students (29\%) reporting lower engagement than the in-person class that had live participation. However this number greatly decreases with in-person classes that do not incorporate live participation as only two students (8\%) reported lower engagement experiences in the flipped online classroom.

In conclusion, live participation changes perceptions of engagement with activities in the flipped online classroom showing improvements over prior live participation in-person classes, but even more so in comparisons of prior in-person classes without live participation. The flipped online instructional design outweighs the traditional in-person lecture design with $66 \%$ of all students experiencing similar or higher engagements with the activities in live participation settings, and $96 \%$ in non-live participation settings in the in-person lecture-based course.

\section{Overall Comparisons to Prior Experiences in Traditional Lecture-Based In-Person Classes}

Comparisons between the online flipped classroom and the traditional in-person lecturebased classes are analyzed in two areas: former classes that included active participation, and classes that did not include active participation. The following figure gives an outline of how the two types of instructional design compare based on participant responses, removing those that stated that this area was not applicable (3 students). 


\section{Figure 36}

Comparing flipped online to active and passive lecture-based in-person classes

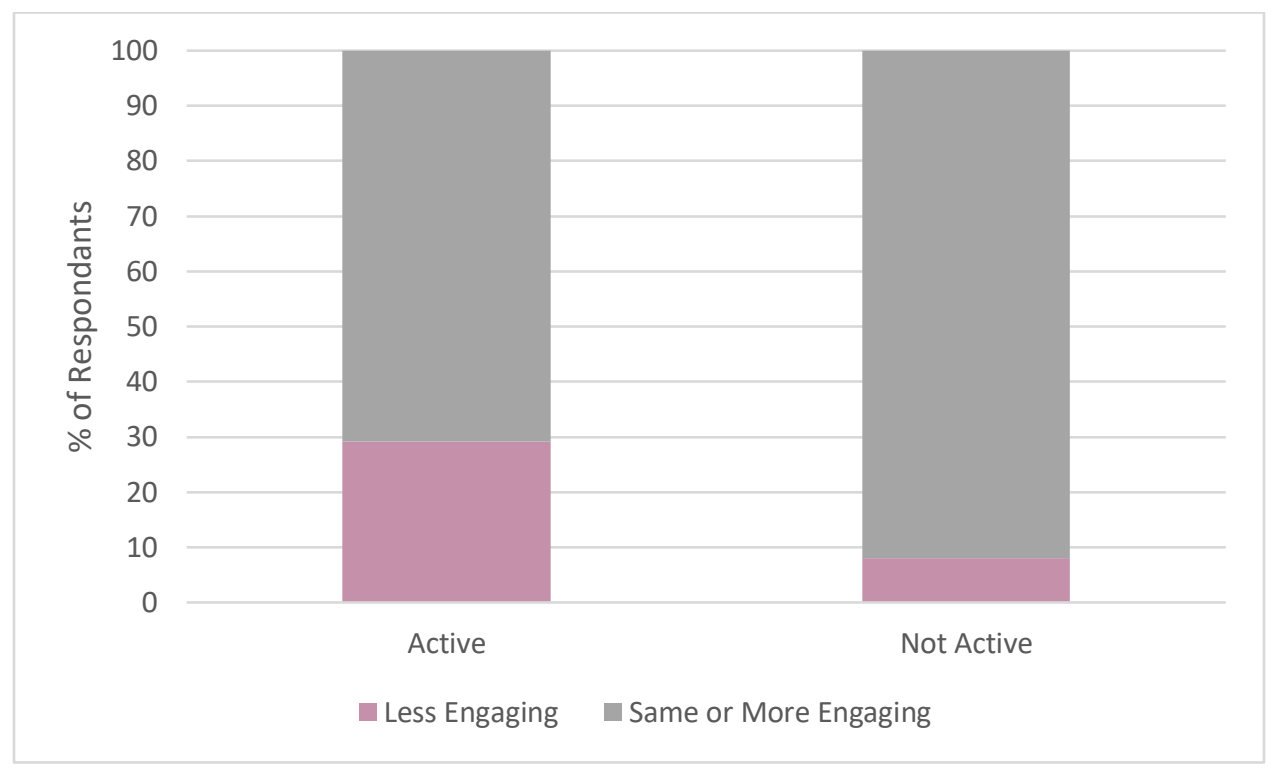

What this shows is that in general, the flipped online classroom experience is the same or more engaging than either an active or passive, traditional in-person lecture-based course approximately $71 \%$ greater than active courses and $92 \%$ greater than passive courses, which is substantially higher than the less engaging experience reported at $29 \%$ in active courses and $8 \%$ in passive courses.

\section{Looking at Overall Experiential and Engaging Components of the Flipped Online Class}

The final component of this study looks at observable areas of the flipped online classroom to draw out areas that show experiences of interaction. These are completed through the course evaluations that are coded for topics around engagement and interaction, as well as other class observations such as in-person observations, communications with students and asynchronous observations through the Canvas learning management system.

\section{Evaluations of the Course and Class Observations}

The final evaluation metrics look at observable criteria such as the faculty course evaluations (FCEs); communication through a variety of mechanisms, both in and out of class (either through synchronous sessions in Zoom, GoToMeeting, etc. or other asynchronous communications such as chat, email, etc.), and observable actions both in the live classroom as 
well as in asynchronous components through the learning management system Canvas. A sentiment analysis was performed to code phrasing of the observations of student opinions based on perceptions of negative, neutral or positive emotions. Invoking sentiment analysis across the data allows for better understanding of key influencers, humanistic motivations, activities and behaviors across all domains incorporating social situations (Liu, 2012). This is an effective method in small and large data subsets that include text, audio, visual or other types of observable data, and can also allow for understanding emotion versus opinion (Yadollahi et al., 2017). Digital, and more specifically, web 2.0 technology enhances the abilities of collecting sentiment data, and in particular shared views referred to as electronic word of mouth (eWOM) that can correlate to others (Ravi \& Ravi, 2015). Many studies have employed sentiment analysis to better understand emotional responses as well as any cultural, economic or environmental implications (Beasley, 2020; Reyes-Menendez et al., 2018; Sankar et al., 2020; Sloan \& QuanHaase, 2020).

All data collected and analyzed were used to determine the following table shows a breakdown of criteria that look at components of engagement, learning and overall experience either in a positive, neutral or negative sentiment based on the observables from the students. Steps in determining sentiment were collecting the observations from the class, manual coding of each observable to group within one of the three emotion criteria, and grouping based on one of the three criteria of learning, engagement and overall class experience. This is performed through evaluation of all metadata and the pre-determined meta-categories for analysis (Baralt, 2011; Skjott Linneberg \& Korsgaard, 2019; Stuckey, 2015). 
Table 41

Observation results for engagement, learning and experience in an online flipped classroom

\section{Classroom observation descriptives among all subsamples (87) of distance students (looking at the distance flipped classroom instructional design from their current results)}

Observations of this class in terms of student's perceptions of engagement experiences.

Observations of this class in terms of student's perceptions of learning experiences.

Observations of this class in terms of student's perceptions of overall experiences.

\section{Negative Neutral Positive \\ n $(\%) \quad n(\%) \quad n(\%)$}

$7(10) \quad 15(22) \quad 47(68)$

$10(24) \quad 16(38)$

$8(14) \quad 23(41)$

$25(45)$

The data shows engagement, learning and overall experiences rate higher in the flipped online class than in the traditional in-person lecture-based class. The following sections break down the three criteria of engagement, learning and experience to better understand the sentiment analysis that was collected and analyzed through the aforementioned instruments.

\section{Evaluations of the Course and Class Observations - Engagement}

This section looks at the examination of students' engagement experiences in the flipped classroom through online mechanisms. As observed in the following figure, a larger percentage of students found the online flipped classroom to be more engaging overall (68\%), with the remaining students either feeling neutral (22\%) or negative (10\%) about the types of engagement that they had in the flipped online classroom. 


\section{Figure 37}

Observation data for engagement in a flipped online classroom

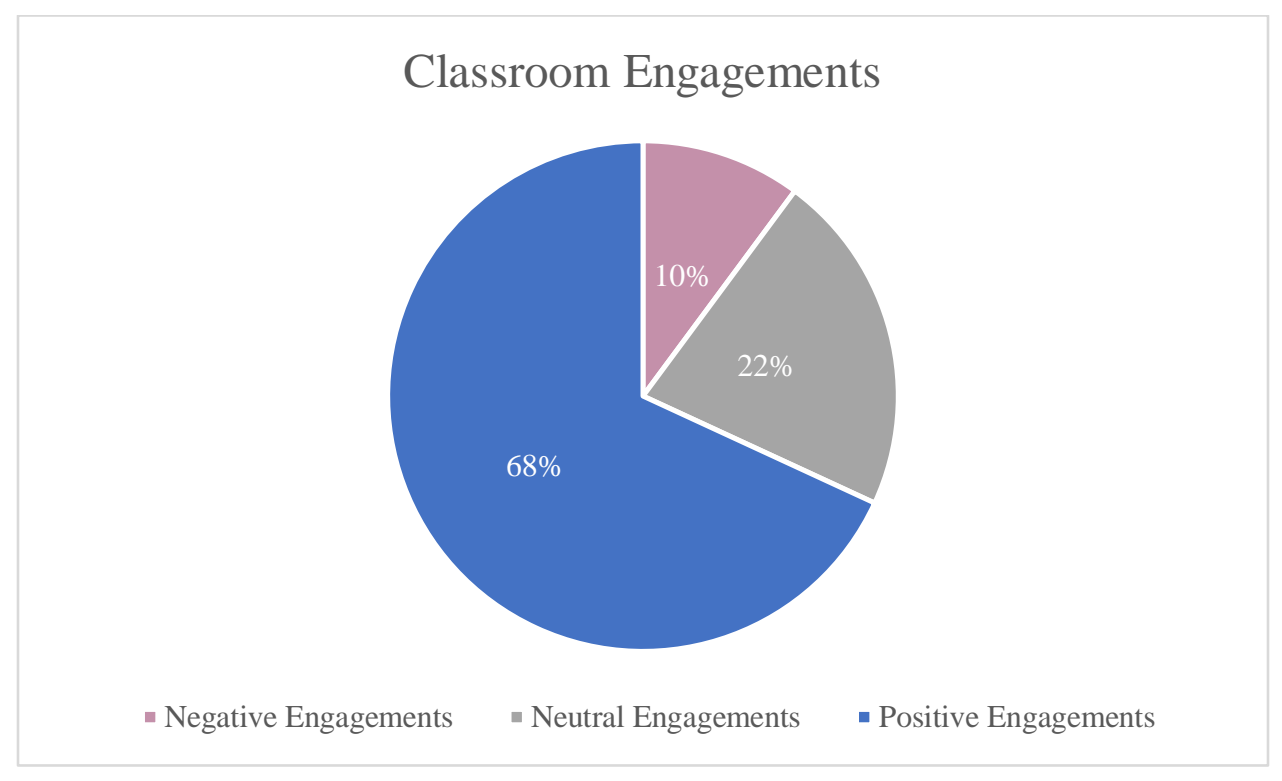

In examining the results further, the following figures contain word clouds that were used to determine key words and phrases that were used more often than others. This allows for a more specific understanding of what may have been the driver for more of the student's responses about experiences, whether positive, neutral or negative in terms of experiencing engaging activities in the classroom. 


\section{Figure 38}

Word cloud of positive engagement key terms and phrases

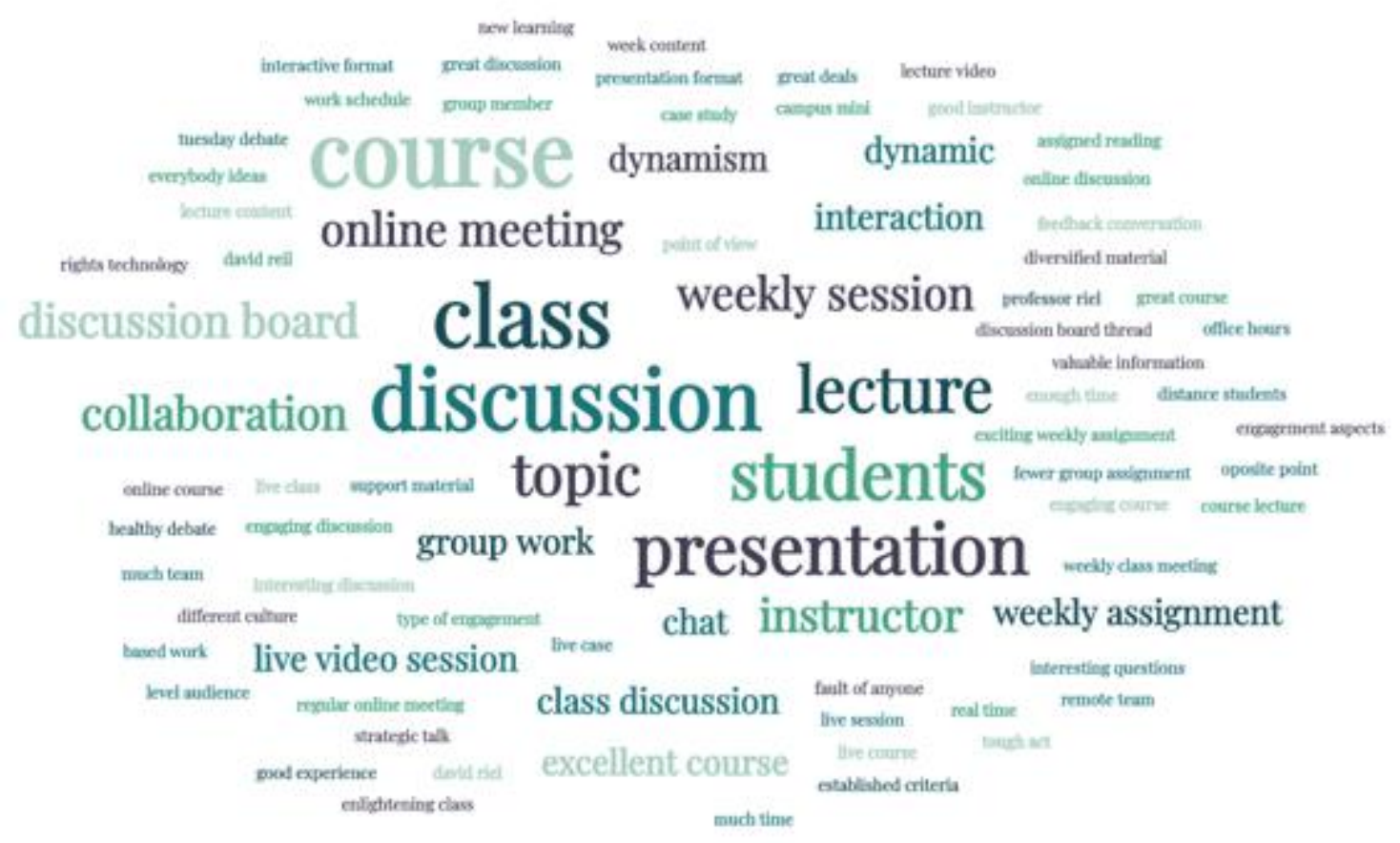

In examining student's perceptions of positive engagement results, several terms are more prominent than others, including: discussion or class discussion (28), presentation (8), online meeting (3), live video session or weekly session (5), collaboration (3), interaction (2), group work (2) and dynamic or dynamism (4). There are two common threads in the results. The first is that any type of situation that gets the class together, whether a discussion or activity, promotes engagements between students. These situations resulted in students gaining valuable class and peer information, expanding horizons through group work, analyzing topics more deeply and collaborating more to get into topics more deeply.

The second common thread is that group, team or collaborative activities also encourage and increase positive engagements as evident through positive experiences in reported group and/or team-based work. Learning from others of differing cultures and backgrounds through class debate to learn the materials more deeply has shown positive results. It is also important to note that the dynamic nature of an online flipped classroom is observed commonly throughout the analysis of the results. 
The next figure contains a word cloud of key words and phrases observed to be used more often than others, but in a neutral or negative connotation regarding engagement.

\section{Figure 39}

Word cloud of key terms and phrases for neutral or negative engagement

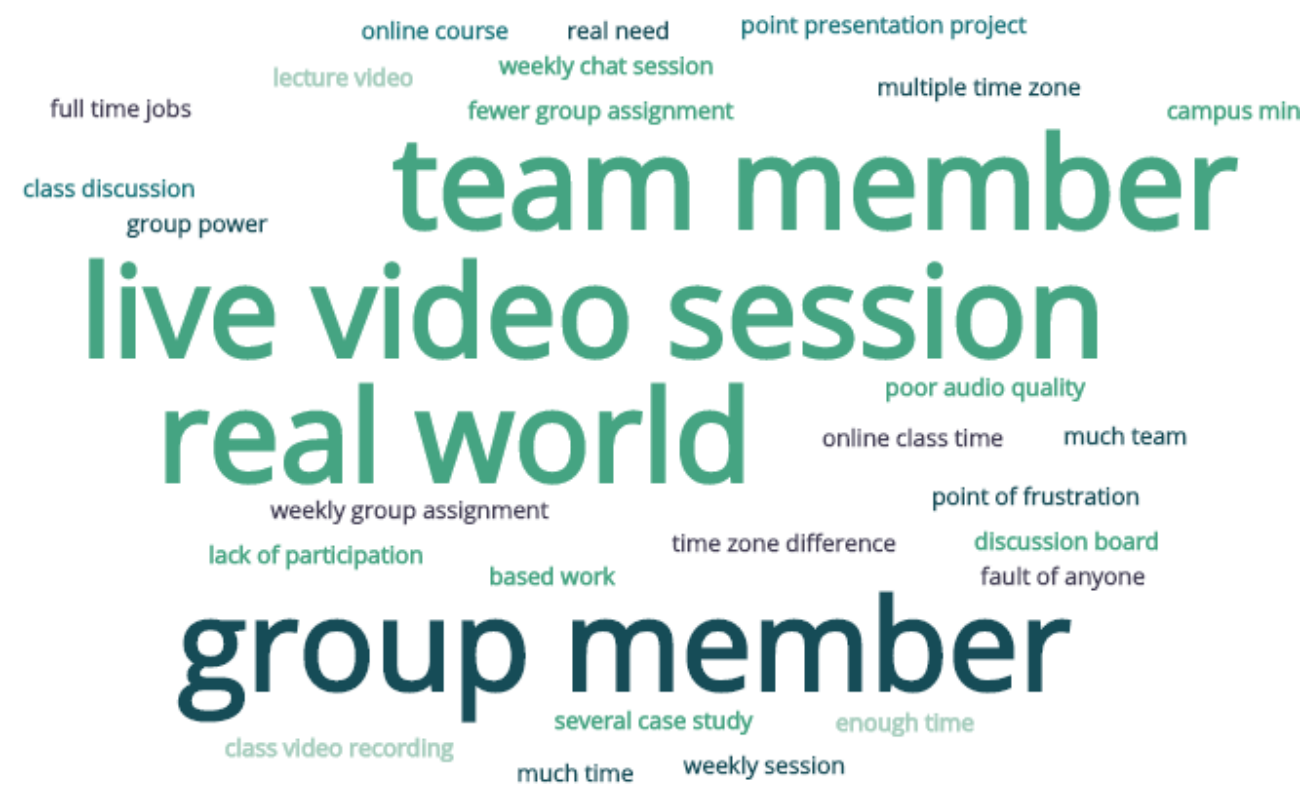

In examining student perceptions of neutral or negative engagement results, several terms are more prominent than others, including: team or group member (4), live video session (2) and real world (2). The most common thread here is neutral or negative experiences in working with other people in group or team formats, whether in activities or deliverables. The second common thread is whether the engagements create a real-world experience for the students. Finally, the live sessions were not always viewed as engaging for the students which were due to some of the classes being larger and with a requirement to post chat questions instead of asking live questions (which was designed to help with organization and reduce noise). Students also experienced issues in attending live sessions because their prior online courses had not required specific meeting times which could disrupt other activities outside of the class. 


\section{Evaluations of the Course and Class Observations - Learning}

The second section examines student learning experiences in the flipped classroom through online mechanisms. As observed in the following figure, a larger percentage of students found the online flipped classroom design to increase overall learning (38\%), with the remaining either feeling neutral (38\%) or negative (24\%) about the types of learning experiences they had.

\section{Figure 40}

Observation results for learning in a flipped online classroom

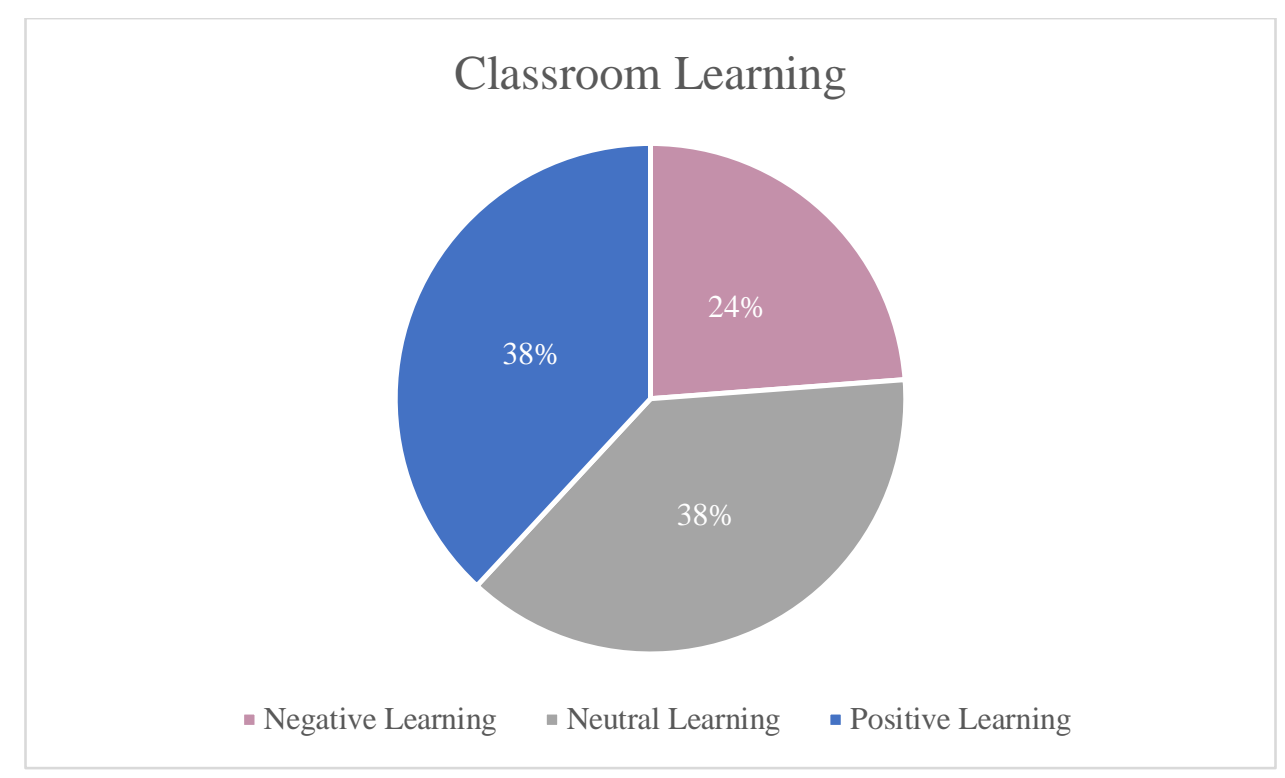

In examining the results further, the following figures contain a word cloud that was used to determine key words and phrases that were observed to be used more often than others which relate back to the overall sentiment of students. This allows for a more specific understanding of what may have been the driver for more of the students' responses about learning experiences, whether positive, neutral or negative. 


\section{Figure 41}

Word cloud of key terms and phrases about positive learning experiences

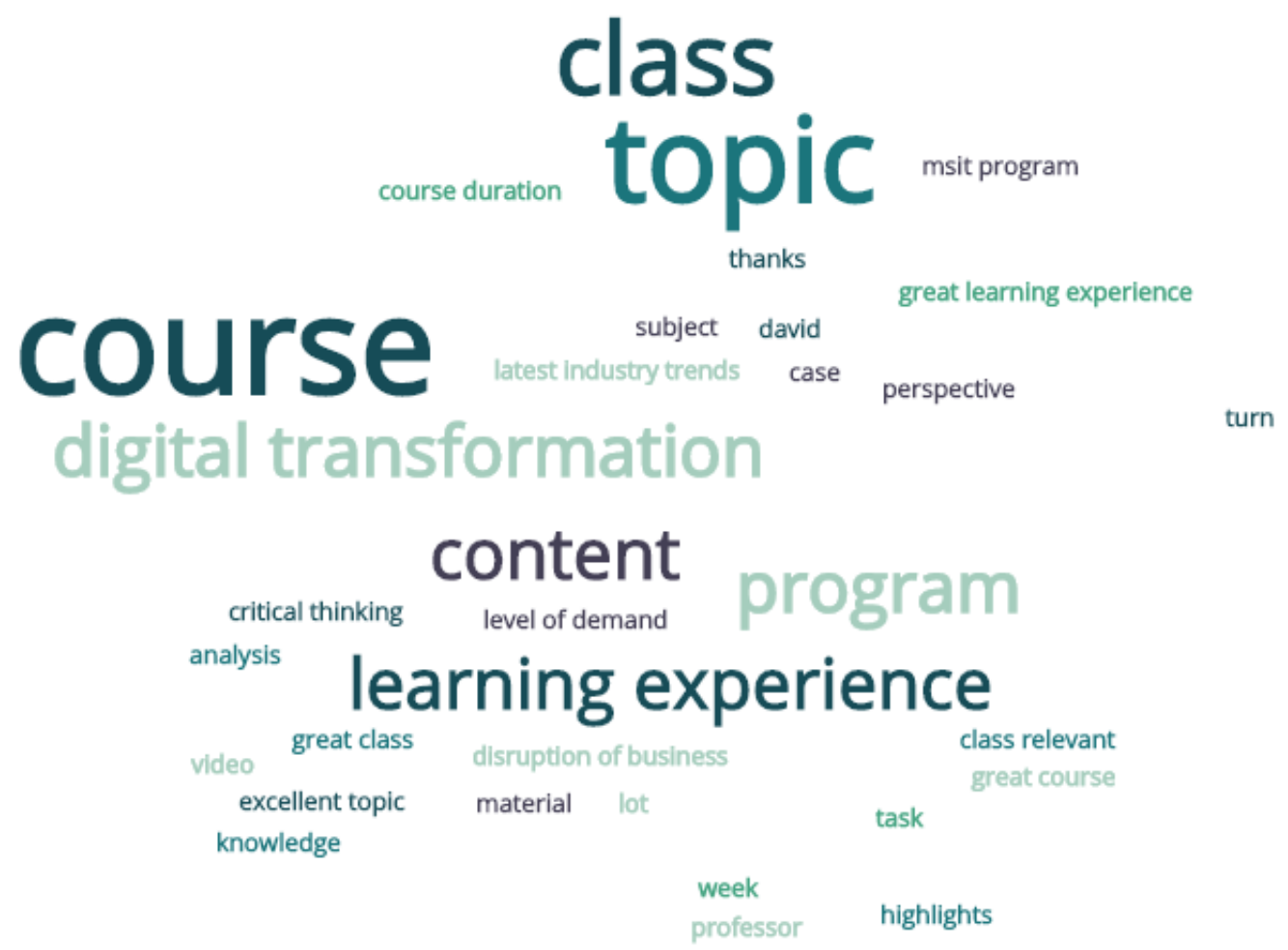

In examining students' perceptions of positive learning results, several terms are more prominent than others, including: course or class (8), topic or content (6), program or digital transformation (4), and learning experience (2). The most common thread here is positive learning experiences in working with the overall content that drives the topics within the course, whether in activities or deliverables that included hands-on work experience, funny and/or entertaining lecture videos, or content that allows the participant to put it all together. The second common thread is whether the learning addresses the real world in terms of digital transformation or if the program driven by that digital transformation derives from course demand, sharing knowledge in active situations and overall superior materials compared to other experiences. The learning experiences were also viewed as positive in driving participant retention and were due to demands from larger class sizes or that those demands were through tasks that they felt met or exceeded their expectations in the learning they could obtain from 
them, as well as reaching a level of critical thinking that allowed for better analysis and synthesis of content.

The next figure contains a word cloud to illustrate key words and phrases that were observed to be used more often than others, but in a neutral or negative connotation in terms of the students' learning experiences.

\section{Figure 42}

Word cloud of key terms and phrases in neutral or negative learning experiences

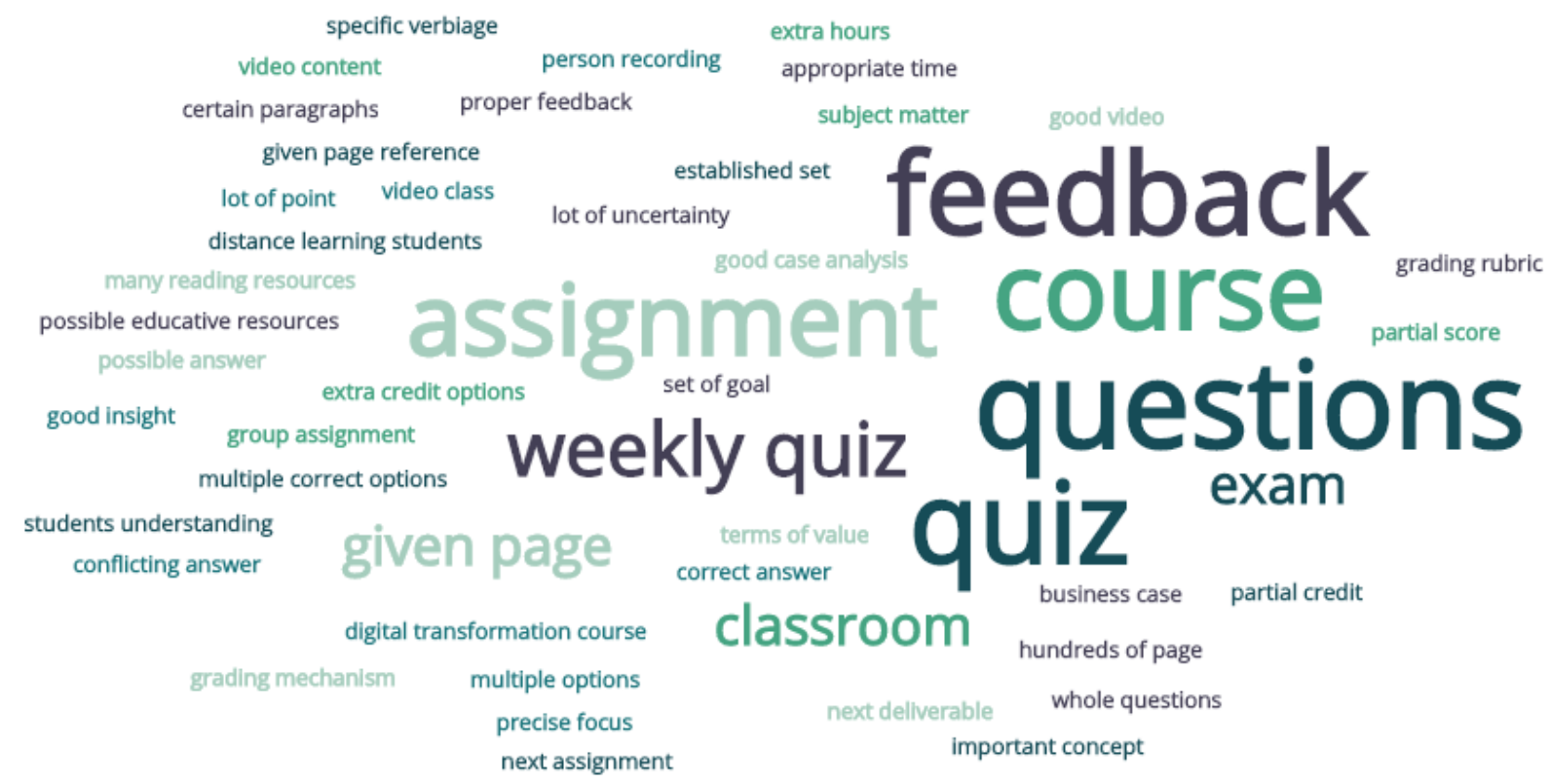

In examining perceptions of neutral or negative learning results, several terms are more prominent that others, including: questions, quiz, weekly quiz or exam (20), feedback (7), course or classroom (8) and assignment (5). The most common threads here are neutral or negative learning experiences in working with quizzes or exams that were derived from the topics within the course or class, whether in activities or deliverables, and could be seen as tricky, confusing, hard, too detailed or were not as effective in capturing knowledge. The second common thread is whether the learning is built through feedback effectively, whether too late for application, or students felt the feedback wasn't effective enough in understanding. The third common thread was around the course or classroom, whether there was a lack of focus, difficulty in working with the lecture videos or issues with grading in the course. Finally, the learning experiences 
were also viewed as neutral or negative in driving student learning through assignments, which were due to the group or team nature of the assignment, late feedback for proper application, or the age of some of the cases worked with.

\section{Evaluations of the Course and Class Observations - Overall Experience}

The final section looks to examine students' overall experiences in the flipped classroom through online mechanisms. As observed in the following figure, a larger percentage of students found the distance flipped classroom to be a positive experience $(45 \%)$, with the remaining either feeling neutral $(41 \%)$ or negative $(14 \%)$ about the overall experience they had in the classroom.

\section{Figure 43}

Observation data for overall experiences in a flipped online classroom design

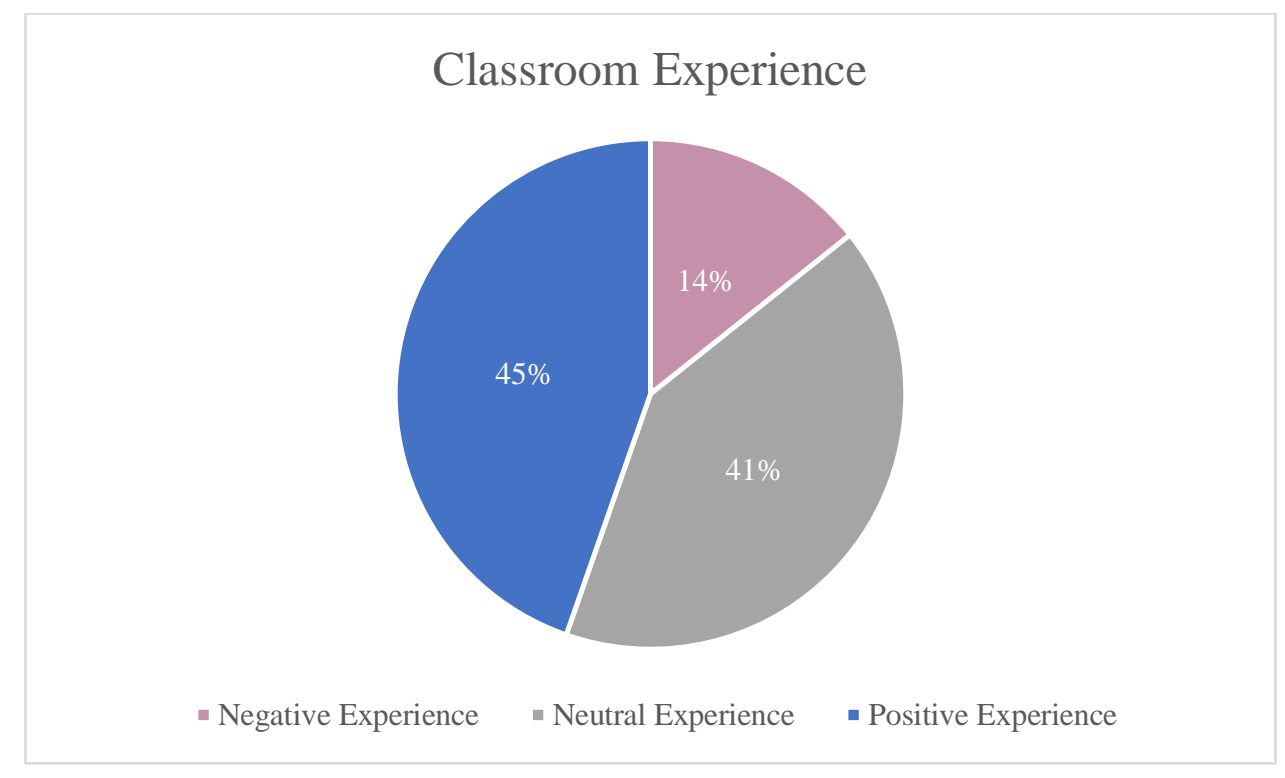

In further examination, the following figures contain word clouds that were used to determine key words and phrases that were observed to be used more often than others. This allows for a more specific understanding of what may have been the driver for more of the students' responses to classroom experiences, whether positive, neutral or negative. 


\section{Figure 44}

Word cloud of key terms and phrases in positive overall experiences

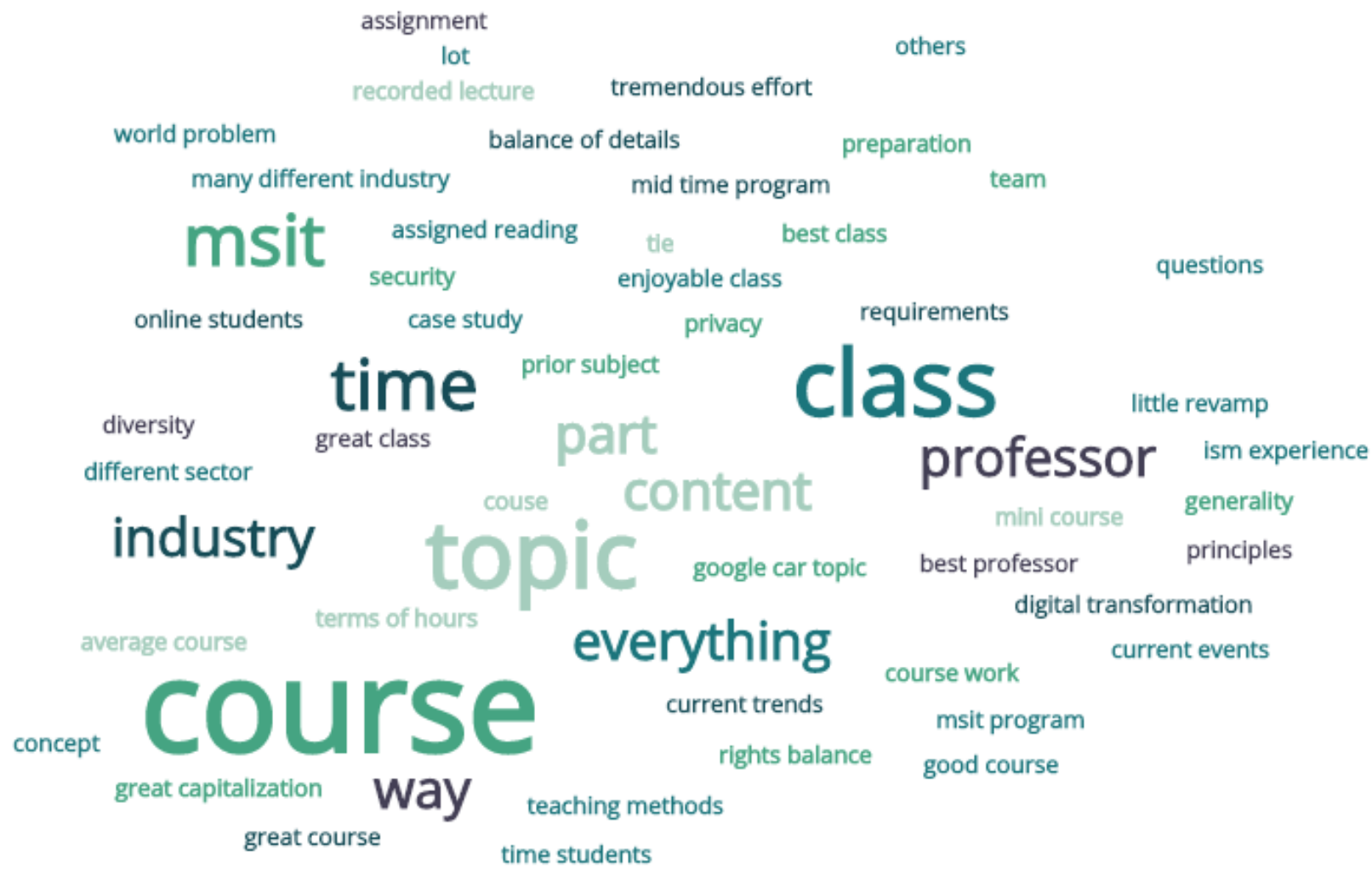

In examining student perception of positive learning results, several terms are more prominent than others, including: course or class (16), topic or content (7), msit (4), everything (2), time (3), professor (2) and industry (2). The most common threads here are positive overall experiences, whether in class activities, lectures or deliverables, and tend to speak to the structure or format, the instructor in terms of engagement, effort put into the class, relevance to industry and technological materials, and enjoyment of the teaching method. Other common threads fall into other areas of the experience such as time commitments, the professor teaching the course, the degree program and how the class fits into it, and everything that combines into the overall experience for the participant. Some of those results stem from positive results because of demands of the course, a grounding of good understanding in concepts and principles, and diversity of work. Finally, learning experiences also viewed as positive in driving the overall experience were due to the application and knowledge gained through industry 
application and learning, whereas some studies specifically found the industry contexts to be very relevant and valid.

The next figure contains a word cloud that was used to determine key words and phrases that were observed to be used more often than others, but in a neutral or negative connotation in terms of the students' overall experiences.

\section{Figure 45}

Word cloud of key terms and phrases for neutral or negative overall experiences

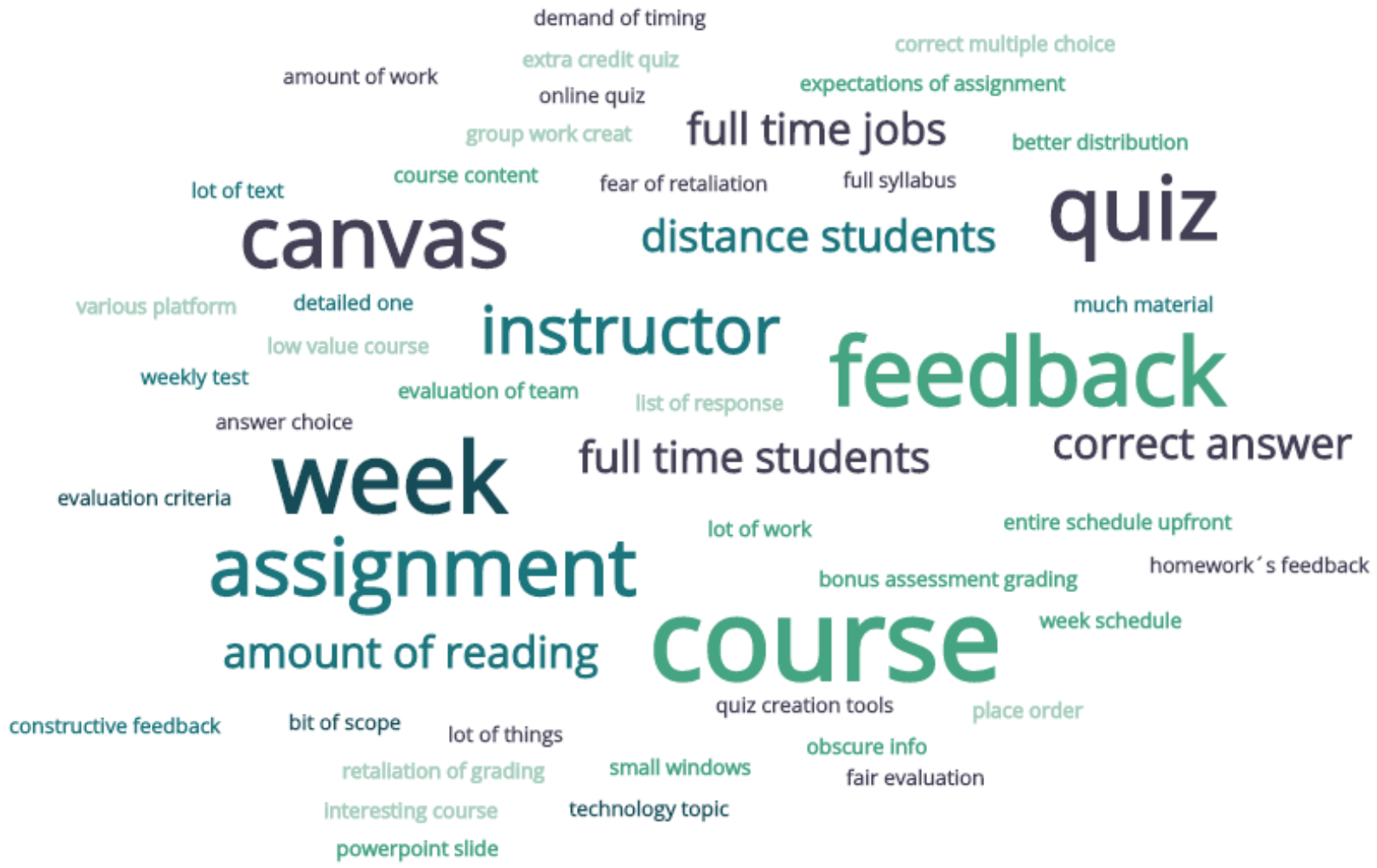

In examining student perception of neutral or negative learning results, several terms are more prominent that others, including: course (16), week or amount of reading (in a given week) (12), feedback (9), quiz (8), Canvas (7), assignment (6) and instructor (4). The most common threads here are neutral or negative overall experiences within the overall course, whether in activities, lectures or deliverables. This included the course being too light compared to others, having too heavy a workload, not meeting expectations, being uninteresting, having organizational issues, and having issues with time commitment. Other common threads tend to 
fall into other areas of the experience such as time commitments, the professor teaching the course, issues with Canvas, and everything that combines into the overall experience for the participant. Some of the areas included here surround lack of knowledge of expectations, too much subjectivity in feedback, grading that is too rigorous, problems with prerecorded lectures, confusing grading schemes or slow delivery of feedback. Finally, the overall experiences were also viewed as neutral or negative due to the quizzes and assignments given in the class. Some of the areas identified here were improving the quiz process or format, too many errors in the quizzes, too much content to cover per quiz, and that quiz grading policies were confusing.

\section{Chapter Summary}

The examination of the data and results within this chapter cover multiple areas through a mixed-methods research design to look at measuring learning, engagement and overall experience in the classroom. The objective of the study is in looking at comparisons of online distance education as compared to the traditional, in-person lecture, and this is accomplished through the results garnered through this study. The quantitative results show strong, but not definitively clear, leanings toward positive learning results for distance students that experience a flipped classroom instructional design. In analyzing the qualitative results, there are specific themes that are persistent across the sentiment analysis of the three criteria, having a positive/more, neutral/same, or negative/less response to the criteria outlined, which show areas

of engagement with comparable or more positive results. These findings are discussed in further detail in Chapter 5. 


\section{Chapter 5: Discussion}

This study looks to examine potential changes in achievement and perceptions of learning and engagement through comparisons of two types of instructional design across in-person and online classes. The first design features a traditional instructional design model using a passive, lecture-based delivery and is implemented in an in-person class. The second design features a flipped classroom model using a more active, activity-based delivery and is implemented in an

online class. Both class types examined include synchronous and asynchronous components. The areas examined include students' experience and engagement perspectives, as well as changes in learning based on quantifiable results through the overall grade point average, assessment scores and a numerical scoring of perceived learning from the student.

In terms of changes in learning, the following areas were examined: quantifiable learning through assessment scores and grade point averages from the entire class, a quantifiable learning through perceptions of learning key concepts based on a Likert scale rating comfortability of knowledge in addressed areas, and a qualitative measure gauging key terms and phrases as compared to experiences within the class that correlate to learning. In terms of engagement, experiences examined for perceptions of engagement were addressed through an assessment gauging engagement polarity compared to prior experiences of online classes and in-person classes, and a qualitative measure gauging key terms and phrases as compared to experiences within the class that correlate to engagement or engaging activity. The following table outlines all key result criteria that are used in the focus for analysis of learning and engagement changes in students within this study. 


\section{Table 42}

Key observation points for results in changes in learning and engagement

\section{Observation Results Point}

Observations of this class in terms of student's perceptual and actual

learning experiences.

\section{High Level Observable}

\section{GPA}

\author{
Assessment (quiz) \\ scores
}

Pre-post assessment

Engagement survey

students' perceptions of engagement experiences.

Observations of this class in terms of students' perceptions of overall experiences.

\section{Key Observable(s)}

Type of Comparison(s)

Actual
Actual

$$
\begin{aligned}
& \text { Total score per } \\
& \text { assessment, } \\
& \text { analysis of total } \\
& \text { scores }
\end{aligned}
$$

Pre-score, postscore, change in pre-post score

$$
\begin{gathered}
8 \text { criteria } \\
\text { for assessing } \\
\text { engagement } \\
\text { FCE, in-class } \\
\text { activity, } \\
\text { asynchronous } \\
\text { activity }
\end{gathered}
$$

Classroom observations

In supporting previous work in active learning, and specifically, utilizing a flipped classroom instructional design in online settings (AlJarrah et all, 2018; Chen et all, 2014; Knapp, 2018; Lin et all, 2019; Phillips, 2019; Romero et all, 2019; Tseng et all, 2018; Van Wyk, 2019; Wang, 2019), this chapter discusses the key theoretical, pedagogical, andragogic (adult pedagogy), findings, implications, limitations, recommendations and summations of the study.

For this study, the flipped classroom approach is a developed model referred to as the Flipped Distance Education Model (FDEM) (see Appendix L) based on components of the ADDIE and ASSURE structures (See Appendix N1), and applied to the class for flipping the lectures, as well as the remaining components of the instructional design. This allowed for a structured approach to the flipped classroom teaching strategy that met the needs for digitizing 
the lectures, creating in-class activities and for having an overall approach to the teaching methods. Also having an understanding that most classes and students' experiences in those classes generally do not approach instructional design through flipped classroom modeling, so the instructor must acknowledge and understand the effect of the flipped classroom to the students and promote a sense of comfort with those changes, particularly in an online setting where much of those experiences come from an asynchronous method of teaching and learning.

As this study's results have supported, the online flipped classroom instructional design in comparison to the traditional, in-person lecture-based class shows some definitive differences in results with both learning and engagement experiences. This is displayed both in how the learning and engagement is perceived by the student, as well as in a quantifiable outcome based on the students' results in the class. Many of the examined responses from students in the flipped classroom showed increases in interactions which led to better learning, however, with certain caveats which were uncovered and are discussed in this chapter.

\section{General Findings}

The results support a generally positive outcome in terms of showing both increases in learning as well as increases in engagement. The flipped classroom model of instructional design with online mechanisms has shown, in most cases, to either mimic the areas of learning and engagement, or increase both areas substantially comparative to the traditional in-person lecturebased class, which supports a positive result in this study. Only one out of the five quantitative areas examined goes against the general positive findings, which were uncovered in the assessments given on a weekly basis that test rote memorization of topics and content of the week's classes. For example, only one out of five assessments had shown increases in learning in the flipped online classroom over the traditional in-person lecture classroom. Barring this anomaly in the results, the data still overwhelmingly supports a positive outcome of the flipped classroom design with online mechanisms.

To be considered a positive result, the distance flipped instruction design should show similar and/or better results than the traditional, in-person lecture instructional design. The reasoning behind these considerations of positivity for similar outcomes is in providing results that counter some theories and research that say online education cannot provide a similar learning and engaging experience as the traditional in-person lecture style classes can, or to 
lessen the negative perceptions of online education as a replacement medium for students' education. If the online flipped classroom design shows similar results, the assumption can then be made that either mode can create positive results of learning and engagement. This is nowhere more important than in the current era of educational delivery where more schools are finding it necessary to move to a digitized and distant form of education. In the following table, the overall results are shown for the outcomes of comparisons of learning and engagement between the traditional lecture and flipped classroom designs in the five areas utilized for data collection and analysis.

\section{Table 43}

High-level outcomes of the two research questions and five observable points

\section{Research Question and Observation Point}

Instructional Design: Greatest Learning/Engagement Outcome

RQ1. Learning

Grade Point Average (GPA) of each student

Flipped

RQ1. Learning

Traditional

Assessment scores of each student

RQ1. Learning

Pre- and post-test scores of each student

Flipped

RQ2: Engagement

Flipped

Post-class assessment of engagement experiences

RQ2. Engagement

Flipped

Classroom observations

In looking at the overall results, four out of the five areas are shown to have more positive outcomes in learning and engagement through the flipped classroom design. To better understand why the flipped classroom has shown more positive results, as well as why one observation point went against this trend, the following sections review the effectiveness of change in both learning and engagement through a further examination based on a theoretical and pedagogical lens driven by the two research questions posed in this research study. 


\section{RQ1: Effects on Learning: Theoretical and Pedagogical/Andragogical Implications}

The flipped classroom design was found to be an effective model for online learning. One important area to note is that in the comparison of learning through the two instructional designs showed the importance of environmental factors within the classroom that can have an effect on student learning. Environmental means the experiences and engagements that also have an effect on the overall learning, and this was made present in the results. This study examines the outcomes of perceived (student reported) and actual (quantifiable) learning, which are shown in the following table (positives reflect a greater outcome for the flipped classroom design, whereas greater negative outcomes are shown for the traditional in-person lecture-based design). 


\section{Table 44}

Comparing learning results between traditional and flipped instructional design

\begin{tabular}{|c|c|c|c|}
\hline Observation & $\begin{array}{l}\text { Observable Component: } \\
\text { Average and ANCOVA }\end{array}$ & $\begin{array}{c}\text { Results of the } \\
\text { Observable } \\
\text { Component }\end{array}$ & $\begin{array}{l}\text { Instructional Design: } \\
\text { Greater Outcome }\end{array}$ \\
\hline \multirow{3}{*}{$\begin{array}{l}\text { Grade point } \\
\text { average (GPA) of } \\
\text { each student }\end{array}$} & $\begin{array}{c}\text { Averages: Overall grade } \\
\text { collection }\end{array}$ & -.5 & Traditional \\
\hline & $95 \% \mathrm{CI}$ & -.2 & \\
\hline & $\begin{array}{l}\text { Adjusted Mean: Overall grade } \\
\text { collection }\end{array}$ & -.2 & Traditional \\
\hline \multirow{8}{*}{$\begin{array}{l}\text { Assessment scores } \\
\text { of each student }\end{array}$} & $95 \% \mathrm{CI}$ & -.2 & \\
\hline & $\begin{array}{c}\text { Assessment } 1 \\
\text { Observed/Adjusted Mean: }\end{array}$ & $-17.41,-18.49$ & Traditional \\
\hline & $\begin{array}{c}\text { Assessment } 2 \\
\text { Observed/Adjusted Mean: }\end{array}$ & $-17.82,-17.82$ & Traditional \\
\hline & $\begin{array}{c}\text { Assessment } 3 \\
\text { Observed/Adjusted Mean: }\end{array}$ & $-8.13,-8.55$ & Traditional \\
\hline & $\begin{array}{c}\text { Assessment } 4 \\
\text { Observed/Adjusted Mean: }\end{array}$ & $+.15,+.078$ & Flipped \\
\hline & $\begin{array}{c}\text { Assessment } 5 \\
\text { Observed/Adjusted Mean: }\end{array}$ & $-7.06,-7.29$ & Traditional \\
\hline & $\begin{array}{c}\text { Total combined } \\
\text { Observed/Adjusted Mean: }\end{array}$ & $-10.05,-10.19$ & Traditional \\
\hline & Observed/Adjusted: $95 \%$ CI & $-10.2,-10.19$ & Traditional \\
\hline $\begin{array}{l}\text { Pre- and post-test } \\
\text { scores of each } \\
\text { student }\end{array}$ & $\begin{array}{c}\text { Averages: Pretest } \\
\text { Averages: Post-test } \\
\text { Averages: Combined change } \\
\text { ANCOVA: Combined change }\end{array}$ & $\begin{array}{c}+8.66 \\
+13.55 \\
+4.54 \\
+12.67\end{array}$ & $\begin{array}{l}\text { Flipped } \\
\text { Flipped } \\
\text { Flipped } \\
\text { Flipped }\end{array}$ \\
\hline
\end{tabular}

Note: Positive numbers represent higher outcomes for flipped classroom, negative numbers represent higher outcomes for the traditional classroom 
The initial findings show that a flipped classroom with online mechanisms is closely related to the traditional, in-person lecture-based design in terms of similar results in GPA. However, there were fewer positive scores in average assessment scores ( 1 out of 5), but more positive scores in perceived learning through the pre- and post-test assessments. We will analyze these findings in detail in the next subsections.

\section{Actual Learning Through Analysis of the Overall Class Grade (GPA)}

The results suggest comparative positive results for actual learning based on the overall grade point averages of students in comparing the online flipped design to the traditional, inperson lecture-based design. If we look at the differences in the ANCOVA results based on the overall student grade, learning is shown as slightly greater, but not statistically significant, in the traditional, in-person lecture-based classroom (-.5, -.2) over the flipped classroom. This also may suggest changes in the learning environment through online mechanisms does not necessarily affect how the students learn throughout the entirety of the course, which is quite contrary to some former research around the instruction and learning quality of online education (Shachar, 2003). In the student's experience, this would include the assignments and activities performed for a grade, the assessments and final exam, and the other activities built into the course. Generally speaking, this would mean students didn't notice any difference in their abilities to learn compared to traditional, in-person students, which is important to note because some of the work requires the use of team-based learning which can introduce some other challenges such as differing time zones, work schedules and other criteria that are outside of the control of the classroom. Much of this can be attributed to asynchronous activities that are performed within the learning management system that enhance flipped classroom learning and increase student access to class content (Zainuddin, 2018).

The results support the hypothesis that a flipped classroom can have similar or greater learning outcomes in online settings and refute suggestions from prior research that students can't learn as well as in the traditional, in-person lecture-style design. The findings are important for the changing demographics of students in that the results suggest an online flipped classroom can meet or exceed predetermined digital education expectations that are changing generationally. These results align with research (Garcia-Sanchez, 2017) shown in teaching graduate level students that support capabilities of knowledge creation, collaboration, interaction 
and thinking critically and independently with and without others, while encouraging more responsibility of the student to own the learning process can lead to increases in overall learning.

\section{Actual Learning Through Analysis of the Assessment Grades}

The results in the weekly assessments to gauge learning in students suggest decreases in their learning that are directly opposed to the findings in an increase in overall grade point averages. Interestingly, there is shown to be a greater gap in the results between flipped and traditional classes, and overall, the traditional classroom results show much higher average scores $(-10.05,-10.19)$ than the flipped classroom. The assessments are delivered similarly through a learning management system quiz platform, so there is no difference in how the assessment is given by the instructor or taken by the students. The content, number of questions, format and amount of time given for the assessment are all similar, so there are no differences that might introduce validity issues in terms of how the quiz is delivered and graded. However, the differences between online and in-class learning environments could play a role in motivations for students to do well on the assessments (Romano, 2005). These could be based on cramming information last minute, expectations of not needing to study, poor distribution of skill sets across the time frame of the assessment, or feelings of detachment from the class when taking it at a distance (Schouwenburg, 2001; Zuriff, 2003) that effect students' rote memorization abilities for assessment taking. This is particularly evident if students are over reliant or overconfident in their perceived learning from the prerecorded videos alone (Szpunar, 2014). This could also be due to supporting online documentation where the student did not perform proper note-taking or properly absorb the content in a live interactive session.

Assessments are given as a bonus option to their overall grade, so one conclusion is that students that take classes in-person feel more obligated to try harder on these compared to distance students, who feel less obligated to try as hard when the risk is low and the reward of taking the quiz is not as important to them (Hidi, 2016). Another theory is that the students taking distance courses tend to take the quizzes without studying as in-depth as the in-person students might, with control over their learning environment and response to the assessment being greater for the distance student (Wilkinson, 1989). It is also worth noting that procrastination levels, particularly in online students who are on a more flexible schedule, have also shown in prior research to drive negative changes to learner motivation, performance in 
learning and self-regulation (Shachar, 2003; Klingsieck, 2012; Young, 2014), particularly in those situations where requirement of doing an assignment or other activity is not made. Motivations for learning, particularly through bonus assessments based on observations are examined in more depth in RQ2.

\section{Perceived Learning Through Analysis of the Assessment Scores}

In looking at the perceived learning outcomes, the online flipped classroom design has shown more positive results from a perceived learning experience than those that had taken the traditional, in-person lecture-based class. The criteria are based on questions asking the students to rate their learning on a Likert-style scale and their perceived confidence on a particular class subject matter on a scale of 1 to 10 with (with 1 being the lowest confidence level). The results show that the students in the flipped classroom rated learning much higher, both in the examination of scores at the end of the class $(+13.55)$ and in the amount of change in the scores between the beginning and end of the class (+12.67). Even though the online flipped classroom students rated, on average, slightly higher in terms of perceived pre-knowledge $(+8.66)$, the posttest also shows a wide gap in perceived learning (+13.55) over the traditional in-person class.

What these results suggest is that even though the students in a flipped classroom have higher confidence from the start of the class, their confidence in learning almost doubles by the time they have finished the class. Likewise, lecture-based students also show increases in their knowledge, but not nearly at the same level of scoring change the flipped classroom students have shown. It's also important to note these assessments are taken before the class starts (so students have no knowledge from the class prior to taking the assessment), and again before they have received a final grade in the class (as to not bias their perceptions of learning). Results then are less biased or skewed by the actual learning result of the GPA earned and help to differentiate between perceived and actual learning. However, perceptions could still be affected by the assessment scores or other assignments they receive when concluding the quiz. This is interesting since flipped classroom students are showing actual scores lower than their lecturebased counterparts even though their perceived learning scores are higher. This suggests that perception confidence versus actual application can be quite different to the learner.

One suggestion for the higher perceptions can be related specifically to the amount of confidence in the student's application of content learned over rote memorization skills for 
content retaining. If the student feels they can effectively apply the content, regardless of accurate memory of it, they will feel more confident in their potential for effective utilization of it. This theory is in line with research from (Mayer, 2002) and a revision of Bloom's taxonomy (Anderson, 2001) in which transfer of learning should include understanding, applying, analyzing, evaluating and creating. The flipped classroom design specifically introduces active areas such as learning and engagement activities in class that meet the later criteria, which give students increased classroom time to actively engage in the content through those interactions and activities. These can be both individual and team-based, and also allow for new avenues of creation from the learning, which would then lead to higher-order understanding and confidence in the materials.

Another suggestion for higher perception in learning is from the increased engagement in the classroom, which goes against the traditional thinking that an online class is less engaging than an in-person class. The addition of the flipped classroom strategy, by design, can allow for classroom time to be used for additional engaging activities between all stakeholders in the classroom - students, instructors and TAs. This increased engagement can also elevate confidence in the materials with continued reinforcement through the activities. Correlations of engagement to learning are reviewed further in the next section that analyzes engagement in the flipped online classroom based on RQ2 and the hypothesis of the proposed question.

\section{Conclusion: $R Q 1$}

In conclusion of the three data points examined (GPA, assessments scores and perceived learning), the results suggest positive changes to learning are generally shown in both the overall grades as well as the perceived learning of the student, and that assessment scores based more on rote memorization may not be as important. Although there are more positive scoring outcomes across assessments in the traditional, in-person lecture-based classes, this did not equate to a higher overall learning experience with the overall GPA showing similar outcomes between the two instructional designs (which also contain the assessment scores within them). With procedural knowledge being one of the strengths of utilizing a flipped classroom design for learning (Milman, 2012), incorporating both summative learning and formative assessments along with face-to-face experiences can bring an increase in knowledge retention. Part of the increase is in the outcomes showing, at minimum, a similar overall GPA in students from both 
instructional designs, and in some cases, a greater positive overall GPA outcome. This is in part due to asynchronous activities that can be performed across current technologies such as Zoom, Canvas, Piazza and other collaborative platforms that also increase the enrichment of learning, increasing student curiosity and interest, and creating more enjoyment within the virtual classroom (Ozpinar, 2016). In differences in assessment scoring alone, it could be that students who take an in-person class feel more responsible in preparing to take the assessments, but this is out of scope for the current study and may be considered for future research.

However, in this study, perceived learning is shown to be much higher in online classes delivered via a flipped classroom design that complements the positive learning outcomes from those experiences. This suggests some of the opportunities learners are given in a flipped classroom may not be present in the traditional, in-person classroom. These opportunities include in-person activities that build upon the lecture materials, through skills that are obtained through passive pre-learning, and are then applied via active learning through synchronous activities within the class. This is in line with research (Verleger, 2013) that has shown that problemsolving and analytical skills develop more positively in students who learn content outside of the class and apply it with guidance within the class. Approaches such as these have shown in this research to reduce plagiarism and increase critical thinking skills because the learner can build upon their ideas harnessed through the structure of the class rather than being fully reliant on self-guidance, creating an overall better balance in the learning process. In doing these types of activities, this can give the learner a greater confidence in their knowledge of materials if they are able to actively apply and build from that knowledge obtained from the prerecorded lectures.

\section{RQ2: Effects on Engagement: Theoretical and Pedagogical/Andragogical Implications}

The results from the research study in applying a flipped classroom design across online mechanisms supports positive results in experiences of and in increase in engagement within the class. Comparing experiences of engagement through the two instructional designs suggests the importance of implications in environmental factors within the classroom that can have an effect on the learning and motivations of the student. In this study, examinations of the outcomes of perceived (quantifiable) engagements which are shown in the following table. Observed (qualitative) engagement is shown in the next table. Values in the second and third number show an even or greater outcome for the flipped classroom design, whereas the first number shows a 
greater outcome for the traditional, in-person lecture-based design.

\section{Table 45}

Comparing engagement results between traditional and flipped instructional design

\begin{tabular}{|c|c|c|c|}
\hline Observation & $\begin{array}{l}\text { Observable Component: } \\
\text { Averages of flipped versus } \\
\text { active/passive }\end{array}$ & $\begin{array}{l}\text { Results (Less, } \\
\text { Same, More } \\
\text { Engaging) } \\
\text { n(26) }\end{array}$ & $\begin{array}{l}\text { Instructional Design: } \\
\text { Greatest Outcome }\end{array}$ \\
\hline \multirow{2}{*}{$\begin{array}{l}\text { Engagement } \\
\text { survey assessment } \\
\text { of each student } \\
\text { (comparing } \\
\text { distance to } \\
\text { distance) }\end{array}$} & $\begin{array}{c}\text { Average of Q.'s 1, 3, 5, } 7 \\
\text { (flipped versus active) }\end{array}$ & $(0,8.5,17.5)$ & Flipped \\
\hline & $\begin{array}{c}\text { Average of Q.'s } 2,4,6,8 \\
\text { (flipped versus passive) }\end{array}$ & $(0,5.75,20.25)$ & Flipped \\
\hline \multirow{2}{*}{$\begin{array}{l}\text { Engagement } \\
\text { survey assessment } \\
\text { of each student } \\
\text { (comparing } \\
\text { distance to } \\
\text { traditional) }\end{array}$} & $\begin{array}{l}\text { Averages of Q.'s 1, 3, 5, } 7 \\
\text { (flipped versus active) }\end{array}$ & $(7,11.25,7.75)$ & Flipped \\
\hline & $\begin{array}{c}\text { Averages of Q. 2, 4, 6, } 8 \\
\text { (flipped versus passive) }\end{array}$ & $(2.75,10.5,12.75)$ & Flipped \\
\hline
\end{tabular}

The early results show that engagements in the flipped classroom instructional design across distance mechanisms are much higher for students than those they have experienced through prior online classes as well as their experiences in the traditional in-person lecture style of instructional design based on the results.

The following table shows the results from the three types of perceptions of engagement in the classroom: negative, neutral or positive, based on the collected observations of the students in the classroom, as well as their feedback shared within and reported outside of the classroom. 
Table 46

Analyzing class observables within the flipped classroom instructional design

\begin{tabular}{|c|c|c|c|}
\hline Observation & $\begin{array}{l}\text { Observable Component: } \\
\text { Total of flipped versus } \\
\text { active/passive }\end{array}$ & $\begin{array}{c}\text { Results (Negative, } \\
\text { Neutral, Positive) } \\
\text { n (\%) }\end{array}$ & $\begin{array}{l}\text { Instructional } \\
\text { Design: Greatest } \\
\text { Outcome }\end{array}$ \\
\hline \multirow{4}{*}{$\begin{array}{l}\text { Observations of } \\
\text { Engagement } \\
\text { (Through the FCE, } \\
\text { communications, } \\
\text { observations) }\end{array}$} & $\begin{array}{l}\text { Total and percentages of } \\
\text { engagement observations }\end{array}$ & $\begin{array}{ll}\text { Negative: } & 7(10 \%,) \\
\text { Neutral: } & 15(22 \%) \\
\text { Positive: } & 47(68 \%)\end{array}$ & Flipped \\
\hline & $\begin{array}{l}\text { Total and percentages of } \\
\text { learning observations }\end{array}$ & $\begin{array}{ll}\text { Negative: } & 10(24 \%,) \\
\text { Neutral: } & 16(38 \%) \\
\text { Positive: } & 16(38 \%)\end{array}$ & Flipped \\
\hline & $\begin{array}{l}\text { Total and percentages of the } \\
\text { overall experience observations }\end{array}$ & $\begin{array}{l}\text { Negative: } 8(14 \%) \\
\text { Neutral: } 23(41 \%) \\
\text { Positive: } 25(45 \%)\end{array}$ & Flipped \\
\hline & $\begin{array}{l}\text { Total and percentages of } \\
\text { engagement, learning and } \\
\text { overall experience observations }\end{array}$ & $\begin{array}{ll}\text { Negative: } & 25(15 \%,) \\
\text { Neutral: } & 54(32 \%) \\
\text { Positive: } & 88(53 \%)\end{array}$ & Flipped \\
\hline
\end{tabular}

The early results for the other class observables show that engagement, learning and overall experiences for the flipped classroom design across online mechanisms are much higher (53\%) than through prior online classes, as well as the traditional in-person lecture style of instructional design based on the participants' experiences. As well, a lower percentage (15\%) saw their experiences as negative, and interestingly, one student viewed their student interactions as a detriment to their learning as causing a part of their negative experience. However, because the experiences were mostly positive, the results for utilization of the flipped classroom design suggest it can increase the potential of positive learning, engagement and overall experiences.

Broken down into the following figures, you can also observe a tally of the engagement, learning and overall experiences based on sentiment analysis of the observations collected. 


\section{Figure 46}

Percentage of perceived sentiments separated by category

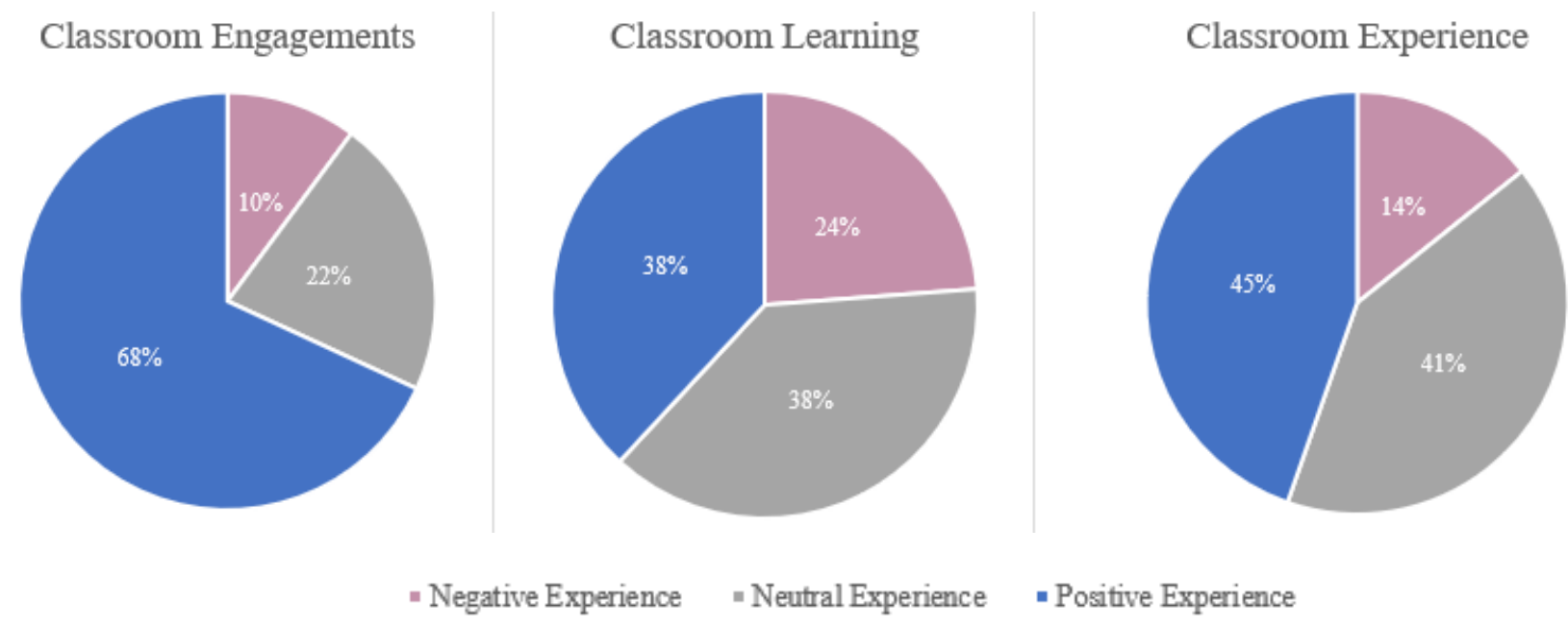

As observed through the breakdown provided, the classroom engagements are seen as generally positive in the flipped online classroom, with learning in-between positive and neutral, and the overall experience also leaning toward a medium between positive and neutral experience, but with far less negative overall experiences perceived. Overall, the observations suggest a higher positive result which is further identified in the following analysis.

\section{Comparing Engagement Experiences Between Current and Prior Distance Classes}

The study also looks to draw comparisons and contrasts between prior online class experiences that are mainly passively taught and the online flipped classroom that is actively taught. These instructional design types are based on students' observations of prior experiences in those types of class as compared to the current class they are taking. In both comparisons, the flipped classroom suggests increased positive experiences of the students in terms of learning, engagement and overall experience which we will discuss in further detail.

The first factor looks at engagement comparisons between current and prior online classes that also include some type of active learning component, whether it be a flipped classroom, activities or other components that require more active participation. Overall, the active learning mode of the flipped classroom design was found to be the same or greater than prior active learning style of classes. This was true in terms of engagement in the class, engaging with the professors and/or TAs, and as the students' overall engagement experience in the class. 
The results for the third criteria which asks students to "rate your activities in this class compared to those in an online class (that included active participation)" were slightly lower than with the other criteria. Even though the outcomes were still generally positive, the activities seem to mimic those of prior class experiences quite evenly (14 respondents), but in some cases are still better (12 respondents). One of the theories for similar correlations between the current and prior classes can be that activities are going to be somewhat limited in a virtual environment and thus will be handled similarly. For example, if you use Zoom to have class meetings and wish to do activities, you can perform breakout room activities, or have a full class involvement such as a presentation, but it can be more cumbersome if the difficulty level of the activity increases, especially when it requires more hands-on instruction. If physical materials are necessary for the activity, those activities will also be much more difficult to perform since all students would need those tools, which again adds layers of complexity to the process.

The second correlating factor looks at engagement within the current versus prior online classes that do not include some type of active learning component but stick to the traditional format of an in-person lecture-style of content delivery. The flipped classroom results suggest a positive rating with students who were asked to "rate your activities in this class compared to those in an online class (that did not include active participation)." This is important as many online classes tend to lean toward an asynchronous method of delivery. In this study, the active learning components of meetings, presentations, activities and discussions all resulted in a much higher level of engagement versus other passive classes, with only six of the 26 respondents stating it was about the same.

One component of having a positive experience in a class is in finding a balance between the time spent in and outside of the class. One student said "I particularly enjoyed the interactive format and how well the discussion board is managed to encourage collaboration and healthy debate between students." Finding the sweet spot between active and passive learning may be one of the key benefits a flipped classroom can harness by creating the environment for active components while still incorporating passive instruction through other means. Having the inclass time used for participation instead of unidirectional content dissemination can lead to higher-order thinking. "I liked all the learning experience, and I appreciate the level of demand, which in turn demanded more from us," a student said. Fostering the application of creativity in class time has suggested positive benefits according to the analysis. 
In conclusion, use of the flipped classroom design with online mechanisms was shown to be effective for engagement, learning and the overall experience for many students (50.33\%) regardless of their prior experiences with active versus passive learning in those classes. Fewer students $(16 \%)$ reported engagement, learning or overall experiences that the analysis would suggest as negative, and the rest of the observations (33.66\%) suggested neutral results that would at minimum meet the standards experienced in prior classes and instructional designs. In the interest of the research, these other instructional designs still show effectiveness and future studies could examine modifications to the class to promote positive results. The study does suggest an active approach instead of the passive distance class positively enhances students' motivations, involving them more in the content and with others in the class, and creates an overall better experience.

\section{Engagement Comparisons Between Current Distance and Prior Traditional Classes}

The study also looks to draw comparisons and contrasts between the traditional, inperson lecture-based design compared to the flipped classroom design across online mechanisms, examining differences in traditional courses that utilized passive versus active modes of instruction. These themes are based on students' observations of past experiences in those types of classes compared to the current class they are taking. In both comparisons, the flipped classroom showed higher positive outcomes in terms of learning, engagement and experience, which will be discussed in further detail.

The first correlating factor looks at engagement comparisons and contrasts between current online classes and prior traditional in-person, lecture-based classes that also include some type of active learning component, whether it be a flipped classroom, activities involving multiple students, or other components that require more active participation. The key component in evaluating the results is whether students show similar or increased engagement experiences in the flipped class over the traditional, in-person lecture-style of online classes that also included some type of active participation.

This is a key finding in all four areas of engagement that were evaluated. Engagements between students, engagements with TAs and professors, engagements with activities and the overall engagement experience were seen to be quite equal. There are several studies (Galusha, 1997; Klingsieck et al., 2012; Wilkinson \& Sherman, 1989; S. Young \& Duncan, 2014) claiming 
that the active learning components in the in-person experience cannot be mimicked in the online setting, but the findings in this study show the opposite in that active learning components can be effectively accomplished through online mechanisms. This finding aligns with other studies (Alonso et al., 2009; Lim et al., 2008; Ni, 2013; A. Young \& Norgard, 2006) that show comparative results. This is particularly interesting when addressing issues such as balancing engagement with flexibility in the course. Flexibility in distance courses is a prominent need for many students, and the study suggests that flexibility can be obtained along with creating an enhanced learning environment that students would appreciate.

Overall, the active learning method of the flipped classroom was found to be the same or better than prior classes with active learning. This was true in terms of engagement in the class, engagement with the professors and/or TAs, and an overall more engaging experience in the class. The digital transformation class is a great example of a course that can have its content activated for students, as well as give opportunities for active learning based on prior classes that have incorporated these styles of instructional design. Online students are looking for a voice to prove the outcomes of the distance class can be equal to or greater than a traditional class, and also have similar effects on the distance versus traditional student, equalizing or improving the playing field for the online student. The results outlined above give reason to believe that this instructional design can work to the benefit of the online student.

The second correlating factor looks at comparing student engagement experiences between current online classes and prior traditional, in-person lecture-based classes that do not include some type of active learning component. What has been uncovered through this study, which prior research dissuades against, is that the online class that incorporates flipped classrooms can, in many ways, create more opportunities for active learning through in-person meetings online which can give an increased engagement environment. This can increase learning potential and create a better overall experience compared to traditional classes that teach with a very passive style of instructional design. However, these classes rely more on technology to help the guidance and management of course materials, and may still put the onus for selfmotivation heavily on the student as they work without the boundaries of the physical class.

Passive lecture-based courses have, by design, a tendency to reduce a key feature that can be well integrated within the flipped classroom, called team-based learning or simply referred to as group work. This is mainly due to time constraints the instructor puts on the class to spend 
more with content and less with activity. Prior studies have shown that team-based and grouprelated interactions can greatly enhance cognitive learning and improving outcomes (Shi et al., 2020). There can be a sense of distancing from the course, peers and the school in general when taking an online course. Team-based learning gives the instructor another tool to close gaps in engagement opportunities between students, instructors and TAs. Utilizing the flipped classroom design empowers tools such as team-based learning for projects and other multi-student activities, as it gives the in-class time to increase team-based learning.

Team-based learning is one way to increase active approaches to content absorption in the classroom and harness the power of active learning, but individual-based activities and assignments can also improve active learning. One method that harnesses active participation is through class discussion and applying a form of dichotomous debating, an approach of arriving to a conclusion from differing perspectives where multiple pathways can be taken. This allows for debate over differing opinions of the merits and downfalls of either a student's own team conclusions. This can also be done through individual arguments for one side or approach to an assignment or topic. This allows individuals to make their own assumptions and arguments on a particularly interesting topic, through utilizing a mix of experience, content and instinct, and where their participation in the debate from an informed perspective can give an individual feel and accomplishment to those results. It's not to say that passive-based modes of teaching cannot include class discussions, but that discussions can be driven through activities with increased class time. Debates by individuals and teams were both utilized in this study and also supported positive increases to student sentiment of their engagement experiences.

In conclusion, use of the flipped classroom instructional design in online education suggests increased effectiveness for engagement, learning and the overall experience for the students regardless of prior experiences with active versus passive learning in the traditional, inperson lecture-style classes. Very few students reported negative engagement, learning or overall experiences and the rest report neutral results that would at least correlate to experiences prior to the flipped design, which in terms of overall effect, still shows effectiveness and could be slightly modified to increase positive results. The study does show that an active approach instead of a passive online class will greatly enhance students' motivations, involving them more in the content and with others in the class, and create an overall better experience for learning. 
Perceptions/Sentiments in the Current Online Flipped Classroom Design for Engagement, Learning and Experience

There are three main themes from a sentiment analysis of student perceptions this study identifies for examining the flipped classroom across online mechanisms. The first analyzes student perceptions of engagement in the class, the second analyzes student perceptions of learning and the third analyzes students' perceptions of the overall class experience. These three themes are then analyzed in three types of sentiments, whether negatively (that the specific criteria were reported as a negative experience), neutral (that the specific criteria were neither detrimental nor positive for the engagement experience), or positive (that the specific criteria gave an increased impression of engagement experience in the classroom). These themes are based on student observations and perceptions from classroom experiences utilized in this study, some of which may or may not make comparisons to prior classes but directly correlate to the current class they are taking.

In comparing students' perceptions and sentimental analysis of these three themes, the flipped classroom design suggested greater positive outcomes in all three criteria of learning, engagement and overall class experience. The following table gives a high-level identification of key words that correlate to perceptions of either positive or neutral/negative observations collected in this research study. 


\section{Table 47}

Correlations between students' observed keywords in engagement, learning and overall experience

\begin{tabular}{|c|c|c|c|c|c|c|}
\hline $\begin{array}{l}\text { Word } \\
\text { Count }\end{array}$ & $\begin{array}{c}\text { Engagement } \\
\text { (Positive) }\end{array}$ & $\begin{array}{c}\text { Engagement } \\
\text { (Negative or } \\
\text { Neutral) }\end{array}$ & $\begin{array}{l}\text { Learning } \\
\text { (Positive) }\end{array}$ & $\begin{array}{l}\text { Learning } \\
\text { (Neutral or } \\
\text { Negative) }\end{array}$ & $\begin{array}{c}\text { Experience } \\
\text { (Positive) }\end{array}$ & $\begin{array}{c}\text { Experience } \\
\text { (Neutral or } \\
\text { Negative) }\end{array}$ \\
\hline \multirow{3}{*}{ Higher } & presentation & team & \multirow{2}{*}{$\begin{array}{l}\text { course } \\
\text { class } \\
\end{array}$} & questions & \multirow{2}{*}{$\begin{array}{l}\text { course } \\
\text { class } \\
\end{array}$} & Course \\
\hline & \multirow{2}{*}{$\begin{array}{l}\text { online meeting } \\
\text { live video } \\
\text { sessions }\end{array}$} & \multirow{2}{*}{$\begin{array}{l}\text { group } \\
\text { live video } \\
\text { session } \\
\end{array}$} & & quiz & & $\begin{array}{l}\text { amount of } \\
\text { reading }\end{array}$ \\
\hline & & & topic & exam & topic & feedback \\
\hline \multirow{4}{*}{ Mid } & \multirow{2}{*}{$\begin{array}{l}\text { weekly session } \\
\text { collaboration }\end{array}$} & \multirow[t]{4}{*}{ real world } & content & feedback & content & quiz \\
\hline & & & program & course & MSIT & canvas \\
\hline & interaction & & $\begin{array}{l}\text { digital } \\
\text { transformation }\end{array}$ & classroom & \multirow[t]{2}{*}{ everything } & assignment \\
\hline & group work & & $\begin{array}{l}\text { learning } \\
\text { experience }\end{array}$ & assignment & & instructor \\
\hline & dynamic & & & & professor & \\
\hline Lower & dynamism & & & & industry & \\
\hline
\end{tabular}

The following examines the three themes identified above with sentiment analysis to identify positive versus neutral or negative feelings to give a better understanding of their context and meaning. The table above also shows how words or phrases were ranked between higher usage of that particular word or phrase compared to the lower usage which is analyzed in the results.

Analysis of Students' Strictly Positive and Neutral/Negative Sentiments Across Learning, Engagement and Overall Class Experience

In the analysis of students' positive sentiments in learning, engagement and overall class experiences in the flipped online class, several keywords were common including "topic," "program" and "MSIT" (which is the degree program the studied classes are identified with, called the Masters of Information Technology), and "content" which all suggested positive sentiment from the observations of the students. Many of these observations were due to the activeness of the class and thus led to students' rating as one of the best in their curriculum. 
Some of the active components addressed included live presentations, live discussions and activities built into those live sessions.

In terms of topic, both from an experience and a learning aspect, these show a relevancy being taught that it is applicable to the students, and that they found the topic interesting and engaging. The topic, which refers to digital transformation (the focus area of the classes observed), is an important buzzword in the age of digitization, and this shows that not only the topic has relevancy but also that it was addressed through engagements in the class. Program (or MSIT) were another positive set of words that came up in many of the observations. Content was the third keyword, and this correlates into the necessary ingredients that build the foundations for the class. It was observed that many students see the content as useful, helping to build on prior course knowledge and capitalizing on current trends. Students also reported content delivery was very well done through the flipped classroom pedagogy. This was suggested through observations of recorded videos, documentation that would support those videos and the activities that would build from the content.

These results suggest the flipped classroom design can give an enhanced experience to the student, encouraging increased engagement and accountability, which was also identified in research (Shatto et al., 2017) as important to the student experience. Similarly, learning the major focus topic of digital transformation, the importance of what is learned, and how to analyze and apply these concepts were all identified as increasing through the flipped classroom.

In the analysis of students' neutral and/or negative perceptions in learning, engagement and overall experience in the flipped online class, several keywords and phrases identified the assessments taken by the students, including "quiz" (both in learning and experience), "questions," "exam," "feedback" and "assignment." Being that the combination of these keywords can be directly correlated to different types of deliverables, or the core of what goes into the deliverable (such as questions being in relation to a quiz question), this suggests that some issues in the way students perceived these deliverables were not optimal.

None of these require live or active participation based on the flipped classroom that allow time for in-class environments, but that the assignments or quizzes were difficult based on necessity of rote memorization of facts rather than applicability of content. This would directly relate to the strength of the flipped classroom in giving opportunities for students to utilize skills and tools they learn rather than memorizing facts and figures which are not always necessary for 
successfully applying content. In some cases, the students viewed the quizzes as "very confusing and frustrating" or that quizzes "did not capture knowledge, rather were for how closely you read an article, and if you remembered specific verbiage in certain paragraphs," which again suggests that memorization may not help or lead to applicability.

One study (Rawas et al., 2020) suggested that the flipped classroom design can increase effectiveness in an exam where cooperative learning gives responsibilities to students and can harness critical thinking and increased problem-solving skills. It could be the case that the quiz design is flawed in that it does not harness the problem-solving skills students would expect to utilize when taking the quiz. However, there is other research (Schaffzin, 2016) that suggests a flipped classroom does not lead to statistically significant differences in scoring or GPA, and rather that this could be dependent on the types of learner that may learn better in one method versus another method, even though the learning environment and engagements increase motivation and may lead to an overall enjoyable learning experience.

In analyzing these results, there is one correlation between quantifiable and qualifiable results which suggests the flipped classroom may not be as effective in areas of rote memorization used for quizzes or exams. Again, the research would need to go deeper into whether the negative perception of students' is from the quiz design or from instructional design. In this study, the student perceptions tend to suggest poor or inadequate quiz design as a neutral or negative sentiment, but that learning, engagement and overall experience of a flipped classroom are suggested as positive overall.

Correlations of Positive Versus Neutral and Negative Perceptions/Sentiments in Current Online Flipped Classroom for Engagement, Learning and Overall Experience

In the analysis of students' perceptions of positive, neutral or negative sentiment results in their engagements in the flipped online class, one distinct category of live classes surrounding the phrases "online meetings" and "live video sessions" were identified. In a positive sentiment, the students see the online live classes as an asset to their learning and engagement, including obtaining and dissecting valuable information from the discussions and activities. Students reported finding the experience different than other online classes such as those that are fully asynchronous. One student said the class "engaged me as a distance student more so than simply using a discussion board." 
Much of the positive experience stems from students' abilities to interact with peers and instructors, and to have control over the video recording of the session (Yilmaz, 2015) which gives added flexibility and increases abilities to consume class content at any time. Some of the neutral or negative experiences with live sessions involved the time of the class, the need to have more flexibility to attend a live class, audio/video quality issues, or technology issues that disrupted the flow of learning such as freezing of live streaming, slow or jittery audio or failure to connect.

Being that technology was one of the most commonly identified problems with the classes, suggests the flipped classroom design wasn't a significant part of the neutral or negative results, and that if the technology can be improved, the class itself may receive positive reviews. Similar experiences are identified in prior research (Abakumova et al., 2019; Mahmood et al., 2012) which underlines the importance of the teacher's role in the learning environment, specifically with the understanding and use of combined independent and cooperative technologies that can hinder student experiences in live sessions if not properly deployed. Flexibility is also a challenge when students are used to an asynchronous mode of content delivery. In general, the perceptions of online education are that they are asynchronous only, and that dependent on the demographic of the student (younger versus older), they could have differing roles and responsibilities outside of the classroom that could create or hinder their class time flexibility (Rafiq et al., 2014). Combining the results of these areas helps to define the potential explanation for neutral or negative sentiment with taking a live class as most students in the MSIT program tend to be older, full-time employees that have to make time for class.

The flipped classroom design has many positives in areas critical to student development and experience. The design allows students increased visibility to content in new ways from live interactions, as well as with their peers and instructors. It also suggests that positive new experiences and a better connection to the class as well as the school take place through the flipped classroom. The neutral or negative issues tended to gravitate toward problems in technology and lack of flexibility in the live sessions, but not directly related to the flipped classroom design itself.

In the analysis of students' perceptions of positive and neutral or negative sentiment in learning perceptions in the flipped online class, two similar keywords of "course" and "class" were identified. The positively identified words were found in correlation to enjoying the 
content, liking the positive dynamics of the content, and finding the course very interesting or useful. One student noted the "content and materials of this course were superior than the one found in previous" courses. Another student said it was the "best class in their MSIT-ISM experience." Another said "I really enjoyed this course and the tie-in to current events and searching the web for support materials for the case studies, discussions and presentations." The combination of these sentiments suggests a direct correlation to the flipped classroom, allowing for more class time for presenting and discussion, as well as activities within the class. Another comment stated, "Great course, loved the dynamism and interaction of live sessions". Or another, "keep up the live courses, those are unique to this program." Prior research shows that cognitive interest and the desire to learn new things increases with active learning in online education, as well as with individual motivations which can be viewed as very independent in distance learners (Abakumova et al., 2019), but can be modified to increase positive emotional beliefs and learning outcomes with increases in engaging activities (J. S. Jeong et al., 2019).

From an analysis of sentiments that have a neutral or negative perception, one strongly identified keyword or phrase was "recording quality," with one student noting differences in the class recordings as compared to what they had experienced in other professional online courses such as those by Coursera. Another student said it was "impossible to hear the comments made by students during class on the videos of the lectures so some of the content was lost when class discussion was encouraged." Another student said it "took us five weeks into the course to locate the instructor's feedback, because it was not published on Canvas on time," identifying there may have been issues with the distance mechanisms used to host the class in some of the synchronous as well as asynchronous content.

Other issues identified through results were around the focus of the course, lack of interesting topics or a desire to complete coursework individually instead of with teams. Technology issues introduce new sources of potential problems, especially more so with increased reliance on the technology and the limitations of such. There is not a one-size-fits-all solution for educational delivery, so instructors tend to rely on multiple platforms and tools to deliver course content. This can cause disconnects and compatibility issues that in many cases can only be remedied with practice and repeated use to build comfort with technology in class environments. This still does not eliminate the potential for issues, rather only helps to remediate them. 
Some of the students' comments around focus and precision can be attributed to the inherent subjectivity in the course content, the dichotomous team debate approach, and how individuals approach these types of environments and the dynamic problems within materials of subjective nature. Prior research (Woods, 2020) shows that information technology (IT) or information science (IS) focused classes, such as the ones analyzed for this research study, tend to have positive learning effects through successful use of debates which lead to greater intrinsic motivations of the students, higher confidence in knowledge and use of the material, as well as a change of pace from written submissions. There were plenty of examples of positive reinforcement in this study to show greater learning outcomes and successful applications of dichotomous debating to experiential settings. Research (Dy-Boarman et al., 2018) has also shown these types of approaches are conducive to learning, however subjective materials and open-endedness of cases that students are tasked with engaging and solving do not always work for all types of learners. In one example, individuals that tend to be quieter and more reserved may not absorb as much information from these types of active learning environments as those that actively participate. Also, ineffectiveness in learning could be attributed to poor or inadequate preparation for a debate or live activity (Hawkins et al., 2019). However, this does go back to the premise of this study in which those that embrace the class opportunities afforded through the flipped classroom can increase their learning through these increased class engagements.

To conclude, the results of the study suggest that the positive results from the flipped classroom design were very supportive to the overall engagement, learning and experience in the classes which were observed as unique, lively and gave students a more overall engaged feeling in the class. The neutral or negative issues tended to be very similar to neutral or negative engagement experiences that were mostly driven by technology-related areas, and not directly related to the flipped classroom. A second theme that was apparent from the results was class content related, which can be addressed from the method of class pedagogy design but can continue to be enhanced through the flipped classroom based on the key factors listed above. The major takeaways here are that the flipped classroom design resulted in more positive outcomes than neutral or negative outcomes for what the students perceived to have learned in the class.

Lastly, from an analysis of sentiments that showed a positive, neutral or negative outcome in overall experience perceptions in the flipped online class, several key words or 
phrases were identified including "content," "amount of reading (as correlated to content)," "course," "class," "professor" and "instructor." Interestingly, in the key words or phrases identified in the analysis, there were many dichotomous or conflicting results that warranted further investigation. The following examines these results further to better understand the differences in the results.

In analyzing sentiment around "content" and "amount of reading" (amount of content to read), the students reported varying degrees in their workloads. Some felt it was light, such as one student stating "the course can be made more rigorous. I felt it was light compared to the other course I am taking," or that "the content and materials of this course was superior than the one found in previous." In looking at the lightness of workload compared to their other classes, it can be stated that research (Gross et al., 2015) has shown that some approaches to flipping the classrooms can reduce cramming and tend to have more accurate submissions which can make this course seem lighter as students are more prepared. Generally, the overall sentiment observed was that the content was good and just about right in terms of weight. This is an especially important component to examine in the class as the work weight can become heavier with lecture content moved outside of the normal class, while addition of activities within the class based on the flipped classroom design take up most or all of the normal time that would be dedicated to reviewing that content. Research (Bouwmeester et al., 2019) has shown that a heavier workload in a flipped classroom leads to decreased time commitments in final assignment or exam preparations, but that student habits and study patterns may need to adapt to the differing approach to improve their chances of success.

On the contrary, other students felt that the workload increase from flipping the class was very heavy, such as another student stating the "content was useful, however, most of the readings required extra hours" or that "the amount of reading coupled with the constant group work created a lot of work to keep up with during the week." Some of the other feedback was around the use of the readings for the end-of-week assessments which they felt were created for rote memorization of content and were "wildly difficult." Shortcomings in the assessments have been addressed in this study, however, the content given to the flipped versus non-flipped students is still the same and content alone would not dictate between success and failure of the student, however motivations and approaches in the differing instructional designs can still have indirect effects. This can then go back to the type of student in this study, which includes 
working and part-time students who also perceive more demands from online instruction. Other research (Tune et al., 2013; van Alten et al., 2019) has shown that with online instruction the effects of perceived and/or actual time commitment increases when using a flipped classroom design, and this aligns with some of the neutral or negatively perceived results observed from this study.

To conclude, the results suggest the flipped classroom design created positive sentiment from the students as the classes were viewed as balanced between workload and their perceptions of the workload. The neutral or negative issues focused on earlier identified areas such as quiz and/or assessment design based on rote memorization of readings, or increased perceptions of the workload, however these areas can be modified by design without major change to the flipped classroom design, the use of which this study supports. The major takeaways here are that the flipped classroom contributed much more to positive than neutral or negative outcomes for student perceptions in the overall classroom experience.

\section{Conclusions: $R Q 2$}

In conclusion, the objective of the research question is to look at the effects of the flipped classroom on engagement, examining observations of effects through student results that affect their perceived learning, areas of engagement and overall experience in the classes. Results of the analysis will have one of three sentiments. The first sentiment regards negative results that in some way adversely affected the students' learning or engagements. The second sentiment regards results that were observed as neutral, which didn't have an effect on engagement experience either positively or negatively but show that engagements took place. The third sentiment was that the experiences were deemed as having a positive effect on the students' perceptions of engagement. The following figure shows percentages of the reported observations for the three sentiments which gives a clear view of the amount of overall positive, neutral and negative results from the student's observed engagements, learning and overall experiences. 


\section{Figure 47}

Percentage of perceived sentiments across the three categories

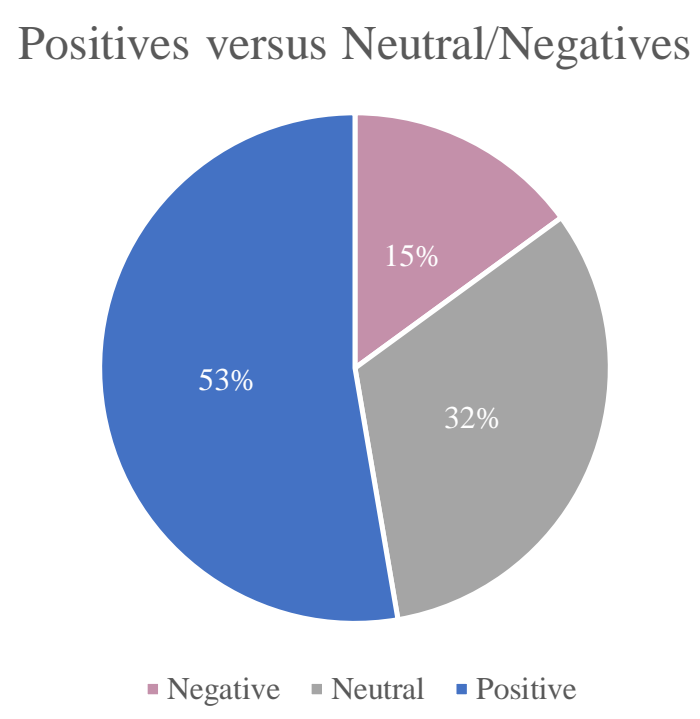

In looking at this chart, you can see that most of the students (85\% overall) show similar or greater value in their learning, engagement and experience with only a small percentage (15\%) showing a negative sentiment. In-class observations of activities did not result in anything that could be deemed as negatively impacting the overall class goals, but were shown to have increased positive effects, such as some students stating "Most of the activities really made me think out of the box and at the end of the course," or "The presentation format of two presentations from opposite points of view was interesting." The results suggest the activities, regardless of whether they were viewed as equal as or better than other class engagement experiences, generally foster increasing engagements. As well, having more class time with the flipped classroom design also allows for the deeper thinking activities, as noted by one student, "weekly online presentations done by two teams where each one defends opposite points of view about the topic selected. In this way, critical thinking and analysis is fostered." Students involved in activities felt like they had a better grasp of the material through increased and longer engagements, which ultimately lead to better experiences and stronger feelings through confidence in the class materials. 


\section{Correlations Between RQ1 Learning and RQ2 Engagement Findings}

From both a learning and engagement perspective, this study was able to support success of the flipped classroom design with online mechanisms which aligns with other study results about utilization of an online flipped classroom (AlJarrah et al., 2018; Y. Chen et al., 2014; Knapp, 2018; Lin et al., 2019; Phillips \& O'Flaherty, 2019; Romero et al., 2019; M. Tseng et al., 2018; Van Wyk, 2019; F. H. Wang, 2017). An overall view of results from the data collection is shown in the following table and looks to support the instructional design that shows the greater outcome.

\section{Table 48}

Overall correlations and comparisons of the research questions

Observation

Observable Component

Instructional

Design:

Greatest

Outcome

\section{RQ1:}

Grade Point Average (GPA) of each student

Assessment scores of each student

\author{
Observed/Adjusted Mean \\ ANCOVA
}

Assessment 1

Assessment 2

Assessment 3

Assessment 4

Assessment 5

Observed/Adjusted Mean

ANCOVA
Traditional

Traditional

Traditional

Traditional

Traditional

Flipped

Traditional

Traditional

Traditional
Pre- and post-test scores of each student
Pretest (Observed/Adjusted Mean)

Pretest (ANCOVA)

Post-test (Observed/Adjusted Mean)

Post-test (ANCOVA)

Combined Change (Observed/Adjusted Mean)

Combined Change (ANCOVA)
Flipped

Flipped

Flipped

Flipped

Flipped

Flipped 
Instructional

Design:

Greatest

Outcome

\section{RQ2:}

Engagement survey assessment of each student (comparing

distance to distance)

Comparing flipped to other active

Flipped

Comparing flipped to other passive

Flipped

Engagement survey assessment

Comparing flipped to other active

Flipped

of each student (comparing

distance to traditional)

Comparing flipped to other passive

Flipped

Observations of Engagement (Through FCE, communications and observations)

\section{Average of percentages of:}

Engagement Learning

Overall experience
Flipped

Flipped

As identified in the analysis, the perceptions of engagement results supported the flipped classroom design as the most effective for online students. This is in comparison to both the traditional, in-person style of lecture-based instructional design, and whether those classes incorporated some type of active learning. Correlating this to learning, one can see the flipped classroom was rated highly in perceived learning, and more importantly, overall GPA of the student. The one area that was identified as less supportive to the results were in the assessments, where the traditional, in-person lecture style seemed to fare better. More research would need to be done to draw more concise conclusions on why assessment taking was not as favorable in the flipped classroom setting, however several plausible areas were identified, including structure and the type of content needing to be memorized to take the assessments. Interestingly, the negative effects of the assessments did not reduce the overall GPA for the flipped classroom student, which suggests that activities utilizing course content rather than rote knowledge used for the assessment can help student success.

From this study, you can see that creating the course with an effective flipped classroom strategy may be the biggest challenge, particularly in assessing which types of activities work 
well and which may not. Secondly, ensuring adequate assessment criteria can help lead to better effectiveness of student results, which is not solely reliant on the instructional design but also from a pedagogical approach. Lastly, having effective modes of engagement through activities to create better experiences for students can be critical in increasing positive results as well as positive perceptions in learning, engagement and overall experiences through the flipped classroom.

\section{Limitations of the Study}

Although this study has taken steps to mitigate internal and external validity issues, there can still be potential issues in terms of the evaluation of the students' experience in the flipped classroom. It's important to note this research was performed in real-time through actual courses taught through eight different semesters and 21/2 years of observations. Keeping a more controlled environment reduces the amount of validity issues but it also can reduce the degree of generalizations outside of that environment. In regard to addressing these issues, this study has identified the major limitations and has determined ways to remediate those issues through the students observed, the courses used and the technology that is used by both students and instructor.

The students were selected based on criteria identified in the introduction. Although the demographics of the students vary depending on nationality, age, sex and location, the study could have further reach into underrepresented cultures and socioeconomic classes to determine if there are differences in perceptions and outcomes. Students are also from specified educational backgrounds and current study paths, as well as from a specific school and college which limits the participant pool. A better understanding of the flipped classroom design in different learning paths (different types of classes, degree programs, institutions) could strengthen the results. Finally switching replications of the independent variable (IV) between groups could show changes in learning and engagements between the two IV types.

This study was restricted to one type of class, which is a STEM-based course and is further limited to students who must meet certain prerequisites to take the course. Further research would look to re-run this study across different types of courses in different major concentrations that would offer potential for a wider range of students that can build better understanding of the research questions posed in this study. 
Technology usage can also be a limitation due to the differences in how one might experience their learning through an identified type of tool or platform, particularly in a naturalized state of the classes observed in this study. Limitations are two-fold; from one side, the learner can choose their technology to a varying degree, such as document management, social media platforms (YouTube for MOOCs, Facebook for group chats) or settings changes within platforms for enhancements (such as alerts). From the instructor side, technology is limited to several areas such as the learning management system (Canvas) and the meeting technology (Zoom), however using Blackboard for the learning management system or Adobe Connect for video meetings could result in changes to the outcomes. It may be worth reviewing these technologies in future studies to see if there is an effect on the learning and engagement outcomes.

It should also be mentioned that as of 2018, there were over 6,600 degree-granting institutions of higher education in the United States alone, enrolling over 20 million students and being taught by over 1.4 million instructors (Snyder et al., 2019). The students and focus school used for this study reach only a small sample of the overall opportunities in higher education that could be used. As well, education technology companies range across hundreds of types and many different concentrations which can bring with them proprietary nuances that may have differing effects. Finally, if the classes have differing objectives and/or potential outcomes or are taught in different ways, results could vary. Any changes mentioned previously would allow for investigating student changes in learning and engagement in the flipped classroom design for future studies.

It's also important to note that this study spans many months, semesters, classes and students, all of which can bring different challenges. For example, an examination of traditional versus online education (Shachar, 2008) shows that the ability to have conclusive results in comparison studies is difficult due to the vast topics, environments, measurements, research methods, treatments and types of students. Though the premise of this study is to validate the use of a flipped classroom approach with online mechanisms and has shown to be supportive of positive learning and engagement outcomes in this regard, it can also invalidate other research, and as such, further studies should be conducted to learn more about the applicability regarding such settings and other criteria previously addressed. 


\section{Recommendations for Future Research}

This study could not have come at a more important time to understand the implications of teaching through online mechanisms, as we are currently faced with a growing pandemic through the spread of the COVID-19 virus across the globe. The United Nations Educational, Scientific and Cultural Organization (UNESCO) reports approximately 1.2 billion displaced or affected learners, making up approximately $68 \%$ of all learners worldwide (Atchoarena, 2020) from impacts caused by the pandemic. With this pandemic requiring social distancing measures including the shutting down of many public locations and schools, all students have had to adopt and adapt to many of the different tools and technologies to migrate their learning experiences to online mechanisms and at a very rapid pace. Instructors have had to quickly apply those technologies to instructional designs to provide a learning experience to students who were, in many cases, expecting to take their classes in-person from the essential learning element of the "rock star professor on the stage" (O’Malley \& McCraw, 1999), and instead are taking them from a distance or not at all.

\section{Impacts of COVID-19 and Correlations to Shifts from In-Person to Online Classes}

During the course of this study came an impact the world could not have imagined, where quarantining and social distancing became the norm. With this came a substantial change in the final semester of this study, requiring students to decide on whether to take the digital transformation class remote over the summer, in keeping with their current curriculum trajectory, or to delay summer classes and take them in the fall. Those that decided to take classes over the summer at a distance were also evaluated for this study, however, because there was such a dramatic shift to those students, they were not included in the data collection.

In this case, it was still of interest to collect and analyze the data that would be available from the small sample size of students $\mathrm{n}(9)$ to draw some comparisons and conclusions with those that expected to take a class in the traditional, in-person lecture style and then changed to the online flipped classroom.

\section{Impacts of COVID-19-Quantitative Results}

The following table shows the comparisons of the COVID-19 affected cohort, called the "Traditional to Distance Flipped" (T2DF) students to the earlier samples. 
Table 49

Comparing learning results between T2DF and traditional/flipped instructional design

\begin{tabular}{|c|c|c|c|}
\hline Observation & $\begin{array}{l}\text { Observable } \\
\text { component: } \\
\text { Average and } \\
\text { Independent } \\
\text { Samples t-test }\end{array}$ & Results & $\begin{array}{l}\text { Instructional Design: } \\
\text { Greatest Outcome }\end{array}$ \\
\hline $\begin{array}{l}\text { Grade Point } \\
\text { Average (GPA) of } \\
\text { each student }\end{array}$ & Average of & $\begin{array}{c}90.46 \text { (Traditional) } \\
90.59 \text { (Flipped) } \\
91.86 \text { (TradtoDistanceFlipped) }\end{array}$ & $\mathrm{T} 2 \mathrm{DF}$ \\
\hline & $\begin{array}{l}\text { Independent } \\
\text { Samples t-test }\end{array}$ & $\begin{array}{l}+.126 \text { (Flipped versus Trad) } \\
+1.396 \text { (T2DF versus Trad) } \\
+1.269 \text { (T2DF versus Flipped) }\end{array}$ & $\begin{array}{l}\text { Flipped } \\
\text { T2DF } \\
\text { T2DF }\end{array}$ \\
\hline $\begin{array}{l}\text { Assessment } \\
\text { scores of each } \\
\text { student }\end{array}$ & $\begin{array}{c}\text { Averages: } \\
\text { Assessment } 1 \\
\text { Assessment } 2 \\
\text { Assessment } 3 \\
\text { Assessment } 4 \\
\text { Assessment } 5 \\
\text { Total Averages }\end{array}$ & $\begin{array}{c}\text { (T2DF, Flip, Trad) } \\
(66.42,65,88.44) \\
(52.63,56.83,82.88) \\
(72.29,65.04,84.85) \\
(80.69,70.61,72) \\
(74.58,71.77,82.25) \\
(69.32,65.85,82.08)\end{array}$ & $\begin{array}{l}\text { Traditional } \\
\text { Traditional } \\
\text { Traditional } \\
\text { T2DF } \\
\text { Traditional } \\
\text { Traditional }\end{array}$ \\
\hline \multirow{4}{*}{$\begin{array}{l}\text { Pre- and post-test } \\
\text { scores of each } \\
\text { student }\end{array}$} & $\begin{array}{l}\text { Independent } \\
\text { Samples t-test }\end{array}$ & $\begin{array}{l}\text {-16.23 (Flipped versus Trad) } \\
\text {-12.76 (T2DF versus Trad) } \\
+3.47 \text { (T2DF versus Flipped) }\end{array}$ & $\begin{array}{l}\text { Traditional } \\
\text { Traditional } \\
\text { T2DF }\end{array}$ \\
\hline & $\begin{array}{l}\text { Averages: } \\
\text { Pretest } \\
\text { Pretest (t-test) }\end{array}$ & $\begin{array}{c}\text { (T2DF, Flip, Trad) } \\
\text { (52.67, 65.35, 60.19) } \\
+5.154 \text { (Flipped versus Trad) } \\
-0.75 \text { (T2DF versus Trad) } \\
-1.27 \text { (T2DF versus Flipped) }\end{array}$ & $\begin{array}{l}\text { Flipped } \\
\text { Flipped } \\
\text { Traditional } \\
\text { Flipped }\end{array}$ \\
\hline & $\begin{array}{l}\text { Posttest (avg) } \\
\text { Posttest (t-test) }\end{array}$ & $\begin{array}{c}(82.89,89,81,76.27) \\
+13.54 \text { (Flipped versus Trad) } \\
+0.66 \text { (T2DF versus Trad) } \\
-0.72 \text { (T2DF versus Flipped) }\end{array}$ & $\begin{array}{l}\text { Flipped } \\
\text { Flipped } \\
\text { T2DF } \\
\text { Flipped }\end{array}$ \\
\hline & $\begin{array}{l}\text { Combined Change } \\
\text { (avg) } \\
\text { Combined Change } \\
\text { (t-test) }\end{array}$ & $\begin{array}{l}\quad(30.22,24.46,16.08) \\
+13.538 \text { (Flipped versus Trad) } \\
+14.15 \text { (T2DF versus Trad) } \\
+5.76 \text { (T2DF versus Flipped) }\end{array}$ & $\begin{array}{l}\text { T2DR } \\
\text { Flipped } \\
\text { T2DR } \\
\text { T2DR }\end{array}$ \\
\hline
\end{tabular}


Interestingly, the GPA results saw an increase for the "traditional to distance flipped" students, which supports the students that shifted from a traditional, in-person lecture-style of course taking to the flipped online design. Those students seemingly fared better than the students that were taking fully distance classes and the students taking the traditional classes. The assessment scores, however, show a better outcome for the traditional students (though the traditional to distance flipped students show an increase over the other two for the fourth assessment, which before showed an increase for the flipped students). This is interesting as it shows that the T2DF students' results were in line with the original analysis, and still showing the flipped instructional design supporting a more positive outcome for the same assessment (\#4), and more negative outcome for the other four assessments. Finally, the pre- and post-test analysis shows that the T2DF students perceived their learning to be more positive from their experiences in the class. This is a very important statistic as it shows that learning was perceived to be lower (according to the pretest), and ended up lower (according to the post-test), but there was a dramatic change in terms of the overall learning (pre to post). In all cases, the traditional students fared worse than both the flipped and the T2DF students.

\section{Impacts of COVID-19 - Qualitative Results}

In looking at engagement experiences for the T2DF students, the following table shows comparisons of the COVID-affected cohort compared to the earlier samples of traditional, inperson lecture-based classes as well as the online flipped classroom design. All students had taken prior online classes, and all but one student mentioned that their prior classes had also included some type of active learning or active component. 


\section{Table 50}

Comparing engagement results between T2DF and traditional/flipped instructional design

\begin{tabular}{|c|c|c|c|}
\hline Observation & $\begin{array}{c}\text { Observable Component: } \\
\text { Averages of flipped versus } \\
\text { active/passive }\end{array}$ & $\begin{array}{l}\text { Results (Less, } \\
\text { Same, More } \\
\text { Engaging) } \\
\text { (percentages) }\end{array}$ & $\begin{array}{l}\text { Instructional Design: } \\
\text { Greatest Outcome }\end{array}$ \\
\hline \multirow{2}{*}{$\begin{array}{l}\text { Engagement } \\
\text { survey assessment } \\
\text { of each student } \\
\text { (comparing } \\
\text { distance to } \\
\text { distance) }\end{array}$} & $\begin{array}{l}\text { Average of Q.'s } 1,3,5,7 \\
\text { (flipped to active) } \\
\text { (T2DF to active) }\end{array}$ & $\begin{array}{c}\text { Flipped } \\
(0 \%, 33 \%, 67 \%) \\
\text { T2DF } \\
(6 \%, 56 \%, 39 \%)\end{array}$ & Flipped/T2DF \\
\hline & $\begin{array}{l}\text { Average of Q.'s } 2,4,6,8 \\
\text { (flipped to passive) } \\
\text { (T2DF to passive) }\end{array}$ & $\begin{array}{c}\text { Flipped } \\
(0 \%, 22 \%, 78 \%) \\
\text { T2DF } \\
(22 \%, 22 \%, 56 \%)\end{array}$ & Flipped/T2DF \\
\hline \multirow{2}{*}{$\begin{array}{l}\text { Engagement } \\
\text { survey assessment } \\
\text { of each student } \\
\text { (comparing } \\
\text { distance to } \\
\text { traditional) }\end{array}$} & $\begin{array}{l}\text { Averages of Q.'s 1, 3, 5, } 7 \\
\text { (flipped versus active) } \\
\text { (T2DF versus active) }\end{array}$ & $\begin{array}{c}(27 \%, 43 \%, 30 \%) \\
(64 \%, 33 \%, 3 \%) \\
(11 \%, 40 \%, 49 \%)\end{array}$ & Flipped/In-Person \\
\hline & $\begin{array}{l}\text { Averages of Q. 2, 4, 6, } 8 \\
\text { (flipped versus passive) }\end{array}$ & $(39 \%, 28 \%, 22 \%)$ & Flipped/T2DF \\
\hline
\end{tabular}

These results show that engagement experiences for the online flipped classroom compared to the T2DF cohort are much more numerous than those experiences garnered through prior online classes as well as the traditional in-person classes. One difference to note from the earlier findings is that the in-person style of instructional design rated higher in engagement than the T2DF cohort, which was not the case in comparing flipped instructional design to the inperson design. If this is the case, the transition from an in-person class to distance class could create a more dramatic effect than the effect based on prior experiences.

The table below shows the results from observations that would garner one of three types of engagement perceptions: negative, neutral or positive based on the observations of the students in the T2DF cohort classroom, as well as their feedback shared. 


\section{Table 51}

Comparing engagement results between traditional and flipped instructional design through observations

\begin{tabular}{lccc}
\hline Observation & $\begin{array}{c}\text { Observable Component: } \\
\text { Averages of flipped } \\
\text { versus active/passive }\end{array}$ & $\begin{array}{c}\text { Results (Negative, } \\
\text { Neutral, Positive) n(\%) }\end{array}$ & $\begin{array}{c}\text { Instructional Design: } \\
\text { Greatest Outcome }\end{array}$ \\
\hline $\begin{array}{l}\text { Observations of } \\
\text { engagement } \\
\text { (through FCE, } \\
\begin{array}{l}\text { communications, } \\
\text { observations) }\end{array}\end{array}$ & $\begin{array}{l}\text { Average of percentages of } \\
\text { engagement, learning, and } \\
\text { overall experience }\end{array}$ & $\begin{array}{c}\text { Flipped } \\
(16 \%, 33.66 \%, 50.33 \%)\end{array}$ & T2DF \\
\hline
\end{tabular}

Much like the prior flipped classroom experiences, the T2DF cohort also seemed to experience similar engagements, learning and experiences when moved to the online classroom that incorporated a flipped instructional design. In fact, the ratings were generally neutral or positive, with very few negative experiences reported. The primary reasoning identified for a negative experience seemed to be based more on the experiences of not being in-person, with one student writing that "online streaming/distance learning is a really, really poor proxy for inperson education. Overall experience across all classes was negative. No matter how educators put it, there is no comparison between the two modes of teaching." In this regard, even more class time with active engagements in the class did not substitute for the in-person experience, even if the activities were similar.

However, there were plenty of positive experiences, engagements and feelings of increased learning in this environment. In looking at the following figure examining student sentiment in a word cloud of the three criteria of learning, engagement and overall experience, there are several keywords that show support of the flipped classroom. 


\section{Figure 48}

Examining positive keyword phrasing for learning, engagement and experiences in T2DF students

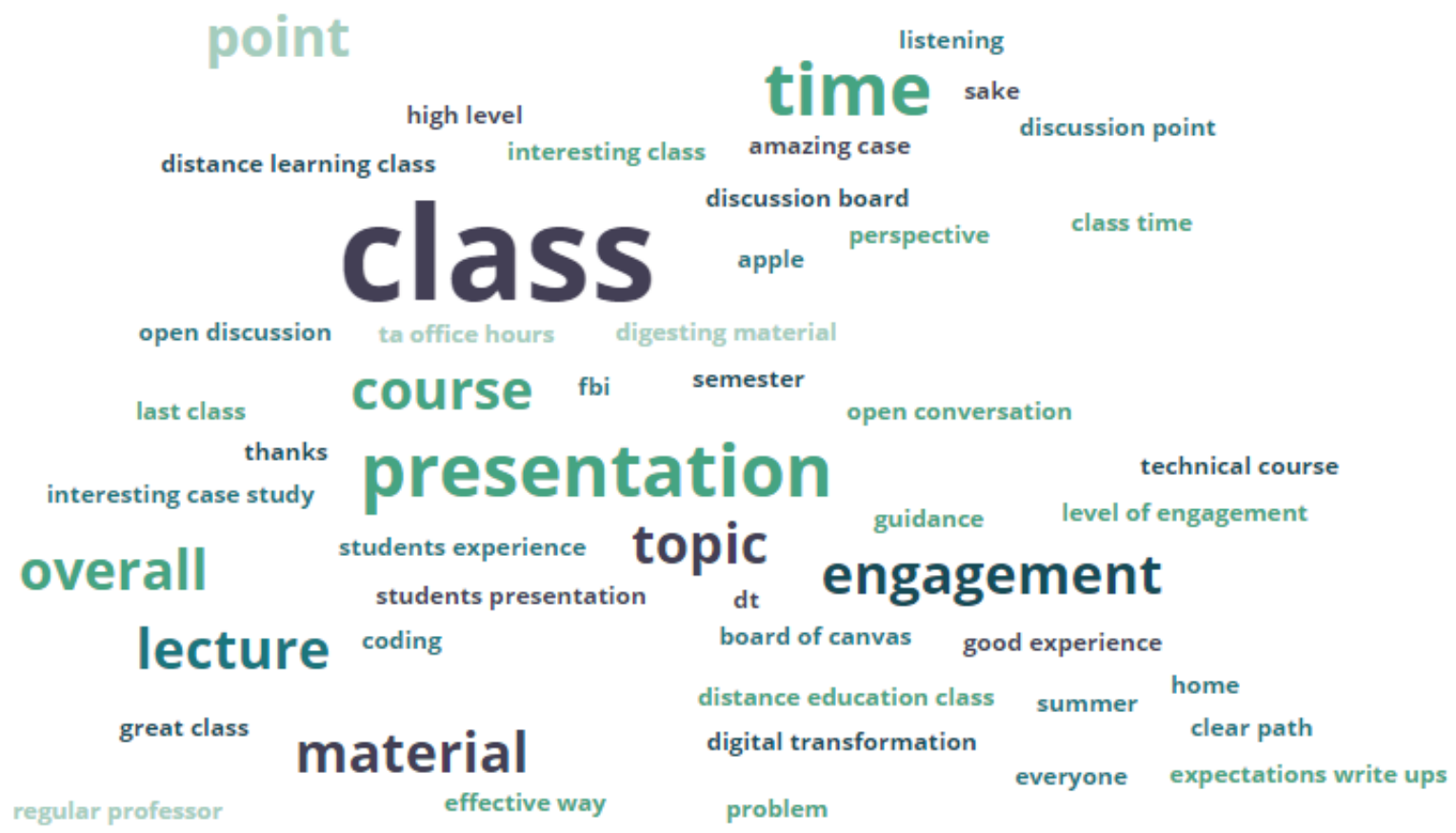

One correlation to positive support was identified in the presentation activities. Students felt that having team or group work allowed for more time to actively work with the content and projects. This is promoted through giving more class time to interactive projects such as debates and presentations from teams to show their perceptions of the work. One example of this was in one student stating they "felt like in the last class on Apple v. FBI, we had more of this open discussion and it was interesting to hear everyone's perspective, separate from strictly the position they were assigned to represent for the sake of the presentation." Opening up class time to allow for more interaction between all students in the class seems to raise interest among the students as well as increase their mastery of the class content.

The last figure shows a breakdown of the three criteria in classroom engagements, learning and overall experience to illustrate how each were balanced in the observable feedback. 


\section{Figure 49}

Three charts showing engagement, learning and experience sentiments of T2DF students

\begin{tabular}{|l|l|}
\hline $\begin{array}{c}\text { Classroom } \\
\text { Engagements }\end{array}$ & $\begin{array}{c}\text { Classroom } \\
\text { Learning }\end{array}$ \\
\hline
\end{tabular}

With the data and analysis supporting a positive experience through the use of a flipped classroom, there may be opportunity in evolving current and future distance courses into the flipped classroom design for similar research, and especially in times of dramatic shifts such as the current pandemic. This may also prove to be beneficial in application during other life experiences that might shift the learning to a different modality without the student's full control over these situations. Further studies of these challenges could bring to light areas that could be addressed for creating a more transparent and smooth transition to different learning environments that are unexpected, as well as address access to education and challenges of that access in a digital era (Chander, 2020). This could include issues that would directly affect online education needs for students that are affected by broadband access and connectivity issues. House bill "H.R. 6814 - Supporting Connectivity for Higher Education Students in Need Act," from 2020 aimed to address a current lack of adequate technology access during national emergencies, much like what we experienced during the COVID-19 pandemic.

\section{Other Future Research Opportunities}

This study was conducted to create a springboard into further study of applying the flipped classroom designs to online classes to increase engagement and learning. Secondly, if online distance education can be proven to show increases in learning as well as increases in 
positive engagements and experiences of students through quality assessments (objective and subjective), this may minimize resistance and negative perceptions of online education as a replacement medium for delivering course content. Third, there is an extreme importance and need for educators as well as administrators to be cognizant of digital disruption to our educational systems. Online education has been thrust to the forefront during the COVID pandemic, with teachers in pre- and post-secondary education having been forced into roles they were not necessarily comfortable with. As well, students have shown negative results through a loss of a third of their expected progress, and in some cases, have fallen behind almost a full academic year (Goldstein, 2020). Research in online education and flipped classroom application such as this can never be considered complete and rather should be considered as ongoing due to the ever-changing needs of society as well as how technology impacts how we do and perform within the areas of education.

Future recommendations for research are myriad, and include several areas that could be explored, including passive asynchronous methods that can work positively in tandem with active methods, examination of current and future technologies, the types of learners examined, the components of a classroom, the types of content being studied, and examining all the criteria listed in differing combinations to analyze whether there might be other criteria affecting learning and engagement.

In looking at active versus passive instructional designs, having a solid understanding of the types of pedagogical and technical content that work best should be include a continual search for combinations that lead to optimal results. Studies can examine readings, videos, activities and other synchronous and asynchronous components. Material types can also vary between the concentration areas. For example, the online flipped classroom may work great for a programming class in Python but may not work as well for an anatomy class that requires live dissection. Or another example would be that a class of 20 students may have much greater engagement experiences as compared to a class of 250 students. As technology continues to evolve and bridge the gaps between the physical and digital worlds, research will continue to find the harmonious balance of application of that technology through passive and active modes of instruction. Looking at asynchronous and passive methods of instructional design specifically, there is a need for future research to understand the effectiveness of this mode of instructional design and delivery and its positive or negative impacts. There can be synergies in utilizing 
passive modes to enhance material for the flipped classroom for supporting positive learning experiences and engagements.

Examining digital transformations and technologies used within and outside of the classroom are extremely important to the overall shifting landscape of instructional design and education in its entirety. Research on platforms for learning, where no two platforms are alike, can point out similarities as well as differences in how students and instructors adapt and adopt them for their educational experiences. Researching how active learning instructional designs, such as the flipped classroom, may work for or against the learning and engagement outcomes can be further and continually examined in some of the many areas identified in the limitations section of this study, as well as exterior technologies that can connect learner to content and to the instructor responsible for the experience. These can include mobile device platforms, which become increasingly common among newer generations of students (Generation Y, Z and Alpha) as many day-to-day activities and actions become digitized and introduce more interest in mobile devices as the go-to platform for their educational needs. Social media has such an impact on current generations and is expected to continue through future generations. Tying social media into education is becoming more commonplace and may have other effects that should be further explored. As well, having a solid understanding of those that may be technology-agnostic or "under-teched" can be examined to determine how those students may adopt these types of instructional designs, particularly across technologies that could be difficult to access or use.

Having an understanding and better analysis of different types of students and how they can be affected by learning and engagement is also recommended for future research. These differences can include the types of areas and concentrations being learned and demographics (race, gender, age, socio-economic, etc.) that can affect learning and engagement through a flipped classroom and most pointedly, with the live activities that are presented in these types of instructional models.

Looking at the different types of content and topics across subjects that can affect learning and engagement in a classroom would also be very useful for understanding how flipped classrooms in online education can work in these areas. Understanding whether topics or content within those topics will be easily mimicked or enhanced through flipped versus traditional instructional design in online education would be of interest for future research. 
Finally, application and research of effects from varying combinations of the above future research areas would be ideal to understand the nature of what can work versus what may need to be improved. There are myriad touch points within the life cycle of the educational experience for a student as well as the instructor. Others that can also be considered and included are the type of university the study uses for data collection and analysis, or the instructors in what might be very differing ways of teaching. This is not to say that the findings in this study could not be replicated, but that similar data collection and analysis procedures could be employed to measure potential differences across those topics that might allow for interesting explorations.

\section{Implications, Lessons and Suggestions}

Much was learned through this study in terms of how students learn, engage, experience and react to the differences in instruction models. Some of the areas of learning identified through this study include how the students in an online flipped classroom do not show a major difference in abilities to learn compared to the traditional, in-person, lecture-based classes that students might take. Results from this study suggest learning can be equally applied in either modality and in some cases, increase through the flipped classroom. Secondly, learning may not be directly correlated to rote memorization (e.g., for quiz prep). As shown in this study, even though students might approach quizzes differently or have differing outcomes, the general outcome for learning does not change dramatically between the two. This is shown even though traditional classes may increase rote memory and thus show increases in test outcomes. Much of this may have to do with these outcomes including how students approach bonus versus highstakes assessments and the environments that may affect test motivations (traditional learning vs. distance learning). There may also be nonexistent synergies between activities and quiz taking showing that regardless of how well you might do on an assignment or activity, the type of learning that takes place may not apply to the testing. In this regard, it may be of importance to the instructor in deciding what they feel may be the most important takeaways from the class between rote memorization and applicability of content.

This results of this study have also suggested that activities based on content may increase long-term applicability and give students more confidence in their learning. This can be achieved both individually and in group work, however, a balance between team-based learning 
and individual tasks may better enhance the overall experience for the student. This study has also supported the flipped classroom as a model that can promote increased activity in place of passive content dissemination through skills obtained via passive pre-learning such as watching prerecorded lectures, asynchronous activities on a learning management system or through other readings and materials. What the research shows is that in applying the normally outside-of-class assignments through live interactions and activities in the synchronous in-class session, students can build from the pre-learning as well as encourage increase engagement experiences that the results of this study have supported. This is in contrast to results from an in-person and online class that do not support active or live participation which reported less positive results.

Even though team-based learning has many benefits as outlined in this study, there are also potential challenges that must be considered, including students being in different time zones, potential conflicts in work schedules, as well as other criteria that are outside of the control of the classroom which could include family, hobbies or other obligations.

Greater procedural knowledge in this study was pointed out as being one of the strengths of a flipped classroom, which has been shown in traditional classrooms, can also incorporate both formative and summative assessments similarly to other instructional design models. One area of importance includes the potential need to distinguish between and consider both formative and summative classroom evaluation methods to determine what works best. Dependent on the specific case or need from the evaluation of a student's aptitude, this could be through an examination to test knowledge of the content, or it could be a summation project looking at applicability of important areas of class content.

Another interesting implication from the study was in how students react to a culmination of knowledge through engagements with their peers within and outside of the classroom. Regardless of whether students agree or disagree with other students in some materials that can have more subjectivity to them, these increased engagements supported higher critical thinking skills and lowered reliance specifically on self-guidance. Also, increasing the face-to-face learning experiences may have a positive impact on knowledge retention as shown in this study.

Finally, the confidence levels in the students that experienced class content through the flipped classroom supports higher positive results in how they felt about the materials as well as feelings of retaining the learning compared to those that took traditional classes. One area of this study that showed positive student confidence is learning from application of skills and engaging 
students through multiple synchronous and asynchronous contexts. Though rote memorization of content was not as positive in the flipped classroom, this was not a deterrent in the overall confidence levels as students reported sentiments showing that if they could apply the materials in a real-world situation, accurate memorization may not be as important to them. Activities, on the other hand, allow for new avenues of creation from the learning, which may lead to higher order understanding and support greater student confidence in the materials.

\section{Experiences and Knowledge Gained}

Throughout this study there have been some fascinating findings that are not necessarily related to the research questions of learning and engagement. Some of these areas include what works well and what can use improvement, both from an instructor and instructional design perspective, as well as through the lens of the learner, and most pointedly, understanding the learner's motivations and constraints within and outside of the classroom.

A very delicate situation in terms of teaching graduate level students that are also working full-time or taking a full course load is in having a balance between work, school and life. It's easy for an instructor to get lost in their interests, wanting to include every piece of content that they feel is important without taking into consideration that time can be a very definitive factor in a learner's success and is not directly related to their abilities. In knowing this, care must be taken when applying learning components such as live discussions, activities and group/team work, particularly those that require a specific day and time for everyone to be present and actively engaged in the activity.

Other areas of interest that have come up within this study are components that work well and those that may not from the student's perspective. Care in how assessments and quizzes are designed and given to the students must be considered and follow a metric that will allow students to be successful as well as feel a sense of accomplishment through confidence in their knowledge achieved in the class. Even quizzes that can be viewed as extra credit can have negative effects if the students do not feel their knowledge or abilities are correctly assessed.

Scheduling, particularly with graduate and continuing education students that also work full-time, becomes another major hurdle when implementing live sessions. With traditional oncampus students you can easily work live sessions into the class schedule, but with distance students, their schedules tend to be more ad hoc based on the students' needs. These students 
also tend to have a predetermined notion that the instructor will work around their schedule instead of them working around the instructors, further complicating scheduling.

Finally, group and team-based work can show benefits in terms of the problem-solving work that allows engagements and experiences to come into play. It can also create adversarial challenges. Care and structure must be put in place to address dissension between hardworking students and those who are less motivated, as well as making sure that everyone on that team is getting a similar learning experience. The joy of research is in finding areas that may or may not be within the scope of the study but can lead to new and prior unknown pathways of continued enhancement of education.

\section{Summation of this Study}

In summary, this study looks to answer whether online education with a flipped classroom design can have any effect on the learning or engagement of a student, and compares them to the traditional, in-person lecture-style courses to see whether there are changes or differences in those outcomes. The first chapter introduces the research of online education and active learning instructional designs. A literature review in Chapter 2 looks at online education, educational technologies, instructional design and impacts of these areas through former research and areas of interest, and specifically looks at research exploring flipped classrooms in online education. In the third chapter, a mixed-methods approach to the research is shown through the research design. The results of this design are then shown in Chapter 4 which gives an in-depth analysis of the data collection and outcomes. Chapter 5 provides a discussion of the results and quantifiable assumptions that can be made from the findings.

As no research study should be considered complete, especially in our rapidly changing digital world, continuing to improve upon student learning and engagement should take priority in any teaching and learning modality that instructors, educational leaders and students themselves improve and benefit from. As this study gives hope in the sense of new, adaptive and digitally harnessed ways of disseminating information and turning this into applicable knowledge, many theories exist on what may create the ideal learning environment. It will be up to the research and the decisions we make as researchers to explore and uncover these new findings that can better embrace effective learning, engagement and knowledge retention. 


\section{References}

Abakumova, I., Bakaeva, I., Grishina, A., \& Dyakova, E. (2019). Active learning technologies in distance education of gifted students. International Journal of Cognitive Research in Science, Engineering and Education, 7(1), 85-94. https://doi.org/10.5937/IJCRSEE1901085A

Abdallah, S. (2009). Learning with online activities: what do students think about their experience? International Journal of Web-Based Learning and Teaching Technologies. $4(2), 1+$.

Abdurachmanov, B. (2016). How to engage the mind \& get students to love homework. The Learning Mind. Retrieved from: http://thelearningmind.com/flipped-classroom

Abeysekera, L., \& Dawson, P. (2015). Motivation and cognitive load in the flipped classroom: definition, rationale and a call for research. Higher Education Research \& Development, 34(1), 1-14, DOI: 10.1080/07294360.2014.934336.

Abrami, P. C., Bernard, R. M., Bures, E. M., Borokhovski, E., \& Tamim, R. M. (2011). Interaction in distance education and online learning: Using evidence and theory to improve practice. Journal of Computing in Higher Education, 23(2-3), 82-103. https://doi.org/10.1007/s12528-011-9043-X

Afflerbach, P., Pearson, P. D., \& Paris, S. G. (2008). Clarifying Differences Between Reading Skills and Reading Strategies. The Reading Teacher, 61(5), 364-373. https://doi.org/10.1598/RT.61.5.1

Ahlstrom, C. (2016). Review of Online Programming Characteristics and Pricing at Private Notfor-Profit Two-Year Colleges in the United States. Online Journal of Distance Learning Administration, Volume XIX(3), 7. 
Allen, I. E., \& Seaman, J. (2017). Digital Learning Compass: Distance Education Enrollment Report 2017. Babson Survey Research Group, e-Literate and WCET, pp. 1-39.

Albert, M., \& Beatty, B. J. (2014). Flipping the Classroom Applications to Curriculum Redesign for an Introduction to Management Course: Impact on Grades. Journal of Education for Business, 89(8), 419-424. https://doi.org/10.1080/08832323.2014.929559

Alessandrini, M. (2012). Non-positivist Approaches to Research in the Third Sector: Empowered Policy-making. International Society for Third-Sector Research, 17.

Ally, M., \& Prieto-Blázquez, J. (2014). What is the future of mobile learning in education? Mobile learning applications in higher education. Revista de Universidad y Sociedad Del Conocimiento, 11(1), 142. https://doi.org/10.7238/rusc.v11i1.2033

Alonso, F., Manrique, D., \& Viñes, J. M. (2009). A moderate constructivist e-learning instructional model evaluated on computer specialists. Computers \& Education, 53(1), 57-65. https://doi.org/10.1016/j.compedu.2009.01.002

Alsaadat, K. (2018). The Impact of Social Media Technologies on Adult Learning. International Journal of Electrical and Computer Engineering (IJECE), 8(5), 3747. https://doi.org/10.11591/ijece.v8i5.pp3747-3755

Alt, D. (2017). Constructivist learning and openness to diversity and challenge in higher education environments. Learning Environments Research, 20(1), 99-119. doi: http://dx.doi.org.proxy.library.cmu.edu/10.1007/s10984-016-9223-8

Anderson, L. W., Krathwohl, D. R., Airasian, P. W., Cruikshank, K. A., Mayer, R. E., Pintrich, P. R., Raths, J., Wittrock, M. C. (2000). A Taxonomy for Learning, Teaching, and Assessing: A revision of Bloom's Taxonomy of Educational Objectives. New York: Pearson, Allyn \& Bacon. 
Anderson, T. (2004). Teaching in an online learning context. Theory and Practice of Online Learning, 273-294. Retrieved from http://citeseerx.ist.psu.edu/viewdoc/download?doi=10.1.1.511.1503\&rep=rep1\&type=pdf

Anderson, T., \& Dron, J. (2018). Integrating learning management and social networking systems. Italian Journal of Educational Technology, 25(3). https://doi.org/10.17471/2499-4324/950

Andrews, F. M. (1984). Construct Validity and Error Components of Survey Measures: A Structural Modeling Approach. Public Opinion Quarterly, 48(2), 409. https://doi.org/10.1086/268840

Anshari, M., Alas, Y. \& Guan, L.S (2016). Developing online learning resources: big data, social networks, and cloud computing to support pervasive knowledge. Education and Information Technologies, 21(6), 1663-1677. doi:10.1007/s10639-015-9407-3

Aslanian, C. B., Clinefelter, D. D. L., \& Magda, A. J. (2019). Online college students: Comprehensive Data on Demands and Preferences. Learning House, 2019, 1-60.

Atchoarena, D. 2020. COVID-19 impact on education. UNESCO Institute for Lifelong Learning. Retrieved from: https://en.unesco.org/news/covid-ideas-ed?field type article tid=28621

Bacow, L., Bowen, W., Guthrie, K., Lack, K., \& Long, M. (2015). Barriers to Adoption of Online Learning Systems in U.S. Higher Education. Ithaka $S+R$. https://doi.org/10.18665/sr.22432

Bailey, B. P., \& Konstan, J. A. (2006). On the need for attention-aware systems: Measuring effects of interruption on task performance, error rate, and affective state. Computers in Human Behavior, 22(4), 685-708. https://doi.org/10.1016/j.chb.2005.12.009 
Bauer, A., \& Haynie, A. (2017). How Do You Foster Deeper Disciplinary Learning with the "Flipped" Classroom? New Directions for Teaching and Learning, 2017(151), 31-44. https://doi.org/10.1002/tl.20247

Beasley, Z. (2020). Sentiment analysis in peer review (Order No. 28021769) [Doctoral Dissertation, University of South Florida]. ProQuest Dissertations and Theses Global.

Beckett, D. (1998). Disembodied Learning: How Flexible Delivery Shoots Higher Education in the Foot, Well Sort of. Electronic Journal of Sociology, ISN: 1198-3655.

Bergmann, J., Sams, A. (2012). Flip your classroom: Reach every student in every class every day. International Society for Technology in Education. (pp. 1-112). Association for Supervision and Curriculum Development.

Bergmann, J., \& Sams, A. (2014). Flipped learning: maximizing face time. Association of Talent Development, (pp. 28-32).

Biggs, J. (1988). The Role of Metacognition in Enhancing Learning. Australian Journal of Education, 32(2), 127-138. https://doi.org/10.1177/000494418803200201

Bina, O., Inch, A., \& Pereira, L. (2020). Beyond techno-utopia and its discontents: On the role of utopianism and speculative fiction in shaping alternatives to the smart city imaginary. Futures, 115, 102475. https://doi.org/10.1016/j.futures.2019.102475

Bishop, J. L., University, U. S., Verleger, D. M. A., Univ, E.-R. A., \& Beach, D. (2018). The Flipped Classroom: A Survey of the Research. American Society for Engineering Education, \#6219, 1-18.

Black, D., Bissessar, C., \& Boolaky, M. (2019). Online Education as an Opportunity Equalizer: The Changing Canvas of Online Education. Interchange, 50(3), 423-443. https://doi.org/10.1007/s10780-019-09358-0 
Blau, I., \& Shamir-Inbal, T. (2017). Re-designed flipped learning model in an academic course: The role of co-creation and co-regulation. Computers \& Education, 115, 69-81. https://doi.org/10.1016/j.compedu.2017.07.014

Blumenstyk, G. (2014). Starbucks plan shines a light on the profits in online education. The Chronicle of Higher Education, Retrieved from https://search-proquestcom.proxy.library.cmu.edu/docview/1543463005 ?accountid=9902

Bodycott, P., Mak, A. S., \& Ramburuth, P. (2014). Utilising an Internationalised Curriculum to Enhance Students' Intercultural Interaction, Engagement and Adaptation. The AsiaPacific Education Researcher, 23(3), 635-643. https://doi.org/10.1007/s40299-013-0136$\underline{3}$

Bornstein, R. F. (2011). Toward a process-focused model of test score validity: Improving psychological assessment in science and practice. Psychological Assessment, 23(2), 532544. https://doi.org/10.1037/a0022402

Bouwmeester, R. A. M., de Kleijn, R. A. M., van den Berg, I. E. T., ten Cate, O. Th. J., van Rijen, H. V. M., \& Westerveld, H. E. (2019). Flipping the medical classroom: Effect on workload, interactivity, motivation and retention of knowledge. Computers \& Education, 139, 118-128. https://doi.org/10.1016/j.compedu.2019.05.002

Bozkurt, A., Koutropoulos, A., Singh, L., \& Honeychurch, S. (2020). On lurking: Multiple perspectives on lurking within an educational community. The Internet and Higher Education, 44, 100709. https://doi.org/10.1016/j.iheduc.2019.100709

Bryan, C. \& Leeds, E. \& Wiley, T. (2018). The Cost of Online Education: Leveraging Data to Identify Efficiencies. Online Journal of Distance Learning Administration, Volume XXI(24). 
Bruner, J. (2007). Factors Motivating and Inhibiting Faculty in Offering Their Courses via Distance Education. Online Journal of Distance Learning Administration, X(II).

Brynjolfsson, E. \& McAfee, A. (2014). The second machine age: work, progress, and prosperity in a time of brilliant technologies. New York: W.W. Norton \& Company. (First edition, pp. 10-274)

Burke, A. S., \& Fedorek, B. (2017). Does "flipping" promote engagement? A comparison of a traditional, online, and flipped class. Active Learning in Higher Education, 18(1), 11-24. https://doi.org/10.1177/1469787417693487

Burnette, D. M. (2015). Negotiating the mine field: strategies for effective online education administrative leadership in higher education institutions. Quarterly Review of Distance Education, 16(3), 13+. Retrieved from https://link-galecom.proxy.library.cmu.edu/apps/doc/A439953328/AONE

Carpenter, J. (2006). Effective teaching methods for large classes. Journal of Family \& Consumer Sciences Education, 24(2), 13-23.

Carr, N. (2007). The disappearance of IT; controversial author Nicholas Carr says the networkthe internet, that is--has become, literally, our computer. CIO Insight, (88) Retrieved from https://search-proquest-com.proxy.library.cmu.edu/docview/212919215

Caruth, G. \& Caruth, D. (2013). The impact of distance education on higher education: A case study of the United States. Turkish Online Journal of Distance Education-TOJDE October 2013. 14(4), 121-131. 2007 ISSN 1302-6488

Caspi, A., Chajut, E., \& Saporta, K. (2008). Participation in class and in online discussions: Gender differences. Computers \& Education, 50(3), 718-724. https://doi.org/10.1016/j.compedu.2006.08.003 
Chan, T.-W. (2010). How East Asian classrooms may change over the next 20 years. Journal of Computer Assisted Learning, 26(1), 28-52. https://doi.org/10.1111/j.13652729.2009.00342.x

Chander, M. (2020). Inequities and challenges surrounding access to education amidst COVID19. Bar \& Bench, NA. Retrieved from: https://link-galecom.proxy.library.cmu.edu/apps/doc/A623433793/ITOF

Chen, B. \& deNoyelles, A. (2013). Exploring Students' Mobile Learning Practices in Higher Education. Educause Review 13. Retrieved from https://er.educause.edu/articles/2013/10/exploring-students-mobile-learning-practicesin-higher-education

Chen, B., Bastedo, K., \& Howard, W. (2018). Exploring Best Practices for Online STEM Courses: Active Learning, Interaction \& Assessment Design. Online Learning, 22(2). https://doi.org/10.24059/olj.v22i2.1369

Chen, N., Ko, H., Kinshuk *, \& Lin, T. (2005). A model for synchronous learning using the Internet. Innovations in Education and Teaching International, 42(2), 181-194. https://doi.org/10.1080/14703290500062599

Chen, W., Looi, C.-K., \& Tan, S. (2010). What do students do in a F2F CSCL classroom? The optimization of multiple communications modes. Computers \& Education, 55(3), 11591170. https://doi.org/10.1016/j.compedu.2010.05.013

Chen, Y., Wang, Y., Kinshuk, \& Chen, N.-S. (2014). Is FLIP enough? Or should we use the FLIPPED model instead? Computers \& Education, 79, 16-27. https://doi.org/10.1016/j.compedu.2014.07.004

Cheng, Y., Weng, C., \& Adjustment Teacher, Sha-lu Primary School, Taiwan, R.O.C. (2017). Factors influence the digital media teaching of primary school teachers in a flipped class: 
A Taiwan case study. South African Journal of Education, 37(1), 1-12. https://doi.org/10.15700/saje.v37n1a1293

Christensen, C. M. (1997). The innovator's dilemma: When new technologies cause great firms to fail. Harvard Business School Press, 1-252.

Christensen, C. M. \& Eyring, H. J. (2011). The innovative university: Changing the DNA of higher education from the inside out. Jossey-Bass: A Wiley Imprint, 1-403.

Chu, H.-C. (2014). Potential Negative Effects of Mobile Learning on Students' Learning Achievement and Cognitive Load - A Format Assessment Perspective. Educational Technology \& Society, 17(1), 332-344.

Chuang, H.-H., Weng, C.-Y., \& Chen, C.-H. (2018). Which students benefit most from a flipped classroom approach to language learning?: Flipped classroom does not fit all students. British Journal of Educational Technology, 49(1), 56-68. https://doi.org/10.1111/bjet.12530

Clow, K. E. (1999). Interactive distance learning: Impact on student course evaluations. Journal of Marketing Education. 21(2), 97-105.

Cook, T., \& Campbell, D. (1979). Quasi-experimentation: Design \& analysis issues for field settings. Houghton Mifflin.

Courser, M. W., \& Lavrakas, P. J. (2012). Item-Nonresponse and the 10-Point Response Scale in Telephone Surveys. Survey Practice, 5(4), 1-5. https://doi.org/10.29115/SP-2012-0021

Cox III, E. P. (1980). The Optimal Number of Response Alternatives for a Scale: A Review. 17.

Crosman, P. (2019). Steve Wozniak on common innovation mistakes. American Banker. 
Retrieved from https://search-proquest-

com.proxy.library.cmu.edu/docview/2232748116?accountid=9902

Cutrer, W. B., Castro, D., Roy, K. M., \& Turner, T. L. (2011). Use of an expert concept map as an advance organizer to improve understanding of respiratory failure. Medical Teacher, 33(12), 1018-1026. https://doi.org/10.3109/0142159X.2010.531159

Darkwa, O. (2019). Emerging Trends and Challenges in Higher Education [interview]. AllAfrica Global Media. Retrieved from https://search.proquest.com/docview/2321177811

Derry, S. J., Hmelo-Silver, C. E., Nagarajan, A., Chernobilsky, E., \& Beitzel, B. D. (2006). Cognitive Transfer Revisited: Can We Exploit New Media to Solve Old Problems on a Large Scale? Journal of Educational Computing Research, 35(2), 145-162. https://doi.org/10.2190/0576-R724-T149-5432

Dewey, J. \& Bentley, A. F. (1949). Knowing and the known. Boston, Beacon Press, 1-334. https://doi.org/10.1177/000271625026800166

Dewiyanti, S., Brand-Gruwel, S., Jochems, W., \& Broers, N. J. (2007). Students' experiences with collaborative learning in asynchronous Computer-Supported Collaborative Learning environments. Computers in Human Behavior, 23(1), 496-514. https://doi.org/10.1016/j.chb.2004.10.021

Dillenbourg, P. (1999). What do you mean by collaborative learning? Collaborative learning: Cognitive and Computational Approaches., Oxford: Elsevier, pp.1-19, 1999. ffhal00190240f

Dixson, M. D. (2010). Creating effective student engagement in online courses: What do students find engaging? M. D., 10(2), 13.

Downes L. \& Nunes, P. F. (2013). Big-Bang Disruption. Harvard Business Review, 91(3), 44- 
56. Retrieved from

http://search.ebscohost.com.proxy.library.cmu.edu/login.aspx?direct=true \&db=buh\&AN $\underline{=85463190}$

Dy-Boarman, E. A., Nisly, S. A., \& Costello, T. J. (2018). It's no debate, debates are great. Currents in Pharmacy Teaching and Learning, 10(1), 10-13. https://doi.org/10.1016/j.cpt1.2017.09.016

Elfeky, A. I. M., Masadeh, T. S. Y., \& Elbyaly, M. Y. H. (2020). Advance organizers in flipped classroom via e-learning management system and the promotion of integrated science process skills. Thinking Skills and Creativity, 35, 100622. https://doi.org/10.1016/j.tsc.2019.100622

Eyal-Cohen, M. (2019). Innovation Agents. Washington and Lee Law Review, 76(1), 163-259. Retrieved from https://search-proquest-com.proxy.library.cmu.edu/docview/2234977896

Faul, F., Erdfelder, E., Buchner, A., \& Lang, A.-G. (2009). Statistical power analyses using G*Power 3.1: Tests for correlation and regression analyses. Behavior Research Methods, 41(4), 1149-1160. https://doi.org/10.3758/BRM.41.4.1149

Ke, F. \& Kwak., D. (2013). Constructs of student-centered online learning on learning satisfaction of a diverse online student body: A structural equation modeling approach. Journal of Educational Computing Research. 48(1), 97-122.

Findlay-Thompson, S., \& Mombourquette, P. (2014). Evaluation of a flipped classroom in an undergraduate business course. Business Education and Accreditation, 6(1), 63-71.

Fischer, G. (2014). Beyond hype and underestimation: Identifying research challenges for the future of MOOCs. Distance Education, 35(2), 149-158. https://doi.org/10.1080/01587919.2014.920752 
Francl, T. J. (2014). Is flipped learning appropriate? Journal of Research in Innovative Teaching, $71,119-128$.

Freeman, S. \& Eddy, S. (2014). Active learning increases student performance in science, engineering, and mathematics. Proceedings of the National Academy of Sciences. 111(23), 8410-8415.

Frederick, Eric, AICP, L.E.E.D.A.P. (2019). Equal access equals opportunity. Planning, 85(7), 20-25. Retrieved from https://search-proquestcom.proxy.library.cmu.edu/docview/2265599778

Fried, C. B. (2008). In-class laptop use and its effects on student learning. Computers \& Education, 50(3), 906-914. https://doi.org/10.1016/j.compedu.2006.09.006

Friedman, L. W. (2013). Using social media technologies to enhance online learning. The Journal of Educators Online. 10(1), 1-21.

Fulton, K. (2012). Upside down and inside out: Flip your classroom to improve student learning. Learning \& Leading With Technology, 12-17. Retrieved from https://files.eric.ed.gov/fulltext/EJ982840.pdf

Galusha, J. M. (1997). Barriers to learning in distance education. Interpersonal Computing and Technology. 5(3-4), 6-14.

Gass, S., \& Mackey, A. (2012). Research methods in second language acquisition a practical guide (1st ed.). Wiley-Blackwell.

García-Sánchez, S., \& Santos-Espino, J. M. (2017). Empowering Pre-Service Teachers to Produce Ubiquitous Flipped Classes. PROFILE Issues in Teachers' Professional Development, 19(1), 169. https://doi.org/10.15446/profile.v19n1.53857 
Garratt, A. M., Helgeland, J., \& Gulbrandsen, P. (2011). Five-point scales outperform 10-point scales in a randomized comparison of item scaling for the Patient Experiences Questionnaire. Journal of Clinical Epidemiology, 64(2), 200-207. https://doi.org/10.1016/j.jclinepi.2010.02.016

Garza Mitchell, R. L. (2009). Online Education and Organizational Change. Community College Review, 37(1), 81-101. https://doi.org/10.1177/0091552109338731

Gaytan, J., \& McEwen, B. C. (2007). Effective Online Instructional and Assessment Strategies. American Journal of Distance Education, 21(3), 117-132. https://doi.org/10.1080/08923640701341653

Gee, J.P. (2003). High score education: Games, not school are teaching kids to think. Wired. Retrieved from https://www.wired.com/2003/05/high-score-education/

Ghadiri, K. (2014). Developing and implementing effective instructional stratagems in STEM. $21^{\text {st }}$ ASEE Annual Conference \& Exposition Paper ID\#10374. American Society for Engineering Education.

Gilboy, M. B., Heinerichs, S., \& Pazzaglia, G. (2015). Enhancing Student Engagement Using the Flipped Classroom. Journal of Nutrition Education and Behavior, 47(1), 109-114. https://doi.org/10.1016/j.jneb.2014.08.008

Glennerster, R., \& Takavarasha, K. (2013). Running Randomized Evaluations: A Practical Guide. Princeton; Oxford: Princeton University Press. doi:10.2307/j.ctt4cgd52

Gobet, F., Lane, P. C. R., \& Lloyd-Kelly, M. (2015). Chunks, Schemata, and Retrieval Structures: Past and Current Computational Models. Frontiers in Psychology, 6. https://doi.org/10.3389/fpsyg.2015.01785

Goldberg, A. K., \& Riemer, F. J. (2020). All Aboard - Destination Unknown: A Sociological 
Discussion of Online Learning. Educational Technology \& Society, 9(4), 166-172.

Goldman, R. H., Cohen, A. P., \& Sheahan, F. (2008). Using Seminar Blogs to Enhance Student Participation and Learning in Public Health School Classes. American Journal of Public Health, 98(9), 1658-1663. https://doi.org/10.2105/AJPH.2008.133694

Goldstein, D. (2020). Research Shows Students Falling Months Behind During Virus Disruptions. The New York Times, June 5, 2020. Retrieved from: https://www.nytimes.com/2020/06/05/us/coronavirus-education-lost-learning.html

Graham, C., \& Jones, N. (2011). Cognitive Dissonance Theory and Distance Education: Faculty Perceptions on the Efficacy of and Resistance to Distance Education. International Journal of Business, Humanities and Technology, 1(2), 212-227.

Greengard, S. (2020). Can nanosheet transistors keep Moore's Law alive? Communications of the ACM, 63(3), 10-12. https://doi.org/10.1145/3379493

Greenstein, S. (2017). The reference wars: Encyclopaedia Britannica's decline and Encarta's emergence. Strategic Management Journal, 38(5), 995-1017. https://doi.org/10.1002/smj.2552

Gritsenko, V. (2016). Interaction on online forums and group communication: A case study of an IT support community. Procedia, Social and Behavioral Sciences. 236(1), 14-24. doi:10.1016/j.sbspro.2016.12.004

Gross, D., Pietri, E. S., Anderson, G., Moyano-Camihort, K., \& Graham, M. J. (2015). Increased Preclass Preparation Underlies Student Outcome Improvement in the Flipped Classroom. CBE-Life Sciences Education, 14(4), ar36. https://doi.org/10.1187/cbe.15-02-0040

Grub, H. (2014). What is the ASSURE model? Assure Model IDT 8074. Retrieved from https://idtassuremodel.wordpress.com/2014/09/11/23/ 
Grushka-Cockayne, Y. (2018). 2U: Higher Education Rewired. Harvard Business School Publishing. HBS 9-620-044.

Gulati, S. (2008). Compulsory participation in online discussions: Is this constructivism or normalisation of learning? Innovations in Education and Teaching International. 45(2), 183-192.

Hao, Y. (2016). Exploring undergraduates' perspectives and flipped learning readiness in their flipped classrooms. Computers in Human Behavior, 59, 82-92. https://doi.org/10.1016/j.chb.2016.01.032

Hamdan, N., McKnight, P., McKnight, K., \& Arfstrom, K. M. (2013). The flipped learning model: A white paper based on the literature review titled a review of flipped learning, Pearson, pp. 1-16. Retrieved from https://flippedlearning.org/wpcontent/uploads/2016/07/WhitePaper FlippedLearning.pdf

Handy, R., Harwood, E. C., Dewey, J., \& Ratner, J. (1973). Useful procedures of inquiry. Behavioral Research Council.

Hawkins, W. A., Fulford, M., \& Phan, S. V. (2019). Using debates as the primary pedagogy to teach critical care in a PharmD curriculum elective course. Currents in Pharmacy Teaching and Learning, 11(9), 943-948. https://doi.org/10.1016/j.cpt1.2019.05.010

Hemmi, A., Bayne, S. and Land, R. (2009). The appropriation and repurposing of social technologies in higher education. Journal of Computer Assisted Learning. 25(1), 19-30. doi:10.1111/j.1365-2729.2008.00306.x

Herreid, C. F., \& Schiller, N. A. (2013). Case Studies and the Flipped Classroom. Journal of College Science Teaching, 42(5), 62-66 
Hidi, S. (2016). Revisiting the Role of Rewards in Motivation and Learning: Implications of Neuroscientific Research. Educational Psychology Review, 28(1), 61-93. https://doi.org/10.1007/s10648-015-9307-5

Hollands, F. \& Tirthali, D. (2014). MOOCs: Expectations and reality full report. Center for Benefit-Cost Studies of Education: Teachers College, Columbia University, pp. 1-211.

Holzweiss, P. C., Polnick, B., \& Lunenburg, F. C. (2019). Online in Half the Time: A Case Study with Online Compressed Courses. Innovative Higher Education, 44(4), 299315. https://doi.org/10.1007/s10755-019-09476-8

Homavazir, M. M. F., \& Gopal, D. R. (2018). A research study on the digitalisation of higher education and its impact on teaching and students assessment in commerce, management and science colleges in Mumbai. AADYA-Journal of Management and Technology (JMT), 8(1), pp. 93-100. Retrieved from http://www.ischolar.in/index.php/AADYA/article/download/183168/170344

Howitt, C., \& Pegrum, M. (2015). Implementing a flipped classroom approach in postgraduate education: An unexpected journey into pedagogical redesign. Australasian Journal of Educational Technology, 31(4). https://doi.org/10.14742/ajet.2439

Hrastinski, S. (2008). A study of asynchronous and synchronous e-learning methods discovered that each supports different purposes. Asynchronous and Synchronous E-Learning, Educause Quarterly, 4(2008). 51-55.

ICT Monitor Worldwide (2020). Rural broadband getting state and federal push. Syndigate Media. Retrieved from https://link-galecom.proxy.library.cmu.edu/apps/doc/A612457176/

Israel, M. J. (2015). Effectiveness of Integrating MOOCs in Traditional Classrooms for Undergraduate Students. The International Review of Research in Open and Distributed 
Learning, 16(5). https://doi.org/10.19173/irrodl.v16i5.2222

Jackson, N. (2004). Developing the concept of metalearning. Innovations in Education and Teaching International, 41(4), 391-403. https://doi.org/10.1080/1470329042000276995

Jaschik, S., \& Lederman, D. (2014). The 2014 Inside Higher Ed survey of faculty attitudes on technology: A study by Gallup and Inside Higher Ed. Inside Higher Ed, 1-44.

Jeong, H., \& Hmelo-Silver, C. E. (2016). Seven Affordances of Computer-Supported Collaborative Learning: How to Support Collaborative Learning? How Can Technologies Help? Educational Psychologist, 51(2), 247-265. https://doi.org/10.1080/00461520.2016.1158654

Jeong, J. S., González-Gómez, D., Cañada-Cañada, F., Gallego-Picó, A., \& Bravo, J. C. (2019). Effects of active learning methodologies on the students' emotions, self-efficacy beliefs and learning outcomes in a science distance learning course. Journal of Technology and Science Education, 9(2), 217. https://doi.org/10.3926/jotse.530

Jia, J., \& Zhang, B. (2018). Design Guidelines for Mobile MOOC Learning - An Empirical Study. In S. K. S. Cheung, L. Kwok, K. Kubota, L.-K. Lee, \& J. Tokito (Eds.), Blended Learning. Enhancing Learning Success (pp. 347-356). Springer International Publishing.

Jonassen, D. (2012). Theoretical Foundations of Learning Environments: Second Edition. Routledge, Taylor \& Francis Group, 1-350

Jones, G., Gobet, F., \& Pine, J. M. (2007). Linking working memory and long-term memory: A computational model of the learning of new words. Developmental Science, 10(6), 853873. https://doi.org/10.1111/j.1467-7687.2007.00638.x

Jordan, K. (2014). Initial trends in enrolment and completion of massive open online courses. 
The International Review of Research in Open and Distributed Learning, 15(1). https://doi.org/10.19173/irrodl.v15i1.1651

Karagiorgi, Y., \& Symeou, L. (2005). Translating constructivism into instructional design: potential and limitations. Journal of Educational Technology \& Society. 8(1), 17-27.

Kay, K. \& Greenhill, V. (2011) Twenty-First Century Students Need 21st Century Skills. Bringing schools into the 21st century, Springer, pp. 41-66.

Kim, K.-J., Liu, S., \& Bonk, C. J. (2005). Online MBA students' perceptions of online learning: Benefits, challenges, and suggestions. The Internet and Higher Education, 8(4), 335-344. https://doi.org/10.1016/j.iheduc.2005.09.005

Kim, M. \& Hannafin, M. (2011). Scaffolding problem solving in technology-enhanced learning environments (TELEs): Bridging research and theory with practice. Computers \& Education. 56(2), 403-417.

Kim, M., \& Kim, S., \& Khera, O., \& Getman, J. (2014). The experience of three flipped classrooms in an urban university: An exploration of design principles. The Internet and Higher Education, 22(2014), 37-50.

Kim, M., \& Jung, E., \& Siqueria, A., \& and Huber, L. (2016). An investigation into effective pedagogies in a flipped classroom: A case study. International Journal of ELearning \& Distance Education, 31(2), 1-15.

Knapp, N. F. (2018). Increasing Interaction in a Flipped Online Classroom through Video Conferencing. TechTrends, 62(6), 618-624. https://doi.org/10.1007/s11528-018-0336-z

Klingsieck, K. B., Fries, S., Horz, C., \& Hofer, M. (2012). Procrastination in a distance university setting. Distance Education, 33(3), 295-310. https://doi.org/10.1080/01587919.2012.723165 
Kolowich, S. (2013). The Professors Behind the MOOC Hype. The Chronicle of Higher Education, 16. Retrieved from https://www.chronicle.com/article/The-Professors-Behindthe-MOOC/137905

Koohang, A., Paliszkiewicz, J., Goluchowski, J., \& Nord, J. H. (2016). Active learning for knowledge construction in e-learning: A replication study. The Journal of Computer Information Systems. 56(3), 238-243.

Koper, R. (2014). Towards a more effective model for distance education. E-learning and Education. 1(10), 1-12.

Koper, R. (2015). How do students want to learn in online distance education? Profiling student preferences. The International Review of Research in Open and Distributed Learning, 16(1). https://doi.org/10.19173/irrodl.v16i1.2000

Kumar, P., \& Chaudhary, S. (2017). Massive open online courses and modern education. International Journal of Education and Management Studies, 7(2), 422-424.

Kumar, S., McLean, L., Nash, L., \& Trigwell, K. (2017). Incorporating active learning in psychiatry education. Australasian Psychiatry, 25(3), 304-309. https://doi.org/10.1177/1039856217689912

Kurt, G. (2017). Implementing the Flipped Classroom in Teacher Education: Evidence from Turkey. Educational Technology \& Society, 20(1), 211-221.

Lage, M. J., Platt, G. J., \& Treglia, M. (2000). Inverting the Classroom: A Gateway to Creating an Inclusive Learning Environment. The Journal of Economic Education, Vol. 31, No. 1 (Winter, 2000), pp. 30-43

Lah, N. C., Saat, R. M., \& Hassan, R. (2014). Cognitive Strategy In Learning Chemistry: How 
Chunking And Learning Get Together. The Malaysian Online Journal of Educational Science, 2(1), 9-15.

Larson, J. R., \& Christensen, C. (1993). Groups as problem-solving units: Toward a new meaning of social cognition. British Journal of Social Psychology, 32(1), 5-30. https://doi.org/10.1111/j.2044-8309.1993.tb00983.x

Lee, K. (2017). Rethinking the accessibility of online higher education: A historical review. The Internet and Higher Education, 33, 15-23. https://doi.org/10.1016/j.iheduc.2017.01.001

Lee, P. \& Roddis, E. (2020). How do today's students use mobiles? Game of phones. Deloitte $U K$. Retrieved from https://www2.deloitte.com/uk/en/pages/public-sector/articles/howdo-todays-students-use-mobiles.html

Lewis, C. E., Chen, D. C., \& Relan, A. (2018). Implementation of a flipped classroom approach to promote active learning in the third-year surgery clerkship. The American Journal of Surgery, 215(2), 298-303. https://doi.org/10.1016/j.amjsurg.2017.08.050

Li, L., Conn, S., \& Markham, C. (2014). Promoting active learning in distance education: A case of student-centered guest lecturing. Southern Association for Information Systems Conference. 21(1), 1-3.

Lim, J., Kim, M., Chen, S.S., and Ryder, C.E. (2008). An empirical investigation of student achievement and satisfaction in different learning environments. [Electronic version]. Journal of Instructional Psychology, 35 (2).

Lin, C.-H., Zheng, B., \& Zhang, Y. (2017). Interactions and learning outcomes in online language courses: Online interactions and learning outcomes. British Journal of Educational Technology, 48(3), 730-748. https://doi.org/10.1111/bjet.12457

Lin, L.-C., Hung, I.-C., Kinshuk, \& Chen, N.-S. (2019). The impact of student engagement on 
learning outcomes in a cyber-flipped course. Educational Technology Research and Development, 67(6), 1573-1591. https://doi.org/10.1007/s11423-019-09698-9

Liu, B. (2012). Sentiment Analysis and Opinion Mining. Synthesis Lectures on Human Language Technologies, 16, 1-184.

Lo, C., \& Hew, K. (2017). A critical review of flipped classroom challenges in K-12 education: Possible solutions and recommendations for future research. Research and Practice in Technology Enhanced Learning, 12(4), 1-22.

Lopes, A. P., \& Soares, F. (2018). Perception and performance in a flipped Financial Mathematics classroom. The International Journal of Management Education, 16(1), 105-113.https://doi.org/10.1016/j.ijme.2018.01.001

Lu, Y., Wang, B., \& Lu, Y. (2019). Understanding key drivers of MOOC satisfaction and continuance intention to use. Journal of Electronic Commerce Research. 20(2), 14.

Mackey, A. \& Gass, S. M. (2012). Research Methods in Second Language Acquisition: A Practical Guide: Vol. 1. Wiley-Blackwell. https://onlinelibrary.wiley.com/doi/book/10.1002/9781444347340

Mahmood, S. T. (2012). A Comparative Study of Student Satisfaction Level in Distance Learning and Live Classroom at Higher Education Level. Turkish Online Journal of Distance Education, 13(1), article 7.

Maki, R.H. \& Maki, W.S. (2007). Online Courses. In F.T. Durso (Ed.), Handbook of applied cognition (2nd ed., pp. 527-552). New York: Wiley \& Sons, Ltd.

Manyika, J. Chui, M., Miremadi, M., Bughin, J., George, K., Willmott, P., \& Dewhurst, M. (2017). A future that works: Automation, employment and productivity. McKinsey 
Global Institute. Retrieved from http://www.mckinsey.com/global-themes/digitaldisruption/harnessing-automation-for-a-future-that-works

Martin, F., \& Bolliger, D. U. (2018). Engagement Matters: Student Perceptions on the Importance of Engagement Strategies in the Online Learning Environment. Online Learning, 22(1). https://doi.org/10.24059/olj.v22i1.1092

Mayer, R. E. (2002). Rote Versus Meaningful Learning. Theory Into Practice, 41(4), 226-232. Retrieved from: https://doi.org/10.1207/s15430421tip4104_4

McInnerney, J. M., \& Roberts, T. S. (2004). Online learning: Social interaction and the creation of a sense of community. Educational Technology \& Society, 7(3), 73-81.

McLean, S., Attardi, S. M., Faden, L., \& Goldszmidt, M. (2016). Flipped classrooms and student learning: Not just surface gains. Advances in Physiology Education, 40(1), 47-55. https://doi.org/10.1152/advan.00098.2015

Michel, N., Cater, J. J., \& Varela, O. (2009). Active versus passive teaching styles: An empirical study of student learning outcomes. Human Resource Development Quarterly, 20(4), 397-418. https://doi.org/10.1002/hrdq.20025

Middleton, R.A. \& Prince, B. L. (2010). Redesigning Teacher Education from the Ground Up A Collaborative Model. Bringing schools into the 21st century, Springer, pp. 225-246.

Miller, A. (2012). Five best practices for the flipped classroom. Edutopia: George Lucas Educational Foundation. Retrieved from http://www.edutopia.org/blog/flippedclassroom-best-practices-andrew-miller

Miller, G. A. (1956). The magical number seven, plus or minus two: Some limits on our capacity for processing information. The Psychological Review, 63(2), 81-97. 
Milman, N. B. (2012). The Flipped Classroom Strategy: What Is it and How Can it Best be Used? Distance Learning, 9(3), 4.

Mizad, M., Yusoff, Z. S., Sayadi, Z. A., Latif, A. A., \& Sukiman, S. L. (2018). Students Readiness and Motivation to Use Mobile Phone for Learning English at Higher Learning Institution. International Journal of Asian Social Science, 8(11), 1077-1087. https://doi.org/10.18488/journal.1.2018.811.1077.1087

Mlitwa, N., \& Belle, J.-P. (2010). A Proposed Interpretivist Framework to Research the Adoption of Learning Management Systems in Universities. Communications of the IBIMA, 1-11. https://doi.org/10.5171/2010.574872

Moore, C. (2020). Now is the Time to Embrace Mobile Learning. Transforming Higher Ed. Retrieved from: https://er.educause.edu/blogs/2020/6/now-is-the-time-to-embracemobile-learning

Moore, G. E. (1998). Cramming More Components Onto Integrated Circuits. Proceedings of the IEEE, 86(1), 82-85. https://doi.org/10.1109/JPROC.1998.658762

Moore, M. G. (1972). Learner autonomy: The second dimensions of independent learning. Convergence, 5(2), 76. Retrieved from https://search-proquestcom.proxy.library.cmu.edu/docview/1437898934

Moore, M. G. (1993). Three types of interaction. In K. Harry, M. John, \& D. Keegan (Eds.), Distance education theory (pp. 19-24). New York: Routledge.

$\mathrm{Ni}$, Anna Ya (2013). Comparing the effectiveness of classroom and online learning: Teaching research methods. Journal of Public Affairs Education. 19(2), 199-215.

Nichols, K., Burgh, G., \& Kennedy, C. (2017). Comparing Two Inquiry Professional Development Interventions in Science on Primary Students' Questioning and Other 
Inquiry Behaviours. Research in Science Education, 47(1), 1-24.

https://doi.org/10.1007/s11165-015-9487-5

Nokes-Malach, T. J., Meade, M. L., \& Morrow, D. G. (2012). The effect of expertise on collaborative problem solving. Thinking \& Reasoning, 18(1), 32-58. https://doi.org/10.1080/13546783.2011.642206

Noonoo, S. (2012). Flipped Learning Founders Set the Record Straight. The Journal. Retrieved from https://thejournal.com/articles/2012/06/20/flipped-learning-founders-q-and-a.aspx

Ni, A. Y. (2013). Comparing the Effectiveness of Classroom and Online Learning: Teaching Research Methods. Journal of Public Affairs Education, 19(2), 199-215.

O'Flaherty, J., \& Phillips, C. (2015). The use of flipped classrooms in higher education: A scoping review. The Internet and Higher Education, 25, 85-95. https://doi.org/10.1016/j.iheduc.2015.02.002

O’Malley, J., \& McCraw, H. (1999). Students Perceptions of Distance Learning, Online Learning and the Traditional Classroom. Online Journal of Distance Learning Administration, 2(4), 1-10.

Özkurkudis, M. J., \& Bümen, N. T. (2019). Flipping the Writing Classroom: Using Grammar Videos to Enhance Writing. Journal of Education and Future, 15, 1-16. https://doi.org/10.30786/jef.425632

Özpinar, İ., Yenmez, A. A., \& Gökçe, S. (2016). An Application of Flipped Classroom Method in the Instructional Technologies and Material Development Course. Journal of Education and Training Studies, 4(12), 213-226. https://doi.org/10.11114/jets.v4i12.1934

Paas, F. G. W. C., \& Van Merriënboer, J. J. G. (1994). Instructional control of cognitive load in 
the training of complex cognitive tasks. Educational Psychology Review, 6(4), 351-371. https://doi.org/10.1007/BF02213420

Paas, F., Renkl, A., \& Sweller, J. (2003). Cognitive Load Theory and Instructional Design: Recent Developments. Educational Psychologist, 38(1), 1-4. https://doi.org/10.1207/S15326985EP3801_1

Pappas, C. (2013). The History of Distance Learning - Infographic. eLearning Industry. Retrieved from: https://elearningindustry.com/the-history-of-distance-learninginfographic

Petkovics, I. (2018). Digital Transformation in Higher Education. Journal of Applied Technical and Educational Sciences, 8(4), 77-81. https://DOI:10.24368/jates.v8i4.55

Phillips, C., \& O’Flaherty, J. (2019). Evaluating nursing students' engagement in an online course using flipped virtual classrooms. Student Success, 10(1), 59-71. https://doi.org/10.5204/ssj.v10i1.1098

Pienta, N. (2016). A “flipped classroom" reality check. The Journal of Chemical Education 93(1), 1-2.DOI: 10.1021/acs.jchemed.5b00996

Pološki Vokić, N., \& Aleksić, A. (2018). Which are the most effective methods for teaching management at a graduate level? - FEB students' perceptions of individual teaching methods and teaching method bundles effectiveness. Zbornik Ekonomskog Fakulteta $u$ Zagrebu, 16(1), 59-76. https://doi.org/10.22598/zefzg.2018.1.59

Powell, W. W. (2017). A sociologist looks at crowds: Innovation or invention? Strategic Organization, 15(2), 289-297. https://doi.org/10.1177/1476127016644642

Prevalla, B., \& Uzunboylu, H. (2019). Flipped Learning in Engineering Education. TEM Journal, 8(2), 656-661. 
Prince, M. (2004). Does Active Learning Work? A Review of the Research. Journal of Engineering Education, 93(3), 223-231. https://doi.org/10.1002/j.21689830.2004.tb00809.x

Radunovich, H. L., \& Acharya, S. (2018). If You Flip It, Will They Watch? Case Evaluation of a Hybrid Course. NACTA Journal, 62(1), 84-88.

Rafiq, N., Shoaib, M., \& Arshad, S. (2014). Exploring the Impact of Flexibility on Quality Benchmarks in Distance Education. Pakistan Journal of Science, 66(4), 6.

Ravi, K., \& Ravi, V. (2015). A survey on opinion mining and sentiment analysis: Tasks, approaches and applications. Knowledge-Based Systems, 89, 14-46. https://doi.org/10.1016/j.knosys.2015.06.015

Rawas, H., Bano, N., \& Alaidarous, S. (2020). Comparing the Effects of Individual Versus Group Face-to-Face Class Activities in Flipped Classroom on Student's Test Performances. Health Professions Education, 6(2), 153-161. https://doi.org/10.1016/j.hpe.2019.06.002

Rawlings, D., Miller-Lewis, L., Collien, D., Tieman, J., Parker, D., \& Sanderson, C. (2017). Lessons Learned from the Dying2Learn MOOC: Pedagogy, Platforms and Partnerships. Education Sciences, 7(3), 67. https://doi.org/10.3390/educsci7030067

Reyes-Menendez, A., Saura, J., \& Alvarez-Alonso, C. (2018). Understanding \#WorldEnvironmentDay User Opinions in Twitter: A Topic-Based Sentiment Analysis Approach. International Journal of Environmental Research and Public Health, 15(11), 2537. https://doi.org/10.3390/ijerph15112537

Rivera, E. (2015). Using the Flipped Classroom Model in Your Library Instruction Course. The Reference Librarian, 56(1), 34-41. https://doi.org/10.1080/02763877.2015.977671 
Rivkin, A., \& Gim, S. (2013). Student Preferences Regarding Teaching Methods in a DrugInduced Diseases and Clinical Toxicology Course. American Journal of Pharmaceutical Education, 77(6), 123. https://doi.org/10.5688/ajpe776123

Robinson, C. C., \& Hullinger, H. (2008). New Benchmarks in Higher Education: Student Engagement in Online Learning. Journal of Education for Business, 84(2), 101-109. https://doi.org/10.3200/JOEB.84.2.101-109

Roehl, A., Reddy, S. L., \& Shannon, G. J. (2013). The Flipped Classroom: An Opportunity To Engage Millennial Students Through Active Learning Strategies. Journal of Family \& Consumer Sciences, 105(2), 44-49. https://doi.org/10.14307/JFCS105.2.12

Romano, J., Wallace, T. L., Helmick, I. J., Carey, L. M., \& Adkins, L. (2005). Study procrastination, achievement, and academic motivation in web-based and blended distance learning. The Internet and Higher Education, 8(4), 299-305. https://doi.org/10.1016/j.iheduc.2005.09.003

Romero-Garcia, M. del C., Buzón-García, O., \& Touron, J. (2019). The flipped learning model in online based education for secondary teachers. Journal of Technology and Science Education, 9(2), 109. https://doi.org/10.3926/jotse.435

Safei, S. (2011). Instant e-teaching framework model for live online teaching. International Journal of Computer Science Issues. 8(2), 84-91.

Sankar, H., Subramaniyaswamy, V., Vijayakumar, V., Arun Kumar, S., Logesh, R., \& Umamakeswari, A. (2020). Intelligent sentiment analysis approach using edge computing-based deep learning technique. Software: Practice and Experience, 50(5), 645-657. https://doi.org/10.1002/spe.2687

Schaffzin, K. (2016). Learning Outcomes in a Flipped Classroom: A Comparison of Civil 
Procedure II Test Scores Between Students in a Traditional Class and a Flipped Class. The University of Memphis Law Review Spring 2016, 46(3), 661

Schaffhauser, D. (2020). New Online Certificate Program to Teach Educators How to Use Tech in the Classroom. THE Journal. Retrieved from https://thejournal.com/Articles/2020/01/28/New-Online-Certificate-Program-to-TeachEducators-How-to-Use-Tech-in-the-Classroom

Schouwenburg, H. C., \& Groenewoud, J. (2001). Study motivation under social temptation; effects of trait procrastination. Personality and Individual Differences, 30(2), 229-240. https://doi.org/10.1016/S0191-8869(00)00034-9

Schwarz, N., Knauper, B., Hippler, H.-J., Noelle-Neumann, E., \& Clark, L. (1991). Rating Scales: Numeric Values May Change the Meaning of Scale Labels. Public Opinion Quarterly, 55(4), 570. https://doi.org/10.1086/269282

Seaman, J. E., Allen, I. E., \& Seaman, J. (2018). Grade Increase: Tracking Distance Education in the United States. Babson Survey Research Group, (pp. 1-49). Online Learning Consortium.

Sehgal, P. (2010, June 21). Here comes Clay Shirky: One of the digital age's great thinkers talks to PW about his new book, "Cognitive Surplus," web "values," and the changing world of publishing. Publishers Weekly, 257(24), 24+. Retrieved from https://link-galecom.proxy.library.cmu.edu/apps/doc/A229834642

Shabani, K., Khatib, M., \& Ebadi, S. (2010). Vygotsky’s Zone of Proximal Development: Instructional Implications and Teachers' Professional Development. English Language Teaching, 3(4), p237. https://doi.org/10.5539/elt.v3n4p237

Shachar, M., \& Neumann, Y. (2003). Differences Between Traditional and Distance Education Academic Performances: A Meta-Analytic Approach. The International Review of 
Research in Open and Distributed Learning, 4(2).

https://doi.org/10.19173/irrodl.v4i2.153

Shachar, M. (2008). Meta-Analysis: The preferred method of choice for the assessment of distance learning quality factors. The International Review of Research in Open and Distributed Learning, 9(3). https://doi.org/10.19173/irrodl.v9i3.493

Shank, P. (2018). What Research Tells Us About Chunking Content. ELearning Industry. Retrieved from https://elearningindustry.com/chunking-content-what-research-tells-us

Sharples, M. (2013). Mobile Learning: Research, Practice and Challenges. Distance Education in China, 3(5), pp. 5-11.

Shatto, B., L'Ecuyer, K., \& Quinn, J. (2017). Retention of Content Utilizing a Flipped Classroom Approach: Nursing Education Perspectives, 38(4), 206-208. https://doi.org/10.1097/01.NEP.0000000000000138

Skjott Linneberg, M., \& Korsgaard, S. (2019). Coding qualitative data: A synthesis guiding the novice. Qualitative Research Journal, 19(3), 259-270. https://doi.org/10.1108/QRJ-12$\underline{2018-0012}$

Sloan, L., \& Quan-Haase, A. (2020). The SAGE Handbook of Social Media Research Methods. https://doi.org/10.4135/9781473983847

Sletten, S. (2017). Investigating Flipped Learning: Student Self-Regulated Learning, Perceptions, and Achievement in an Introductory Biology Course. Springer Science and Business Media. 26(1), 347-358.

Shi, Y., Yang, H., MacLeod, J., Zhang, J., \& Yang, H. H. (2020). College Students' Cognitive 
Learning Outcomes in Technology-Enabled Active Learning Environments: A MetaAnalysis of the Empirical Literature. Journal of Educational Computing Research, 58(4), 791-817. https://doi.org/10.1177/0735633119881477

Smith, F. (2007). How to Use Social-Networking Technology for Learning. Retrieved January 20, 2020 from https://www.edutopia.org/how-use-social-networking-technology

Smith, T. (2012). Writing measurable learning objectives, TeachOnline Resources for Teaching Online. Retrieved from https://teachonline.asu.edu/2012/07/writing-measurable-learningobjectives/

Snyder, T. (2019). Digest of Education Statistics 2018. National Center for Education Statistics, Institute of Education Sciences, NCES 2020-009. Retrieved from: https://nces.ed.gov/pubs2020/2020009.pdf

Starr, P. (1996, July-August). Computing our way to educational reform. The American Prospect, (27), 50+. Retrieved from https://link-galecom.proxy.library.cmu.edu/apps/doc/A21099419

Stein, K. (2013). Penn GSE Study Shows MOOCs Have Relatively Few Active Users, With Only a Few Persisting to Course End. Penn GSE. Retrieved from https://www.gse.upenn.edu/news/press-releases/penn-gse-study-shows-moocs-haverelatively-few-active-users-only-few-persisting-

Stuckey, H. (2015). The second step in data analysis: Coding qualitative research data. Journal of Social Health and Diabetes, 03(01), 007-010. https://doi.org/10.4103/2321$\underline{0656.140875}$

Sun, J., \& Wu, Y., \& Lee, W. (2017), The effect of the flipped classroom approach to OpenCourseWare instruction on students' self-regulation. British Journal of Educational Technology, 48(3), 713-729. doi:10.1111/bjet.12444 
Suner, A., Yilmaz, Y., \& Pişkin, B. (2019). Mobile learning in dentistry: Usage habits, attitudes and perceptions of undergraduate students. PeerJ, 7, e7391. https://doi.org/10.7717/peerj.7391

Szpunar, K. K., Jing, H. G., \& Schacter, D. L. (2014). Overcoming overconfidence in learning from video-recorded lectures: Implications of interpolated testing for online education. Journal of Applied Research in Memory and Cognition, 3(3), 161-164. https://doi.org/10.1016/j.jarmac.2014.02.001

Tanner, C. (1994). Innovative teaching for active learning and Distance Delivery. Journal of Nurse Education. 33(4), 147-148. doi: 10.3928/0148-4834-19940401-03

Thompson, P. M. (2012). The Popular Profile of the Digital Learner: Technology Use Patterns and Approaches to Learning. Michigan State University. Retrieved from https://search.proquest.com/docview/1033212558

Tomas, L., Evans, N., Doyle, T., \& Skamp, K. (2019). Are first year students ready for a flipped classroom? A case for a flipped learning continuum. International Journal of Educational Technology in Higher Education, 16(1), 5. https://doi.org/10.1186/s41239-019-0135-4

Torregrosa, J., \& Jiminez-Rodriguez, M., \& Torralba-Estelles, J., \& Garzon-Farinos, F. \& PerezBermejo, M. \& Fernandez-Ehrling, N. (2016). Distance learning ects and flipped classroom in the anatomy learning: comparative study of the use of augmented reality, video and notes. BMC Medical Education, 16(230), 1-9.

Trach, E. (2020). A Beginner's Guide to Flipped Classroom. Schoology. Retrieved from: https://www.schoology.com/blog/flipped-classroom

Tseng, M., Lin, C.-H., \& Chen, H. (2018). An immersive flipped classroom for learning Mandarin Chinese: Design, implementation, and outcomes. Computer Assisted Language 
Learning, 31(7), 714-733. https://doi.org/10.1080/09588221.2018.1440603

Tseng, S.-F., Tsao, Y.-W., Yu, L.-C., Chan, C.-L., \& Lai, K. R. (2016). Who will pass? Analyzing learner behaviors in MOOCs. Research and Practice in Technology Enhanced Learning, 11(1), 8. https://doi.org/10.1186/s41039-016-0033-5

Tune, J. D., Sturek, M., \& Basile, D. P. (2013). Flipped classroom model improves graduate student performance in cardiovascular, respiratory, and renal physiology. Advances in Physiology Education, 37(4), 316-320. https://doi.org/10.1152/advan.00091.2013

Unal, Z., Unal, A. (2017). Comparison of Student Performance, Student Perception, and Teacher Satisfaction with Traditional versus Flipped Classroom Models. International Journal of Instruction, 10(4), 145-164. https://doi.org/10.12973/iji.2017.1049a

University at Buffalo (2020). Scaffolding process. Center for Educational Innovation (CEI). Retrieved from http://www.buffalo.edu/ubcei/enhance/teaching/guidingstudents/scaffolding.html

Useem, J. (2014). Business School, Disrupted. The New York Times, BU(1). Retrieved from https://www.nytimes.com/2014/06/01/business/business-school-disrupted.html

Van Alten, D. C. D., Phielix, C., Janssen, J., \& Kester, L. (2019). Effects of flipping the classroom on learning outcomes and satisfaction: A meta-analysis. Educational Research Review, 28, 100281. https://doi.org/10.1016/j.edurev.2019.05.003

Van Wyk, M. M. (2019). Flipping the Economics Class in a Teacher Education Course. Technology, Knowledge and Learning, 24(3), 373-399. https://doi.org/10.1007/s10758018-9377-9

Vaughan, M. (2014). Flipping the Learning: An Investigation into the use of the Flipped Classroom Model in an Introductory Teaching Course. Education Research and 
Perspectives, An International Journal, 41(1), 25-41.

Vey, K., Fandel-Meyer, T., Zipp, J. S., \& Schneider, C. (2017). Learning \& Development in Times of Digital Transformation: Facilitating a Culture of Change and Innovation. International Journal of Advanced Corporate Learning (IJAC), 10(1), 22. https://doi.org/10.3991/ijac.v10i1.6334

Wan, G., \& Gut, D. M. (2011). Bringing schools into the 21st century. Springer Nature Switzerland AG. Retrieved from https://link.springer.com/content/pdf/10.1007\%2F97894-007-0268-4.pdf

Wang, C., Fang, T., \& Gu, Y. (2020). Learning performance and behavioral patterns of online collaborative learning: Impact of cognitive load and affordances of different multimedia. Computers \& Education, 143, 103683. https://doi.org/10.1016/j.compedu.2019.103683

Wang, S. (2015). Online vs. On-Campus: An Analysis of Course Prices of U.S. Educational Institutions. Online Journal of Distance Learning Administration, Volume XVIII(2), 4.

Wasserman, N. H., Quint, C., Norris, S. A., \& Carr, T. (2017). Exploring Flipped Classroom Instruction in Calculus III. International Journal of Science and Mathematics Education, 15(3), 545-568. https://doi.org/10.1007/s10763-015-9704-8

Weir, J. A. (2005). Active learning in transportation engineering education. Worcester Polytechnic Institute, Ann Arbor.

White, C. (2005). Contribution of Distance Education to the Development of Individual Learners. Distance Education, 26(2), 165-181. https://doi.org/10.1080/01587910500168835

Widyasari, Y. D. L., Nugroho, L. E., \& Permanasari, A. E. (2019). Persuasive technology for enhanced learning behavior in higher education. International Journal of Educational 
Technology in Higher Education, 16(1), 15. https://doi.org/10.1186/s41239-019-0142-5

Wiley, J. (2019). How the 2019 Tech Landscape Maps Higher Ed Technology. ACT-NRCCUA. Retrieved from: https://encoura.org/revealing-the-2019-tech-landscape/

Wilkinson, T. and Sherman, T. (1989). Distance Education and Student Procrastination. Educational Technology, 29(12), pp. 24-27.

Windschitl, M. (2002). Framing constructivism in practice as the negotiation of dilemmas: An analysis of the conceptual, pedagogical, cultural, and political challenges facing teachers. Review of Educational Research, 72(2), 131-175.

Woods, D. M. (2020). Active Learning Using Debates in an IT Strategy Course. Journal of Information Systems Education, 31(1), 12.

Xu, Z., \& Shi, Y. (2018). Application of Constructivist Theory in Flipped Classroom - Take College English Teaching as a Case Study. Theory and Practice in Language Studies, 8(7), 880. https://doi.org/10.17507/tpls.0807.21

Yadollahi, A., Shahraki, A. G., \& Zaiane, O. R. (2017). Current State of Text Sentiment Analysis from Opinion to Emotion Mining. ACM Computing Surveys, 50(2), 1-33. https://doi.org/10.1145/3057270

Yang, J. C., Quadir, B., Chen, N.-S., \& Miao, Q. (2016). Effects of online presence on learning performance in a blog-based online course. The Internet and Higher Education, 30, 1120. https://doi.org/10.1016/j.iheduc.2016.04.002

Yellin, B. (2019). Saving the future of Moore's Law. Dell Technologies' Proven Professional Knowledge Sharing. Retrieved from: https://education.dellemc.com/content/dam/dellemc/documents/en-us/2019KS Yellin-Saving The Future of Moores Law.pdf 
Yilmaz, O. (2015). The Effects of "Live Virtual Classroom" on Students' Achievement and Students' Opinions About "Live Virtual Classroom" at Distance Education. The Turkish Online Journal of Educational Technology, 14(1), 8.

Yilmaz, R., \& Keser, H. (2015). Transactional Distance Perception and Its Reflections on Distance Education Practices. Journal of Faculty of Educational Sciences, 48(2), 37-59.

Young, A., \& Norgard, C. (2006). Assessing the quality of online courses from the students' perspective. The Internet and Higher Education, 9(2), 107-115. https://doi.org/10.1016/j.iheduc.2006.03.001

Young, S., \& Duncan, H. E. (2014). Online and face-to-face teaching: How do student ratings differ? MERLOT Journal of Online Learning and Teaching, 10(1), 70-79.

Yousef, A. M. F., Chatti, M. A., Schroeder, U., \& Wosnitza, M. (2015). A usability evaluation of a blended MOOC environment: An experimental case study. The International Review of Research in Open and Distributed Learning, 16(2). https://doi.org/10.19173/irrodl.v16i2.2032

Zainuddin, Z., Habiburrahim, H., Muluk, S., \& Keumala, C. M. (2019). How do students become self-directed learners in the EFL flipped-class pedagogy? A study in higher education. Indonesian Journal of Applied Linguistics, 8(3), 678. https://doi.org/10.17509/ijal.v8i3.15270

Zhu, C. (2012). Student Satisfaction, Performance, and Knowledge Construction in Online Collaborative Learning. Educational Technology \& Society, 15(1),127-136.

Zong, N., Li, W., \& Jia, B. (2018). A Brief Discussion About the Accessibility and Usability of Web-Based Instruction in Software Design Teaching. In S. Liu, M. Glowatz, M. Zappatore, H. Gao, B. Jia, \& A. Bucciero (Eds.), E-Learning, e-Education, and Online 
Training (Vol. 243, pp. 8-16). Springer International Publishing. https://doi.org/10.1007/978-3-319-93719-9 2

Zuriff, G. E. (2003). Science and Human Behavior, Dualism and Conceptual Modification. Journal of the Experimental Analysis of Behavior, 80(3), 345-352. https://doi.org/10.1901/jeab.2003.80-345 


\section{Appendix}

\section{Appendix A. Summary of Comments:}

The following are a selection of comments and questions posed to me from former and current students, one teaching assistant and two current faculty members that I have had discussions with. To learn more about my course, how it is delivered, and the content that students get out of it, it was quite helpful to discuss the course with those that have had experience in it, those that are experiencing it and other like-minded individuals that can give a true assessment of the course.

These discussions are a mix of in-person, e-mail and phone calls. The questions and comments are a combination of the evaluation questions used in the end evaluation, questions from my program evaluation and other topics of interest that have been identified through the digital transformation course. Comments here are referenced in the instructional design to help analyze and configure the aspects of the course.

\section{A1. From Current Students:}

Q: Is there a chance we could suggest a team? A couple of my partners and friends and I had been working together as a group and we could accommodate quite well for our schedules which in this distance learning classes class?? helps quite a bit.

Q: I do prefer (to work) with team that has four members since I have the same zone time and close experience collaborating with some of them, with help me out to save time and avoid a learning curve within the restrictions of time I have due to a strong work load I'm facing currently.

Q: Sometimes I am on the field supervising jobs with explosives and radiation days on a row without a public internet access. I hope attending the net meetings in real time is not a requirement?

Q: Is it ok to reuse some ideas/discussion points that I previously used in a discussion board post (as long as my entire exam isn't just a rehash of it)?

Q: I have some time to review the answers of our presentation 1 (iOS vs Android). But, I do not know where to look for my answers to take your word on finding questions and answers that could cover some of your comments. Is it possible to review the log of those Q\&A?

Q: I dislike group projects, especially those where there really is no recourse for lack of participation by group members. I understand the desire to recreate the real world, but in the real world I have recourse where team members do not fulfill requirements. I would have rather that I did EVERY assignment on my own. In one case I did that only to find out that another team member was also working on parts of the assignment without my knowledge despite frequent communications. 
C: Our presentation went a little longer because I had technical issues with my Internet connection when I was presenting and asked permission to go back to my slides at the end (we lost several minutes there), but still the team was able to answer most if not all the questions in our write-up. Hopefully this is taken into consideration when grading.

$\mathrm{C}$ : I have found really complicated the format for this class. I don't understand the evaluation criteria for the deliverables. For some write-ups we make references to only material from class and it was not enough. For others we make references from to material and again it was not enough. In the presentations we made references to class material and outside material and again we have an important downgrade.

$\mathrm{C}$ : We lost points for not having extremely detailed analysis in the paper, however, the problem we have been faced with is that we only have two pages to cover the whole topic, which doesn't allows us to get extremely deep into any specific example. If we deep dive into any one example we would run out room to provide any additional examples, which would equally lessen our overall argument (and hurt our grade). In this paper we had three specific examples which we supplied to make our case, and given the structure of the paper it would be difficult to go deeper into any one example without adding additional pages.

Q: I am part of Team 3 that will present next week. We are dealing with the topic 'IT will lead to more centralization'. I have gone thru the readings (really heavy information). I think IT can be both centralized and de-centralized based on what you want it to be for your organizational culture or other parameters. They both can be good if applied relevantly and will fail if not. IT gives you flexibility for both options.

Today everything we do with our computers / tablets / phones is known to someone somewhere. How do we support one versus other?

Q: Are we allowed to undertake any research as part of the final? Can we cite sources? I'm trying to explore whether older CEOs are preventing their companies from leveraging the potentials and possibilities of digital transformation, but it's hard to do without being able to do any research.

Q: This is the last course of the program, and it is the first time we are asked to do a peer evaluation, so I have some doubts. Is it "secret"? I mean, I would like to have feedback from my peers, but I don't know if each feedback would have a name on it.

Q: Should I include and cover all the following points or just some of them? My previous understanding about IT and its impact on certain area (example, financial industry)? What I've learned from the class? How the course changes or impacts my view on the subject? My further research on IT and its impact on that area/ those areas outside the course?

\section{A2. From Former Students:}

C: The readings were great. I wish there had been a better way to talk/ask questions during the webinars. The chat window was so small that it was next to impossible to keep track of all the discussions flying by.

Q: If you allow me a suggestion I think is better to have a sixth group and ending with three 3members groups instead of one 4-members and another 5-members, specially more complicated for the last where collaboration challenge is not linear with an additional member and I think is not fair for us being in that group, in other hand it can be thought as less work per member in average but I think is opposite within this context. 
Q: I was wondering whether it is ok for only two of us to present (maybe three, if Brent is up for it). The reason that I'm asking is because Joel Garcia has not participated up to this point and I don't feel confident that he will join us tomorrow, causing us to scramble again. We also would expect Joel to step up at some point; I hate to write a note like this - this is my last semester at <university> and I haven't experienced anything like this before. I know this sort of nonsense happens in life and that we have to deal with it. I am just requesting that we cut Joel out of this presentation and ask whether we can work out the details with Brent (whether he wants to get up to speed and present) because of his recent life event. If it is mandatory that everybody present then we'll have to coordinate something.

$\mathrm{C}$ : I didn't have any issue on being in a group of two, although I don't agree with the fact that the effort would be the same for a 2 student group than for groups of 3 or 4 students. To me presenting is not the issue, additional research, essays and presentations are harder to generate for 2. This should be taken into consideration.

C: Well, I have really enjoyed this class because we do not have a textbook to memorize, and that forces us to think, and to defend an argument even if you don't believe in it.

$\mathrm{C}$ : There needs to be some some consideration and some way to compensate for unbalanced work assignments. In my point of view you did not provide enough time to complete them nor a timely feedback to improve them.

$\mathrm{C}$ : I think my grade was low and not according to the criteria established in the case submission examples, where clearly stands that format is not the main element to fulfill the grade, also that there is not right or wrong answers, and in top of everything it encourage us to avoid being wimps.

$\mathrm{C}$ : My perception about the class is an environment for making opinions with support on references. We made an opinion with references for the presentation. But your comments makes me think we don't have an opinion.

Q: I just want to add that this was one of my two last classes in my master's program and this was the worst grade that I have received. I am feeling a little disoriented about what is missing in my write-ups, and I want to know what things we need to consider in order to get better grades. C: I think this class was more approaching IT to fix problems, I didn't realize the importance of having a good IT strategy and how it can make a competitive advantage not for getting the latest technology, but by doing something unique with IT resources.

C: I appreciate your leadership in this class, and the information you shared, and the way you presented it made a difference to understand and see the real value of all these lectures.

C: Some of Your comments point out discrepancies about the fact IT matters, but one of the main points in Carr's document is the fact that he uses irony to remark the fact that IT matters, and in the other extreme you make comments about some ideas in our documents as been excellent or positively affirming it. So, as everything else in the course it was confusing and hard to follow, and more difficult to properly plan in advance, since we didn't have the time that a regular student has attending presentation classes.

\section{A3. From Faculty:}


Q: The due dates for assignments can be confusing as there are multiple locations stating when things are due, and there can be conflicts. Can this all be centralized?

Q: I would like to understand what will be the criteria for the final exam, For example, are you looking at grammar, or answering more of the questions you have in the documents. What if "Music Industry" topic caught my eye and I develop the whole paper based on this?

Q: I would like to understand your evaluation criteria. You mentioned to me that the grades are based on a curve depending how the whole class does. How does losing one point on an assignment impact the grade without knowing the real impact? I just want to understand how this grade system moves towards $0-100$ grade or to $\mathrm{D}$ or $\mathrm{A}+$ grade.

$\mathrm{C}$ : The class video recording is $\mathrm{OK}$, but 1) It is hard to understand what the students say when they are presenting (poor audio quality). 2) Not sure if the in-person recording is the best possible educative resource, by comparing the video classes available in Coursera it's clear they spent time designing and creating the video contents and it shows.

C: Just to be completely honest, the course is very interesting, and make students have a clear perspective and develop a personal opinion on what digital transformation is and how it affects society. However, the questions seems a little generic, and the grading might be a little too specific and subjective. Maybe, you can change that a little bit for the next iteration of the course, because, besides that, it is really a great course.

C: From a student's perspective, GPA matters! If you spend several nights studying and doing homework, keeping a good GPA is a motivation for not quitting, even when family and work become overwhelming. I see a generational gap in the course, but that's what makes it more interesting.

Q: How do you calculate the percentage of participation? By time spent? Production in the meetings? Length of each write-up? The quality of each contribution?

$\mathrm{C}$ : The grading rubric is good. Focus on the assignments, presentations and final over the rest is a solid approach.

Q: I have a question about final exam question 1. Is this write-up mainly focusing on how student learn from the class and course and how the course influences their view on IT? When you say focusing on a particular subject, it could be an industry or even a company. Am I understanding it in the right way?

\section{A4. From the Teaching Assistants:}

Q: How much impact on the grading of a paper should following a format other than the one specified in the Notes on Case Analysis and Sample Case Write-up PDFs? In other words, if the paper was written NOT from the perspective of an outside consultant writing a business memo to a member of senior management, should the paper be graded adversely? And, if so, by how much?

Q: How much should I let grammar and mechanics impact the grade (if at all)? It seems we have a large contingent of students whose primary language is probably not English, which is to be expected in a distance learning course, of course, so it stands to reason that there will be some grammatical and mechanical errors in submissions. Should I simply ignore these and focus on the content, or should I allow this to play some factor in the overall grading of a paper? I'll warn you that I was almost an English major as an undergrad, so I can have fun doing that ... but I'm 
not sure if I should assume that these guys should write good English as a part of this class or not.

Q: I have had some students come to me in the past asking us about efficient strategies to make the most out of team meetings. What are your suggestions?

Q: How do we represent the grade percentage? Is it for each write-up/presentation? Is it a percentage for summary and another for presentations? Of just a total percentage (calculating it with an excel sheet)?

\section{Appendix B. Faculty Course Evaluation (FCE) Form for Engagement Assessment}

This course also provides and end-of-course evaluation for the students to fill out and give feedback on. This is used by the instructor and the school to provide data on how the course is run, what can be done to improve the course and anything else that could add value to the course.

Course evaluations are also helpful in looking at particular statistics on course content, materials covered, assignments, lectures/readings, relevancy to their degree/curriculum and to get an overall rating of how the course works from an unbiased but experienced reviewer.

Course Evaluation Questions:

- Course content matched goals?

- $\quad$ Exams covered material?

- Assignment covered material?

- Lectures, readings helped learn?

- Discussions/readings helped?

- $\quad$ Relevant to the curriculum?

- Overall rating of this course? 


\section{B1. Faculty Course Evaluation Form:}

\section{Faculty Course Evaluation}

Course Number:

Section:

Carnegie Mellon University

Instructor:

\begin{tabular}{llllllllll} 
& \multicolumn{5}{c}{ Fill in the appropriate circle for each question. } \\
\hline $1-3$ & $4-6$ & $7-9$ & $10-12$ & $13-15$ & $16-18$ & $19-21$ & $22-24$ & $25+$
\end{tabular}

I. On average, how many hours per week have you spent on this class, including attending classes, doing readings, reviewing notes, writing papers and any other course related work?

2. Does the faculty member display an interest in students' learning?

3. Does the faculty member provide a clear explanation of the course requirements?

4. Does the faculty member provide a clear explanation of the learning objectives or goals of the course?

5. Does the faculty member provide feedback that helped students improve their performance?

6. Does the faculty member demonstrate the importance and significance of the subject matter?

7. Does the faculty member explain the subject matter of the course (e.g. concepts, skills, techniques, etc.)?

8. Does the faculty member show respect for all students?

9. Overall how would you rate this faculty's teaching?

Io. How would you rate the overall quality of the course?

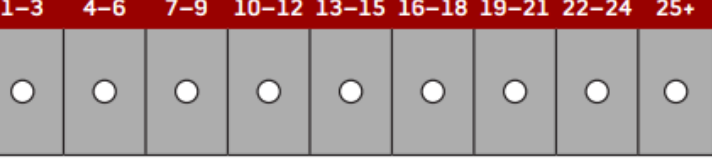

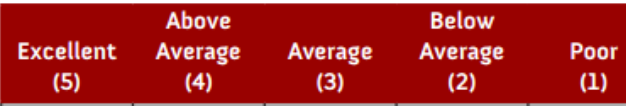

Comments: 


\section{Carnegie Mellon University}

Institutional Review Board

Federalwide Assurance No: FWA00004206

IRB Registration No: IRB00000352

\section{APPROVAL OF SUBMISSION}

August 20, 2019

\begin{tabular}{|r|l|}
\hline Type of Review: & Initial Study \\
\hline Title of Study: & $\begin{array}{l}\text { A review of kinesthetic learning as applied to distance } \\
\text { education. }\end{array}$ \\
\hline $\begin{array}{r}\text { Investigator: } \\
\text { Study Team Members: }\end{array}$ & $\begin{array}{l}\text { James Riel } \\
\text { Jared Simmer }\end{array}$ \\
\hline IRB ID: & STUDY2019_00000295 \\
\hline Funding: & None \\
\hline
\end{tabular}

The Carnegie Mellon University Institutional Review Board (IRB) has reviewed and granted APPROVAL under Exempt on 8/20/2019, in accordance with 45 CFR 46.104. You will be asked to update the IRB on the progress of your study at the assigned "Check-In" date of $8 / 20 / 2021$.

However, if you wish to make modifications to this protocol, please contact the IRB regarding these changes prior to their implementation to ensure compliance with this designation.

The Investigator(s) listed above in conducting this protocol agree(s) to follow the recommendations of the IRB of any conditions to or changes in procedure subsequent to this review. In undertaking the execution of the protocol, the investigator(s) further agree(s) to abide by all CMU research policies including, but not limited to the policies on responsible conduct research and conflict of interest.

Sincerely,

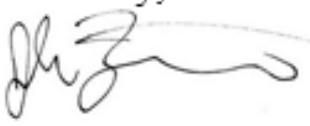

John Zimmerman, IRB Chair

Teresa Reiche 


\section{Appendix D. Pre-Post Assessment Instrument}

The pre-assessment is given during the first week of the class. The post-assessment is given during the final week of the class (week 8). Both surveys are the same to correlate data between each perceived learning engagement.

\begin{tabular}{|c|c|c|}
\hline $\begin{array}{l}\text { My overall level of confidence in examining digital } \\
\text { transformation initiatives within a } \\
\text { business/industry context: }\end{array}$ & [ Select ] & $\checkmark$ \\
\hline $\begin{array}{l}\text { How comfortable I am in making managerial } \\
\text { decisions through the lifecycle (early to late } \\
\text { adoption) of technology: }\end{array}$ & [ Select ] & $\checkmark$ \\
\hline $\begin{array}{l}\text { My confidence level in how IT can effect changes } \\
\text { in organization and industry structure: }\end{array}$ & [ Select ] & $\checkmark$ \\
\hline $\begin{array}{l}\text { The degree to which I understand how IT drives } \\
\text { changes in supply and demand through short and } \\
\text { long tail markets: }\end{array}$ & [ Select ] & $\checkmark$ \\
\hline $\begin{array}{l}\text { The degree to which I understand and can apply } \\
\text { theories and/or methodologies of different digital } \\
\text { transformation models: }\end{array}$ & [ Select ] & $\checkmark$ \\
\hline $\begin{array}{l}\text { The degree to which I understand and can apply } \\
\text { methodologies surrounding whether IT matters in } \\
\text { a business/managerial context: }\end{array}$ & [ Select ] & $\checkmark$ \\
\hline $\begin{array}{l}\text { The degree to which l'm comfortable considering } \\
\text { current digital transformation trends and } \\
\text { emergent technologies for future } \\
\text { business/industry scope: }\end{array}$ & [ Select ] & 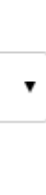 \\
\hline $\begin{array}{l}\text { The degree to which I understand and } \\
\text { acknowledge the difference between disruptive } \\
\text { versus sustaining innovations: }\end{array}$ & [ Select ] & $\checkmark$ \\
\hline $\begin{array}{l}\text { Confidence in understanding how IT decisions can } \\
\text { impact competitive advantage through } \\
\text { businesses and industries: }\end{array}$ & [ Select ] & $\vec{v}$ \\
\hline $\begin{array}{l}\text { An understanding of what disruptive change can } \\
\text { mean to a business/industry: }\end{array}$ & [ Select ] & v \\
\hline
\end{tabular}




\section{Appendix E. Quantitative Learning Assessment Instrument}

Learning assessments contain 20 "multiple answer" and/or "true or false" questions in total.

Student in the digital transformation classes take up to five of these assessments per semester.

E1. Sample of the Learning Assessments:

Question 1
Early theories stated that computers couldn't do what?
$\square$ Complex Communication
$\square$ Neither
$\square$ Pattern Recognition

Question 2
Productivity is a concept that looks at:
$\square$ Output quantity produced from a single input unit
$\square$ The value of a proxy
$\square$ The measurement of IT investment in production scale
$\square$ Production from business investments


E2. Example Summary:

\section{Quiz Summary}

(4) Average Score

$71 \%$

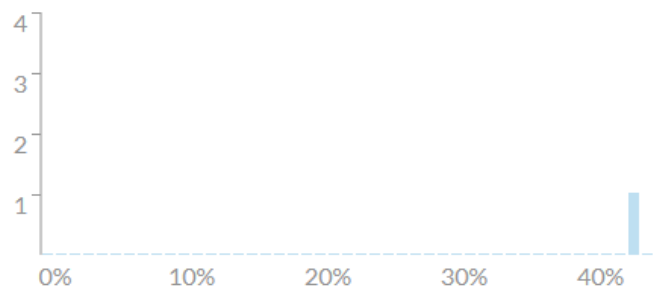

Section Filter $\mathbf{v} \quad$ 夰 Student Analysis

萂Item Analysis

() Low Score

(1) Standard Deviation

(1) Average Time

$90 \%$

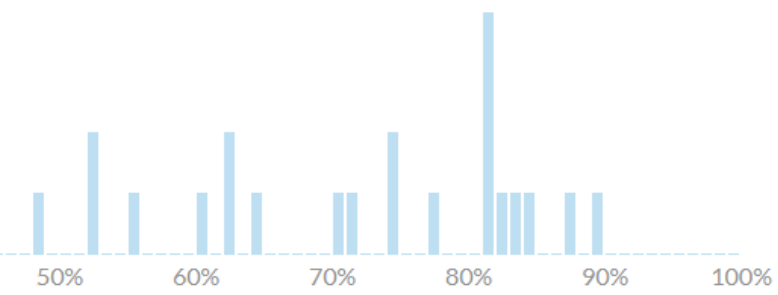

\section{Appendix F. Learning Engagement Survey Instrument}

Learners are given an engagement experience survey to take at the conclusion of the course to gauge their experiences comparative to other traditional and distance courses in terms of their engagement experiences.

\section{F1. Learners Engagement Experience Assessment:}

\begin{tabular}{|l|}
\hline Question 1 \\
\hline Have you ever taken a distance education class before this class (a class that did not meet physically \\
in-person)? \\
Yes \\
No \\
\hline
\end{tabular}

\begin{tabular}{|l|}
\hline Question 2 \\
\hline \\
Were any of your distance education classes including active participation (e.g. live meetings, live \\
interactive lectures, live activities, live workshops, etc.)? \\
Yes \\
No
\end{tabular}




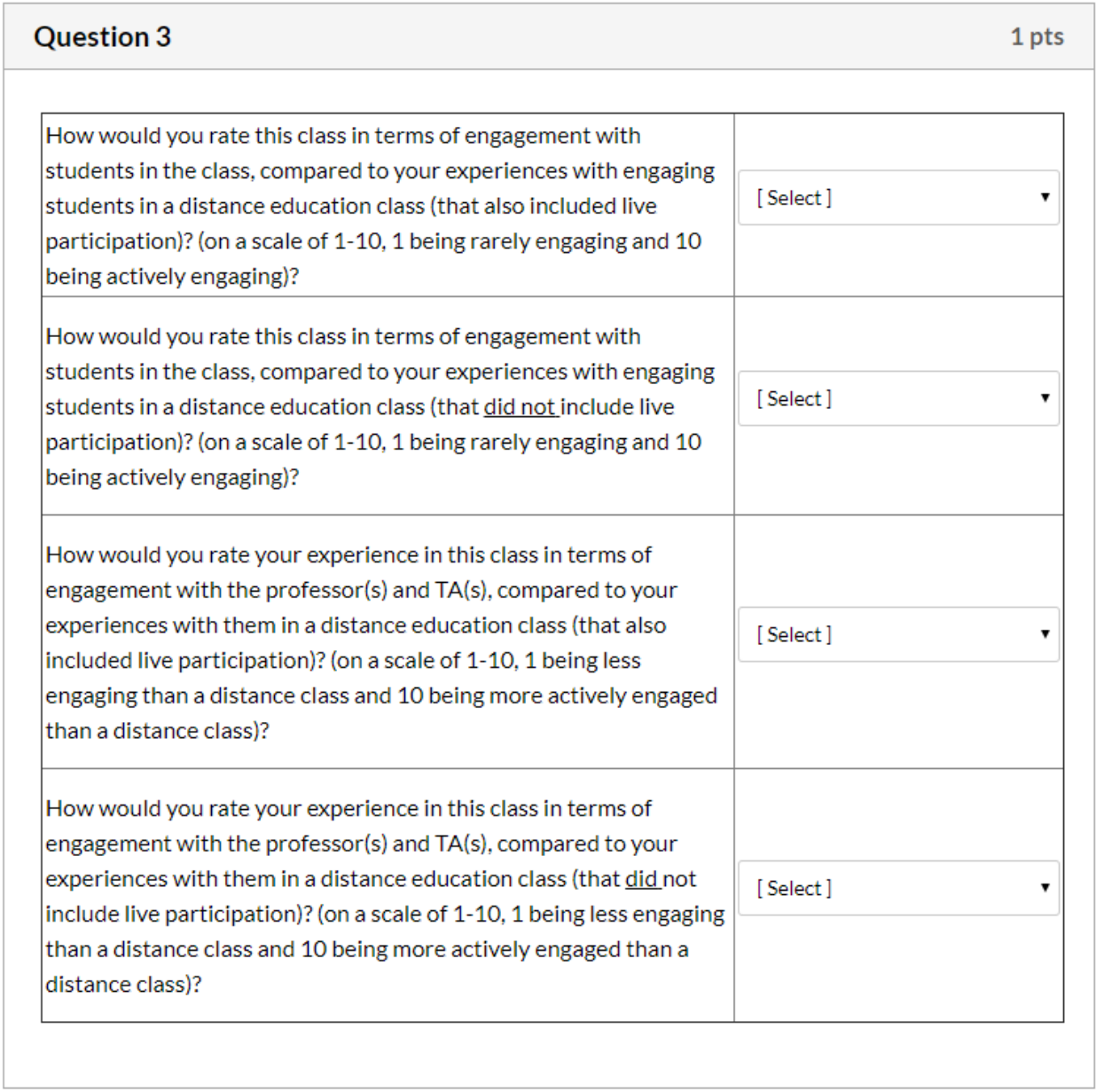

\section{Question 4}

\begin{tabular}{|l|l|}
\hline $\begin{array}{l}\text { How would you rate your activities in this class compared to those } \\
\text { in a distance education class (that included active participation)? }\end{array}$ & [ Select ] \\
\hline $\begin{array}{l}\text { How would you rate your activities in this class compared to those } \\
\text { in a distance education class (that did not include active } \\
\text { participation)? }\end{array}$ & [ Select ] \\
\hline $\begin{array}{l}\text { Overall, did your experiences in this class compared to your } \\
\text { experiences in distance education classes (that included active } \\
\text { participation) seem: }\end{array}$ & [ Select ] \\
\hline $\begin{array}{l}\text { Overall, did your experiences in this class compared to your } \\
\text { experiences in distance education classes (that did not include } \\
\text { active participation) seem: }\end{array}$ & [ Select ] \\
\hline
\end{tabular}




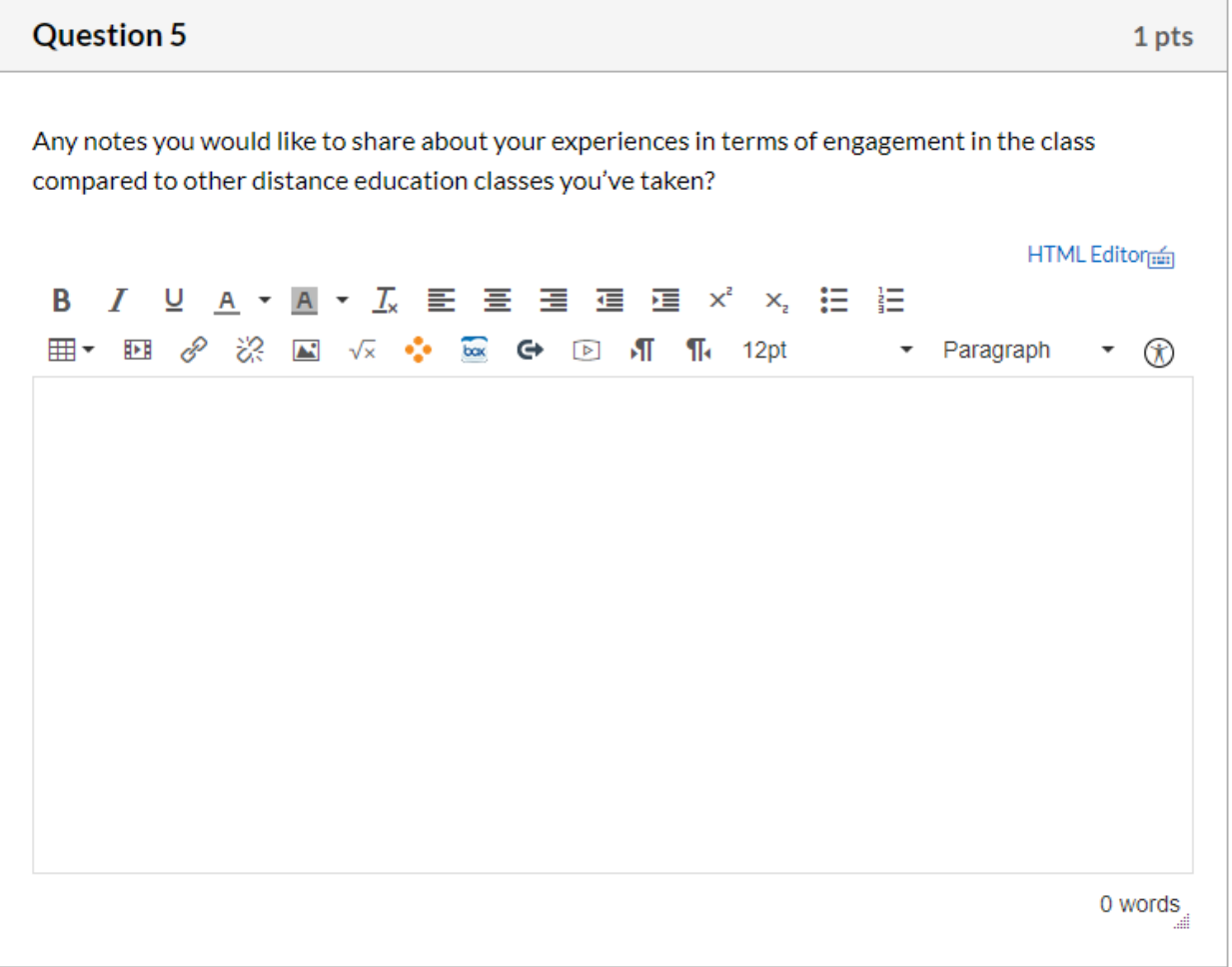

$\begin{array}{ll}\text { Question } 6 & 1 \text { pts }\end{array}$

Have you ever taken an in-class (on-campus class) before this class (a class that did meet physically inperson) in your higher education (anything beyond high school)?

Yes

No

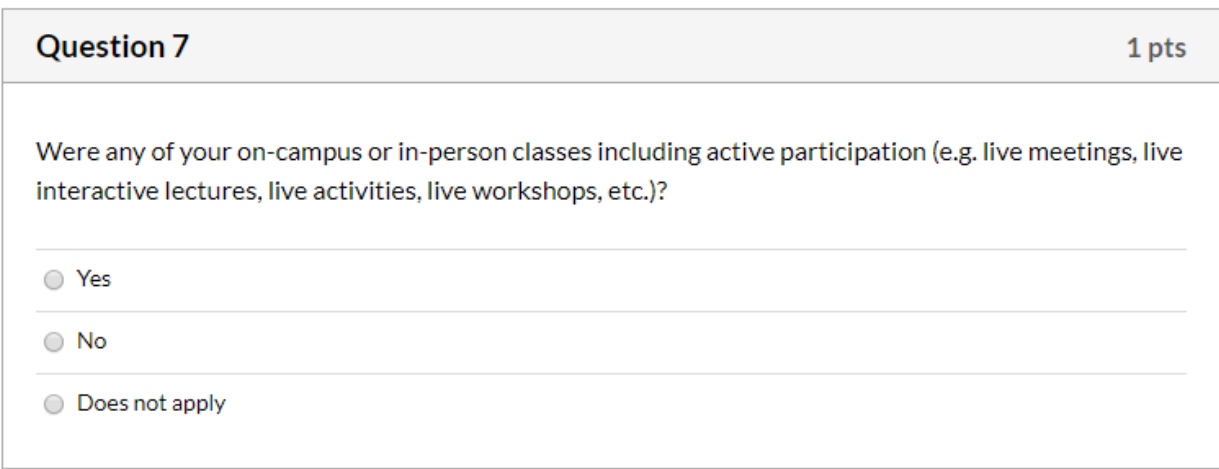




\begin{tabular}{|c|c|c|}
\hline \multicolumn{2}{|l|}{ Question 8} & $1 \mathrm{pts}$ \\
\hline $\begin{array}{l}\text { How would you rate this class in terms of engagement with } \\
\text { students in the class, compared to your experiences with engaging } \\
\text { students in an in-person education class (that also included live } \\
\text { participation)? (on a scale of 1-10, } 1 \text { being rarely engaging and } 10 \\
\text { being actively engaging)? }\end{array}$ & [ Select ] & $\checkmark$ \\
\hline $\begin{array}{l}\text { How would you rate this class in terms of engagement with } \\
\text { students in the class, compared to your experiences with engaging } \\
\text { students in an in-person education class (that did not include live } \\
\text { participation)? (on a scale of 1-10, } 1 \text { being rarely engaging and } 10 \\
\text { being actively engaging)? }\end{array}$ & [ Select ] & $\checkmark$ \\
\hline $\begin{array}{l}\text { How would you rate your experience in this class in terms of } \\
\text { engagement with the professor(s) and TA(s), compared to your } \\
\text { experiences with them in an in-person education class (that also } \\
\text { included live participation)? (on a scale of } 1-10,1 \text { being less } \\
\text { engaging than a distance class and } 10 \text { being more actively engaged } \\
\text { than a distance class)? }\end{array}$ & [Select ] & v \\
\hline $\begin{array}{l}\text { How would you rate your experience in this class in terms of } \\
\text { engagement with the professor(s) and TA(s), compared to your } \\
\text { experiences with them in an in-person education class (that did not } \\
\text { include live participation)? (on a scale of 1-10, } 1 \text { being less engaging } \\
\text { than a distance class and } 10 \text { being more actively engaged than a } \\
\text { distance class)? }\end{array}$ & [ Select ] & $\checkmark$ \\
\hline Question 9 & & $1 \mathrm{pts}$ \\
\hline $\begin{array}{l}\text { How would you rate your activities in this class compared to those } \\
\text { in an in-person education class (that included active participation)? }\end{array}$ & [ Select ] & v \\
\hline $\begin{array}{l}\text { How would you rate your activities in this class compared to those } \\
\text { in an in-person education class (that did not include active } \\
\text { participation)? }\end{array}$ & [ Select ] & v \\
\hline $\begin{array}{l}\text { Overall, did your experiences in this class compared to your } \\
\text { experiences in an in-person education class (that included active } \\
\text { participation) seem: }\end{array}$ & [Select ] & v \\
\hline $\begin{array}{l}\text { Overall, did your experiences in this class compared to your } \\
\text { experiences in an in-person education class (that did not include } \\
\text { active participation) seem: }\end{array}$ & [ Select ] & $\checkmark$ \\
\hline
\end{tabular}




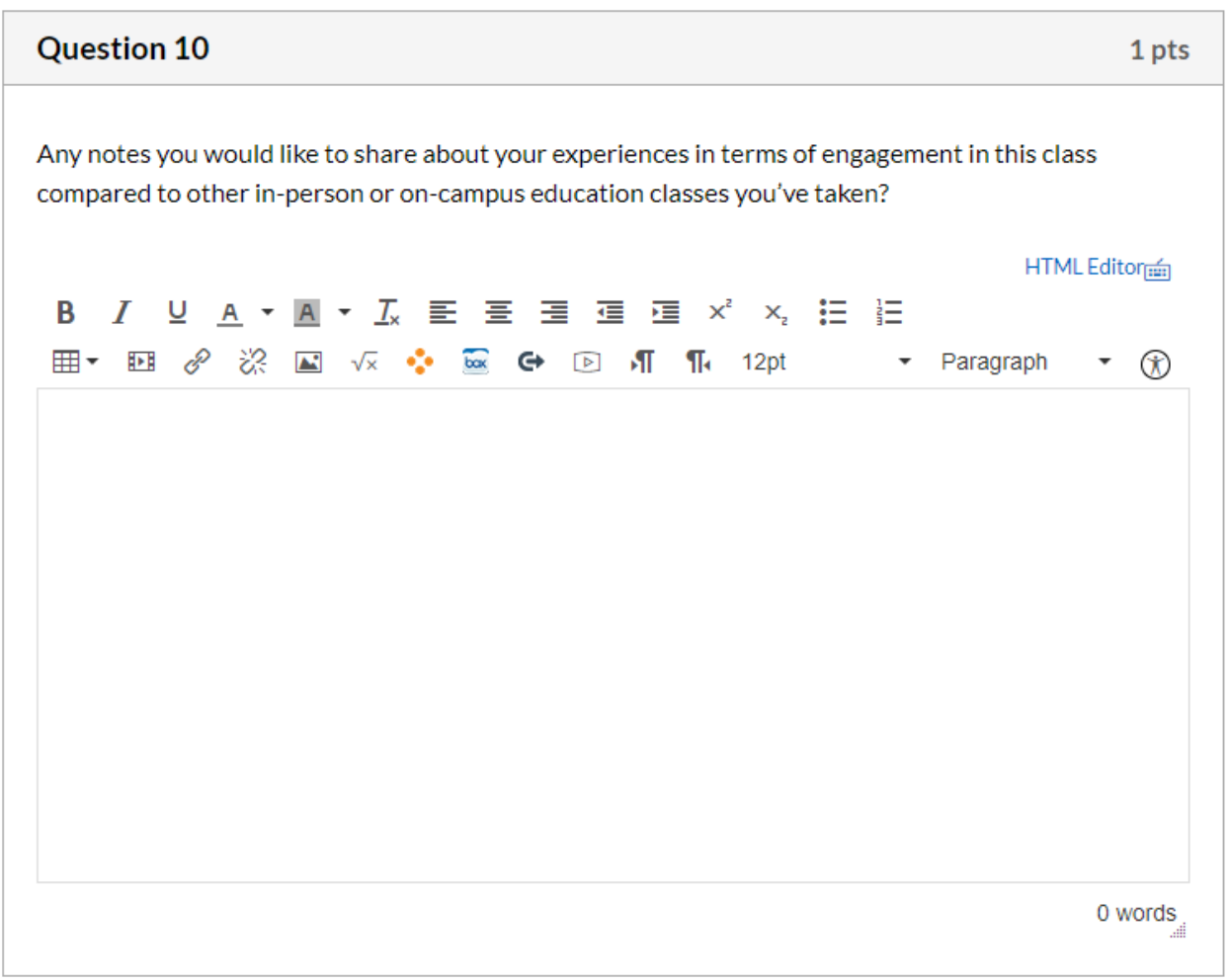

Appendix G. Miscellaneous Active Learning Exhibits

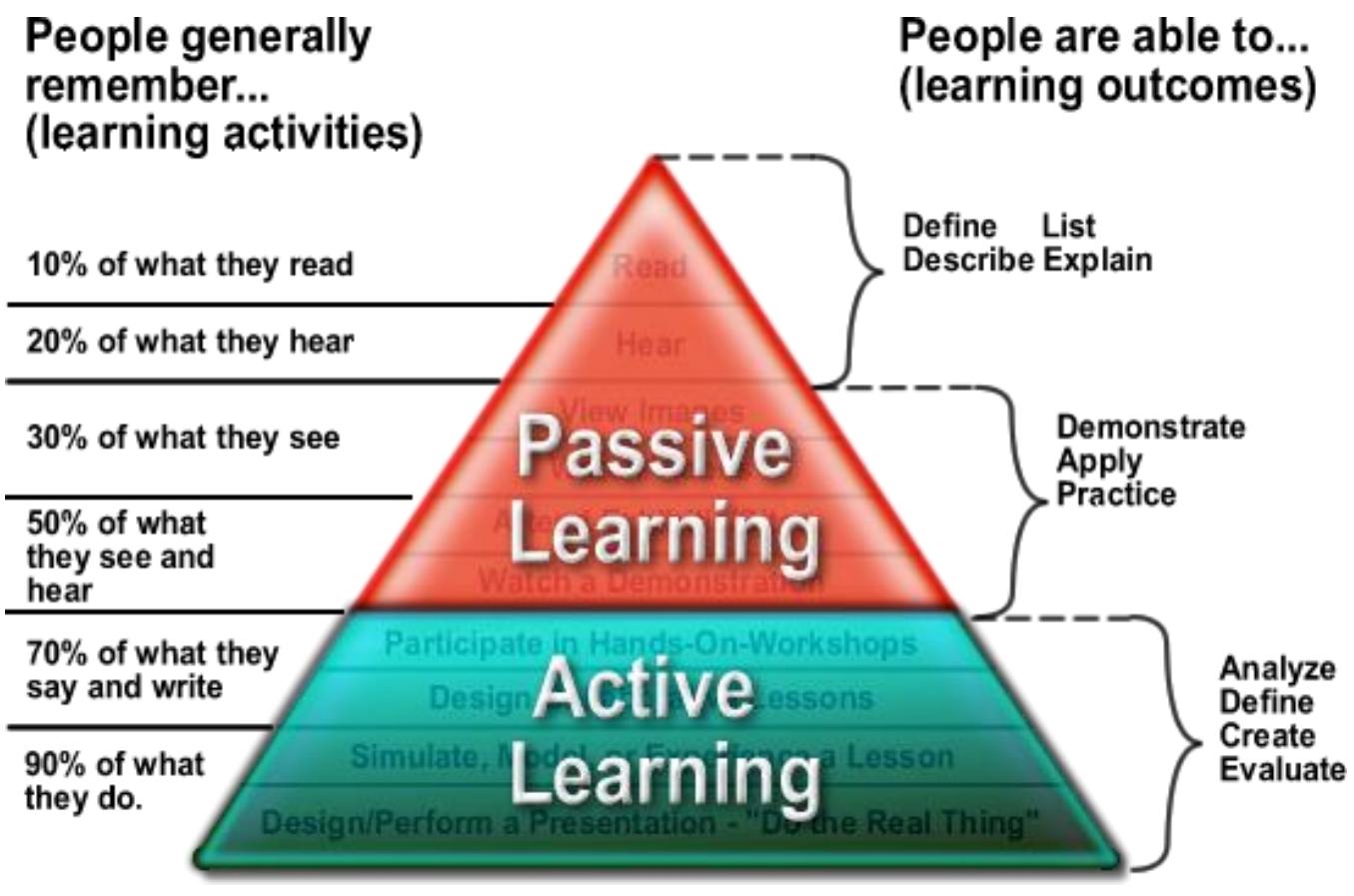

Figure G1. A Chart of Active Versus Passive Learning Retention. 


\section{Characteristics of Passive \& Active Learners}

\begin{tabular}{|c|c|c|}
\hline & Passive & Active \\
\hline Class lectures & Write down what the Instructor says & Decide what is important to write down \\
\hline $\begin{array}{l}\text { Textbook } \\
\text { Assignments, } \\
\text { Studying }\end{array}$ & $\begin{array}{l}\text { Read } \\
\text { Reread }\end{array}$ & $\begin{array}{l}\text { Read, think, ask questions, try to connect } \\
\text { ideas }\end{array}$ \\
\hline $\begin{array}{l}\text { Writing, Class } \\
\text { Assignments }\end{array}$ & $\begin{array}{l}\text { Carefully follows the professor's } \\
\text { instructions }\end{array}$ & $\begin{array}{l}\text { Try to discover the significance of the } \\
\text { assignment; look for the principles and } \\
\text { concepts it illustrates }\end{array}$ \\
\hline $\begin{array}{l}\text { Writing, Class } \\
\text { Assignments }\end{array}$ & Do what is expected to get a good grade & $\begin{array}{l}\text { Make outlines and study sheets, look for } \\
\text { trends and patterns. }\end{array}$ \\
\hline $\begin{array}{l}\text { Writing term } \\
\text { papers }\end{array}$ & Do what is expected to get a good grade & $\begin{array}{l}\text { Try to expand your knowledge and } \\
\text { experience with a top ic and connect it to the } \\
\text { course objective or content }\end{array}$ \\
\hline
\end{tabular}

Figure G2. A Chart of Characteristics of Passive and Active Learners.

\section{Appendix H. Future Research Questions and Opportunities}

The two research questions in this study can also be examined in correlation to each other to address the following third research question:

RQ3: Do the perceived engagements from students change the learning in a positive or negative fashion?

H3: Increases in perceived engagement of students lead to positive increases in learning.

Other research opportunities including looking at changes across demographics, degree types, courses and other universities to gauge differences in learning and engagement.

\section{Appendix I: Study Reports}

\section{I1. Development Timeline}

To ensure progress of the research and deliverables, a timeline had been created that can be assessed and approved by both the doctoral student and committee members. The following 
Gantt chart in Figure I1 shows the timeline for data gathering and analysis. This gathering will be repeated through 2018-2020 to get the required amount of data needed for a successful research study.

\begin{tabular}{|c|c|c|c|c|c|c|c|c|c|c|c|c|c|}
\hline & 2018 & Jan & Feb & Mar & Apr & May & Jun & Jul & Aug & Sept & Oct & Nov & Dec \\
\hline $\begin{array}{l}\text { Course } \\
\text { Duration }\end{array}$ & & & & & & & & & & & & & \\
\hline $\begin{array}{l}\text { Data } \\
\text { Collection }\end{array}$ & & & & & & & & & & & & & \\
\hline $\begin{array}{l}\text { Data } \\
\text { Analysis }\end{array}$ & & & & & & & & & & & & & \\
\hline & 2019 & Jan & Feb & Mar & Apr & May & Jun & Jul & Aug & Sept & Oct & Nov & Dec \\
\hline $\begin{array}{l}\text { Course } \\
\text { Duration }\end{array}$ & & & & & & & & & & & & & \\
\hline $\begin{array}{l}\text { Data } \\
\text { Collection }\end{array}$ & & & & & & & & & & & & & \\
\hline $\begin{array}{l}\text { Data } \\
\text { Analysis }\end{array}$ & & & & & & & & & & & & & \\
\hline & 2020 & Jan & Feb & Mar & Apr & May & Jun & Jul & Aug & & & & \\
\hline $\begin{array}{l}\text { Course } \\
\text { Duration }\end{array}$ & & & & & & & & & & & & & \\
\hline $\begin{array}{l}\text { Data } \\
\text { Collection }\end{array}$ & & & & & & & & & & & & & \\
\hline $\begin{array}{l}\text { Data } \\
\text { Analysis }\end{array}$ & & & & & & & & & & & & & \\
\hline
\end{tabular}

Figure I1. Data Collection Timeline

Proper data collection through this timeline to keep to this schedule relies on there being an ample number of students, and that all data collected from students is usable for the purposes of this study. The data collection completion and analysis deadline for use in the study is July 2020.

\section{Appendix J: Course Tools (Hardware and Software)}

For purposes of this study, the technical tools used to deliver content and collect data are from the Canvas Learning Management System. Keeping in mind that any learning management 
system is adequate for collecting this type of data, this is what is currently being utilized at the focus university for online distance education. Figure 8 shows the interface for Canvas and its ability to address the robust needs of the student learner.
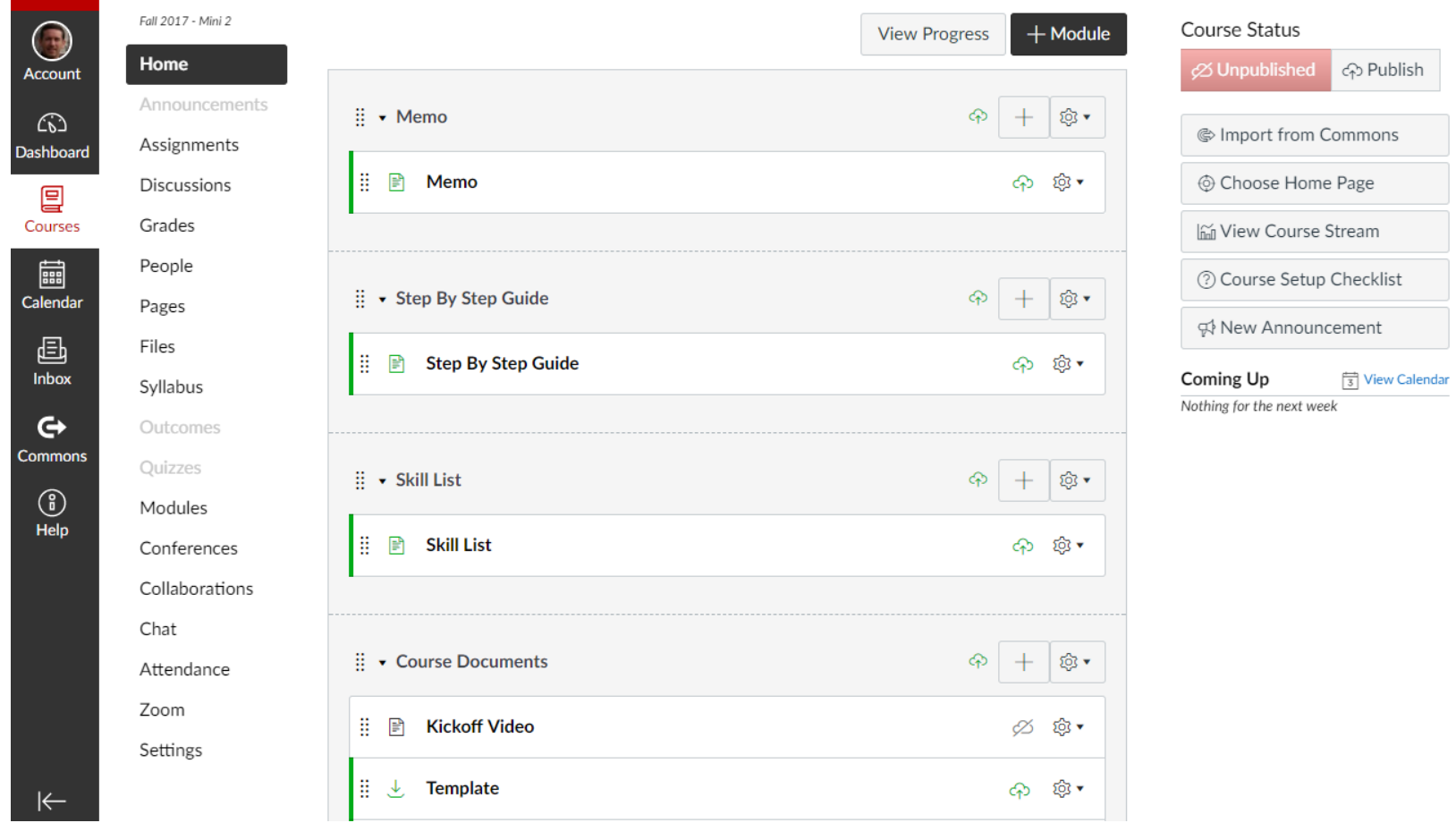

Figure J1. Main Screen for the Canvas LMS

This learning management system allows for full online collaboration between students and instructor and provides the necessary tools for the learner to perform their actions as a student as well as let the instructor perform their full duties. From a research perspective, the quantitative data needed to drive the research study was successfully collected through this LMS via the quiz creation. This provides the necessary pre- and post-assessments that will be collected for the data needs.

Media and technology in this course are greatly used, and with more implementation of technology can come more problems. Figure 9 below identifies the items that would be required to teach and take the course (Table Row 1 - Media \& Technologies), and the issues that may arise with them (Table Row 2 - Use Issues). 


\begin{tabular}{|l|l|}
\hline \multicolumn{1}{|c}{ 1. Media \& Technologies } & \multicolumn{1}{c|}{ 2. Use Issues } \\
Canvas Website & $\begin{array}{l}\text { Students need to purchase cases directly from } \\
\text { HBS. }\end{array}$ \\
Email Access & $\begin{array}{l}\text { Students may have issues accessing HBS site. } \\
\text { Students may not find the right cases. }\end{array}$ \\
GoToMeeting Software & $\begin{array}{l}\text { Access needs to be granted to the Canvas site. } \\
\text { Must have email for assignment submissions. }\end{array}$ \\
Computer or Access to Computer Lab & $\begin{array}{l}\text { Instructional/Tutoring Meetings by } \\
\text { Appointment. }\end{array}$ \\
Internet Access & Able to Create and Give Presentations. \\
PowerPoint or other Presentation Software & Canvas Support. \\
8-Week Semester & PC or Mac Computer Software Support. \\
Day or Evening Class & Cloud Data Storage and Sharing. \\
$\begin{array}{l}\text { Maximum 35 Students (to ensure classroom } \\
\text { capacity) }\end{array}$ & AV Support. \\
Any Last Semester Enrollee's & \\
Facilities on Campus
\end{tabular}

Figure J2. Media, Technology and Use Case Issues.

Media and technology are described in more detail below and the use issues that would pertain to each.

HBS cases would need to be bought directly through the Harvard Business School website. This can cause problems with the student in several ways: accessing the site, finding the right cases (a direct link to their packet is provided but sometimes students stray away from this and try to buy them individually) and paying for the cases.

Students will need access to Canvas (which needs to be requested by the instructor and is also reliant on the correct data from the registrar). They must also use a computer and web browser that can adequately read the site.

Students must have email access and be able to use this for updates from the instructor and for homework submissions. Any email client or software is fine to use as long as students can receive and send communications this way. 
They also need to have access to a computer or computer lab, they must have internet access, and the computer must be able to run GoToMeeting software (for distance students) and PowerPoint (or other software) for presenting their cases. The computers should also be able to use and access some type of cloud sharing mechanism for working with their teams (Box is provided but others may be used).

The course is eight weeks long and must be within the last semester of the student's degree program. The student has the option of taking a day class (two classes of 1 hour and 20 minutes per week) or an evening class (one 2 hour and 50 minute class per week), or the distance class (one 2-hour online meeting per week). The students can only enroll if the course is below the course size of 35 students. For the purposes of this study, the student must take the distance course.

\section{Appendix K: Course Timeline}

Figure K1 shows a typical class structure for the classes used for the data collection.

Distance: (Class runs from 8 to 10 p.m. Monday)

\begin{tabular}{|c|c|c|c|c|}
\hline $\begin{array}{l}\text { Time } \\
\text { Period }\end{array}$ & $\begin{array}{c}\text { Instructional } \\
\text { Activity }\end{array}$ & Project Goal & Media/Technology & $\begin{array}{c}\text { Teaching- } \\
\text { Assessment }\end{array}$ \\
\hline 6 p.m. & $\begin{array}{l}\text { Review of the } \\
\text { class material } \\
D T-2 a \text { and DT- } \\
2 b\end{array}$ & $\begin{array}{l}\text { - Review of the } \\
\text { week's case } \\
\text { analysis - IT } \\
\text { Doesn't Matter } \\
\text { - Review of next } \\
\text { week's case - iOS } \\
\text { vs. Android } \\
\text { - Review of } \\
\text { provided } \\
\text { documentation } \\
\text { Review any } \\
\text { outstanding } \\
\text { student requests }\end{array}$ & $\begin{array}{l}\text { HBR Case-iOS } \\
\text { vs. Android } \\
\text { - Supplemental } \\
\text { Readings } \\
\text {-Dog Eat Dog } \\
\text {-Scale Without } \\
\text { Mass } \\
\text {-Pillars of } \\
\text { Productivity } \\
\text { Required } \\
\text { Readings } \\
\text {-Beyond The } \\
\text { Productivity } \\
\text { Paradox } \\
\text { Laptop }\end{array}$ & $\begin{array}{l}\text { Teaching: } \\
\text { Preparation. } \\
\text { Assessment: } \\
\text { Review of course } \\
\text { materials. } \\
\text { Formative } \\
\text { evaluation of } \\
\text { students and } \\
\text { student requests. } \\
\text { Evaluation of the } \\
\text { program, determine } \\
\text { any last minute } \\
\text { changes. }\end{array}$ \\
\hline 7:30 p.m. & Setup Room & $\begin{array}{ll}\text { - } & \text { Set up } \\
& \text { GoToMeeting } \\
& \text { Room }\end{array}$ & $\begin{array}{l}\text { - Lesson plan book } \\
\text { - } \quad \text { Boot computer } \\
\text { - Access Canvas }\end{array}$ & $\begin{array}{l}\text { Teaching: } \\
\text { Preparation. }\end{array}$ \\
\hline
\end{tabular}




\begin{tabular}{|c|c|c|c|c|}
\hline $\begin{array}{l}\text { Time } \\
\text { Period }\end{array}$ & $\begin{array}{c}\text { Instructional } \\
\text { Activity }\end{array}$ & Project Goal & Media/Technology & $\begin{array}{l}\text { Teaching- } \\
\text { Assessment }\end{array}$ \\
\hline & & 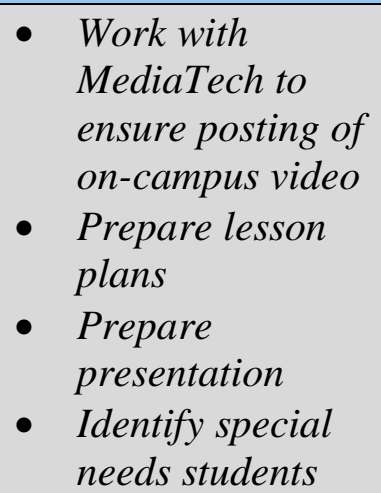 & $\begin{array}{l}\text { - Supplemental } \\
\text { Materials }\end{array}$ & $\begin{array}{l}\text { Assessment: } \\
\text { Review of delivery } \\
\text { methods for the } \\
\text { course. }\end{array}$ \\
\hline 8 p.m. & Introduction & $\begin{array}{ll}\text { - } & \text { Lecture } \\
\text { - Setup Team } \\
\text { Presentation }\end{array}$ & $\begin{array}{l}\text { - GoToMeeting } \\
\text { Presentation } \\
\text { Manager }\end{array}$ & $\begin{array}{l}\text { Teaching: } \\
\text { Lecture of course } \\
\text { materials. } \\
\text { Assessment: } \\
Q \& A \text { from teams } \\
\text { and individuals. } \\
\text { Personal } \\
\text { inventories. } \\
\text { Team inventories. }\end{array}$ \\
\hline 8:10 p.m. & Presentation & $\begin{array}{l}\text { - Team 1 } \\
\text { Presentation-IT } \\
\text { Doesn't Matter }\end{array}$ & 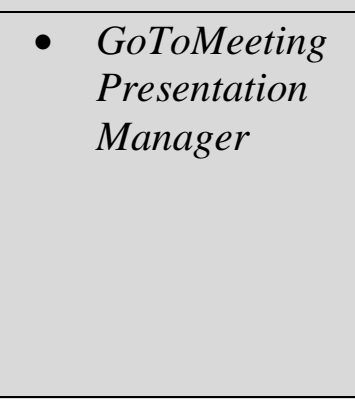 & $\begin{array}{l}\text { Teaching: } \\
\text { Team presentation. } \\
\text { Assessment: } \\
\text { Criterion- } \\
\text { referenced } \\
\text { observation of the } \\
\text { class. }\end{array}$ \\
\hline 8:30 p.m. & $Q \& A$ & - $\quad$ Team $Q \& A$ & & $\begin{array}{l}\text { Teaching: } \\
\text { Review of course } \\
\text { materials and } \\
\text { findings; } \\
\text { roundtable. } \\
\\
\text { Assessment: } \\
\text { Formative } \\
\text { discussion. }\end{array}$ \\
\hline 8:50 p.m. & Presentation & $\begin{array}{ll} & \text { Team } 2 \\
& \text { Presentation - IT } \\
& \text { Does Matter } \\
\end{array}$ & $\begin{array}{l}\text { - GoToMeeting } \\
\text { Presentation } \\
\text { Manager }\end{array}$ & Teaching: \\
\hline
\end{tabular}




\begin{tabular}{|c|c|c|c|c|}
\hline $\begin{array}{l}\text { Time } \\
\text { Period }\end{array}$ & $\begin{array}{c}\text { Instructional } \\
\text { Activity }\end{array}$ & Project Goal & Media/Technology & $\begin{array}{l}\text { Teaching- } \\
\text { Assessment }\end{array}$ \\
\hline & & & & $\begin{array}{l}\text { Team presentation. } \\
\text { Assessment: } \\
\text { Criterion- } \\
\text { referenced } \\
\text { observation of the } \\
\text { class. }\end{array}$ \\
\hline 8:20 p.m. & $Q \& A$ & - Team $Q \& A$ & & $\begin{array}{l}\text { Teaching: } \\
\text { Review of course } \\
\text { materials and } \\
\text { findings; } \\
\text { roundtable. } \\
\\
\text { Assessment: } \\
\text { Formative } \\
\text { discussion. }\end{array}$ \\
\hline 8:40 p.m. & Lecture & $\begin{array}{ll}\text { - } & \text { Discuss Current } \\
& \text { Case } \\
\text { - } & \text { Discuss } \\
\text { supplemental } \\
\text { information } \\
\text { - } & \text { Present upcoming } \\
& \text { case - iOS vs. } \\
& \text { Android } \\
\text { - } & \text { Q\&A }\end{array}$ & $\begin{array}{l}\text { - GoToMeeting } \\
\text { Presentation } \\
\text { Manager }\end{array}$ & $\begin{array}{l}\text { Teaching: } \\
\text { Lecture of course } \\
\text { materials. } \\
\text { Introduction to the } \\
\text { week's case. } \\
\text { Assessment: } \\
\text { Q\&A from teams } \\
\text { and individuals. } \\
\text { Personal } \\
\text { inventories. } \\
\text { Team inventories. }\end{array}$ \\
\hline 10 p.m. & Closing & - End the class & $\begin{array}{ll} & \text { Shut down } \\
& \text { GoToMeeting } \\
& \text { Presentation }\end{array}$ & $\begin{array}{l}\text { Teaching: } \\
\text { Preparation. } \\
\text { Assessment: } \\
\text { Review of course } \\
\text { materials. } \\
\\
\text { Formative } \\
\text { evaluation of } \\
\text { students and } \\
\text { student requests. }\end{array}$ \\
\hline
\end{tabular}




\begin{tabular}{|l|l|l|l|l|}
\hline $\begin{array}{c}\text { Time } \\
\text { Period }\end{array}$ & $\begin{array}{c}\text { Instructional } \\
\text { Activity }\end{array}$ & Project Goal & Media/Technology & \multicolumn{1}{c|}{$\begin{array}{c}\text { Teaching- } \\
\text { Assessment }\end{array}$} \\
\hline & & & $\begin{array}{l}\text { Evaluation of the } \\
\text { program, determine } \\
\text { any last minute } \\
\text { changes. }\end{array}$ \\
& & & $\begin{array}{l}\text { Review of delivery } \\
\text { methods for the } \\
\text { course. }\end{array}$ \\
\hline
\end{tabular}

Figure K1. Outline of a Typical Digital Transformation Course

\section{Appendix L: The Flipped Distance Education Model (FDEM)}

The FDEM was implemented to aid in flipping the distance classroom for this study. Distance education utilized with this model are courses are to be taught fully online via $\mathrm{A} / \mathrm{V}$ and computer technologies, and without physical face-to-face interaction, such as in a classroom or other meeting area.

\section{L1. Implications of the Applicability of the FDEM}

A successful FDEM will allow for a full life cycle of course content creation, delivery and analysis through the IIA instructional design model. The complete FDEM includes using the instructional design model (IIA) and the flipped classroom workbook, both of which contain evaluation mechanisms for processes within the combined FDEM instrument. This is to identify needs of the learner and instructor, implement those needs and evaluate the outcomes to determine whether components of the course should be altered to address any issues from the current model's implementation. 


\section{L2. Overview of the Complete FDEM}

Figure L1 looks at the complete life cycle of course creation through the FDEM. Content is gathered by the instructor and disseminated throughout the life cycle for course creation and eventual reevaluation of the content via the IIA instructional design model.

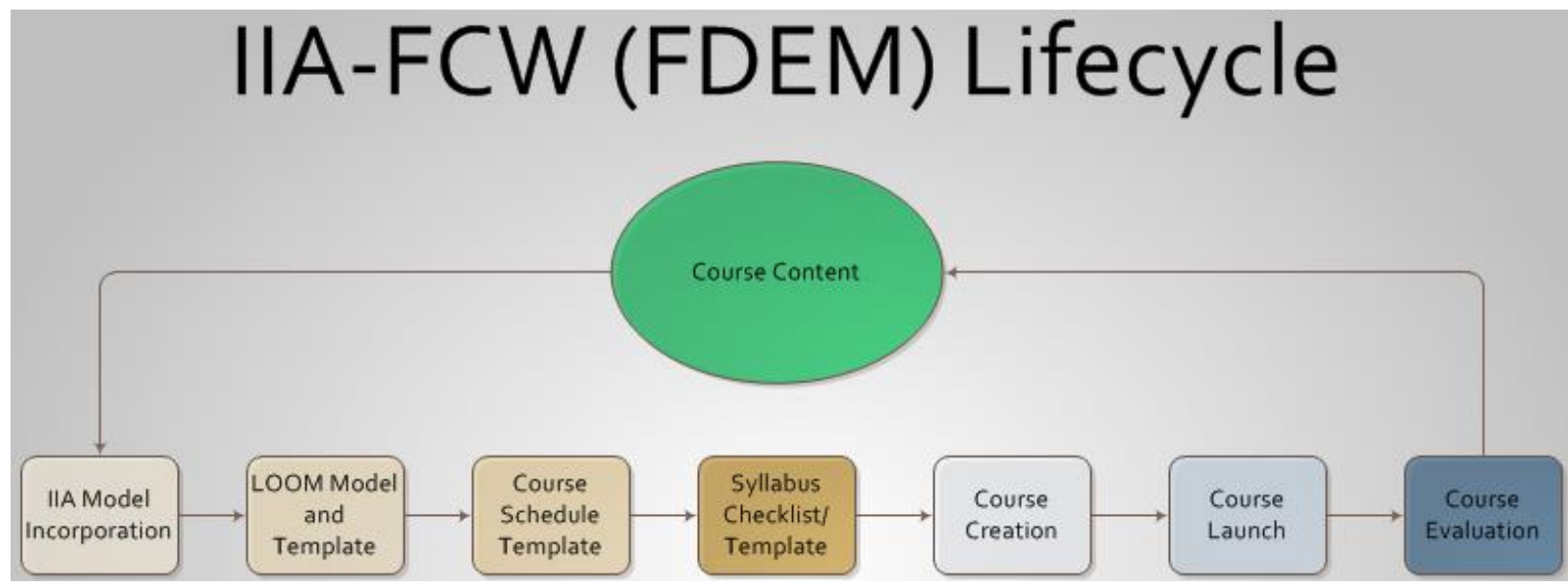

Figure L1. The Full Flipped Classroom over Distance Education Course Creation Life Cycle

The two major tools that make up the FDEM course creation and evaluation toolkit are listed in the following sections:

- The Identity-Implementation-Analysis (IIA) Model (See Figure L2)

- The FCW tool which includes the following instruments:

- The Learning Objectives and Outcomes Model (LOOM, See Figure L3)

- Learning Objectives and Outcomes Template (See Figure L4)

○ Course Schedule Template (See Figure L5)

- Syllabus Checklist/Template (See Figure L6) 
The first part of the IIA model (Identity) addresses initial course content implementation. The remaining four tools address the first phase of the IIA model.

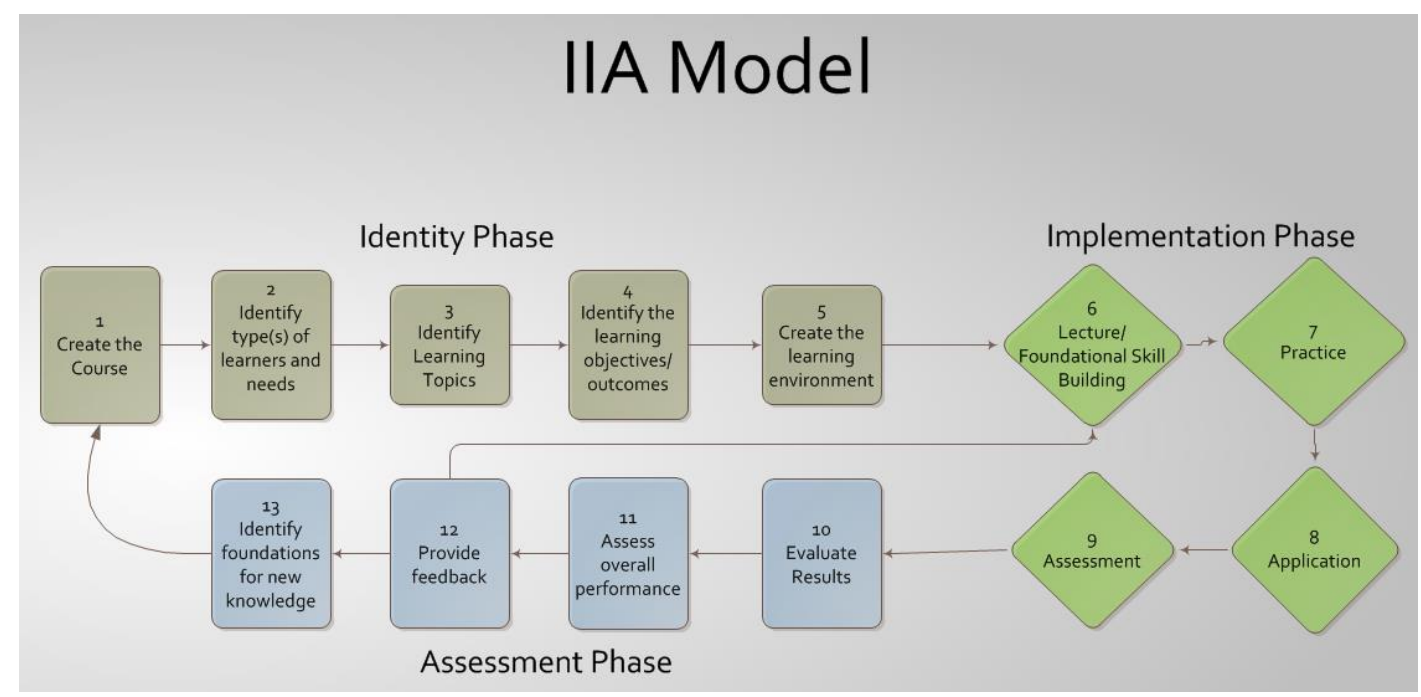

Figure L2. The Identity - Implementation - Analysis Model

This instrument creates outcomes to successfully build a flipped classroom learning environment through online distance education platforms and mechanisms.

\section{L4. The Flipped Classroom Workbook (FCW)}

Following are the four components to the Flipped Classroom Workbook: The LOOM, Learning Objectives and Outcomes Template, Course Schedule Template and the Syllabus Checklist/Template.

\section{L4a. The Learning Objectives and Outcomes Model (LOOM)}

The flipped online classroom is based on a successful design, implementation and analysis of results from using the Learning Objectives and Outcomes Model (LOOM, Figure L3). A successful utilization of the LOOM for creation of learning objectives for the instructional design of the online Digital Transformation course was completed. By configuring the course content, prerequisites, learning topics and subtopics, learning objectives and 
outcomes, and then creating the flipped learning environment built into the course schedule, the course can be evaluated via the instruments in this study to analyze the results on the effectiveness of the course through a flipped classroom model of instruction.

\section{Learning Objectives/Outcomes Model}

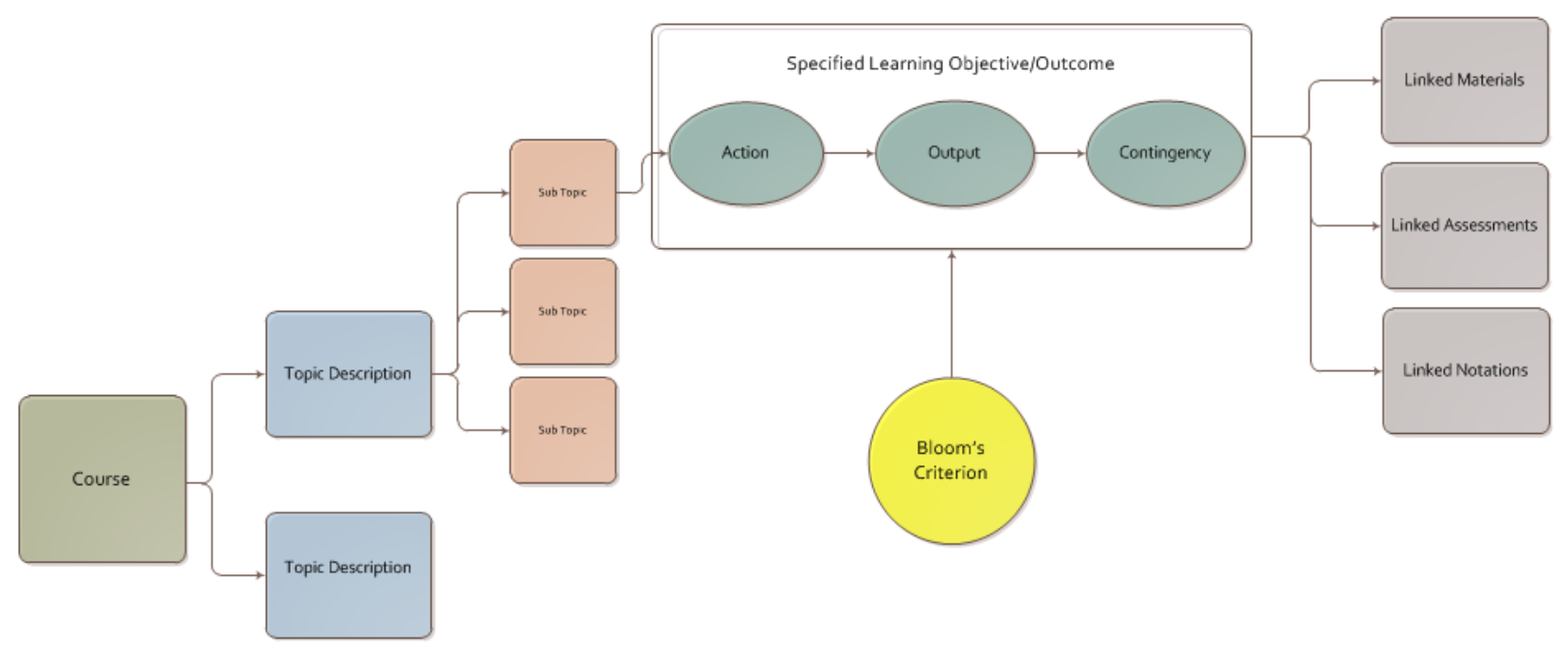

Figure L3. The Learning Objectives and Outcomes Model (LOOM)

Use of this instructional design for the study aids in both quantitative and qualitative aspects of the results to be created.

\section{L4b. Experimental Design for the LOOM}

The study consists of looking at three key questions that, as an instructional designer and teacher, would explicitly need to examine the LOOM instrument for proper effectiveness. The questions reviewed ask whether the "instrument solves the problem of creating clear learning objectives specifically for the course being developed," "does the instrument allow for linking learning objectives and outcomes to overall course creation needs" and "is the instrument clearly developed to allow anyone to easily follow through and create learning objectives and outcomes for their course?" Examination of these questions include utilizing the LOOM instrument to 
create specified learning objectives and successfully apply them to materials such as a syllabus, course schedule or course description.

Examination the outcomes from use of the LOOM to determine usability and effectiveness of this instrument for the Digital Transformation course (Figure L3a) was completed. This is done through choosing a specific course (in this case, Digital Transformation), a specific topic based on that course, any subtopics related to that topic, learning objectives based on the three criteria utilizing Bloom's Taxonomy (See Appendix M) (The action verb - the proposed outcome - the contingent material) and a learning objective that would then be linked to materials that correspond to the learning environment being developed.

\section{LOOM Experimental Design}

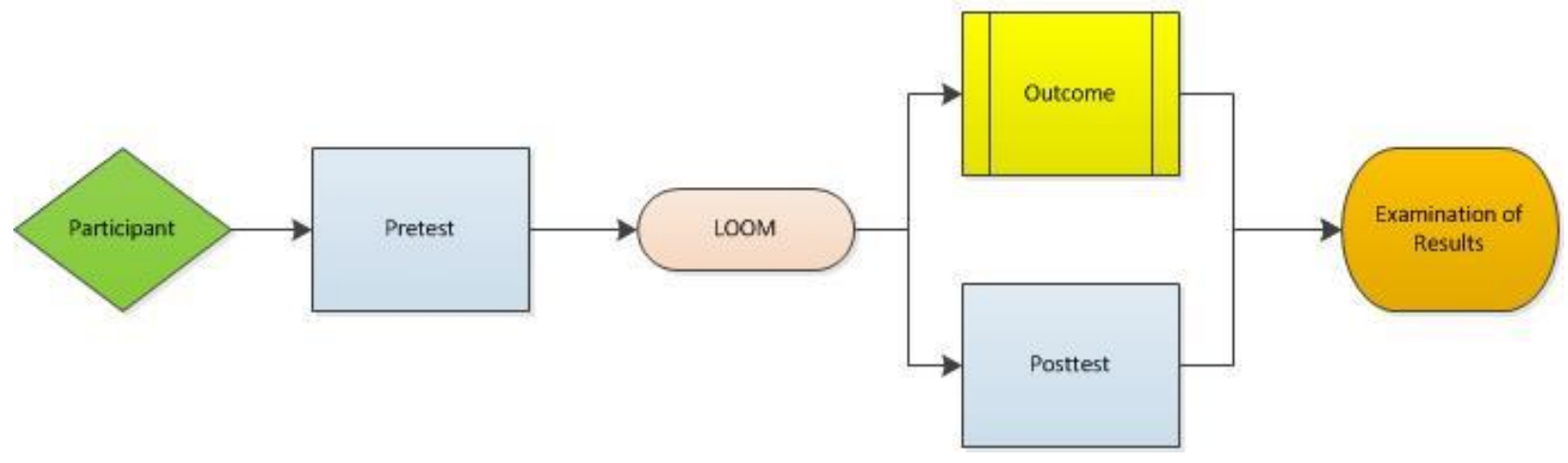

Figure L3a. Methodology for Gathering Data for LOOM Utilization

Working as the instructional designer, data gathered from the life cycle of using the LOOM looks at each step to determine whether all key components are present for successful learning objective creation, that good practice is present and encouraged through use of the model, that the output from the model aligns with the instructors learning environment and that all necessary learning areas are identified and addressed by the instructional designer through use of the proposed model. Learning objectives are to be clear and concise and have applied use for both the educator and the learner. As necessary, revisions based on feedback from the instrument will take place after examination of the data to increase usability and effectiveness of the instrument. 


\section{L4c. Learning Objectives and Outcomes Template}

The following is an example of the LOOM template builder for identifying key constructions in building the flipped classroom for online classrooms. The following example shows a completed template for one week of the Digital Transformation class.

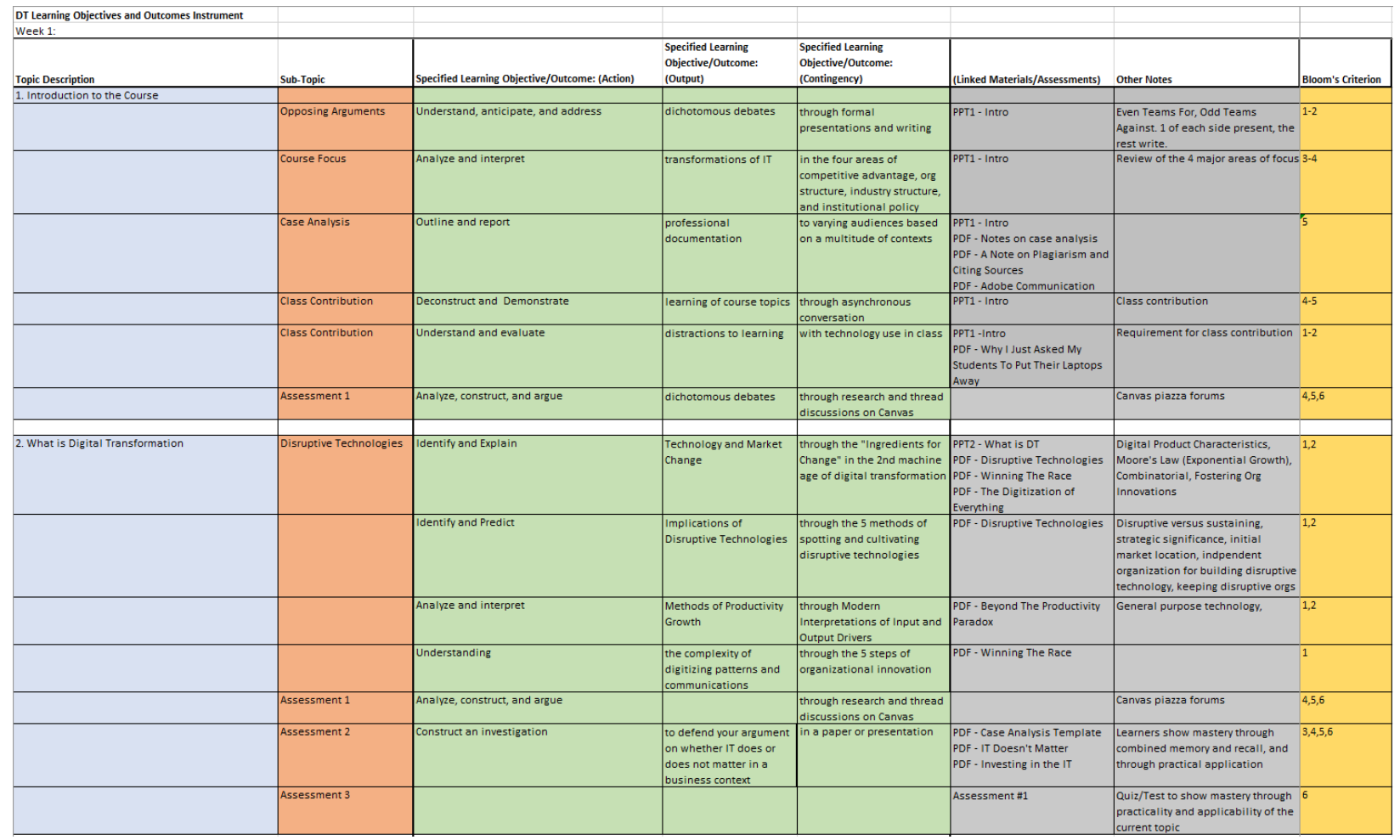

Figure L4. The Template for Building Objectives and Outcomes for the LOOM

\section{L4d. Course Schedule Template}

Figure L5 is the course schedule template with example data from the Digital Transformation class used in the study. This shows the template used for one week of content building. 


\title{
Week 1, March $18^{\text {th }}-23^{\text {rd }} 2020$ (Wednesday start)
}

\author{
Topics: \\ Week 1: \\ Introduction to DT. 3/18 - In Class 1:30pm-2:50pm EST (or refer to recorded lecture 1) \\ Learning Objectives:
}

- Understand, anticipate, and address dichotomous debates through formal presentations and writing

- Analyze and interpret transformations of IT in the areas of competitive advantage, org structure, industry structure, data adoption and privacy, and institutional policy

- Outline and report professional documentation to varying audiences based on a multitude of contexts

- Deconstruct and demonstrate learning of course topics through synchronous and asynchronous conversation

- Understand and evaluate distractions to learning with technology use in class

What is DT? 3/18 - 7:OOPM-8:20PM EST (or refer to recorded lecture 2)

Learning Objectives:

- Identify and Explain Technology and Market Change through the "Ingredients for Change" in the 2nd machine age of digital transformation

- Identify and Predict Implications of Disruptive Technologies through the 5 methods of spotting and cultivating disruptive technologies

- Analyze and interpret Methods of Productivity Growth Through Modern Interpretations of Input and Output Drivers

- Understanding the complexity of digitizing patterns and communication through the 5 steps of organizational innovation

- Construct an investigation in a paper or presentation to defend your argument on whether IT does or does not matter in a business context

- Analyze, construct, and argue questions and concerns surrounding digital transformation through research and discussion of autonomous vehicle adoption

\section{Assignments:}

1. DUE 3/18: Introduction to DT and Pre-Assessment surveys. Take the two pre-class surveys as soon as you can.

2. DUE 3/22: Student Homepage Wiki. Fill out the wiki located on Canvas in Piazza with a few things about yourself to share with the class.

\section{DUE 3/23: Does IT Matter?}

The Task:

A little over 15 years ago, Nick Carr wrote an influential article in the Harvard Business Review entitled "IT Doesn't Matter." In this assignment, I would like for you or your team to think about whether you should adopt Nick Carr's advice in the present timeframe and in the focus areas outlined below.

Presentations:

IT Does Matter: Team 1

Case Analysis Write-Ups:

IT Does Matter: Individuals on odd numbered teams

You or your team have been asked by the mayor of Pittsburgh, Mr. Bill Peduto, to evaluate current and new visions in IT for the City of Pittsburgh's "Smart Cities" initiatives (http://smartpittsburgh.org/). His vision is not only to have Pittsburgh become the tech leader as a smart city, but to also come up with new creative ways to drive tax revenues into the city so that he can pay for the new $150+$ mile bike lane network currently being proposed. Mr. Peduto is looking for evaluations that consider only IT implementations or changes and can be physical or data driven. These can also be current or future visions already proposed for Pittsburgh, or they can be new visions that you come up with. For example, a physical change could be the "smart streetlamps" being proposed or a data driven change could be Al driven smart vehicles to remove human drivers from the streets (think about what you have learned in the provided case). The challenge, however, is not that you are envisioning all of the money that can be saved by implementing a smart lamp in terms of electricity saved, or the decrease in congestion envisioned through autonomous vehicles, but that the technology would be something that would drive sustainable competitive advantage for Pittsburgh in competing with other cities to drive up tax revenues (think tax income from new residents or new businesses enticed to setup shop in Pittsburgh). By sustained competitive advantage, this means that the technology would have to do something that increases the viability of Pittsburgh as a city in competition with other cities but is something that cannot be immediately or easily replicated (it should give at least a 
5-year advantage over its rivals). In this regard, its main purpose should be to drive money from other areas to Pittsburgh, and not what would increase it from within. I have provided some readings that will delve further into this topic and to help drive your recommendations.

Presentations:

IT Doesn't Matter: Team 2

Case Analysis Write-Ups:

IT Doesn't Matter: Individuals on even numbered teams

You or your team has been asked for a similar evaluation given to Team 1, except it should be the opposite. Mr. Peduto would like you to evaluate technological or data driven implementations, either current or future, that you feel will not drive sustained competitive advantage for Pittsburgh. Using the same example as above, make the argument that IT is not the solution and why this is the case, keeping in mind that your belief is that the IT investment would be easily copied and thus give little to no competitive advantage. As you prepare your write-up, a useful thought experiment might be to imagine whether Pittsburgh would be better or worse off by following Nick Carr's advice. As well, think about other examples of companies that have been neutralized by rivals copying and/or making better a potential IT investment.

Feel free to be creative about what you feel is important in terms of technology in this landscape, tech and management of digitization being the focus of the argument in the assignment.

4. Posts DUE by 3/24: Canvas Discussion on the Week 1 case, "Testing Autonomy in Pittsburgh".

For our discussion on vehicle autonomy testing in Pittsburgh, I would like everyone to read the case provided, "Testing Autonomy in Pittsburgh", and provide responses to the following situational questions and concerns outlined below.

For Mayor Peduto's recommendations to be followed, Uber would have to do so voluntarily. But, in response to public safety concerns and fear, should the mayor ask more of the company?

The press release and the conditions were directed at Uber. Should they apply to Argo Al, Aurora Innovation, Aptiv, and GM? Was there moreor less - that Mayor Peduto should do?

Is the mayor's mostly hands-off approach appropriate?

Should the companies, Uber and others, prefer the hands-off approach or something more rigorous?

Think about how safe is too safe for proper testing and to operate within normal road conditions and stipulations. Lean Startup and other entrepreneurial techniques extol the virtues of going out and testing non-final products, so that feedback can enhance the final version. But how limited are these techniques when the prototypes, minimally viable products, etc. present potential hazards, even potentially fatal ones.

Responses can be new, or in response to another student's response, supporting or countering.

5. DUE 3/30: Canvas Assessment 1.

A bonus weekly assessment based on criteria you have learned from the lectures and readings will be posted to Canvas.

\section{Supplemental Information:}

Section 1 - Introduction to the course

I will briefly review the course objectives and student expectations we will use during the mini. The objective of the course is to engage you in analytical thinking regarding important information technology management issues. You will combine your knowledge of information technology, decision-making, strategy and data analysis in these case analyses and discussions. There will be no lectures per se in this course beyond a few professor-led discussions to provide a set of analytic frameworks. You will be tasked with preparing cases and evaluated on the quality of your participation and analysis.

Section 2-What is DT?

In this class we will discuss why understanding "Digital Transformation" is important for future IT leaders, including its conceptual origins, what questions it raises for managers, and the cases and topics we will use in this class to illustrate these concepts.

For Section 3 (next week) - Does IT Matter debate?

We will debate whether IT will make it easier or harder for firms to gain competitive advantage over their rivals. There are two broad schools of thought about how IT will impact competitive strategy. The first says that investment in IT can lead to proprietary advantages to the firm that are hard for competitors to copy. The second says the exact opposite: that the very nature of IT means that investments are readily and easily available to competitors, and as such IT is a commodity input, providing strategic advantage to no one. Which side is right? 


\section{Supporting Documentation:}

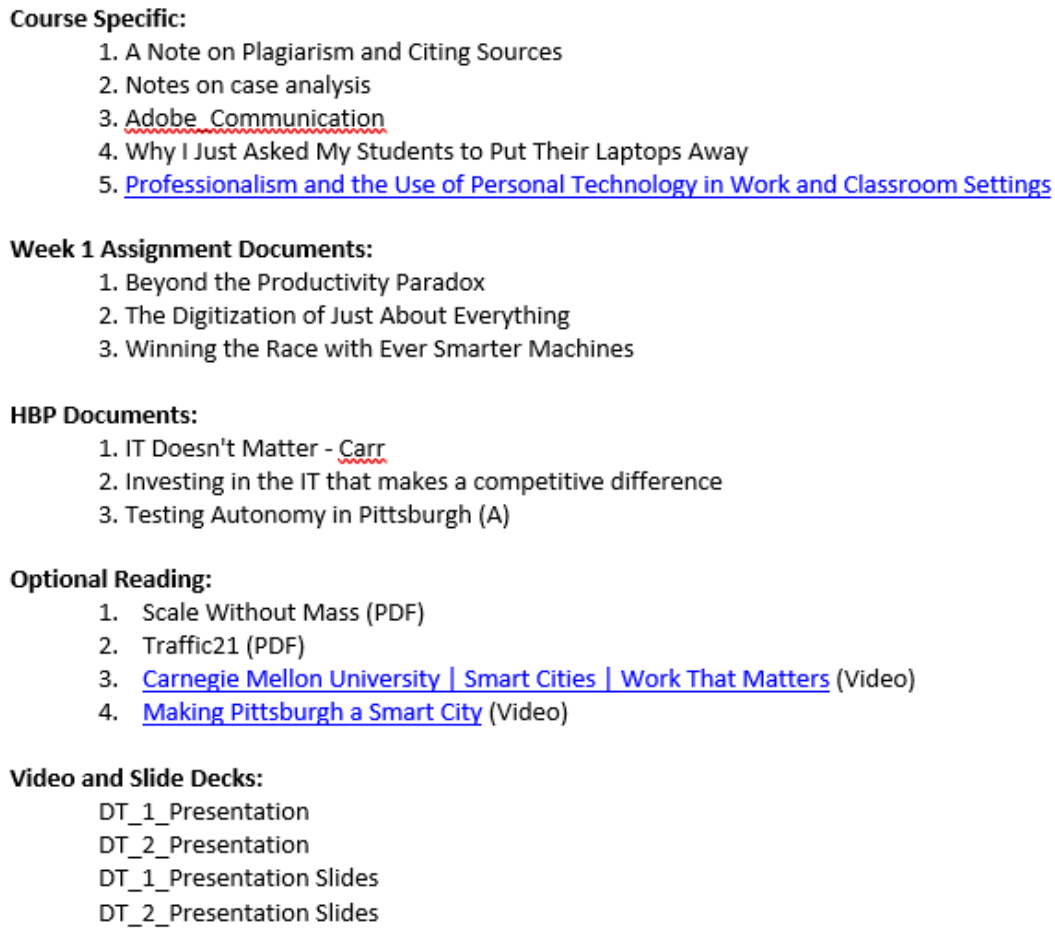

Figure L5. The Template for Building Objectives and Outcomes for the LOOM

\section{L4e. Syllabus Checklist}

The following allows for building out the syllabus for a flipped online classroom utilizing the FDEM.

\section{Identity and Course Creation Section 1: \\ Course Name and Number: \\ Course Details: \\ School and Program: \\ Semester/Mini: \\ Date(s): \\ Time(s): \\ Course Website/LMS:}

Course Description:

Course Instructor(s), Contact Information, Office Location and Hours:

Course Teaching Assistant(s), Contact Information, Office Location and Hours: Course Administrator(s), Contact Information, Office Location and Hours: 
Grading:

Standards and Requirements:

Grading Scale/Breakdown:

Regrades:

Late Submissions:

Make-Up Work:

Course Policies:

Attendance:

Academic Integrity Statement:

Course Specific:

\section{Section 2:}

Course Prerequisites:

Course Materials:

Books and Readings:

Hardware/Software:

Other Components:

Section 3:

Learning Topics:

Learning Objectives and Outcomes:

One Major Piece of

Observability:

Measurability:

Knowledge, Skill, or

Attitude/Value (Bloom's):

Figure L6. The Template for Building the Flipped Online Classroom Syllabus 


\section{Appendix M. The Bloom's Taxonomy Verb Wheel}

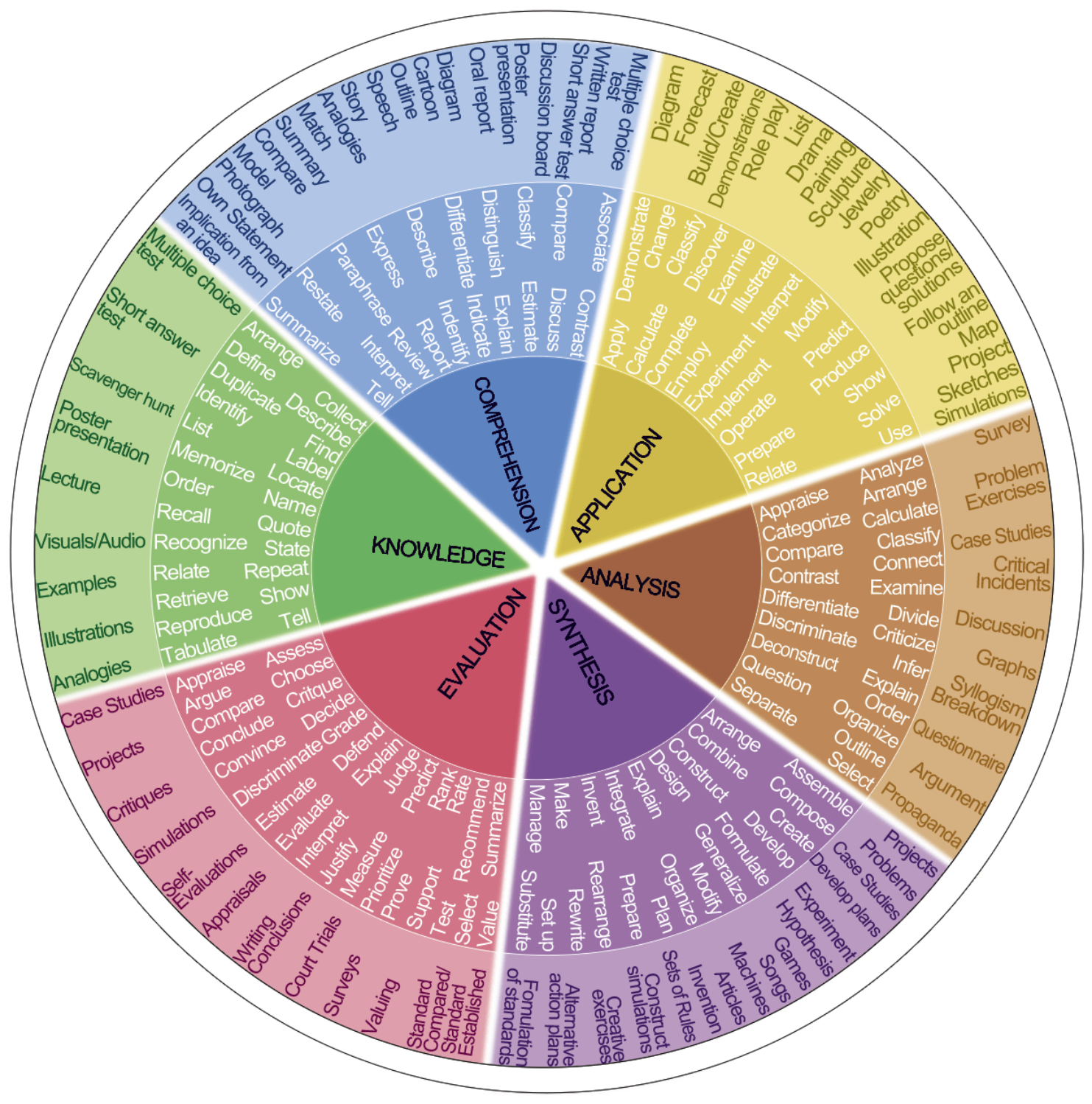

Figure M1. The Bloom's Taxonomy Verb Wheel for use in Development of the LOOM Model Instrument. 
Appendix N. The ADDIE and ASSURE Models of Instructional Design

\begin{tabular}{|l|l|}
\hline \multicolumn{1}{|c|}{ ADDIE } & \\
\hline \begin{tabular}{l} 
Model \\
\hline $\begin{array}{l}\text { Gearning Problem } \\
\text { Goals/Objectives } \\
\text { Audience Needs } \\
\text { Existing Knowledge }\end{array}$
\end{tabular} \\
\hline $\begin{array}{l}\text { Design } \\
\text { Learning Objectives } \\
\text { Overall Nature (look, feel, etc.) }\end{array}$ & $\begin{array}{l}\text { Analyze Learners } \\
\text { competencies, learning styles }\end{array}$ \\
\hline $\begin{array}{l}\text { Development } \\
\text { Creating content }\end{array}$ & $\begin{array}{l}\text { State Objectives } \\
\text { Select instructional methods, media, } \\
\text { materials }\end{array}$ \\
\hline $\begin{array}{l}\text { Implementation } \\
\text { Training/Learning Activities } \\
\text { Materials Used }\end{array}$ & $\begin{array}{l}\text { *-Require learner participation active } \\
\text { participation to ensure engagement in } \\
\text { activities (not a necessary component of } \\
\text { ADDIE) }\end{array}$ \\
\hline $\begin{array}{l}\text { Evaluation } \\
\text { 2. Formative } \\
\text { 3. Revision (if needed) }\end{array}$ & $\begin{array}{l}\text { Evaluate and *Revise } \\
\text { Reflect upon lesson, objectives, strategies, } \\
\text { materials, and assessment (neglected } \\
\text { stage in ADDIE). }\end{array}$ \\
\hline
\end{tabular}

Figure N1. The ADDIE and ASSURE Models Used to Help Guide Development of the FDEM. 


\section{Appendix O. Looking at the Current EdTech Landscape}

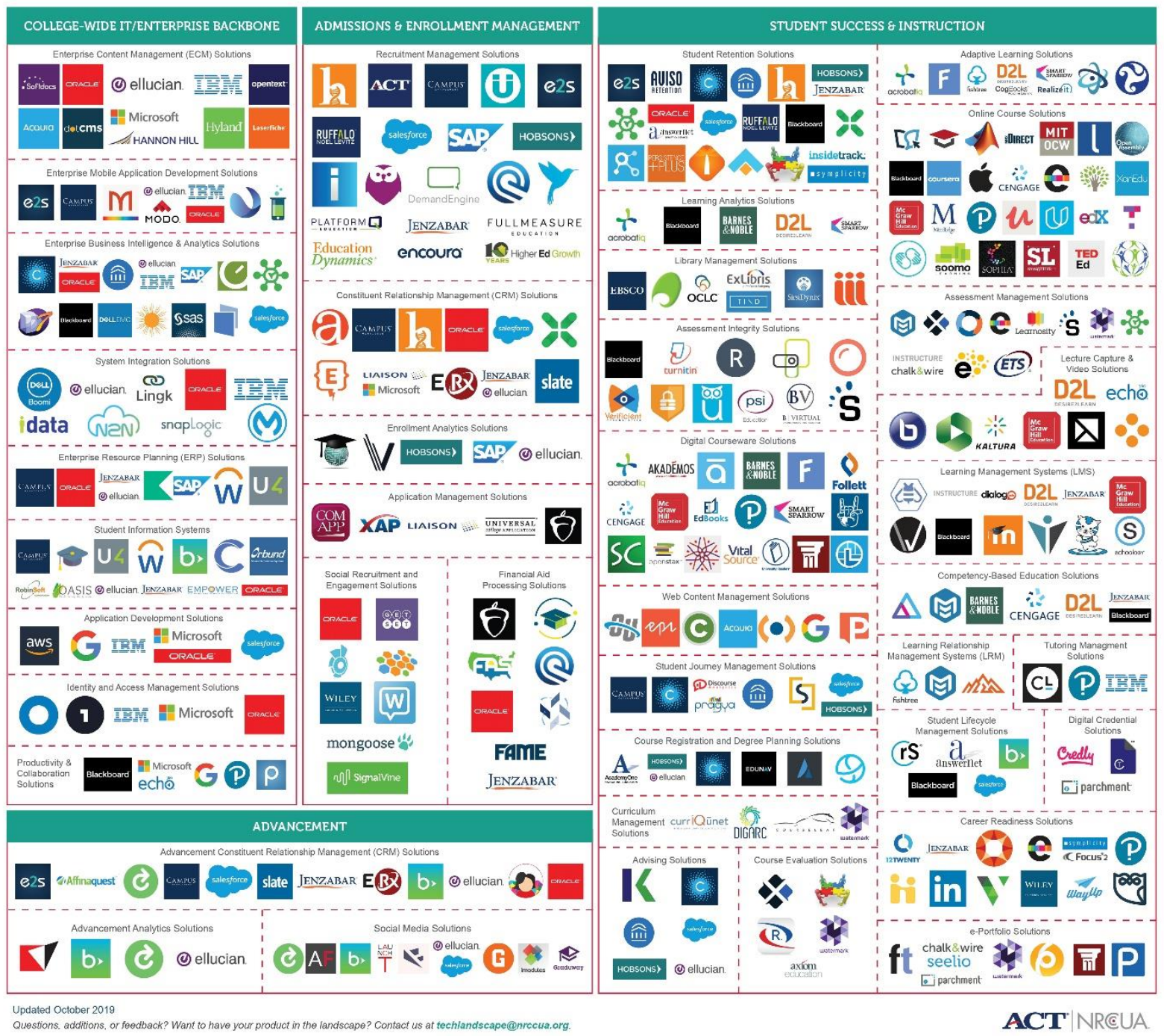

Figure O1. The 2019 Higher Education Technology Landscape (Encoura, 2019) 


\section{Appendix P. A Historical Look at Distance Education}

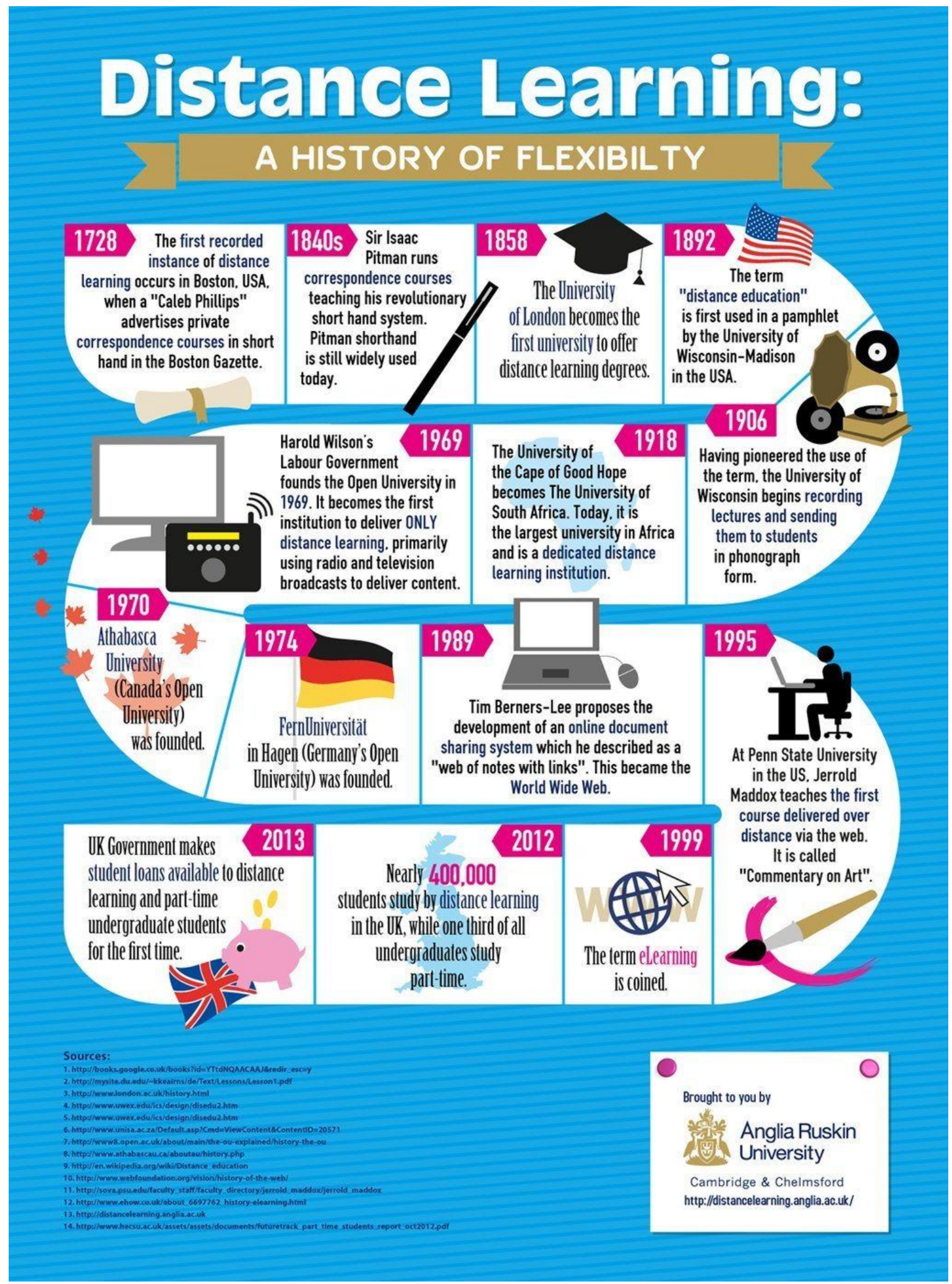

Figure P1. A Condensed View of the History of Distance Education (Pappas, 2013) 